University of Louisville

ThinkIR: The University of Louisville's Institutional Repository

Electronic Theses and Dissertations

8-2014

\title{
Composing college and career : mobility, complexity and agency at the nexus of high school, college and work.
}

Brice Nordquist

University of Louisville

Follow this and additional works at: https://ir.library.louisville.edu/etd

Part of the English Language and Literature Commons

\section{Recommended Citation}

Nordquist, Brice, "Composing college and career : mobility, complexity and agency at the nexus of high school, college and work." (2014). Electronic Theses and Dissertations. Paper 1068.

https://doi.org/10.18297/etd/1068

This Doctoral Dissertation is brought to you for free and open access by ThinkIR: The University of Louisville's Institutional Repository. It has been accepted for inclusion in Electronic Theses and Dissertations by an authorized administrator of ThinkIR: The University of Louisville's Institutional Repository. This title appears here courtesy of the author, who has retained all other copyrights. For more information, please contact thinkir@louisville.edu. 
COMPOSING COLLEGE AND CAREER: MOBILITY, COMPLEXITY AND AGENCY AT THE NEXUS OF HIGH SCHOOL, COLLEGE AND WORK

\author{
By \\ Brice Nordquist \\ B.A., Midwestern State University, 2004 \\ M.A., Abilene Christian University, 2007

\begin{abstract}
A Dissertation
Submitted to the Faculty of the

College of Arts and Sciences of the University of Louisville

in Partial Fulfillment of the Requirements

for the Degree of
\end{abstract} \\ Doctor of Philosophy \\ Department of English \\ University of Louisville \\ Louisville, Kentucky
}

August 2014 


\section{Copyright 2014 by Brice Nordquist}

All rights reserved 

COMPOSING COLLEGE AND CAREER: MOBILITY, COMPLEXITY AND AGENCY AT THE NEXUS OF HIGH SCHOOL, COLLEGE AND WORK

\author{
By \\ Brice Nordquist \\ B.A., Midwestern State University, 2004 \\ M.A., Abilene Christian University, 2007 \\ A Dissertation Approved on
}

June 13, 2014

by the following dissertation committee

Bronwyn T. Williams

Dissertation Director

Bruce Horner

Min-Zhan Lu

Aaron Jaffe

Ann Elisabeth Larson 


\section{DEDICATION}

To

Abigail

For the emotional and material support that made this project possible

and

Katherine

For pushing me to finish 


\section{ACKNOWLEDGEMENTS}

I would like to thank the members of my committee: Bronwyn Williams, Bruce Horner, Min-Zhan Lu, Aaron Jaffe and Ann Larson for their guidance, insight and patience. Thanks particularly to Dr. Williams, who was available to offer feedback and support through every phase of the project, and to Drs. Horner and Lu, who helped shape the work through courses, conversations, written responses and through their own teaching and scholarship. Thanks to the teachers and students who participated in this project and generously gave of their time, energy and expertise. The depth of your insight and thoughtfulness of your practice could fill volumes. I would also like to thank students, professors and administrators in the Rhetoric and Composition program; particularly, Karen Kopleson, Carol Mattingly, Vanessa Kraemer Sohan, Lisa Arnold, Carrie Kilfoil and Mike Sobiech for their generosity as teachers, mentors, classmates, scholars and friends. Special thanks to Samantha NeCamp for her selfless investment in the success of this work and for her willingness to read, reread and discuss a multitude of ideas and texts with remarkable candor and consideration. Thank you, Mom and Dad, for pushing me to achieve my goals while enabling me to define them for myself. Your hard work, guidance and support have undergirded my education at every stage. Finally, thank you, Abby, for encouraging and enabling me to do this work. Your belief in and love for me has informed every step of this process. This accomplishment is as much yours as it is mine. 


\section{ABSTRACT \\ COMPOSING COLLEGE AND CAREER}

Brice Nordquist

June 13, 2014

This dissertation offers and theorizes findings of a two-year mobile ethnography investigating the complexity of students' movements within and among secondary and tertiary educational institutions and the labor market. The project illustrates the lateral and recursive natures of students' educational and occupational trajectories and thereby reveals the mutually constitutive relations among scenes of writing across space and time. While the study follows eleven students moving from different tracks of high school English through their first years at research universities, colleges and full-time jobs, this text focuses specifically on the mobilities of three students: Nadif, Katherine and James. I draw upon a range of data types collected while participating in these students' patterns of movement in and across scenes of writing, conducting interviews in single sites and on the move, and analyzing their print-based and digital texts to represent intersecting and diverging movements across educational and occupational localities. Moreover, I use this data to investigate the ways in which students draw upon multiple literacies and linguistic resources to accommodate, resist and reformulate conventions of discourse, genre and discipline. Intersections and divergences among Nadif's, Katherine's and James' trajectories reveal how language and literacy practices are informed by the ideologies, 
experiences and habituated practices of and desires for mobility available in past, present and future scenes of reading and writing.

By working with co-researchers in and across scenes of writing in high school, college, at work, home, in transit, and elsewhere this project complicates apparent boundaries between secondary and tertiary and in-school and out-of-school literacy practices; attends to conceptualizations of college writing from stakeholders "outside" the academy; provides insight into the complexity of students' movements within and between educational institutions; challenges notions of fixed locations and standards of language and literacy; and, thereby, works against the relentless future orientation of the U.S. educational-occupational system to recognize the value of students' literacy practices in the present. 


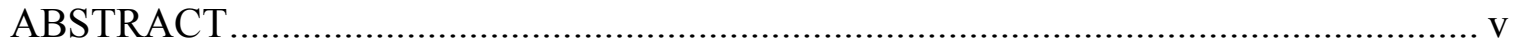

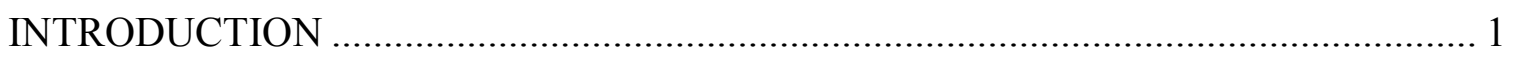

Location and Intervention .............................................................................. 6

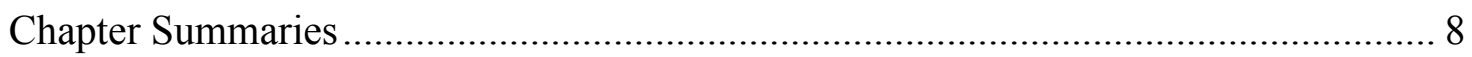

CHAPTER I: FRAMING MOBILE LITERACIES: READING-WRITING AS MOBILE

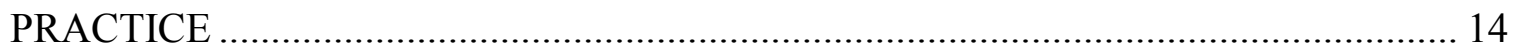

Key Terms for Mobile Practice.............................................................................. 17

Space-Time and Movement: Assumptions and Alternatives...................................... 21

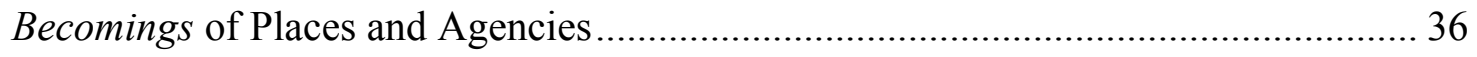

CHAPTER II: IMAGINED MOBILITIES IN COMPOSITION STUDIES .................... 42

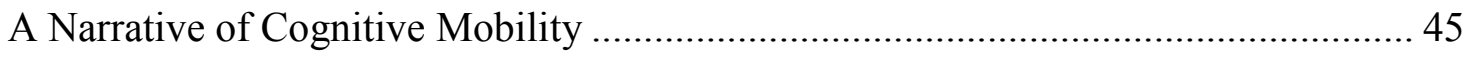

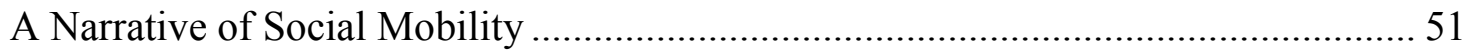

A Narrative of College and Career Mobility ............................................................ 58

Toward a Mobile Methodology for Composition Studies ........................................... 66

CHAPTER III: PROJECTIONS OF IM(MOBILITY) AT THE NEXUS OF HIGH

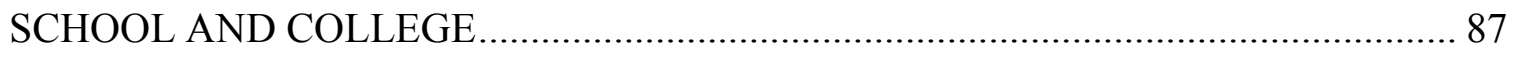

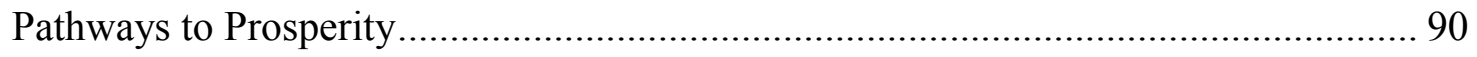


Buying (and Selling) a Stairway to Heaven....................................................................... 94

Educating for the Future by Reducing the Past and Present ..................................... 102

\section{CHAPTER IV: LITERACY IN MOTION: PLURALIZING LOCALITIES AND}

IDENTITIES THROUGH MOBILE COLLECTIVES ................................................. 130

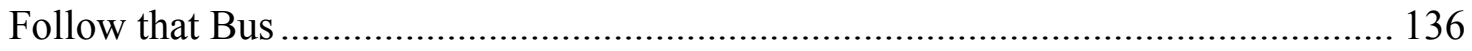

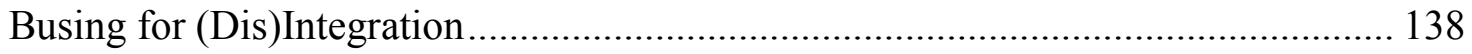

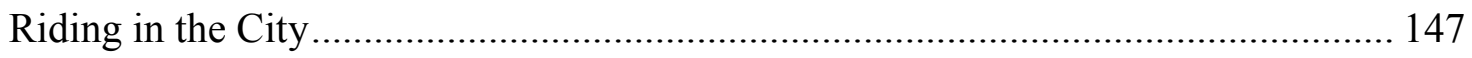

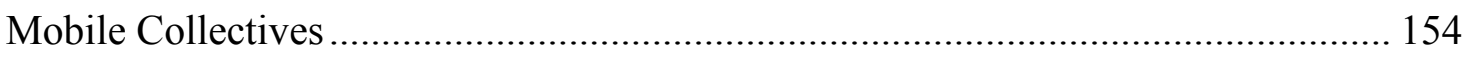

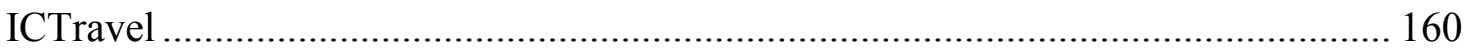

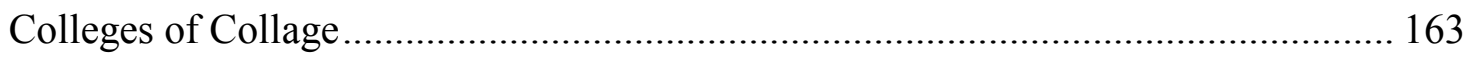

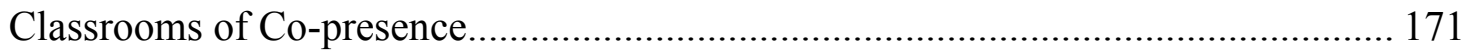

Mapping and Translating Mobile Practice............................................................ 178

CONCLUSION: PEDAGOGICAL POSSIBILITIES FOR MOBILE LITERACIES ... 182

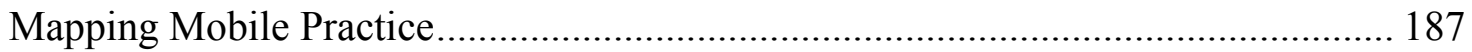

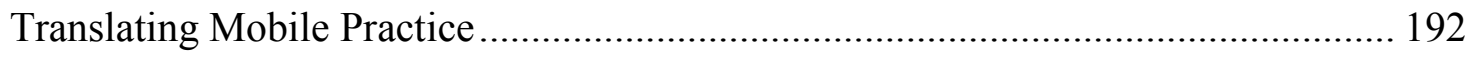

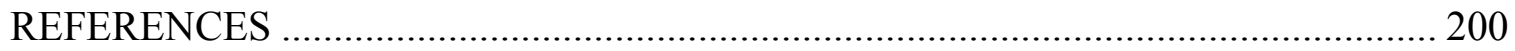

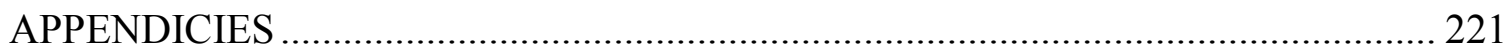

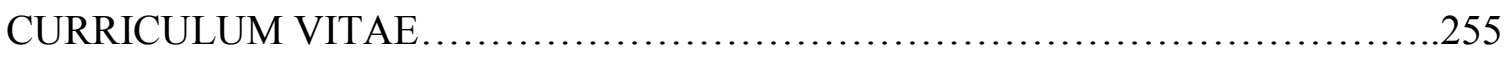




\section{LIST OF TABLES}

TABLE

PAGE

1. Common Core Anchor Standards: Writing Arguments - Grades 11\&12..........103

2. Common Core Anchor Standards: Writing Explanatory/Informative Essays - Grades $11 \& 12$

3. Common Core Anchor Standards: Narrative Essays_-Grades 11 \& $12 \ldots \ldots \ldots \ldots \ldots . . . .120$

4. Nadif's, James' and Katherine's ACT and Compass English/Reading Scores........125

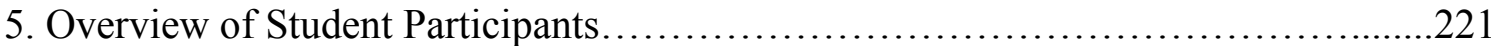




\section{INTRODUCTION}

That I never fully assimilated the bourgeois belief that rehearsal predicts the future is without a doubt a working-class legacy - Linda Brodkey

In many ways, the themes of this dissertation echo refrains that filled the ranchstyle rental houses, used sedans and minivans, poster-clad classrooms, family gatherings, and church meetings of my childhood and adolescence. In their efforts to discern and, in some ways, determine the futures of the children under their care, the adults that filled these spaces — parents, grandparents, aunts and uncles, family friends, teachers and ministers — issued a familiar call: "What will you be when you grow up?" And from earliest childhood, I knew my part: "baseball player," "musician," "writer." It didn’t take long for me to sort out a hierarchy of attainable careers from reactions to these answers. And in efforts to avoid condescension, I stopped sharing my desire to play in the big leagues and, instead, began offering more reasonable options: doctor, lawyer, minister. If they were within earshot, my mother or father faithfully concluded the refrain: "So as long as you go to college. College is not optional."

The inevitability of this proclamation, for which I am now truly grateful, was anchored by the weight of my parents' own educational pasts and occupational presents. They did not attend college, nor did their parents or their parents before them. In contrast to their own experiences at school and work, a college degree offered a sense of freedom and control, an opportunity to be your own boss, to call the shots. It promised stability 
and comfort. Like many in the working class, my parents considered these achievements unattainable for themselves but essential for their children.

My family came from people on the move, people in pursuit of work and foodmigrant cotton workers, soldiers, Swedish immigrants, Cherokee Indians. And we ourselves were a family on the move. Following my father's work, we moved at least once a year for the first seven years of my education. From kindergarten through the sixth grade, I attended seven public schools in seven districts in four states. This itinerancy meant that my intellectual ability was measured by the unique district and state standards operating in each new educational environment. Upon joining a fourth grade class in Lafayette, Indiana in the middle of the school year, I failed to spell a single word correctly on a test over the names of state counties: Tippecanoe, Kosciusko, Bartholomew, Vermillion. Each name the teacher recited, pushed me further away from the geographical and curricular space I was obliged to occupy. And each of my failed attempts to render these names correctly set me further back on the developmental timeline operating in this new environment. Kindly, the teacher patted my shoulder and assured me that the test wouldn't hurt my grade; she only wanted to determine where to start with me. And so the invisible boundaries that demarcated this unfamiliar state served as a diagnostic, marking me not only as an outsider but also as a student developmentally behind my classmates and "at risk" of falling further behind. My struggle to catch up in classes that I did not begin and would not finish continued throughout primary school.

I was a student at risk in transit across "a nation at risk." Beginning my educational career three years after the publication of the Reagan Administration's 
infamous report, I came to an understanding of the purpose of education and of myself as a student during the rise of an era of standardization that has now reigned for over three decades. ${ }^{1}$ To stem the "rising tide of mediocrity" that threatened, and apparently still threatens, "our very future as a Nation and a people," the state departments responsible for my education took up the report's charge of school reform for the maintenance of the country's "competitive edge... in world markets" (The National Commission on Excellence in Education 9, 10). To ensure that my peers and I would someday support and perhaps help extend this competitive edge through "gainful employment" in a "new information economy," we would be trained and measured in accordance with state standards of achievement and arranged on appropriate tracks of study (The National Commission on Excellence in Education 11). In Texas my academic ability and future potential was measured by the Texas Assessment of Academic Skills or the TAAS, in Oklahoma the OMAAP, in Kansas the KSA, and in Indiana the ISTEP. ${ }^{2}$ My inconsistent performances on these exams, due in large part to my inconsistent presence in any one school or state system, kept me securely situated in "regular" academic tracks and out of honors and advanced level classes. I expected little from these classes, and, for the most part, they demanded little from me.

By the time I reached middle school and my family entered a period of financial and geographic stability, my identity as an average student was firmly established among family, friends and teachers. Through middle and high school, I floated by with grades

\footnotetext{
${ }^{1}$ While standardized testing emerged alongside the Industrial Revolution, I follow Diane Ravitch and others in attributing the rise of the "standards movement" to A Nation at Risk (Death 22).

${ }^{2}$ These accountability systems have since been modified — in some cases, several timessince the passage of No Child Left Behind in 2001.
} 
good enough to keep me out of trouble at home and on sports fields after school. In this way, I spent my K-12 career riding the tide of mediocrity that threatened the nation. I graduated with a grade point average and test scores just good enough to gain access to an essentially open-admissions state university in the North Texas city that, by then, had become my family's home.

Unsurprisingly, upon entering college, I had very few ideas about what to make of the opportunity or of myself as college student. Slow to come to terms with the demands of late capitalism, my family and I still operated under the assumption that a college degree would ensure future success. It didn't matter what I studied, so long as I graduated. At the same time, my family's class status and the itinerancy of my childhood instilled a conviction that the future was ultimately out of my control. As Linda Brodkey expresses in the epigraph to this introduction, an assurance of or, at least, an illusion of control over the future may be a luxury of the middle-class, and, like Brodkey, I've never been able to fully embrace this assurance. ${ }^{3}$

I didn't gain a sense of control over my own academic work or educational trajectory until my junior year of college—a grade level I attained only because my parents were patient and insistent. Under the guidance of a few professors who challenged me to identify and investigate ideas important to me and to see my literacy practices as tools of meaning-making and self-construction, I gradually became more comfortable experimenting with language and literacy and different ways of knowing and understanding myself and the world. Perhaps for the first time in my life, I began to make

\footnotetext{
${ }^{3}$ I would add that, in an age of standardization and high-stakes testing, this sense of control may also be a luxury of enrollment in educational institutions with greater degrees of autonomy from state standards and assessments than those I attended or have researched.
} 
connections between ways of reading and writing and ways of thinking and living. Subjects became interesting because I began to approach them as discourses, as malleable and in process. Possibilities for meaning and, thus, possibilities for being could me made with and from them. In other words, I began to see myself as a contributor to the becomings of particular classes, conversations, identities and lines of inquiry shaping them. More and more, I gravitated toward teachers and courses that invited such becomings and avoided those that didn't.

As I reflect on this time in my life, I don't feel I was being called to a particular occupation or life pursuit; I wasn't discovering my passion. Rather, I was learning to exercise autonomy and exert agency in and through my work. I was not inspired to invest in this work by great texts or professors, though these certainly helped. Nor was I inspired by what this work might accomplish for me in the future. I was motivated by the work itself, in the present, and by the agencies made available through this work. It is important to note that I didn't experience this stage of my education as epiphanic; I was not once and for all transformed into an agent. Rather, I was beginning to realize the agency that emerged from my language and literacy practices. I was beginning to understand practice and structure as mutually constitutive and to recognize and reflect upon the ways in which my reading and writing choices both accommodated and transformed the institutional structures that enabled and constrained my work.

While still I don't read this as a period of dramatic conversion, I do consider it a time when my education became meaningful to me, in large part because of this increased sense of control. So as I think about how to encourage my own students or the students participating in my research to recognize the value and complexity of their 
literacy practices in and out of school and to consider what they might accomplish with these practices, this time in my life imposes itself as both a guide and a puzzle. That I'm much more interested in encouraging students to see themselves as active shapers of identities and societies than I am in bestowing the skills they are sure to need in the future is certainly a consequence of my own experience. However, I don't claim to fully understand how this gradual process of educational investment began nor could I inventory the host of influences that enabled it. Consequently, the question of how students begin to see themselves as agents, as makers of the becomings of place and identities that constitute the educational and occupational organizations in which they participate, is one I pursue throughout this dissertation (Pennycook, Language 140).

\section{Location and Intervention}

Of course, my social and historical situatedness and my own political interests have shaped my pursuit of this question and the others that drive this research. My perceptions and interpretations have been shaped by the experiences recounted above, along with many others. In "Beyond the Personal: Theorizing a Politics of Location in Composition Research," Gesa Kirsch and Joy Ritchie employ feminist interventions to consider how a politics of location might inform and change traditional research practices. They suggest that it is not enough for the researcher to claim experience as a source of knowledge and locate herself unproblematically in the text. She must rather reflexively examine her histories, positions and desires and the social, economic, cultural, ethnic, gender and personal forces and ideological structures shaping them.

Considering my own histories, alignments and affiliations, I am particularly attuned to the roles literacy plays in maintaining and demarcating inequalities among 
social classes. My own history of educational mobility has conditioned me to recognize and promote the values of students' complex and concurrent mobilities and has made me perhaps less inclined to attend to their drawbacks. In celebrating the opportunities these mobilities create, I frequently neglect the possibilities they prevent. I am also especially sensitive to the consequences of academic tracking and standardization and sympathetic to the struggles of first-generation college students. While not a deliberate decision, this concern likely influenced my choice to focus on the mobility narratives of two firstgeneration students and one would be first-generation student in the following chapters.

Reflecting on my changing locations as a participant-observer throughout this project, I've attempted to draw out the multiple, often conflicting and ultimately unknowable positions assumed by both myself and my participants and make apparent the asymmetries of power that have informed our interactions. I have also tried to make use of these positions to move the project, however cautiously, beyond concerns of interpretation to intervention - from reflecting on, to telling about, to changing. Kirsch and Ritchie assert that unlike the seemingly objective and strictly hermeneutic projects of traditional research, feminist research is characterized by its pursuit of change: "Feminist researchers not only set out to study and describe ... lives and experiences, but actively seek to understand and change the conditions of ... social and political realities" (536).

Of course, a researcher must pursue interventionist objectives with care, as asymmetries of power can undermine and threaten relations with participants. Kirsch and Ritchie suggest that researchers avoid attempting to create a false of sense of equity and instead make their unequal relations transparent and engage in collaborative practice to help reduce the distance between themselves and participants (538). In this way, research 
as interventionist praxis works from an admittance that the social hierarchies inherent in material, economic and political contexts remain intact but that their potentially oppressive operation is mitigated through an open negotiation with participants through reciprocal practice.

Thomas Newkirk suggests that when engaging in this process of researcherparticipant negotiation "university researchers who study the classrooms of public school teachers and subordinates (students and teaching assistants, nontenured faculty) have a special obligation to recognize the vulnerability of those they study" (5). In light of the vulnerability of the high school and college students and teachers who participate in this study, I have taken special care to introduce and carry out this research in a way that makes potential problems, issues and critical depictions apparent. To accomplish this transparency, I have attempted to design this project to be truly pedagogical. By creating opportunities for my participants to not only reflect on their own linguistic and literacy practices in academic contexts, but also to reflect upon and talk back to my interpretations of these practices and reflections, I feel that they and I have been shaped and reshaped through the ongoing process of negotiation that constitutes this critical ethnographic project.

\section{Chapter Summaries}

Following these feminist research orientations, the following chapters of this dissertation offer and theorize findings of a two-year mobile ethnography investigating the complexity of students' movements within and among secondary and tertiary educational institutions and the labor market. This project illustrates the lateral and recursive natures of students' educational and occupational trajectories and thereby 
reveals the mutually constitutive relations among scenes of writing across space and time. While the study follows eleven students moving from different tracks of high school English through their first years at research universities, colleges and full-time jobs, this text focuses specifically on the mobilities of three students: Nadif, Katherine and James. I draw upon a range of data types collected while participating in these students' patterns of movement in and across scenes of writing, conducting interviews in single sites and on the move, and analyzing their print-based and digital texts to represent intersecting and diverging movements across educational and occupational localities. Moreover, I use this data to investigate the ways in which students draw upon multiple literacies and linguistic resources to accommodate, resist and reformulate conventions of discourse, genre and discipline. Intersections and divergences among Nadif's, Katherine's and James' trajectories reveal how language and literacy practices are informed by the ideologies, experiences and habituated practices of and desires for mobility available in past, present and future scenes of reading and writing.

For example, the daily paths of Nadif and James intersect on a bus that shuttles them from economically depressed neighborhoods in South Louisville to their high school in an affluent East Louisville neighborhood. When they arrive at school, Nadif, a first-generation Somali immigrant, joins Katherine, a Mexican-American student, in advanced-level courses such as AP English. Meanwhile, James, an African American student, is assigned to "regular" courses, including a remedial English class. After school Nadif and James meet again at a city bus stop, where a northbound bus takes Nadif to his dual enrollment Pan-African Studies course at a research university, and a southbound bus takes James back to his neighborhood and part-time job as a grocery store clerk. 
Katherine drives her own car to work at the law firm of a family friend, where she takes dictations for legal documents and correspondence. After graduation, Nadif attends university on a full scholarship, Katherine's family pays for her enrollment at a community college, and James is forced to take on a second job after failing to secure funding for tertiary education.

Despite these diverging trajectories, my research reveals all three students as adept language users who blend a variety of languages, forms and styles to multiple effects in their writing. However, Nadif finds his own literate, lingusitic and discursive adaptations rewarding in ways that James and Katherine do not. In his movement from a refugee camp in Dadaab, Kenya to a preparatory school in Nairobi and from regular to advanced courses in U.S. high school and through college, Nadif comes to see his language and literacy practices as means of mobility. Contrastingly, authoritative sources of "standard English" often mark James' literate and linguistic innovations as deficiencies that prevent him from progressing from one predetermined level of education to the next. And Katherine's relentless attempts to conform to perceived standards and conventions of "college-level" writing belie the transformative aspects of her language practice. My reflections on the similarities and differences of these students' trajectories, along with the others followed over the course of this project, lead to considerations of the ways in which perceptions of language and literacy differences influence the material, imaginary, virtual and communicative mobilities of student writers. In light of these observations, I develop a theory of reading and writing as mobile practices and assemble a methodology to show how these practices are shaped by and shape the demands, constraints and possibilities for action in various scenes of writing. 
In Chapter One, I draw from fields of critical geography, mobility studies and theories of social and linguistic performativity to build the theoretical frame for the project. This frame presents space and time as essential elements of practice, produced through practice, and thereby challenges presentations of contexts as fixed and discrete locations. In other words, this framing reveals the ways in which such contexts are actually becomings of place constituted by institutional structures, social relations and individual movements through multiple frames of space and time. In this way, a theory of reading and writing as mobile practice highlights the irreducible complexity of students' conceptualized and enacted movements across educational and occupational scenes of writing.

I begin Chapter Two with a review of representative accounts of student mobility in composition studies to consider how our disciplinary stories configure the spaces, times, subjectivities and social relations of students' past, present and future scenes of writing. This review reveals a tendency in the field to reduce the complexity of students' language and literacy practices by essentializing writing contexts, students' subjectivities and language conventions and strategies. In the second half of this chapter, I draw upon complementary research methodologies - mobile ethnography, actor-network theory and participatory-action research — to construct a methodology for approaching the mobile practices of my informants in terms of the complex, often conflicting relations they are attempting to create, maintain, sever and transform along lines of race, gender, class, language and more.

Chapter Three employs this theoretical and methodological frame to explore perceptions and assessments of the language and literacy practices of Nadif, Katherine 
and James in the year leading up to their high school graduations. I propose that educational alignment initiatives operate as mobility systems enabling and managing these students' movements through bounded units of accountable space and time and consider how the most influential alignment initiative in the U.S., the Common Core State Standards, is implemented to exert control over the movements of students in and beyond high school. In tracing the trajectories of these students, I test out the limitations of dominant, border-based approaches to transitions and transfers of skills and knowledge from high school to college and/or careers. The chapter challenges neoliberal reform efforts to streamline, standardize, and manage the movements of students within and across educational and occupation environments and considers how writing scholars, teachers and administrators can help students recognize the ways their literacies and linguistic resources not only accommodate but also transform scenes of writing in high school and college.

In my final chapter, I investigate the ways student-object collectives constitute, connect and pluralize scenes of writing across space and time. This investigation reveals how Nadif, Katherine and James makes use of school buses and smartphones to create and maintain literacy networks across countries, cultures, languages, media, academic tracks and stages of education. By sharing resources and coordinating school work in collectives developed and maintained on the bus and from mobile devices, these students and their classmates exploit blind spots in institutional surveillance, challenge myths of individual effort and autonomous authorship, and permeate boundaries between designated tracks and stages of education. By highlighting their mobile practices within these collectives, the chapter suggests that the metalinguistic skills and dispositions they 
develops through these practices are, in many ways, more valuable than the disciplinespecific literate and linguistic competencies promoted by boundary-based pedagogies and curricula.

I conclude this dissertation with a brief consideration of affordances and limitations of metaphors of mapping and translating for literacy research and teaching and, thereby, attend to affordances and limitations of the metaphor of mobility itself for understanding and teaching literacy in high school and college.

By working with co-researchers in and across scenes of writing in high school, college, at work, home, in transit, and elsewhere this project complicates apparent boundaries between secondary and tertiary and in-school and out-of-school literacy practices; attends to conceptualizations of college writing from stakeholders "outside" the academy; provides insight into the complexity of students' movements within and between educational institutions; challenges notions of fixed locations and standards of language and literacy; and, thereby, works against the relentless future orientation of the U.S. educational-occupational system to recognize the value of students' literacy practices in the present. While this work is not without its shortcomings, I hope that, above all else, the depictions and interpretations presented here provide glimpses of the sophistication and innovation of students often overlooked, marginalized or excluded by our systems of education and society. 


\section{CHAPTER I}

FRAMING MOBILE LITERACIES: READING-WRITING AS MOBILE PRACTICE

To write about education is also to write about social attitudes and beliefs, for schools are porous institutions and what is outside their walls manifests within those walls. - Mike Rose

In pursuit of the achievement of "college and career readiness" for all students, stakeholders in the U.S. education system are investing historically unprecedented amounts of monetary, material and human resources in efforts to smooth out transitions among educational and occupational institutions. From the Bush Administration's No Child Left Behind to the Obama Administration's Race to the Top and the National Governors Association and Council of Chief State School Officers' Common Core State Standards, effectively managing the movement of students within and among institutions is presented as key to education reform in America. However, attention to this movement often reveals a valuation of place at the expense of mobility. In our attempts to chart or facilitate journeys from one stage of development, grade level, institution, discourse community or even social class to another, we often become preoccupied with the delineation of destinations, their boundaries and their attendant demands while neglecting the movements that connect and constitute them. We compile lists of content knowledge and skills required on the "college-level" and in the global marketplace. We measure students on scales of achievement and then place them in corresponding tracks of study. We enumerate and codify the genres, languages, activities and practices that ostensibly 
belong to various discourse communities and taxonomize the qualities that distinguish higher-order from lower-order thinking. In these ways and others, we limit conceptualizations of mobility by understanding movement only in reference to place, rootedness, boundedness and belonging.

This valuation of reified place orients educational activity in the present toward an absolute future by representing space-time as a static grid used to individuate and measure students' movements among fixed and discrete locations. To successfully transition from one level or institution to another, students must cultivate habits and accumulate the knowledge and skills demanded by the self-evident geographies of the future. The demands of the job market must be met in college courses, which must meet the demands of more advanced courses, while the demands of college determine the objectives of high school, and so on down the line. By confining conceptualizations of movement to places left behind and places of arrival, we fail to consider the various mobilities of people, objects, ideas and information and the relationships among these. By allowing preoccupations with absolute place to overshadow acts of displacement, we run the risk of missing the values and meanings embedded in individual acts of mobility. ${ }^{4}$

While there are a number of potential explanations for this emphasis on fixity over flux in formal education, two assumptions underlying our preoccupations are central to the purposes of this project. The first imagines movement as isolated from contexts of power, and the second assumes that such contexts preexist the movements that

\footnotetext{
${ }^{4}$ Investigating mechanisms of power that subordinate fluids to paths and lines of movement, philosophers Deleuze and Guattari assert that the power of the state is to direct movement along "pipes, embankments, which prevent turbulence, which constrain movement to and from one point to another." In this way, movement is always "dependent on the solid" and flows proceed "by parallel, laminar layers" (363).
} 
simultaneously constitute and are constituted by them. In this chapter, I challenge these assumptions and explore alternative conceptualizations of movement in space and time to build an interpretive frame for the individual and institutional representations and practices of student mobility that drive this dissertation — representations and practices I've gleaned from a two-year mobile ethnography investigating the complexity of students' movements within and among secondary and tertiary educational institutions and the labor market. This frame will also help me identify and ultimately align my research with theoretical and methodological approaches to composition and literacy teaching and scholarship that attend to relational and recursive dimensions of space-time and thus acknowledge the mutually constitutive relations among literacy practices and contexts of power. Such approaches suggest that space-time cannot exist apart from the practices that constitute it, practices shaped by a wide variety of disparate past, present and future ideologies of mobility.

Building upon these approaches, I seek to develop an understanding of writing and reading as mobile practices with material, imaginary, virtual and communicative dimensions shaped by and shaping the overlapping and diverging demands, constraints and possibilities for action available in high school, college and workplace scenes of writing and their governing institutions. I believe this attention to the complexity of movements within, among and beyond educational environments is crucial in light of an unprecedented exertion of control over student (and, thus, teacher and administrator) mobilities instituted by an educational-occupational regime streamlined to accommodate economic and competitive interests. 


\section{Key Terms for Mobile Practice}

Because terms such as space, place, time, movement and practice are used to build a range of meanings and associations in diverse disciplines, I'd like to take a moment to stake out terminological guideposts for my own movement through overlapping and sometimes conflicting schools of thought and educational environments. Following critical and human geographers (Pred 1981; Thrift 1977), I use the term spacetime to signal both the general context for movement and the inevitable product of movement. Space and time are mutually constitutive: space becomes dynamic and fluid through the passage of time, just as productions and experiences of time are contingent upon spatial variation. Consequently, all practices, activities and events have both spatial and temporal attributes. Moreover, practice doesn't merely occur in space and time; space and time are essential elements of practice and are produced through practice. As Alastair Pennycook suggests, this conceptualization of practice necessitates a spatial-temporal approach to context (Language 56).

This insistence on the indivisibility of space-time is one reason I prefer the term "mobile practice" to other descriptors of literacy practices already established in composition studies, such as Nedra Reynolds" "spatial practice." In an effort to think in terms of a multi-dimensional space-time able to cope with multiplicity, I prefer to configure practice as "mobile" rather than merely "spatial." Reading and writing are practices as temporal as they are spatial because they necessarily entail traversals through and actualizations of both space and time. And so rather than attempt to adjudicate as to the predominance of one dimension over the other, a focus on movement draws attention to the mutually constitutive relations of time and space. 
Of course metaphors of movement present their own problems for conceptualizations of literacy practice. As Reynolds suggests, rhetorics of mobility tend to "leave the materiality of place unexamined and reinforce the assumption that places, or their boundaries, are stable" (40). Rather than attending to how people move-why, with whom, and under what conditions-discourses of travel, journey, border crossing and movement often reveal a preoccupation with transgression that ignores the difficulties and economic realities of movement along with its potentially exclusionary nature based on race, sex, class and ability (38). While Reynolds works against the glorification of movement in postmodern discourses, she does suggest that productive ideas about movement are possible, "including those that try to connect movement to inhabitance, dwelling, or embodiment" (36). Following Reynolds' call for considerations of the materiality of movement, the theory of mobile literacies I trace out in this book attends to the embodied practices that connect and constitute localities and micro and macro scales of space-time.

In response to the prevalence of accounts that generalize or take for granted the natures of space and time, geographical theorists and philosophers offer the concept of place as a designation of socially structured space-time (Lefebvre 1991; Soja 1989; Tuan 1978). For these theorists, place signifies locations imbued with meaning and power: "A place is a center of meaning — we become attached to it, we fight over it and exclude people from it-we experience it" (Cresswell 3). In this way place is conceived as a relatively stable configuration of intersecting actors at a particular point in space-time. In many of these conceptualizations, place is presented as antithetical to movement. It is a break or a pause in the movement of social and historical influences - a "pause that 
allows a location to become a centre of meaning with space organized around it" (Tuan $14)$.

A potential danger for such representations exists in the tendency to take tableaus for realities. Actors frozen in space-time are easier to compare, differentiate and hierarchize than actors on the move. In our neoliberal educational-occupational system, this tendency can be most readily perceived in objectifications of individuals, institutional spaces (home, school, work, etc.), stages of life (freshman, dualist, post-conventional, etc.) and discourse communities (academic disciplines, workplaces, neighborhoods, etc.). Such objectifications necessitate demarcations of boundaries, enumerations and codifications of standards and administrations of measurement for the perpetuation of disciplinary power. They represent place as preexisting, self-evident and immovable. As David Harvey suggests, "If we regard space as absolute it becomes a 'thing in itself' with an existence independent of matter. It then possesses a structure which we can use to pigeon-hole or individuate phenomena" (121).

In language and literacy studies, this presentation of absolute space-time often informs an idea that languages and literacies are systems of communication used by people in different pre-determined contexts. Such notions of objectified context attribute irreconcilable linguistic and literate differences to contextual variation — the language and literacy practices required at "home" have nothing to do with those required at "school" or "work." Because these contexts are not figured as mutually informing-defining, constraining and enabling each other-individuals must translate differences across or between contexts. According to Bourdieu, this attempt to account for difference as a form of contextual variation from a core is bound by the same logic that promotes 
dichotomous relations between space and time and structure and agency (Language 82). Practices must conform to (or resist) the standards and expectations of static, predetermined contexts. In this view, places and contexts are sceneries in which practice occurs (Pennycook 58). Throughout this text, I refer to such representations as boundarybased approaches.

In opposition to presentations of place as static and self-evident, others (Pred 1984; Massey 1994; Giddens 2000; Reynolds 2004; Pennycook 2010) have developed theories of place as a socially and historically contingent process shaped by and shaping institutional and individual practices as well as the structural features with which those practices are interwoven. This relational representation suggests that there is no such thing as space-time apart from the interactions of social relations that constitute it. Place, as a simultaneous coexistence of social relations rather than an absolute context, cannot be conceived as static, as relations are always dynamic. This also means that place is vertical and thus stratified; it is a complex web of power relations, relations of domination and subordination. As Allan Pred suggests, place is a process "whereby the reproduction of social and cultural forms, the formation of biographies, and the transformation of nature ceaselessly become one another at the same time that space-time specific activities and power relations ceaselessly become one another" (282). In these representations, place is emergent and transcultural, constituted by practice, rather than preexistent and self-evident. It is this relational understanding of place that I both adopt and pursue in this project.

To avoid potential semantic slippages between objectified place and relational place, following Alastair Pennycook, I employ the terms locality and becomings of place 
to signify the dynamism, fluidity and stratification of place. The recognition that mobile practices produce space-time allows us to move beyond understandings of contexts as fixed and discrete locations to consider the ways in which they are actually becomings of place. As Pennycook suggests, a "focus on movement takes us away from space being only about location, and instead draws attention to a relationship between time and space, to emergence, to a subject in process - performed rather preformed - to becoming" (Language 140). This process of becoming is shaped by institutional structures, social relations and individual movements in concurrent micro and macro localities. In this way, mobile practices mediate desires, objectives, needs, commitments and affiliations embedded in everyday life (micro) and those pertaining to broader social, cultural or historical organizations (macro). Pennycook identifies these mediating practices as "meso-political" because they operate in accordance with both micro-level (individual life content) and macro-level (societal) scales of observation (23). It is the agencies that emerge from processes of mediation between micro and macro scales of space-time that I'm most interested in understanding and representing in my attention to students' conceptualized and enacted movements within secondary and tertiary writing environments. However, to arrive at viable representations of agency in contexts of literacy education, we must first attempt to unravel the objectifying boundary-based assumptions that ignore, suppress or disguise them.

\section{Space-Time and Movement: Assumptions and Alternatives}

Ideologies of mobility have always served to forward the project of public education. In the late eighteenth and early nineteenth centuries when industrialization, urbanization, and immigration began to reshape the economic and social order of the 
United States, public institutions, including public school systems, were developed to train and discipline a mobile wage-labor force (Katz 391). By crystallizing ideologies of democratic capitalism in institutional forms to assure their transmission, the school system served to reflect, legitimize and reproduce a social order in which individuals succeeded by virtue of their own talents. As Stephan Thernstrom writes: "The function of the ideology of mobility was to supply the citizens of nineteenth century America with a scheme for comprehending and accommodating themselves to a new social and economic order." The defining characteristic of this new industrial capitalist society "was its perfect competitiveness, which guaranteed a complete correspondence between social status and merit" (58). Upward mobility could be achieved in both school and society through the pursuit and attainment of standards of success available on the basis of individual ability.

This industrial-age connection between achievement in school and achievement within the social order has become an axiom of mobility in contemporary American society. In an era of outcomes-based education, the assumption of a causal chain linking academic credentials to occupational opportunity and prosperity has contributed to the expansion of an increasingly integrated educational-occupational hierarchy-a hierarchy that has grown continuously in a vertical direction since the turn of the nineteenth century. As the Harvard Graduate School of Education's Pathways to Prosperity Project asserts, "The message is clear: in $21^{\text {st }}$ century America, education beyond high school is the passport to the American Dream" (2).

In accordance with this truism, "college and career readiness" has become the state sanctioned target of education on every level, as evidenced in the recent development and widespread implementation of the Common Core State Standards. 
Adopted by 43 states, four territories and the District of Columbia, these standards attempt to identify "the knowledge and skills that our young people need for success in college and careers." The initiative also promises to "maintain America's competitive edge, so that all of our students are well prepared with the skills and knowledge necessary to compete with not only their peers here at home, but with students from around the world" (Natl. Governors Assn. Center for Best Practices \& Council of Chief State School Officers). In this way an educational-occupational hierarchy, fueled by the economic and competitive interests of state and business, is unified by an assumption of unidirectional movement linking individual achievement to educational and occupational success and global competitiveness.

However, the fordist model of mobility that undergirds this system becomes increasing difficult to sustain in the midst of a current global economic crisis and the coexistent and often competing presentations of mobility that accompany globalization and fast capitalism (New London Group 1996; Lu and Horner 2009). In "a world fundamentally characterised by objects in motion," it becomes increasingly difficult to manage the flow of "ideas and ideologies, people and goods, images and messages, technologies and techniques" that comprise locations of primary and secondary education, college, the labor market, and a present and future global economy (Appadurai 5). In this light, our valuations of place can be conceived as attempts to stabilize objects in motion. However, "relations of disjuncture" both precipitate and prevent this process of stabilization as objects, individuals, images and discourses travel at different speeds, have multiple and divergent points of origin and termination, and participate in varied relationships within and against institutional structures (Appadurai 5). 
In On the Move: Mobility in the Modern Western World, critical geographer Tim Cresswell suggests that the valuation of place that underlies this fordist assumption of upward mobility may be attributed to a lack of analytical distinction between movement and mobility, which results in a failure to recognize movements of people and things at all scales as products and producers of power. He draws this distinction by positing movement as mobility removed from networks of power. "Movement is the general fact of displacement before the type, strategies, and social implications of that movement are considered" (Cresswell 3). In this way, movement, as a concept distinct from mobility, assumes asocial, apolitical space; it is contentless, apparently natural, and devoid of meaning, history, and ideology.

In language and literacy studies, this positivist presentation of movement is evidenced in narratives of distribution, spread, transition and development in which linguistic and literate resources move in horizontal and stable spaces. Such models conceptualize time and space, often treated separately, in ways that confine the movements of languages and literacies to linear trajectories and discrete bounds of operation. As Jan Blommaert and April Dong assert, in models of language spread or distribution the conceptual development of space and time is superficial: "there is attention to generational transmission (time) and to the distribution of variables in one locality... (space)," but the object of study remains a "snapshot" (367-68). Like assumptions of movement informing most systems of formal education, which focus primarily on places left behind and places of arrival, narratives of distribution are primarily concerned with locating languages, literacies and individuals in their developmental and geographical places. 
Such assumptions are also characteristic of writing scholarship that relies upon cognitive development (time) or contextual variation (space) for representations of movement. The former figures time as an ascending line. Starting in the lower left corner of a graph and rising toward the upper right quadrant, this line charts the movement of a student through Kohlberg's three stages, Piaget's four, Perry's nine, Bloom's taxonomy or any number of alternative schema. Given "normal intelligence" and the right environment and allowing for retrogressions and plateaus, the natural movement of the "growth line" is onward and upward toward post-conventionality, committed relativism, reader-based prose, and so on. As Joseph Williams suggests, this stair step metaphor of movement encourages other metaphors: "If we 'lay a solid foundation in the base[ics],' and then 'reinforce' growth, the person both 'maintains' what she has learned and 'builds' on it toward mastery" (248). This representation freezes the movement of students in time by assigning them coordinates on a grid that correspond with the trending system of measurement: the student is "eighth decile IQ," or "eighth-grade reading level," or " $85^{\text {th }}$ percentile."

Investigating the ways in which such measurements create and delimit subjects (prisoners and students), Foucault identifies these assessments as "means of correct training" that work to separate, analyze and differentiate people as objects and instruments of disciplinary power (Discipline 170). As "observatories of human multiplicity," schools make visible and transform the individuals inside them through strategies of normalization, examination and placement (171). To ensure the efficacy of hierarchical observation upon which networks of relational power rely, students are measured according to fixed academic and behavioral standards - regularities imposed as 
rules - and placed on tracks and in classrooms corresponding with their designated grade levels, developmental stages, grade point averages, skills and aptitudes. Within these isolated and stratified places, students are enveloped and participate in a web of surveillance that works from "top to bottom but also from bottom to top and laterally" (176). Disciplinary power imposes upon and is perpetuated by students in an "uninterrupted play of calculated gazes" to ensure the objectification and partitioning of individual ability and behavior (177).

This surveillance is extended by a "network of writing," "a whole mass of documents that capture and fix" individuals (189). This network presents students as describable, analyzable objects with particular features and developmental trajectories and establishes a comparative system to designate groups and calculate gaps of achievement (190). In this way disciplinary power shows its potency by arranging objects in an endless process of assessment. "The examination is, as it were, the ceremony of this objectification" (187). Of course, these measurements are intended to serve as predictors and determiners of socioeconomic achievement. The measurements of some individuals, especially those whose "real-world" identities and values already correspond with the middle-class enterprise of formal education, will allow them to continue their ascendances, while the measurements of others will track them off the grid. ${ }^{5}$

Measurements of "natural" or "normal" development in and through absolute space disguise the ways in which students' movements shape and are shaped by disciplinary power and thus fail to present mobility as socially produced motion. Rather

\footnotetext{
5 James Gee uses the term "real-world" identity to describe students' extracurricular capacities, allegiances, desires, commitments, etc., which influence their school-based performances in various ways (Situated 112).
} 
than constituting a natural force, movement is made meaningful in mobility, and the resulting ideologies of mobility become implicated in the production of mobile practices. As previously stated, I conceive of these practices as combinations of material, imaginative, virtual and communicative mobilities that organize and propel individuals and collectives through space-time. In the context of formal education, writing and reading are mobile practices through which students are not only located in networks of disciplinary power but also continuously relocate themselves and others within and thus actualize these networks. Like de Certeau's well-known conceptualization of "walking in the city" as a practice that actualizes possibilities for movements and meanings available in the spatial order of the urban system, conceiving of reading-writing as mobile practices allows us to attend to the ways in which the things people do with literacies give meaning to the spaces in which they do them.

In the same way that de Certeau's vantage point from the top of the former World Trade Center immobilizes the "opaque mobility" of Manhattan in a "transparent text," educational networks of writing maintain impressions of frozen individuals in a static, self-evident system. However, like the city, this system is "prey to contradictory movements that counterbalance and combine themselves outside the reach of panoptic power" (de Certeau 95). Like urban systems, educational environments are not static, predetermined places; they are localities animated through mobile practice. The mobile practices of readers and writers — students, teachers, administrators, politicians and parents—-form a complex "nexus of practice" that actualizes the conditions of educational life and thus disrupts notions of a fixed grid of ability and achievement (Scollon 16). 
Unlike assumptions of movement across or between absolute places, this conception of mobility demands a more robust theoretical understanding of space-time as comprised of various scales or frames interacting with one another. According to Blommaert and Dong, space-time in this presentation is figured as vertical, as layered and stratified. "Every horizontal space (for instance a neighborhood, a region, a country) is also a vertical space, in which all sorts of socially, culturally, and politically salient distinctions occur" (368). Mobilities are therefore trajectories within and among networks of power - stratified, controlled, and monitored in accordance with various ideologies. It is these ideologies that connect mobility at the situational scale to mobility at other scales - social, economic, cultural and historical. This interplay of micro- and macrolevel scales propels and is propelled by individual and collective material, imaginary, virtual and communicative mobile practices. As Cresswell suggests, "Movement is rarely just movement; it carries with it the burden of meaning and it is this meaning that jumps scales" (6-7).

In Discourse and Social Change, Norman Fairclough, following Michael Halliday, considers this interplay of micro and macro scales by examining mobile practices that traverse and connect "contexts of situation" and "contexts of culture." Attending to the context of situation, Fairclough examines the manners in which meanings and linguistic choices are dependent upon the immediate situation in which a text is used-the time, location, participants and activities surrounding it. When considering the context of culture, he examines a broader notion of context that involves attention to institutions, social structures and ideologies - all of which inform text production and interpretation at the level of context of situation (4). According to Fairclough, mobile practices connect 
these scales because textual production and consumption are partially sociocognitive in nature; that is, they are based upon internalized social structures and conventions. He attempts to account for these sociocognitive processes by examining the elements of orders of discourse - i.e., "the totality of discursive practices within an institution or society, and the relationships between them" (43) — in relation to the "members' resources" individuals drawn upon in their productions and interpretations of meaning (72). Fairclough defines "members' resources" as "effectively internalized social structures, norms and conventions, including orders of discourse, and conventions for the production, distribution and consumption of texts, $[\ldots]$ which have been constituted through past social practice and struggle" (80). He suggests that it is through members' resources that the context of culture is brought to bear on the context of situation in which a socio-discursive event takes place.

Fairclough's configuration of the interplay between members' resources and orders of discourse accords with Bourdieu's theorization of the relationship between the habitus, as a set of dispositions inculcated since childhood that compel agents to act and react in certain ways, and a market that imposes as a system of specific sanctions and censorships (Language 37). According to Bourdieu these dispositions are ingrained in the body in such a way that they endure through the life history of the individual. And so an individual's habitus or member's resources orient her actions and inclinations without strictly determining them. Related to this notion of habitus is a process involving the organization of one's body according to ingrained dispositions, which Bourdieu identifies as the "bodily hexis," "a political mythology realized, em-bodied, turned into a permanent disposition, a durable way of standing, speaking, walking, and thereby of 
feeling and thinking" (Logic 69-70). In this way the body is a site of incorporated history. The structures through which bodies are organized are products of history and, at the same time, sources of practices and perceptions that reproduce history. To emphasize this relationship in which the most fundamental structures of a social group are situated in the primary experiences of individual bodies, Ron and Suzie Scollon substitute Bourdieu's "habitus" with the term "historical body" (Nexus Analysis 13). Because historical body situates social and personal histories more precisely in the individual body, I use this term, rather than habitus or members' resources, to refer to individuals' purposes, goals, dispositions, life experiences, and habitual ways of behaving and thinking.

In light of this conception of the historical body, mobile practices connect micro and macro scales of space-time by re-externalizing and thus reconstituting social and historical meanings in specific discursive events. When a first-year college student offers an interpretation of Morrison's The Bluest Eye for class discussion in her Introduction to Literature course, volunteers to sign up participants for a campus blood drive, reads a chapter on protein synthesis for Anatomy and Physiology, drafts a rhetorical analysis for first-year writing or even refrains from engaging in any one of these activities, she is not merely locating (or failing to locate) herself in the academy, as dominant discourses of transition would suggest, she is bringing a history of participation in multiple and concurrent contexts and cultures to bear in each of these situations and is thereby creating an academy with others through mobile practice. As cognitive scientists Humberto Maturana and Francisco Varela might suggest, this student is not participating in "the world but $a$ world which [she] bring[s] forth with others" (Tree 245). 
In light of Fairclough's presentation of the interplay within and among contexts of situation and contexts of culture, we can observe the ways in which the mobile practices of students in classrooms, at work, home, in neighborhoods, online and so on shape and are shaped by social, economic, cultural and historical ideologies of mobility available in and internalized through participation in various localities. In our attempts to simplify and streamline the movement of students from one reified place or level of experience to another-from home to school, from high school to college, from college to career, from novice to expert—we risk neglecting the complexity of competing meanings, demands, desires and multiple identifications afforded by overlapping and often conflicting micro and macro scales of space-time.

The substitution of this assumption of natural progression for an alternative understanding of mobility as movement within networks of power prompts a critical question for any consideration of students' mobile practices within and among educational environments; namely, what are the relations among networks of power and social and historical acts of mobility? Following this line of inquiry, many theories of composition associated with the field's so-called social turn move from "higherorder/lower-order" spatiotemporalizations of cognition to "insider/outsider" models that shift attention from a writer's development in time to her practices in social space. ${ }^{6}$

Diverging from a tradition of skills-based writing instruction and the attempts of some process-oriented compositionists to address the apparent cognitive deficits of students, many writing teachers, theorists and researchers turn to sociology, cultural studies, sociolinguistics and applied linguistics - to Foucault, Bourdieu, Stuart Hall,

\footnotetext{
${ }^{6}$ This trend is often associated with a larger shift from modernist concerns of "maturity" in time to postmodernist concerns of place and context (Bhabha 1994; Mingnolo 2000).
} 
Raymond Williams, William Labov, Shirley Brice Heath, and others- to draw support for their arguments that first-year students are not necessarily immature or cognitively deficient, but rather unfamiliar with the discourses privileged in the academy. Adopting a conception of discourse as not only constitutive of literacy practices but also of epistemologies, subjectivities and relations of power, many socially oriented compositionists argue that, often times, students' "primary" or "home" discourses inscribe worldviews much different from those privileged in the university.

In their arguments for theories of writing as social practice, these scholars assert that learning to write in academic contexts requires students to adopt new objects of knowledge and ways of being and doing through immersion in the social relations, cultural assumptions and textual traditions that comprise the academy. As Patricia Bizzell suggests, the difficulties experienced by entering college students "are best understood as stemming from the initial distance between their world views and the academic world view, and perhaps also from the resistance to changing their own world views that is caused by this very distance" (168). Drawing from literary-philosophical notions of interpretive communities and sociolinguistic concepts of speech communities, theorists like Bizzell conceive of the academy as a conglomeration of bounded communities and of entering college students as initiates into these communities. While socio- and applied linguists and social learning theorists like John Swales and Etienne Wenger theorize these communities as dynamic and negotiated, compositionists and educationalists—no doubt 
pressured by the material and economic demands of the educational-occupational system — tend to objectify, standardize and then teach the codes of these communities. ${ }^{7}$

Ron Scollon suggests that in the same way social practices become technologized as meditational means or cultural tools and then exert pressure through standardization and objectification of practice, communities of practice are often figured as "objectivized or technologized entities" (16). Even though "practice," and thus mobility, is a central concern for many of these boundary-based formulations, their focus remains on individuals as a group formed within a bounded entity of membership, of inclusion and exclusion.

While such presentations typically recognize academic contexts as layered and stratified, as Blommaert and Dong suggest, they also often operate in accordance with the assumption that contexts, discourse communities, communities of practice, etc. preexist and remain static during and after the movements that constitute them. Through the objectification of academic communities, boundary-based presentations often present school space-time as determined by preexisting and self-evident linguistic and discursive standards and conventions, which introduce and maintain acceptable social relations and worldviews, while outgoing high school and incoming college students are depicted as confronting an already assembled and stabilized state of affairs. While this depiction seems intuitive - first-year students must, after all, adapt to an unfamiliar environmentit relies upon the objectification of students, their historical bodies and university contexts: the world that imposes new demands on "entering" students requires

\footnotetext{
${ }^{7}$ Prefiguring Pennycook's notion of locality, Wenger describes landscapes of practice as "emergent structure[s] in which learning constantly creates localities that reconfigure the geography" (Communities 131).
} 
conformity to preexisting standards, which remain unchanged by the demands of the individuals "entering" it. First-year students assimilate to rather than (re)make the world of college.

In his attempt to reclaim the work of sociology as the "tracing of associations" rather than the designation of what is already assembled together, Bruno Latour characterizes such processes of objectification as consequences of the "sociology of the social," which figures the "social" as a specific domain of reality framing activities that reinforce, express, maintain, reproduce or resist a specific social order (Reassembling 9). Following this dominant conception of sociology, many writing studies limit their treatments of context to elements already assembled and accepted, hence the tendency, especially prevalent in writing scholarship addressing "transitions" and "transfers," to define the subjectivities, relations of power, discourses, genres and practices available in various discourse communities.

For instance, in her longitudinal study of one student's writing development from first-year composition through major courses and into his career, Ann Beaufort argues that a process of naming and articulating discourse communities is essential for providing students "a solid basis for transfer of learning from freshman writing to other contexts for writing" (College 42). For Beaufort, writing expertise is achieved through engagement in a preexistent discourse community that exhibits "a particular network of communicative channels, oral and written, whose interplay affects the purposes and meanings of the written texts produced within the community" (18, emphasis added). To make the transition from novices to experts, students must adopt the goals and values and master the practices and conventions of preexistent and self-evident communities. While the 
demands of various contexts do necessitate certain accommodations, the key problem with this discourse community approach is its singular focus upon student conformity to these demands. This focus often precludes considerations of the ways in which students might need and desire to transform the apparently preexisting practices, communities and environments they are attempting to "enter."

Moreover, the standardized practices associated with these supposedly predetermined communities are substantiated with ideologies of academic and social mobility that homogenize students' needs and desires and reinscribe a causal chain linking individual educational achievement to occupational success and prosperity. For instance, Russell Durst asserts that "one finds very little variation in the overall goals students express. Their aspirations are overwhelmingly pragmatic and utilitarian, far more focused on attaining practical skills and achieving career goals than on critiquing current society or developing reflective capabilities" (50). While Durst goes on to argue that compositionists should take students' goals into consideration when designing curriculum — a suggestion with which I completely agree—-he assumes these needs and desires are singular, stable, fully articulated and trained on a singular target, a target representative of status quo economic and competitive interests.

Responding to the appeals of pragmatic or instrumentalist writing pedagogies such as Durst's, Min-Zhan Lu and Bruce Horner agree that to "ignore students' financial concerns is unconscionable." However, they also assert that "to assume we already know what individual students might mean by the words they use to voice those concerns, and that they've had the chance to fully probe and articulate what they might mean by such terms, is equally unconscionable" ("Composing" 114). And so rather than homogenize 
students' desires in an attempt to simplify their movements toward objectified geographies of the future, $\mathrm{Lu}$ and Horner argue for greater attention to the mobility of social and historical meanings that intersect with and diverge from students' multiple trajectories through past, present and future curricular and extracurricular localities. In this way individuals' desires and practices do not merely reflect the demands of selfevident contexts of power, they also necessarily (re)shape demands and (re)constitute contexts.

This assertion of mutual constitution between practice and structure, individual and environment, is also represented in Alastair Pennycook's theory of language as local practice, which proposes that practices, specifically language practices, are activities that produce time and space. Rather than viewing contexts of power as static matrices within which practices occur, Pennycook conceives of practices as activities creating contexts. He asserts that the tendency to objectify practice and place results from a failure to understand structure as the effect of sedimented repetition and argues that repetition of practice is a "form of renewal that creates the illusion of systematicity" (47). And so the apparently preexistent and self-evident nature of a discourse community and its practices is illusory because "repeating the same thing in any movement through time relocalizes that repetition as something different" (41).

\section{Becomings of Places and Agencies}

In this way every accommodation of context through practice is also a transformation of that context. In their attempts to mimic or repeat the literacies and languages privileged in high school and college, students necessarily transform these languages and literacies and thus the institutions themselves through their "relocalizations" 
of practice (48). ${ }^{8}$ This understanding of repetition as difference imbues locality with a sense of time and mobility, as repeated language practices create rather than merely reflect social environments. "The locality of language practices is not then a stage backcloth against which language is used, but is a space that is imagined and created. The landscape is not a canvas or a context but an integrative and invented environment" (Pennycook 141). This conceptualization helps us move beyond an assumption of contexts of power that preexist movements to consider context as a becoming of place through mobile practice.

Rather than working to provide an explanation of what is already assembled together, Latour's "sociology of associations" addresses this process of becoming by attending to the movement of re-associations and re-assemblages that constitutes any social aggregate (9). Unlike the "sociology of the social" taken up by many compositionists to theorize movements from one domain to another, Latour's "sociology of associations," or Actor-Network Theory (ANT), redefines sociology as the "tracing of associations" involved in the progressive composition of collectives (9). " 9 "Social aggregates are not the object of an ostensive definition - like mugs and cats and chairs that can be pointed at by the index finger-but only of a performative definition" (34). In other words, groups are not stable and fixed but rather sustained through group-making efforts. "For ANT, if you stop making and remaking groups, you stop having groups"

\footnotetext{
${ }^{8}$ Pennycook uses the term "relocalization" rather than recontextualization to capture a sense of co-occurrence in time and place. Because practice is always local practice in the sense that it occurs in a particular time and place, the repetition of that practice elsewhere is always a relocalization, an act of difference and renewal (36). This complicates the dichotomy between the local and the global by conceiving of the latter as a co-occurrence of local practices in different times and places (128).

${ }^{9}$ Latour uses the term "collective" rather than "society" to supplant the notion of an already-established entity with a process of collecting associations (Politics 238).
} 
(35). And so attributions of stability or even ontology to a particular "community" result from the misrecognition of sedimented performance for underling rules. This recognition shifts the focus of movement in and among localities from merely joining and conforming to the making of agents along with the localities they are moving from and to or between.

In accordance with Latour's and Pennycook's performative theories of space-time, educational environments are not self-evident contexts in which linguistic and discursive practices are enacted. They are localities continuously re-imagined and re-invented through mobile practices that reflect and create associations among ideologies, people, objects, images, texts and technologies. Likewise, secondary and tertiary writing courses are emergent and transcultural rather than preexistent places — places constituted by overlapping and diverging linguistic and discursive resources rather than determined by the imposition of preconceived standards. In this figuration, students are not positioned as "insiders," "outsiders," "novices" or "experts" in relation to bounded communities, but rather are conceived as co-creators, actively making the progressive curricular and extracurricular collectives in which they participate.

Of course, figuring context as a becoming of locality through mobile practice does not dissolve the demands and constrictions imposed by these contexts. Stated or unstated, the rules and power relations that comprise social structures are always already built into historically and geographically specific systems, and the pressures they exert necessarily shape the conscious and habitual practices that comprise them. However, recognizing a mutually constitutive relationship between practice and structure can help us and our students see material, imaginary, virtual and communicative mobile practices 
and the contexts of situation and contexts of culture informing them as contributing to such becomings of place.

This alternative understanding of the relations between networks of power and mobile practices brings matters of agency to the fore. As Allan Pred suggests, rules and power relations do not only constrain and enable agency and practice; they also emerge out of agency and practice (281). Here, the idea of agency is not confined to acts of resistance against institutional norms and demands, as such acts work to reify myths of institutions as monoliths. Rather, agency emerges from acts of making in which individuals participate with objects to negotiate the demands of present exigencies in light of partial overlays or echoes from the past and projections of future possibilities. Individuals exert agency in their daily responses to overlapping and sometimes conflicting past, present and future desires, needs, objectives, pressures, affiliations and alignments emerging from their movements in and among concurrent micro and macro localities. Enactments of agency necessarily result from simultaneous and lateral movements in uneven and unstable social, historical, economic and geopolitical landscapes. As Marilyn Cooper suggests, "Individual agency emerges ineluctably from embodied processes; agency is inescapable for embodied beings" (443). And so instead of seeking to enable, allow, or create opportunities for individual agency, writing teachers should recognize students as productive agents already.

In light of an understanding of agency as embodied and emergent, a key objective for literacy instruction becomes helping students respond to the pressures of specific contexts of life and learning in ways that acknowledge their enactments of agency. And so our notions of embodied agency must account for social and historical as well as 
situational possibilities for mobility. To better understand the manners in which their mobile practices contribute to active productions of locality, students must attend to the specificities of micro- and macro-level contexts along with the specificities and complexities of their own goals, motives, desires, allegiances and commitments. Following Latour, this attention can be conceived as a tracing of the associations that constitute and connect micro and macro contexts rather than an enumeration and codification of their components. As students better understand, articulate and locate their own needs and desires within this network of associations, they may come to see their own mobile practices, informed by these needs and desires, as contributions to the assemblages of the collectives in which they actively participate.

To realize the agency that emerges from their mobile practices in various scenes of literacy, students must recognize and reflect upon the ways in which their readingwriting choices both accommodate and transform contextual norms and standards as well as social relations. Whether students choose to conform their practices to what they perceive to be fixed rules for reading-writing or choose to challenge or play with these rules, their decisions emanate from their senses of agency. As Lu suggests, "agency means to engage in proactive deliberation over the what of the actual scene of each instance of leaning and writing and the why of writers' options and decisions" ("Metaphors" 290). In their choices to accommodate and/or deviate from literacy and language standards, students are always, necessarily engaged in acts of difference and renewal through relocalizations of practice that transform standards and social relations (Pennycook Language, 36). In this way, agency is enacted in students' situated efforts to negotiate the demands of concurrent and often conflicting past and present contexts, 
investments, allegiances and ideologies in addition to their visions and desires for the future. According to $\mathrm{Lu}$, this conception of agency shifts attention from "what one produces to how one explores options and makes decisions when writing and learning" (291). Through such explorations, students might begin see themselves as makers of the becomings of dynamic and heterogeneous environments shaped in part by their socially, institutionally and individually informed perceptions and modes of participation.

In the next chapter I continue to flesh out this framework of mobile literacies by considering how epistemologically and methodologically representative accounts of student mobility, or mobility narratives, in composition studies attend to and represent individual and collective movements, reconstruct and project the places in and through which these movements occur, and situate subjects within these places and in relation to each other. In other words, I trace out similarities and divergences in the ways our disciplinary stories configure the spaces, times, subjectivities and social relations of students' past, present and future scenes of writing. This review sets the stage for the proposal of a mobile methodology (Büscher et al. 2010) that draws upon mobile ethnography (Marcus 1995), actor-network theory (Latour 2005), and participatory research traditions (Williams and Brydon-Miller 2004) to attend to enactments of agency evidenced in individual and collective efforts to reproduce and transform dominant practices, discourses, values, beliefs and interests through mobile practice. 


\section{CHAPTER II}

\section{IMAGINED MOBILITIES IN COMPOSITION STUDIES}

\section{It's not beginnings and ends that count, but middles. - Gilles Deleuze}

Composition, perhaps more than any other academic discipline, relies on representations of first-year college students and their educational pasts and futures for the formation of its own disciplinary identities. To maintain an institutional position at the threshold of college and thereby accommodate the material and economic demands of an increasingly integrated educational-occupational system, writing teachers and scholars often reconstruct students' educational histories and forecast their academic and occupational futures to trace trajectories from fixed points of departure to fixed points of arrival. ${ }^{10}$ The narratives of movement that connect these reconstructions and projections can be read as boundary-making devices that reinforce disciplinary differentiation for institutional or public approbation, legitimation, and support (Gal and Irvine 971). Even while some in the field have called for the abolition or revision of this institutional role, the discipline still largely relies upon stories of linear movement in and through educational environments to fortify a specialized knowledge of academic writing and solidify an institutional position as the corridor between students' literacy histories and

\footnotetext{
10 This institutional position is derided by many compositionists (Crowley 1991; Kaufer and Young 1993; Brannon 1995; Petraglia 1995) even while it contributes to the reduction of teaching loads, enables research, and funds graduate students and contingent faculty.
} 
futures. These narratives reify space-time and subjectivities by codifying practices, contexts, social relations, stages of life and discourses.

In the previous chapter, I drew upon sociological, geographical, and linguistic theories of performativity to sketch out an understanding of reading and writing as mobile practice, and I offered this understanding as an alternative to two predominant narratives of mobility in composition studies: the first figuring movement as isolated from contexts of power and the second figuring contexts as preexisting the movements that simultaneously constitute and are constituted by them. Underlying these presentations is a need to situate languages, literacies and individuals in their institutional and developmental places. In contrast, an understanding of mobile literacies with material, imaginary, virtual and communicative dimensions necessitates a spatiotemporal approach to context that sees space and time as essential elements of practice, produced through practice. This approach enables us to move beyond presentations of contexts as fixed and discrete locations and to consider the ways in which they are actually becomings of locality constituted by institutional structures, social relations and individual movements in and through concurrent micro and macro frames of space-time (Pennycook 14). By attending to mobile practices as acts of making space-time and subjectivities, we can shift the focus of student movements in and among educational environments from merely joining and conforming to the making of agents along with the localities they are moving from and to or between. In this way, a theory of reading and writing as mobile practice enables us to recognize the irreducible complexity of students' conceptualized and enacted movements within and among secondary and tertiary writing environments. 
In this chapter, I investigate conceptual and representational tools for attending to this complexity. Following the theory of mobility presented in the previous chapter and drawing more explicitly from mobile ethnography, actor-network-theory and participatory research traditions, I seek to construct a longitudinal methodology that attends to enactments of agency evidenced in individuals' efforts to reproduce and transform dominant practices, discourses, values, beliefs and interests through mobile practice. Central to this attempt is a consideration of the tensions that inhere in the relationship between the fixity of representation and the flux of mobile practice, a tension that presents questions of how to make practices legible without immobilizing practice in a transparent text. Critical geographer Doreen Massey addresses the limitations of representing a transitory world by asserting that texts, whose properties "necessarily fix," appear to deaden a life in flow (Space 15). To work against this deadening, while acknowledging that it cannot ultimately be avoided, I pursue a multivocal and intertextual representation of the mobile practices that constitute emergent high school, college and career nexus of practice.

To introduce the theoretical and practical specificities of this mobile methodology, I'd like to first consider how it overlaps with and diverges from representative stories of student movement in composition studies. This consideration begins with questions of how and why compositionists represent individual and collective movements, reconstruct and project the places in and through which these movements occur, and situate subjects within these places and in relation to each other. How do our disciplinary stories configure the spaces, times, subjectivities and social relations of students' past, present and future scenes of writing? And how do they conceptualize movement in and among 
these scenes? In this investigation of mobility narratives, I am especially interested in the various methods used, materials assembled and data collected to tell them. Because I believe all studies of student writing are also studies of student mobility, I have selected texts for analysis not typically read as mobility studies along with texts that present issues of mobility as a primary concern. By attending to narratives representing diverse stages, schools of thought and research methods in composition studies, I hope to illuminate overlaps and divergences in our disciplinary conceptualizations of student movement in and through academic space-times and situate my own project in relation to these conceptualizations.

\section{A Narrative of Cognitive Mobility}

In “The Composing Processes of Unskilled College Writers," Sondra Perl presents a multilayered narrative of mobility that continues to inform the field's conceptualizations of composing processes as they unfold in space and time (20). And while the "writing process movement" led by Perl, Linda Flower, John Hayes, Janet Emig and others has a become a floating signifier used to pit new theories against a generalized and devalued disciplinary past (Ede 63), retrieving and rereading Perl's study as a narrative of mobility might provide insight into enduring patternings of student movement in composition studies.

In this article, Perl introduces a nascent field of composition studies to Tony, a bilingual first-year college student from the Bronx with a child, an ex-wife, a part-time job and a full course load at a New York City community college. Perl's observations and analyses of Tony's reading and writing practices promise to provide insight into the ways in which "unskilled writers write;" to demonstrate how writing processes can be 
analyzed in a "systematic, replicable manner;" and to consider what these processes suggest "about the nature of composing in general and the manner in which writing is taught in the schools" (17). Through a series of think-aloud protocols from which composing behaviors are isolated and codified according to regularities and patterns within a student's writing process, Perl attempts to apprehend the sequence of behaviors that occur from the beginning of the process to the end so that she can determine the writing strategies employed; the frequency, duration and order of these strategies; and the cognitive "knots and tangles" (39) that "truncate flow[s] of composing" (31). The mobility narrative that contributes to and follows from this study is one in which rhythms of composing are characterized by a recursivity that "sets ideas in motion" through repetition. "Tony rarely produced a sentence without stopping to reread either a part or the whole...talking led to writing which led to reading which led to planning which again led to writing" (26).

Within this movement, the material, observable dimensions of Tony's mobile practices serve as vehicles for and reflections of cognitive, implicit dimensions. When considered in light of its recursivity, composing becomes the carrying forward of an implicit sense into explicit form. And then, through a process of revision, "the explicit written form serves as a window on the implicit sense with which one began" (35). This movement of ideas from brain to page and then back again sharpens Tony's cognitive awareness as his tacit ideas are realized through a process of materialization and revision. In this way, Perl's narrative of Tony's situated composing practices is not linear and straightforward: "movement forward occurs only after one has reached back, which in turn occurs only after one has some sense of where one wants to go" (34). 
Perl's attention to the micro bodily movements of "unskilled" writers reveals the mutually constitutive relations among recursive practices of talking-writing-readingthinking, and she takes this revelation as evidence that correcting any one of these practices will contribute to the correction of others. Clearer thinking will lead to clearer writing and a clearer, more accurate reading of one's own writing, which will ultimately cycle back to clearer, more objective thinking.

While Perl's analysis helps to reveal writing processes as complex phenomena worthy of empirical research and thereby helps to legitimate a marginalized discipline and its correspondingly marginalized scholars, teachers and students, her conflation of revision and clarification precludes considerations of the thoughts, feelings, needs and desires Tony excludes from his verbalizations in response to micro and macro social constraints. Because revision functions in the service of accuracy and clarity in both her research and in her interpretation of Tony's writing process, Perl fails to consider the influence of these constraints and possibilities for working against them and thereby dismisses Tony's potential need or desire to engage in this consideration himself.

This compulsion for clarity emanates, in part, from Perl's embedding of Tony's embodied practice in a meta-narrative of cognitive immobility. The dynamism of his composing process belies his cognitive fixity. Borrowing from Piaget, Perl asserts that students like Tony write from an "egocentric point of view": "While they occasionally indicated a concern for their readers, they more often took the reader's understanding for granted" (37). Following this developmental schema, Perl locates Tony in a state of confusion between the ego and the external world, which makes him unable to effectively participate in socio-discursive transactions. Because "the semantic model in his head 
predominated" (31), Tony "did not see the necessity of making [his] referents explicit, of making the connections among [his] ideas apparent, of carefully and explicitly relating one phenomenon to another, or of placing narratives or generalizations within an orienting, conceptual framework" (37).

To move from egocentricity to objectivity in his writing, Tony's mobile practices must first be extricated from the knotted and tangled habits imposed by his educational history. According to Perl, Tony is unable to move fluidly through local composing processes and progressively through a global developmental process because he has been "handicapped" from years of schooling facilitated by the "baffle[d] ... teachers charged with [his] education" (18). To repair this damage, Tony must be remediated through his access to the knowledge-generating research and theory engine of the university, a body and process of knowledge inaccessible to his previous, primary and secondary school, writing teachers. In this way, Perl's narrative configures knowledge as an intellectual resource rather than effective action in an emergent environment and arranges subjects in accordance with their proximities to this resource. The researcher transcends the network of relations that constitutes the scene of writing so that she can make sense of individual behaviors for the college teacher, who will then use this sense to unlearn the counterproductive behaviors inculcated by students' educational histories. ${ }^{11}$

Taking up the position of a "non-interfering observer," Perl seeks to apprehend observable sequences of behaviors and, thereby, render writing processes "Standardized,"

\footnotetext{
${ }^{11}$ While compositionists have challenged the positivism of writing process studies since their inception (Bizzell 1982; Selzer 1984; Reither 1985; Cooper 1986), such research agendas are still required to garner respect and, perhaps more importantly, financial support from deans, provosts and state and federal officials concerned with issues of literacy and education.
} 
"Categorical," "Concise," "Structural," and "Diachronic" (20). However, this apprehension requires the isolation of a single mobility—-Tony's composing processfrom the multitude of past, present and future mobilities and immobilities that enable it. But as critical geographer Peter Adey asserts, "Mobility is never singular but always plural. It is never one but necessarily many. In other words, mobility is really about being mobile-with" (18). Perl's painstaking attention to the relations among Tony's individual composing behaviors and her commitment to making the truth of these relations visible through examination disregards the constellations of mobilities that intersect with and inform these behaviors by disguising the network of power in which Tony's mobile practices, along with her own, operate.

Through this examination, Tony is rendered a describable, analyzable object-a case - used to produce generalizations about the natures and behaviors of other "unskilled" writers and to build up the knowledge and power base of composition studies. He is emplaced in a narrative of (im)mobility that attributes his "serious writing problems"- his abnormalities - to the interference of habituated practices that impede his movement from egocentricity to objectivity. And so while Tony's composing process is dynamic, his progress toward cognitive and discursive conformity is stalled.

Ultimately, Perl's pursuit of a "replicable method for rendering the composing process as a sequence of observable and scorable behaviors" results in a narrative that cleans the scenes of Tony's writing by individualizing and measuring his movement from one static, predetermined and self-evident cognitive location to another (18). Expanding Tony's "composing style sheet" to include the networks of people, objects, information and ideas that inform and are informed by his practice in these protocols would require 
Perl to undertake a project on the scale of that of the cartographers in Borges' "Del rigor en la ciencia," striking a "Map of the Empire whose size was that of the Empire." To avoid the impossible task of accounting for these influences in the construction of a point-for-point—standardized, categorical, concise, structural, and diachronic — map of Tony's composing process, Perl must eschew the complexity of mobilities both within and across multiple sites of activity by reducing mobility to an action of simply getting from one developmental stage to another. While such attempts to chart movements from fixed points of departure to fixed points of arrival and thereby locate students on a grid of cognitive and/or social conformity accommodate the ideological and material demands of many classroom environments and educational institutions, attention to the complexity of relations assembled by students' mobile practices in and through multiple localities requires the abandonment of any attempt to situate students and their mobilities in metanarratives of writing development.

As I'll assert throughout this chapter, this attention requires a shift from positivistic educational research to multi-sited mobile ethnography and from fixed and controlled research sites and subjects to becomings of localities and subjectivities through mobile practice. However, despite obvious points of conflict with this paradigm, Perl's study might offer some possibilities for mobile methodology in composition studies. As previously suggested, Perl's attention to the ways in which writers physically move through processes of composing points to the import of embodied practice for mobile ethnography. For a field with a long and varied tradition of text-focused attention to conceptual, social and discursive movement, especially in its treatments of student movements in and across multiple sites of learning (institutions, disciplines, communities, 
classrooms, etc.), Perl's attention to the micro bodily movements that comprise textual production - attention to more-than-representational doings of mobility—still serves as a valuable reminder for studies of writing processes. And while Perl ultimately focuses on these movements as physical evidences of tangled semantic models, such attention could provide insight into the ways in which situated practices shape and are shaped by interactions of tools (ideologies, tropes, symbols, pencils, paper, keyboards, computer screens, etc.) and people on micro and macro scales of operation.

\section{A Narrative of Social Mobility}

In their attempts to account for such relations and their influences on students' movements into college, many compositionists shifted their theoretical and pedagogical commitments in the $80 \mathrm{~s}$ and 90 s from coding and correcting writing processes to developing understandings of writing as a social process. As an alternative to the developmental, upward-and-onward narrative of growth offered by Perl and others, "socially minded" writing teacher-researchers proposed narratives of mobility that positioned student-informants as "outsider[s], standing outside a bounded area that defines the community of discourse" (Williams 250). According to Joseph Williams, this narrative exchanges notions of higher and lower thinking for divisions between "insider thinking (socialized/expert thinking) and outsider thinking (not yet socialized/novice thinking)," and requires a reconsideration of students' movements into the academy as processes of joining. Acknowledging mobility as movement within contexts of power, Williams asserts that "the movement from outside the circle to inside is not natural, inevitable, developmental." And so "the student who appears to be unable to join the community may in fact not be unintelligent, intellectually immature, etc., but rather a 
novice, unsocialized in ways that make him appear unintelligent, intellectually immature, etc." (250). As discussed in the previous chapter, narratives of academic socialization continue to dominate descriptions of student mobilities into and through the academy. ${ }^{12}$

For instance, in "The Novice as Expert: Writing the Freshman Year," Nancy Sommers and Laura Saltz review "600 pounds of student writing, 520 hours of transcribed interviews, and countless megabytes of survey data" collected in their extensive longitudinal study of undergraduate writing at Harvard to better understand the role writing plays in students' transitions into college (126). Drawing from this massive store of data, Sommers and Saltz conclude that first-year students must embrace roles as novices - "adopting an open attitude to instruction and feedback, a willingness to experiment, ... and a faith that, with practice and guidance, the new expectations of college can be met"- before they can begin the process of "writing into expertise" (134). In this narrative of social mobility, college is figured as a specific domain of reality constituted by values and activities that maintain a pre-established and self-evident social order. To join this order, students must first acknowledge their locations on the margins of a bounded community and reevaluate their ties to previous communities. Participating in the "sociology of the social,", describes in Introducing English as a "conceptual framework in which preliminary stages of civilizing precede conversion and in which a catechetical socializing of uninitiated

${ }^{12}$ Although many in the field have problematized narratives of academic socialization (Harris 1989; Trimbur 1989; Lu 1992; Horner 1994), their enduring appeal is evidenced in the predominance of place-based accounts of student mobility in composition studies. See Haswell 1991; Carroll 2002; Curtis and Herrington 2002; Beaufort 2007; Yancey 2009.

${ }^{13}$ See Chapter One for a description of Latour's distinction between the "sociology of the social" and a "sociology of associations" (Reassembling 9). 
aspirants is required before a cultural institution will embrace the outsider" (69). ${ }^{14}$ In their application of this framework, Sommers and Saltz figure writing as the mechanism of preliminary civilization, as it "helps to locate [students] in the academic culture, giving them a sense of academic belonging." As students gradually learn to leave familiar models of writing behind, they move through stages of catechetical socialization, learning the disciplinary approaches that make them "legitimate members of a college community" (131).

In the same way that Perl's diagnoses of students' cognitive deficiencies depend upon assumed histories or points of departure, Sommers and Saltz assert that students who fail to make the "paradigm shift" into college are those who "continue to rely on their high school idea that academic success is reflected in good grades" (140). "Freshman [sic] need to see themselves as novices in a world that demands 'something more and deeper' from their writing than high school" (133-134). In this representation, "high school" functions as a floating signifier for meritocracy, mechanization and structural determination; it is the static and uniform absolute space from which all students launch their college careers. And while such depictions may be accurate in some instances, here, a monolithic high school experience is presented without condition or complication even though the Harvard Study of Undergraduate Writing is limited to the single site of Harvard University. So, one obvious question to ask is: Where do these representations come from?

\footnotetext{
${ }^{14}$ While Slevin focuses primarily on the operations of this framework in discourses of colonial America, he suggests that such patterns of initiation continue to inform the ways in which students are introduced to the apparently stable and widely accepted cultural values and knowledge of the academy.
} 
In this narrative, students' histories are made transparent in representations of present (at the time of the study) dispositions and habits: "If there is one great dividing line in our study between categories of freshmen writers, the line falls between students who continue throughout the year not to see a 'greater purpose in writing than completing an assignment' and freshmen who believe they can 'get and give' when they write" (140). The former students cannot escape "high school idea[s] of academic success," while the latter accept the transactional nature of "college-level" writing. While I read the introductory phrase of this quotation as an acknowledgement of an oversimplified presentation of student expectations, perceptions and performances, an unacknowledged, and perhaps more damaging, reduction exists in their dichotomization of the meaningless writing of students' educational histories and "writing that matters" in college (139). This dichotomization not only reduces the complexity of writing in high school, but also precludes or ignores the possibility that students are remembering, participating in and conceptualizing scenes of writing outside contexts of formal education or that such activities might influence their approaches to writing in the first-year of college. In other words, to depict a process of academic socialization, Sommers and Saltz, like Perl, isolate and abstract a single mobility—student trajectories from high school to college—and thereby eschew the complexity of micro and macro mobilities within and across multiple sites of activity. This simplification reifies the historical localities of high school and college and reduces incoming students' histories of participation in various scenes of writing to insufficient ways of doing, being and knowing. As in Perl's narrative of (im)mobility, students in Sommers and Saltz's account are positioned in a state of 
confusion between the ego and the external world; only, this confusion is attributed to underdeveloped historical bodies rather than underdeveloped minds.

For instance, in their recounting of the first-year writing experiences of Jeremy, a student from rural Michigan, Sommers and Saltz seek to demonstrate the ways in which Jeremy's personal investment in the subject matter of his writing initially interferes with his movement from novice to expert, as it prevents him from developing the critical distance required to "offer an argument of interest to others" (144). Presumably, the others uninterested in Jeremy's personal investment are established members of the academic community. Excerpting a passage, "clearly written by a novice," from one of Jeremy's favorite papers composed for a religious studies course-Hindu Myth, Image and Pilgrimage-Sommers and Saltz suggest that Jeremy's desire to affirm his Christian faith, a key aspect of his historical body, leads him to misinterpret the purpose of the assignment that prompted the paper: "While Jeremy's assignment asks him to analyze an image, he instead outlines his process of understanding the image.... He locates the ultimate significance of the image in the way it makes him feel, as if the purpose of the assignment is to explain why he was drawn to the image, preempting any need for analysis" (143). For Sommers and Saltz, the purpose of this assignment is transparent in its call for "analysis," which they associate with a series of interpretive moves that draw upon academically sanctioned bodies of knowledge existing outside Jeremy's experience and understanding of the image. In this way, the purpose of the assignment and the practices required to pursue it preexist and preempt Jeremy's own purposes and mobile practices, and his failures to accurately interpret and accommodate these purposes and practices mark him as a novice. 
According to the authors, Jeremy's freedom to question his own religious identity in this assignment is a necessary first step and a "key difference between high school and college writing" (143); however, to productively use this freedom in the pursuit of expertise, he must learn to locate his interests in a disciplinary body of knowledge. Jeremy must "acquire the breadth of knowledge necessary to learn the disciplinary approaches that enable [him] to move from being [a] novice to being [an] expert" (144). Until he takes this disciplinary knowledge into his historical body, his own purposes, goals, dispositions, life experiences, and habitual ways of behaving and thinking will serve as obstacles to rather than resources for his movement from novice to expert. Ultimately, Jeremy is a novice because he has not yet learned to accommodate the demands of a static and self-evident context, and as a novice he has no formative power in this context.

In their presentation of first-year college students and their educational histories and futures, Sommers and Saltz are participating in an enduring disciplinary pattern of reification that precedes and extends beyond them. And like the objectives of most participants in this trend, theirs are worthy of pursuit. However, what a mobilities paradigm calls into question about such presentations is not the validity of their ends, but rather the methods employed and narratives constructed to chart progress toward them. In other words, like Sommers and Saltz, I want my students to "see what they can 'get' and 'give' through their writing"- I want them to "see a larger purpose for writing other than completing an assignment"- but I question the ways in which space-time and subjectivities are figured in representations of student movements in relation to these ends (146). By charting movements between absolute places left behind and places of 
arrival, such representations neglect the full complexity of verbal, conceptual, material and imaginary mobile practices that connect and constitute secondary and tertiary localities and micro and macro scales of space-time.

Following what Latour identifies as a "sociology of the social," Sommers and Saltz start with ostensive definitions of secondary and tertiary institutions. High school and college are stable spaces comprised of fixed temporal progressions and self-evident social relations, ideologies, values, genres and practices. Rather than the spaces themselves existing in a state of internal complexity, flux and consequent conflict, the only conflict in this figuration resides between spaces and frames of time; the meritocratic and mechanical nature of high school is in tension with the exploratory and generative nature of college. Consequently, incoming students are positioned between two worlds (rather than ten or twenty or sixty): "The first year of college offers students the double perspective of the threshold, a liminal state from which they might leap forward - or linger at the door" (Sommers and Saltz 125). And so students have two options: they can either move forward or not at all. With this frame in place, Sommers and Saltz design a longitudinal methodology to illuminate trends in student movement between two poles. Collecting data from a relatively large and then smaller sample of first-year students, ${ }^{15}$ they identify attitudes, behaviors and expectations that locate students on a scale of progress from points of departure (high school) to points of arrival (college).

As long as beginning and ending points are already established and the actors already determined, such methodologies can reveal a great deal about general trends and

\footnotetext{
${ }^{15}$ The large sample for the Harvard Study of Undergraduate Writing consisted of 422 students $(25 \%)$ of the class of 2001, while the subsample consisted of 65 students.
} 
trajectories. However, when localities and actors are not so stable and possibilities for action not so predictable, these methodologies have a difficult time keeping up with the circulating entities that bring about relationality within and between localities at multiple and varied distances. For instance, instead of cleaning the scene of Jeremy's writing for religious studies by reducing his needs, desires and purposes to obstacles on the road to expertise, we might consider how these needs and desires inform Jeremy's attempt to transform the purposes and practices of this particular scene. Among other questions, such an approach might ask how Jeremy's religious studies professor interprets the assignment and responds to the relocalization of that purpose in Jeremy's text. How do Jeremy's classmates influence his purposes and practices? How are these purposes and practices shaped by Jeremy's participation in concurrent scenes of writing? Where was this essay written and under what conditions? How do the assignment prompt and Jeremy's response to it contribute to the overall project of the course? How does this project relate to the institution's objectives for the course? Of course, these questions are better suited for an ethnographic project rather than the large-scale data collecting efforts of the Harvard Study, which brings us to a third prevalent method for representing student mobilities in Composition Studies.

\section{A Narrative of College and Career Mobility}

In Collision Course: Conflict, Negotiation, and Learning in College Composition, Russell K. Durst presents a narrative of student mobility informed by two years of sustained, ethnographic engagement with teachers and students moving through the firstyear composition sequence at the University of Cincinnati. As UC's Director of Composition, he conducts this research to better understand what he perceives to be 
student resistance to the cultural studies and critical pedagogy framework of the writing curriculum. This resistance, fueled by students' "pragmatic instrumentalism" (65), becomes the central conflict of his narrative. According to Durst, students' desires for the development of writing skills that will ensure success in school and financial security in their future careers and lives are at odds with the political goals of critical literacy; they feel their pursuits of upward mobility are thwarted by the curriculum's concern with fostering "awareness and appreciation of group differences, multi-perspectival consideration of ideas, and the questioning of established ways of thinking” (37). For Durst, the struggle between the vertical desires of students and the lateral, multidirectional pulls of critical pedagogy is key to understanding social relations, subjectivities, practices and outcomes in college composition.

To investigate the consequences of this tension, Durst follows the movements of a group of initial subjects - four students and a graduate student teacher - through two sections of composition. By tracing out the converging and often conflicting desires, objectives and practices of the informants that comprise these courses, he provides a detailed account of the ways in which official curriculums are enacted and transformed in specific scenes of writing. In addition to building thick descriptions (Geertz 1973) from multiple data sources, Durst engages in thick participation (Sarangi 2006) with informants, using his experience as a writing administrator, teacher and tutor to help students and teachers reflect upon, invent, develop and revise texts and patterns of classroom performance. Moreover, he occasionally contributes to class and small group discussions and activities and considers the ways in which these contributions positively and negatively influence group dynamics and courses of action. In this way, Durst goes to 
greater lengths than either Perl or Sommers and Saltz to develop reciprocal relationships with informants and locate himself in his text. Taking care to incorporate findings that do not always support his own conclusions, including a chapter written by his teacherinformant Sherry Cook Stanforth that complicates many of his own observations, Durst opens up possibilities for disrupting the unitary authority of his ethnographic text. In fact, my own reading against the grain of Durst's narrative of mobility is made possible by the transparency of his rigorous and self-reflexive research process.

While the comprehensiveness of Durst's methodology works to reveal the complexity of intersecting micro and macro mobilities in various scenes of writing, his epistemological and ontological assumptions tend to reduce this complexity. Rather than conceiving of social relations, subjectivities and localities as constituted to varying degrees by circulating entities, Durst's narrative of mobility, like Sommers and Saltz's, locates subjects at the threshold of a preexistent and self-evident academic community. Drawing upon the concept of ground rules from speech-act theory and pragmatics to establish the coherency and solidity of this community, Durst suggests that academic insiders rely upon a common set of ground rules - tacit expectations and mutually understood cultural knowledge - to successfully navigate social interactions in the university (66). While these rules are adapted by authorities to fit the demands of various contexts and courses, all members of the community operate in accordance with the same set of overarching principles governing ways of being, doing and knowing. The first-year writing teacher can possess her own underlying expectations of what students need to know and do in order to successfully carry out an academic task, but these expectations must ultimately conform to a preexisting canon of cultural "maxims" (71). And because 
first-year writing programs are largely governed by the expectation that, "in terms of their general behaviors and attitudes, students will begin the process of socialization into the academic community" (72), first-year writing courses are "in large part class[es] about ground rules, that is, about making clear to students the ways of thinking and communicating that will be expected of them [in college]" (71).

This notion of ground rules works particularly well within a sociology-of-thesocial framework as it starts with an assumption of stable overarching principles governing social interaction to investigate the ways in which people draw upon these principles to accomplish certain tasks. For instance, language philosopher J.L. Austin, whom Durst cites as a progenitor of this concept, famously asks how language, with its grammar and words, brings about certain effects on the world when people use itlaunching ships or sentencing criminals in speech acts that are activities in themselves, or convincing someone else to close a window or open a door through speech acts provoking others to take action. When translated from language to discourse theory, which Durst does via Stephen Levinson (67), ground rules become principles governing social interaction in a more general sense. And questions shift from how people do things with language to how they draw upon sanctioned ways of being, doing and knowing to join particular groups and participate effectively in particular settings. While such questions continue to propel productive investigations of language and behavior in various contexts, these investigations tend to begin with the supposed rules of language and discourse — systems and structures — to understand individual and group activity and practice. From this perspective, students' practices accommodate or resist a preestablished set of internal ground rules. 
Conversely, theories of mobility and performativity flip Austin's question, "asking not so much how we do things with words, as if the words instigated the doing, but rather how doing words is in itself doing things" (Pennycook Language, 17). In other words, rather than continuing to begin our investigations of students' movements into and through college by defining the supposed rules of language and discourse that determine and measure their participation in academic contexts, we might conceive of rulefollowing as institutional participation and thus structural (re)constitution. As David Bloor asserts: "The very ontology of rules is social and grounded in patterns of interaction" (104). In every performance and/or resistance of variously interpreted academic ideals, university stakeholders (students, teachers, administrators, politicians, etc.) necessarily transform supposed ground rules and thus the academy itself. "From this point of view, change, difference and flow are the norms, repetition is always different, and any apparent sameness needs to account for itself' (Pennycook 47).

Despite its subscription to the sociology of the social, Durst's narrative of mobility concludes with a call for curricular accommodations of such processes of cocreation or becoming. Only, rather than seeing students' desires as elements of institutional participation, always already making and remaking the ground rules that govern interaction in various scenes of writing in college, Durst wants to revise an existing system to incorporate students' career orientations. He "believe[s] that we need to show greater respect in composition pedagogy — and find a place in our course designs - for the more instrumentalist orientation of most of our students" (176). To make better use of students' careerism in the classroom, Durst proposes a pedagogy of "reflective instrumentalism," which “accepts students' pragmatic goals, offers to help 
them achieve their goals, but adds a reflective dimension that, while itself useful in the work world, also helps students place their individual aspirations in the larger context necessary for critical analysis" (178). As stated in the previous chapter, I agree with the impetus of Durst's call for attention to students' concerns about and desires for financial and career security. In fact, our attention to these concerns has become even more pressing since the publication of his text, as we find ourselves in era of enduring recessions, currency crises, overextended debt and sluggish demand.

However, I don't believe students' (or teachers') desires for mobility are always fully articulated or trained on a stationary target. The assumption that students are singularly motivated by occupational and social advancement- that they are concerned, above all else, with "being very well off financially" (Durst 170)_reduces the multiple and often conflicting needs and desires formed and transformed in their movements within and across concurrent micro and macro frames of space-time. For example, Durst suggests that the conservatism and career-orientation of Louise, a student-informant in her mid-thirties with three school-age children, prevents her from entertaining the social and political agenda of the second course in UC's first-year writing sequence. According to Durst, Louise is "extremely resistant to and confused by the demands of the critical analysis required in the assignments, not to mention suspicious of her teacher and impatient to ... get on with what [is] to her the important part of her college educationher nursing studies" (130). To take seriously Louise's instrumentalist needs and desires, Durst proposes a pedagogy that would welcome, incorporate and build upon her "primary reason for coming to college and studying composition"- - to move closer to a successful nursing career by attaining a necessary credential for the job market (178). However, 
Louise's own conception of a successful career seems to cover much more ground than Durst's static label of instrumentalism implies.

Rather than propelling her movement in a single, vertical direction, it seems to me that Louise's career orientation is informed by her movements within and among multiple localities and frames of space-time. Responding to an essay by Arlene Skolnick that critiques idealized representations of the nuclear family, Louise proclaims her belief in family and "home life" as "the foundation for success in everything" (132). She writes that a family "should have one common goal that they all work toward achieving. In our fast paced, stress filled society that we live in, this is a difficult task" (140). Rather than approaching college and career success as an individual and linear pursuit, Louise's conception of success is measured and attained collectively and is contingent upon her and her family's ability to negotiate the demands and goals of multiple and concurrent localities — in this case, home, school and work. Moreover, she seems to understand her family's pursuit of common goals as a means of resisting the speed of society and systems of education; the work of a family is often slow, inefficient and thus transgressive in a "fast paced, stress filled society." In this way, Louise's "traditional" conception of the nuclear family not only resists elements of the cultural critiques presented in course readings like Skolnick's essay, as Durst suggests, but also resists aspects of the instrumentalism he ascribes to her.

For instance, she is returning to school after fifteen years of working and raising children. During this period of time, Louise contributed to her family's shared goal by supporting her husband's pursuit of a college degree and by preparing her children to enter the public school system. Moreover, her approach to reading-writing assignments is 
calculated, recursive and collaborative, involving self-motivated processes of rereading and discussing difficult course texts with family members (151). Rather than "getting on with" her nursing degree, Louise's collective and lateral mobilities within and across localities of home, school and work complicate the notions of fast-track financial security implied in Durst's ascriptions of students' careerism. Speculating about the potential consequences of privileging vertical over lateral mobilities, Durst's teacher-informant Sherry Cook Stanforth suggests that, “maybe our students aren't really resisting school but its habit of insisting that they compartmentalize their lives" (qtd. in Durst 166). In other words, perhaps Louise is not as adamantly opposed to the social and political agendas of UC's composition sequence as Durst suggests, but is rather resistant to the program's assumption that issues such as race, class, family, gender, religion, etc. can be separated from students' college and career goals and can be treated as separate topics within separate units of study.

Durst's assertion that career aspirations can be accommodated by a writing curriculum that eschews the ways in which these aspirations are informed by complex networks of social relations assembled through mobile practices accords with Perl's and Sommers and Saltz's place-based attempts to reduce mobility to an action of simply getting from one developmental stage to another. Whether these stages are designated by cognitive, social or educational-occupational markers, the narratives that frame them tend to isolate single mobilities from the multitude of past, present and future (im)mobilities that enable them. However, the complexity of student mobilities within and across localglobal localities prevents us from assuming "a stability to what we or our students want (or need) and our ability to achieve it ourselves or give it to them" (Lu and Horner 
"Composing," 130). Lu and Horner assert that rather than making this assumption and disregarding the constellations of mobilities that intersect with and inform students' college and career goals, "we can join our students in thinking through the tensions and various possibilities of what we all might need, desire, and pursue in our work and in our composition" (130).

\section{Toward a Mobile Methodology for Composition Studies}

To better understand how our students' and our own college and career needs and desires shape and are shaped by physical, imaginative, virtual and communicative mobile practices, we must find ways to engage with students in investigations of individual and collective trajectories set in motion by the often conflicting demands of various scenes of writing. Rather than assuming that we or our students fully understand the desires and expectations that propel apparently linear and vertical movements between static, enclosed locations — high school, home, college, career, etc.—we must acknowledge the multiple trajectories set in motion by the demands of various institutional outcomes, material conditions, assignment prompts, class discussions, course readings, technologies, etc. for differently situated students. This understanding challenges us to engage students in grasping the specific, visceral-affective-intellectual labor required by such conceptualized and enacted movements and to help them realize the agency that emerges from their mobile practices in various localities.

To attend to the complexity of associations created and assembled by readingwriting practices in various scenes of writing, a literacy ethnographer must not only employ longitudinal methodologies, like Sommers and Saltz's and Durst's, to examine circulations of people, objects, ideas and information in diffuse space-time, but must also 
adopt an epistemological and ontological sense of space-time in perpetual movement: "The shape of this space is that of a river: not the surveyor's river which is simply a gap on the map, a frozen interval, but the river as a serpentine motion, as an evolving pattern of vortices, expanding and collapsing" (Carter 92). To avoid systems of representation that position subjects on scales of development (cognitive, social or educationaloccupational) in relation to "frozen intervals" - high school, college, career, etc.-I'm interested drawing upon the theoretical frames and representational strategies of what John Urry describes as a mobilities paradigm spreading through the social sciences.

In this paradigm, movement, blocked movement, potential movement (or motility) and immobility, dwelling and place-making are all viewed as constitutive of economic, social, and political realities. Rather than appealing to static systems to find and define underlying rules or methods, studies of mobility are concerned with describing the "methods that people use to achieve and coordinate the making of an always contingent ordering" (Büscher et al. 7). In accordance with this paradigm, I've designed a mobile methodology to investigate the ways in which students' literacy practices contribute to becomings of dynamic and heterogeneous scenes of writing and how they connect these scenes in (trans)formations of larger social, historical and educational systems.

Drawing upon complementary methodologies - participatory research, mobile ethnography and actor-network-theory—-this study seeks to comprehend and represent the mobility narratives of students told from their changing perspectives in the year leading up to and the year following their high school graduations. The study began in the spring of 2011 with high school seniors on three separate tracks of English study at a 
"failing" public high school, which I'll call Hughes High, in Louisville, Kentucky. ${ }^{16}$ I met them all through my work as a tutor-researcher assigned to their English classes by Hughes' "literacy lead," who paired me with three teachers, including herself, and placed me as a tutor-researcher in an AP Literature and Composition course, a Dual Enrollment Composition course and a Regular English course.

I chose to begin my study of student movement at Hughes for a number of reasons: 1.) The school is known for the diversity of its student body. While Hughes is located in a relatively affluent, predominantly white neighborhood in East Louisville, the Jefferson County Public School System buses large numbers of students there from working-class and predominantly minority neighborhoods, contributing to a total minority enrollment of $64 \%$ and a population in which $74 \%$ of students are identified as “economically disadvantaged” (Division Data Management 2012-2013 Data Books). Hughes also has one of the largest contingencies of international students in the district. During the 2011-12 school year, the international population was comprised of students from eighteen different African, Asian, Central European and Near Eastern countries. 2.) Prior to the study, I worked with two of Hughes' English teachers training to teach the first course of the University of Louisville's composition sequence for dual enrollment credit at Hughes. As Assistant Director of Composition, I met with these and other teachers in a small cohort to discuss ideas emanating from a class they were taking on writing pedagogy. My relationships with these teachers challenged many of my preconceptions about the nature of writing in secondary schools and provided insight into

\footnotetext{
${ }^{16}$ I began working in as a writing tutor in these three classes in October 2010. After receiving IRB approval, the official study began in February of 2011. In addition to keeping up with the trajectories of graduating seniors, I returned to Hughes for the 201112 academic year and worked with graduating seniors through the 2012-13 academic year.
} 
the complexity of teaching "college writing" in high school. 3.) Finally, Hughes was only three miles from my residence when the study began, a proximity especially important considering my primary means of transportation at the time was a single passenger motor scooter that I drove in all manner of weather. I introduce more details about the history and current status of Hughes as they relate to the mobility narratives I present in the following chapters.

Following participatory research strategies, which engage all participants as contributors to the research process with equal claims to the ownership and control of the knowledge generated by this process, I spent approximately four months at Hughes as a writing tutor before defining research questions and goals and formulating the framework for the study. During this time, I observed classroom practices, listened to students' and teachers' concerns about past, present and future literacy demands, participated in class discussions when invited, and talked with students about their writing for school and other localities. I tried to learn from students and teachers about the practices that constituted scenes of writing at Hughes and about the institutional, social, cultural and historical influences shaping and shaped by these practices.

When the study began, the school was undergoing an audit by the Kentucky Department of Education because its reading and math proficiency scores on "core content" standardized tests were among the lowest in the state. This process brought rhetorics of college and career readiness to the fore as state auditors pushed school administrators and teachers to intensify their efforts to conform students to newly devised Common Core State Standards. As doubts and fears surrounding issues of college "readiness" spread from administrative offices to classrooms, hallways, local media 
outlets and dining room tables, more and more students began to approach me as an emissary from the realm of their near futures, capable of providing a glimpse of the expectations and demands that they were apparently unprepared to meet. The more the students asked me to map the geographies of their futures, the more I was confronted with my inability to do so. As a result of these interactions, my own questions about the complexity of student movements within and among high school, college and occupational scenes of writing originated from and were developed in collaboration with the people for whom these concerns were most pressing. As Bronwyn T. Williams and Mary Brydon-Miller suggest, this participatory approach changed the one-way direction in which I expected "knowledge and expertise to flow-from the researcher to the participants - to a more complex and truly dialogic process in which all are involved in research, reflection, and education" (249). According to this dialogic process, the development of research questions and objectives, generation of knowledge, collection and interpretation of information and creation of texts, followed from an extended period of listening in which I sought to gain a better understanding of the literacy needs and challenges facing the students involved in this study and to identify the conceptual frames students' and institutions use to describe these challenges and needs.

The political agenda of participatory research, which includes a commitment to the co-creation of knowledge and development of sustainable structures for change, requires a reconceptualization of traditional relationships between researchers and participants and a careful consideration of ethics of representation. Accordingly, an openness to and respect for the knowledge of teacher and student-informants is a primary concern and key element of reciprocity in this study. As Katrina Powell and Pamela 
Takayoshi assert, "authentic reciprocity involves researchers and participants constructing roles for one another and negotiating those roles both within and outside the context of the research project" (401). In this relationship, reciprocity is conceived as a dynamic, contextually contingent process requiring the perpetual reconstitution of the relationship between participants and researchers. As Patricia Sullivan suggests, "if our status is presumed as a given at the outset of the study rather than as a formation in relationship to an other, we may miss opportunities to learn how we are being constructed and the effects such constructions have on the other literacies we then "uncover"' (106$07)$.

This process of co-construction is especially pronounced in a multi-sited ethnography, such as this one, as the movements of participants and researchers within and among localities and over time facilitate a perpetual transformation of subjectivities and relations of power. Attention to this evolving flow of people, objects, information and ideas requires me to continuously reexamine my own historical body, positions and desires and the social, cultural and personal forces and ideological structures (re)shaping them. Over the course of this study, my roles as tutor, researcher, instructor, advisor, advocate, friend, institutional outsider and institutional agent diverge and overlap in accordance with the changing subjectivities of the students I follow within and among scenes of writing in high school, college and work. In some instances and stages of the research process, students conceive of me as an authority of college writing, despite my attempts to complicate the singularity of writing in college and thus my apparent authority, and in others participants approach me as a student, ignorant of their literacy experiences in and outside contexts of school. As you can imagine and as you will see in 
the following chapters, my own movement between poles of authority and ignorance provokes a range of participant responses. From positions of generosity to dependency to frustration to dismissal and resentment, my and my participants' subjectivities and attendant practices and emotions constitute a complex network of power relations in perpetual flux. In light of this complexity, the politics of location informing my work draws out the multiple, often conflicting and ultimately unknowable positions assumed by myself and my participants and seeks to make apparent the asymmetries of power that inform our interactions. The following chapters reveal ways in which my participants, myself and our texts are shaped and reshaped through an ongoing process of negotiation that constitutes the participatory research project.

In light of this process of mutual constitution and following Thomas Newkirk's "ethics of rendering," I conceive of the co-interpretive rights of participants as a crucial component of this study (13). To facilitate this co-interpretation and, thereby, attend to the multivocality, intertextuality and interdiscursivity of the mobile practices under consideration, I approach participants of the study as co-researchers. Roz Ivanič suggests that in participatory research distinctions between researchers and the researched can be minimized as participants take up projects to pursue various objectives (Writing 110). While I seek to gain a better understanding of how student-writers' mobile practices help constitute and propel them through various curricular and extracurricular localities, I believe the students and teachers who participated in the project as co-researchers benefited from literacy work that challenged them to make visible, reflect upon and thus gain greater control of the representational resources they use to make meaning, which I hope has, in turn, enabled them to better understand and pursue possibilities for working 
academic and occupational literacies. By making my own observations and textual representations known to co-researchers over the course of the study through means described below and by creating opportunities for co-researchers to respond to these observations, I present a collaborative and polyvocal ethnographic text that encourages multiple and contested interpretations, "a chorus of competing and perhaps irresolvable readings of the same "text"' (Newkirk 12).

I met all my co-researchers in the English classes where I served as a tutorresearcher. Students were selected from each course according to their expressed interest in the study, their college or career plans after graduation, and their availability to meet during or after school. I did not turn away any student interested in participating in the study. This openness resulted in a group of co-researchers with significant differences on many dimensions. While the findings presented in the following chapters draw upon interviews with and texts collected from three high school English teachers and eleven students, the core of this study was developed in collaboration with three students from Hughes' class of 2012, who continued their work on this project in the year following their high school graduations. One of these co-researchers works part-time and attends the University of Louisville; one works fulltime at multiple jobs; and one works fulltime as a hair stylist after attending community college for one year after high school. Details of these students' lives are introduced through the intersecting and diverging mobility narratives that comprise the following chapters. ${ }^{17}$

Ultimately, I associate the methods used to trace out and represent these narratives most closely with mobile ethnography, which anthropologist George Marcus

\footnotetext{
${ }^{17}$ A table providing demographic information for participants not introduced in the following chapters is included in Appendix A.
} 
describes as an effort to "move out from the single sites and local situations of conventional ethnographic research designs to examine the circulation of cultural meanings, objects, and identities in diffuse time-space" ("Ethnography in/of" 96). By moving with and allowing themselves to be moved by their participants, mobile ethnographers seek to trace connections, associations and relationships formed by the interdependent and intermittent movements of people, things and ideas. This methodology accords with participatory research strategies by acknowledging but not relying upon macrotheoretical concepts or meta-narratives for the contextual architecture framing a set of subjects. As Marcus suggests, "Just as this mode investigates and ethnographically constructs the lifeworlds of variously situated subjects, it also ethnographically constructs aspects of the system itself through the associations and connections it suggests among sites" (96).

And so by tracing the mobile practice of eleven students across and within multiple sites of activity, this study destabilizes distinctions between the micro and macro, local and global, lifeworld and system by revealing how various kinds of "moves" make social and material realities. As sociologists Monika Büscher, John Urry and Katian Witchger suggest, studies of mobility go beyond considerations of how people make knowledge of the world to attend to "how they physically and socially make the world through the ways they move and mobilise people, objects, information and ideas" (14).

By conceiving of scenes of writing as emergent and transcultural, constituted by the overlapping and diverging mobilities of people, objects, ideas and information rather than determined by the imposition of preconceived standards, ground rules and conventions and by recognizing students as co-creators, actively making the progressive 
curricular and extracurricular networks in which they participate, this project shifts the common frame of reference in composition studies from ostensive to performative definitions of movement within and across scenes of writing and shifts research efforts from locating to following actors. As Latour asserts: "Either we follow social theorists and begin our travel by setting up at the start which kind of group and level of analysis we will focus on, or we follow the actors' own ways and begin our travels by the traces left behind by their activity of forming and dismantling groups" (Reassembling 29).

Latour locates this activity of group making and dismantling in actor-networks or associations of humans and nonhumans that present themselves as "matters of concern," which "provoke perplexity and thus speech in those who gather around them, discuss them, and argue over them" (Politics 66). Unlike representations of scenes of writing as indisputable realities, matters of concern have no clear boundaries, "no well-defined essences;" their producers are no longer invisible or detached; they dissolve distinctions between the sociopolitical and the scientific; and their activities have far-reaching and often unexpected consequences (24). In accordance with Latour's schema, attention to writing practices cannot be limited to the performance of a solitary individual, verbalizing a semantic model to fulfill a singular objective, but must rather be distributed among all relevant propositions of humans and nonhumans constituting the process as a matter of concern. He identifies this attention as an act of taking into account characterized by perplexity and suggests that the number of entities contributing to a matter of concern must not be "arbitrarily reduced in the interest of facility or convenience" (110). 
My own attempts to account for all relevant contributors to or actors within a scene of writing have required me to not only reflect upon my own changing locations in relation to my co-researchers, but to also consult other influences acting upon their mobile practices; including, their writing teachers, classmates, families, cultures, socioeconomic statuses, genders, the material affordances and constraints of the study, the tools they write with and on, their needs and desires for composing and for pursuing a college degree, career and so on. Rather than isolating the mobile practices of a single actor in this study, Latour's actor-network theory prompts me to attempt to facilitate the articulation of all relevant propositions in any particular matter of concern.

In "Composition 2.0: Toward a Multilingual and Multimodal Framework," Steven Fraiberg draws upon Latour's actor-network theory to propose that compositionists conceive of "the writing process as bound up in complex cultural and genre ecologies with writers reconceptualized as 'knotworkers' engaged in a continual process of tying and untying of languages, texts, tropes, narratives, images, sounds, and ideologies distributed across far-flung networks" (116-117) ${ }^{18}$ In Fraiberg's presentation, writing becomes a process of rearticulating, reassembling, and redesigning complex associations of tools and people. Rather than untangling composing processes so that students might engage in clearer thinking and writing, as Perl suggests, Fraiberg's framework asks writing students, teachers and researchers to make use of the social, material and semiotic relationships entangled through their mobile practices and to consider the ways in which these knots are distributed, consumed, incorporated and transformed in "wider cultural,

\footnotetext{
${ }^{18}$ To move beyond representations of movements of literacy from one context to another, Ivanič et al. (2009) also make effective use of actor-network theory in their research of college students' literacy practices across the curriculum (176).
} 
national, and global spheres in a continual process of tying and untying” (Fraiberg 106). To approach writing processes in this way, as matters of concern rather than matters of fact, I work with my co-researchers to trace the associations of heterogeneous elements shaping and shaped by these processes. ${ }^{19}$ Rather than attempt to enumerate and codify these elements, I conceive of this mobile research as a revisionary practice in which my co-researchers and I reflect upon, reread and rewrite the specificities of micro- and macro-level contexts along with the specificities and complexities of our own goals, motives, desires, allegiances and commitments to expand possibilities for meaningmaking through mobile practice. In this way, research and revision work in the service of complexity rather than codification, as notions of rhetorical choice, agency and invention are considered in terms of relationality rather than autonomy and mastery.

Conceiving of writing processes as matters of concern shifts the focus of my research from apprehending, measuring and correcting behaviors to tracing connections between ways of reading and writing and ways of thinking and living. This focus enables me to approach the mobile practices of my co-researchers in terms of the complex, often conflicting relations they are attempting to create, maintain, sever and transform along lines of race, gender, class, language, education, religion, profession, family and more. In other words, it allows me to engage with students in a consideration of the ways in which their (im)mobilities in writing environments are informed by historical bodies and historical localities - the ideologies, experiences and habituated practices of and desires for (im)mobility available in their past, present and future lifeworlds.

\footnotetext{
${ }^{19}$ In contrast to matters of concern, Latour identifies matters of fact as "indisputable ingredients of sensation or of experimentation" (Politics 244).
} 
As discussed in the previous chapter, Ron and Suzie Scollon describe the historical body as an individual's purposes, goals, dispositions, life experiences, and habitual ways of behaving and thinking (46). When people enter into social action, they bring along their own skills, experiences and competences, which condition and constrain what they can do in social action. As Jan Blommaert and April Huang assert:

"Participants in social action bring their real bodies into play, but their bodies are semiotically enskilled: their movements and positions are central to the production of meaning, and are organized around normative patterns of conduct" (9). Therefore, the notion of a historical body underscores the inextricability of semiotics and embodiment and situates cognition within a broader paradigm of embodied knowledge. Moreover, individuals bring their bodies into play, as we have seen, in dynamic, agentive and stratified localities. The institutional structures, material conditions, social relations and individual movements that comprise these localities contribute to an accumulated history of normative expectations, and accommodating (and/or resisting) such histories is part of the process that constitutes a historical body. In this way, historical bodies and historical localities are mutually constitutive: We become enskilled through our participation in social and material spaces, and the histories of participation we bring to these spaces contribute to the practices that constitute them. Scollon and Scollon's historicization of bodies and localities provides me with a powerful frame for direct observation of the micro-bodily movements that constitute individual and collective composing processes. For mobile ethnography, it is not enough to consider traces of practice in texts; the researcher must attend to the internalized institutions, structures and ideologies that 
constitute an agent's historical body and the ways in which this historical body influences more-than-representational doings of mobility.

Of course, the task of tracing relationships formed by such traversals within and across far-flung networks presents considerable challenges for this study and for mobile ethnography in general; the greatest of these being the very complexity it works to understand and maintain. Considering the irreducible complexity of associations assembled through mobile practice in various scenes of writing, I've grappled with how to avoid the fate of Borges' map, deemed too cumbersome to be useful, when tracing these associations. Following linguist John Gumperz, Theresa Lillis provides one possible answer to this question by distinguishing between notions of context and contextualization: "Whereas context from a researcher's point of view could be potentially infinite, contextualization comprises participants' activities and understandings that make relevant any specific aspect of context, in this case, to specific acts and practices of academic writing" (360-361). Lillis suggests that one affordance of ethnography as a method for generating conversations with individuals about their writing — what she refers to as "talk around texts" - is its ability to foreground insider or emic perspectives: "Talk around text aimed at seeking out emic perspectives is one important way of exploring what is or isn't significant, from the rather large notion of context, to specific individuals in their specific sociohistorical writing trajectories" (361). In many ways, this description of contextualization accords with actor-networktheory in that actors determine the significance of the connections created, maintained, transformed and severed in their activity. However, as Lillis suggests, this approach also presents a number of limitations. First, there is a temptation to take emic perspectives, 
expressed at single moments in time, as representative of a writer's comprehensive experience and to reify these perspectives at the individual and/or group level (Lillis 361). For example, in Sommers and Saltz's study, Jeremy's principal concern with his own spirituality marks him as a novice not only in a particular scene of writing but also in his general relation to the academy, and this immobilizing concern is taken as representative of the concerns all first-year students must learn to fit into disciplinary pursuits and conventions before they can move up on a grid of social development. Second, focusing exclusively on the perspectives of a few human actors obviously limits the kinds of contextual understandings that can be generated by ethnographic studies (361). As previously suggested, a more holistic understanding of a particular scene of writing might be developed by attending to a range of intersecting micro and macro mobilities of people, objects, ideas and information that contribute to the becoming of a locality. Third, there is a danger of treating the emic perspectives presented in a writer's talk around text as transparent, while the text itself is treated as a complex configuration of relations between words and meanings (361). As Lillis suggests, in addition to accepting what people say as authentic and meaningful, the researcher should attend to the discoursal/indexical and performative/relational aspects of talk around texts (366). Such multilayered analysis might reveal a range of religious, academic, economic, geographical, political, etc. discourses indexed in Jeremy's talk about his work and illuminate ways in which Jeremy and those observing his behaviors are performing various subjectivities in relation to each other at specific points in space-time through this talk.

To mitigate these limitations, Lillis proposes that researchers of academic literacies move beyond the ethnographic method of supplementing textual analysis with 
talk around texts to engage in more comprehensive projects. She suggests that to practice ethnography as more than a single method (talk around texts), researchers must participate in sustained engagement with informants and in research sites, collect and analyze a range of data types and make use of the productive tension between etic and emic perspectives $(362,376)$. Taking up these efforts in my own research, I work to engage the students participating in this study in what Lillis refers to as "long conversations" by drafting talkback sheets after listening to recorded conversations between co-researchers and myself (Writing 147). ${ }^{20}$ These sheets reflect my attempt to consciously listen to writers' concerns and bring those concerns and interests to the center of subsequent discussions. These talkback sheets become tools for developing long conversations in which students reflect upon and articulate connections between elements of their experience and understanding that have previously been construed as separatesuch as their literacy experiences and histories of participation in high school, college, home and work. Moreover, these long conversations provide students with a space to contest dominant representational resources.

In addition to engaging in cyclical talk over a long period of time, my coresearchers and I collect a wide range of data to ensure both thick participation and thick description. The former requires the cultivation of those elements of participatory research introduced above, and the latter involves building up detailed pictures of places, people and resources. As Lillis asserts, “Thick description and participation enable the researcher to explore what's significant and at stake for writers at specific sociohistorical

\footnotetext{
${ }^{20}$ While I conducted at least three interviews with all eleven students participating in the study, "long conversations" with some co-researchers included over 20 individual meetings spanning a period of approximately three years.
} 
moments and, importantly, thus to engage with what is significant contextually for understanding what academic writing, and specific academic texts, signify for the writer" (367). In this project, thick description and participation enable me to select analytical lenses in accordance with concerns identified as significant to my co-researchers from their specific sociohistorical perspectives and thereby make use of relations between emic and etic perspectives, as the latter operate in service of the former.

But how might we make use of the emic/etic tension that inheres in our efforts to follow the movements of human and non-human actors as they constitute various scenes of writing? How might we listen to and hear the challenges and consequences facing different historical bodies connecting, transforming and severing different sets of relations through mobile practices within and across diffuse space-time? In addition to employing methods like Perl's, Sommers and Saltz's and Durst's to attend to the micro and macro bodily movements that comprise (con)textual production, circulation and reception, what analytical (etic) lenses might be used to make sense of informants' own understandings (emic) of the complex networks constituted by their mobile practices in various scenes of writing?

While not factoring significantly into the representations and analyses that comprise the following chapters, I've found Norman Fairclough's analytical framework of Critical Discourse Analysis to work productively in conjunction with strategies of participatory research, mobile ethnography and actor-network-theory. Borrowing from this framework has enabled me and my co-researchers to investigate the ways in which mobile practices span scales of space-time and thereby mediate demands, needs and 
desires embedded in specific scenes of writing (micro) and those constituting broader social, cultural and historical structures (macro).

In Discourse and Social Change, Fairclough presents critical discourse analysis as a methodology for analyzing socio-discursive events on textual, discursive and social levels. Following a Foucauldian notion of discourse as constitutive of subjectivities, social relations and systems of knowledge, valuation and belief, he proposes a threedimensional framework for analyzing discourse as a mode of representation and action: any event is simultaneously a piece of text, an instance of discursive practice, and an instance of social practice. The central concern of this methodology is to trace connections between ways in which texts are put together and interpreted, produced, distributed and consumed and to attend to the nature of these practices in terms of their relations to social structures and struggles (72). Like Fraiberg's knots and Latour's matters of concern, Fairclough's model of analysis is designed to trace out complex systems of people, objects, information and ideas intertwined in perpetual states of flux.

Fairclough explains that on the textual level, researchers attend to grammar, vocabulary, cohesion and structure to address questions concerning a text's form and ascribed and potential meanings. Each of these features reveals ideological and interpersonal (identity and relational) meanings. Choices of wording, design and structure provide insight into the ways in which people signify and construct social identities, social relationships, and systems of knowledge and belief (76). Approaching the event as discursive practice, researchers examine processes of text production, circulation and interpretation. As previously suggested, sociocognitive dimensions of these processes center upon the interplay of historical bodies (what Fairclough refers to a members' 
resources) and the text itself, as a set of traces of production and cues for interpretation. Fairclough asserts that these processes are socially constrained in a double sense: First, by available members' resources, and second, by the specific nature of the social practice, which determines what elements of historical bodies are drawn upon and how (80). The exploration of these constraints constitutes a major feature of Fairclough's model as it reveals connections between the nature of discourse processes in particular instances and the nature of the social practices that occasion them.

Finally, when considering discourse as social practice, researchers examine relations among discourse, ideology and power. Fairclough defines ideologies as "significations/constructions of reality (the physical world, social relations, social identities), which are built into various dimensions of the forms/meanings of discursive practices, and which contribute to the production, reproduction or transformation of relations of domination" (87). In this way, orders of discourse are figured as facets of the contradictory and unstable equilibriums that constitute hegemonies, and thus (re)articulations of orders of discourse are manifestations of hegemonic struggle. While individuals are ideologically positioned in these struggles, they are also make their own connections between discursive practices and ideologies and thereby reposition themselves within and transform hegemonies.

In Fairclough's model, literacy is presented as the ability to negotiate the demands and make use of the resources of an ever-fluctuating multiplicity of discourses. As I proposed in the previous chapter, conceiving of such negotiations and (re)positionings as mobile practices in this study enables me and my co-researchers to attend to the ways in which localities and subjectivities are actualized and connected in our physical, 
imaginary, virtual and communicative traversals across micro and macro scales of spacetime. And as Fairclough's analytical framework demonstrates, in order to (re)position ourselves amid the flux, we must participate in a continuous (re)assemblage of people, objects, localities, ideas, information and languages through mobile practice. ${ }^{21}$

While I acknowledge that no triangulation of methods can accurately reconstruct and represent becomings of localities through mobile practice, I do believe Fairclough's framework for attending to texts, discursive practices, and social practices (located in external and internalized contexts of culture) contributes to more robust representations of the complex associations of people, objects, ideas and information that constitute emergent scenes of writing. By appealing primarily to theoretical elements of Fairclough's critical discourse analysis to supplement other methodologies presented here, this project investigates the ways in which writers draw upon the multiple and competing discourses presented in the various socio-cultural domains of their lives to make meanings and assume identities through the mobile practices of reading and writing. Drawing upon analyses of student writing in secondary and tertiary educational and occupational localities, observations of these localities, and "long conversations" with students and teachers concerning literacy histories and current literacy practices, the following chapters consider how texts produced, circulated and consumed in students' high school and college classrooms and at work accommodate, resist, and reformulate past, present and anticipated future academic orders of discourse.

${ }^{21}$ For more representations of reading-writing as repositioning see Harris 1989; Hull and Rose 1990; Lu 1992; Horner 1994. 
In the following chapters, I present the mobility narratives of three of my coresearchers. I begin with the narrative of Nadif, a high school senior and first-generation Somali immigrant. Nadif's story of movement from the world's largest refugee camp in Dadaab, Kenya to a "failing" public high school in the United States and eventually through his first year at a metropolitan research university helps to flesh out an understanding of reading-writing as mobile practice. I then employ this framework to read the mobility narratives of two of Nadif's high school classmates: James, an African American student seeking full-time employment after his access to higher education is blocked by a number of institutional and economic barriers, and Katherine, a secondgeneration Mexican American honors student who struggles to reconcile the disjunctions between her preconceptions, experiences and projections of academic literacies and career aspirations as she moves from high school through her first year at community college. The stories of these students' intersecting and diverging trajectories reveal ways in which institutionalized constructs of college and career are reproduced and transformed in their language and literacy practice. 


\section{CHAPTER III}

\section{PROJECTIONS OF IM(MOBILITY) AT THE NEXUS OF HIGH SCHOOL AND COLLEGE}

If we want America to lead in the $21^{\text {st }}$ century, nothing is more important than giving everyone the best education possible - from the day they start preschool to the day they start their career. - Barack Obama

In the wake of a housing market bubble and enduring recession, the gap between the wealthiest and the poorest in the U.S. has grown to its greatest size since the Great Depression. Moreover, the wealth gap between whites and non-whites has tripled in the last twenty-five years; the average wealth of white households is now twenty times higher than that of black and eighteen times higher than that of Hispanic households (Kochhar, Fry and Taylor). While the educational achievement gap between these populations has narrowed over the past few decades, the gap between rich and poor students has grown substantially during the same period. The achievement gap between students from high- and low-income families is roughly forty percent larger than it was twenty-five years ago, making the income achievement gap more than twice as large as racial achievement gaps (Reardon 4).

Systems of education have been charged with closing such gaps to ensure economic prosperity and a thriving democracy since the birth of the nation. However, studies of the relations between schooling and class, beginning with Gintis and Bowles (1976) and proliferating among the subfield of the sociology of education, have revealed 
that education as a system does almost nothing to ameliorate class difference and more often works to reproduce it by unequally distributing resources. While there is very little agreement among stakeholders concerning the causes of and solutions to problems with the U.S. education system, there is widespread agreement across class, race and political affiliation that the system is broken. Asserting that public education is well beyond repair in his opening remarks at the 2005 National Summit on High Schools, Bill Gates states:

America's high schools are obsolete. By obsolete, I don't just mean that our high schools are broken, flawed, and under-funded - though a case could be made for every one of those points. By obsolete, I mean that our high schools - even when they're working exactly as designed-cannot teach our kids what they need to know today. Training the workforce of tomorrow with the high schools of today is like trying to teach kids about today's computers on a 50-year-old mainframe. It's the wrong tool for the wrong times.

According to Gates the most effective means of closing individual and national achievement gaps is closing gaps between stages and locations of education.

Toward this end, the primary focus of the Gates Foundation's “Educational Pathways" project is "Improv[ing] transitions between preschool and elementary school, middle school and high school, and high school and college" (gatesfoundation). ${ }^{22}$ President Obama agrees that streamlining and, when possible, collapsing stages of education is a key step to making sure every student has exposure to some form of post-

${ }^{22}$ It is perhaps this desire to develop and streamline a fully aligned educationaloccupational system that has prompted Gates to contribute more money, personally and through his foundation, to the U.S. education system than any other person in history. By most accounts, Gates has contributed over five billion dollars to educational reform, including approximately 300 million dollars for the creation and implementation of the new Common Core State Standards (Osborne). 
secondary education. ${ }^{23}$ Speaking about his "plan to make college more affordable," Obama asserts that if "a higher education is still the best ticket to upward mobility in America - and it is - then we've got to make sure it's within reach. We've got to make sure that we are improving economic mobility, not making it worse" (6). For Obama, Gates, and other contributors to our contemporary educational system, the key to effective reform is shaping K-16 education into a more efficient and coherent mobility system.

In this chapter, I continue to attend to the complexity of students' traversals through and co-creations of scenes of writing in high school and college by considering the ways in which the bounded units of accountable space-time that sequence educational activities operate as mobility systems enabling and managing predictable repetition of movement. I begin with an analysis of educational alignment initiatives to demonstrate how such systems are comprised of processes that circulate people, objects and information at various ranges and speeds via a host of routeways (Urry 52). I then demonstrate the ways in which the most influential alignment initiative in the U.S., the Common Core State Standards, is implemented to exert control over the movements of students in and beyond high school. Finally, I consider how the material, discursive and linguistic mobilities of three of my co-researchers reveal complexities and choices among routeways despite this exertion of control.

Choices among routeways represent the potential for movement or motility, which Vincent Kaufmann defines as "the way in which an individual appropriates what is

\footnotetext{
${ }^{23}$ I use the term collapsing here in reference to the Obama Administration's push for dual enrollment and accelerated courses and credits based on previous learning rather than "in seat" time (Office of Press Secretary).
} 
possible in the domain of mobility and puts this potential to use for his or her activities" (37). High motility provides opportunities for circulation, enhancing mobile-capital for some and diminishing it for others (Urry 52). While social scientists tend to look to fields of transportation and communication - bus routes, footpaths, networked computers, etc.- -when considering the operations of mobility systems, conceiving of secondary and tertiary education as a network of intersecting and adaptive mobility systems emphasizes the ways in which the institutional and individual needs and desires that drive these systems are located in processes and sustained by promises of mobility.

\section{Pathways to Prosperity}

The organization of schools as mobility systems is, perhaps, most evident in the increasingly widespread construction of pathways and pipelines, like Gates' above, aligning learning outcomes and assessments on primary, secondary and tertiary levels of education with anticipated job opportunities and demands. ${ }^{24}$ The Foundation's $A$ Path to Alignment report lays out the neoliberal agenda of such initiatives:

In today's global age - an era in which a well-educated citizenry is absolutely vital to economic success and social progress - a truly aligned education system has become all but indispensable. Without such a system, it will be next to impossible for us to forge the necessary human capitalthe talent - that can power our economy and ensure a thriving democracy. (Conley and Gaston 2, emphasis added)

According to this appeal, a conflation of economic, social and national progress depends upon the design of systems that can efficiently transport individuals "from the day they start preschool to the day they start their career" and thereby effectively transform them into human capital or, to borrow from Heidegger, "standing-reserve" (Obama). Students

${ }^{24}$ See Chapter One for a discussion of a history of education for the sake of mobility in the U.S. 
are convinced to undergo this transformation with a promise that as long as they are willing to be modeled by the needs of capital, they will be granted a secure place in the economic hierarchy.

But as I argued in the previous chapter, such promises are not tenable in an era of late capitalism. While educational credentials have become more and more relevant to one's life choices, we are long past the point when a college education can be presented as a reliable vehicle for social mobility (Blacker 243). As Samir Amin explains, "We speak highly of continuing education, which the rapidity of the transformation of productive systems imposes from now on. But this training is not designed to favour social mobility towards the top, with a few unusual exceptions." Amin goes on to assert that, at its best, continuing education staves off obsolescence (and unemployment); for today's workers, “additional knowledge and perhaps new knowledge is necessary to simply retain their place in the hierarchy" (557).

Despite this reality, or more likely because of it, the quest for a unified curricula and pedagogical innovations that can fulfill promises of prosperity has only accelerated in the reign of neoliberalism. As the Lumina Foundation report makes clear, the objective of this perpetual educational reform is the fabrication of knowledge workers and the enhancement of their productivity. Below is a diagram from Colorado's Department of Education that presents this streamlining and commodification of education in the state's comprehensive college and career pathways project: 


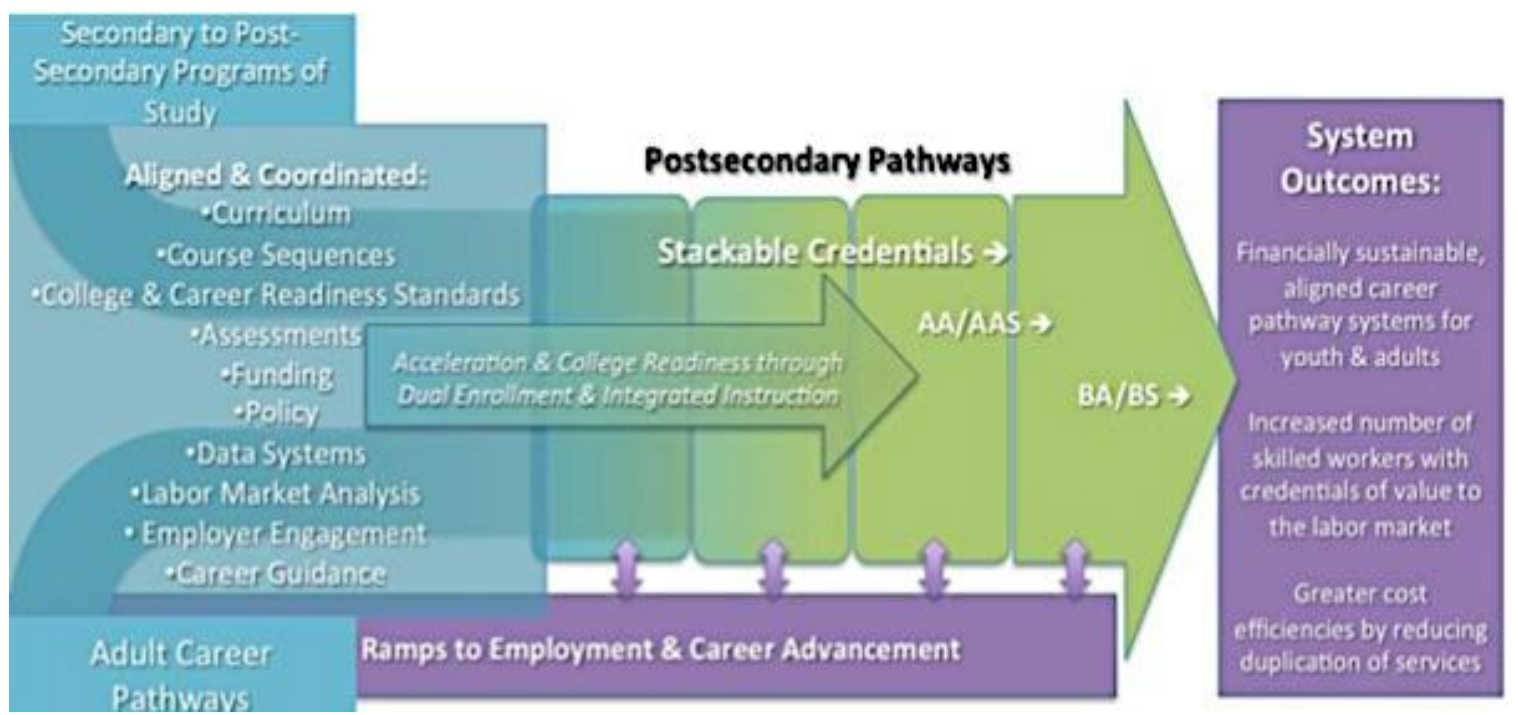

The curriculum that structures this system is organized into "artificial boxes of time" that "bear no relationship to a task" (Heath and McLaughlin 483-484). Moreover, the schooling represented here is predicated solely upon potential payoff in the future. In this way, students' academic activities are conceived as ballistic processes aimed at spacetime reckoned targets and are, thereby, only valued in terms of potential future exchanges. An individual who reaches the farthest boundary-graduating with a BA or BS—is supposedly prepared for life and work in certain kinds of settings to be subsequently encountered, i.e., geographies of the future.

For Bourdieu and Passeron, in this depiction, "to be a student is to prepare oneself by study for an occupational future. [...] the action of studying is a means to an end which is external to it $[\ldots]$ present action takes on its full meaning only in terms of a future which the present prepares for it by preparing its own negation" (56-57). This negation of the value of educational work in the present also has the effect of temporally and spatially encapsulating the activities of formal education from other meaningful activities. Because linear progress in these mobility systems is presented as the primary indicator of future achievement, the only languages and literacies of real value are the 
ones that supposedly measure potential for vertical economic-social-cultural mobility. But as I've asserted elsewhere, this reduction of literacy education to exchange value disregards the complexity of associations assembled through mobile practice in various scenes of writing. Even the most future oriented literacy practices and measures are shaped by students' historical bodies - the ideologies, experiences and habituated practices of and desires for (im)mobility available in their past, present and future lifeworlds.

Of particular interest to me are the ways in which students' motilities are enhanced and diminished through interactions with(in) and exchanges among the scenes of language and literacy in which they participate. For instance, like other co-researchers in this project, Katherine, who I introduced in the previous chapter and will discuss at length in this one, participated in a number of co- and extracurricular literacy activities during her senior year of high school that influenced her perceptions of possibilities for moving through mobility systems of formal education. When I first met Katherine, she was teaching sign language to deaf children and their parents once a week at a local hearing and language academy and working at the law firm of a family friend, where she translated Spanish dictations into legal documents and correspondences in English. Over the course of our work together, Katherine and I became interested in the ways her practices in these seemingly separate scenes of literacy shaped her perceptions of linguistic and literate possibilities in high school and college and, in turn, her motility in these systems. While she readily associated her work in the law firm with her academic writing and saw this work as contributing to her successful movement through high school, she actively attempted to disassociate her work with deaf students from her 
performances of academic identity in high school classes. As I explore later in this chapter, Katherine's own connections between workplace and academic literacies seemed to enhance her linear movement through the highly regulated mobility system of high school. However, her reluctance to connect language and literacy practices at the hearing and language academy with her academic literacies may have served to block choices for lateral movement, which, perhaps, also diminished her motility in these systems.

In an effort to trace such connections and demonstrate the complexity of students' movements within and among locations of high school, college and work, the remainder of this chapter draws upon a range of data types—observations, interviews, images and student texts - to represent three students' intersecting and diverging mobility narratives. Although they are necessarily limited, my hope is that the perspectives offered in these narratives demonstrate ways in which threads connecting scenes of writing are constituted by relocalizations or reenactments of mobile practice that create possibilities for simultaneous sameness and difference within and among these locations (Pennycook Language, 36). While they reveal ways in which educational and occupational mobilitysystems endeavor for control and containment by enabling and imposing predictable repetitions of movement, these narratives also show how individual agency emerges through relocalizations of mobile practice informed by past patterns of thought and action (historical bodies) and imagined future trajectories.

\section{Buying (and Selling) a Stairway to Heaven}

Recognizing the complexity of student trajectories from high school to college and/or career works, in many ways, against the predominant assumptions and political projects of composition scholarship and administration. Without the assumption of a self- 
evident and static paradigm for reading and writing in high school, it becomes difficult to define and facilitate transitions or "paradigm shifts" into college (Sommers and Saltz 140). And as I suggested in the previous chapter, our ongoing project of disciplinary differentiation continues to rely upon conceptualizations of transition from fixed points of departure to fixed points of arrival.

My own tacit acceptance of singular trajectories connecting or, more accurately, separating high school and college almost prevented me from seeing and exploring the emergence and transformation of the scenes of writing in which I participated. At the start of my research, this dynamism was especially difficult to perceive in high school scenes of writing because the linguistic and literate innovation of students and teachers was often obfuscated by the seemingly comprehensive control of national, state, district and institutional literacy policy.

When I began work at Hughes, the school was undergoing an audit by the Kentucky Department of Education (KDE) because its reading and math proficiency scores on core content standardized tests were among the lowest in the state. The school was enveloped in a web of surveillance as teams of auditors collected test data, conducted classroom observations and interviewed faculty, staff, students and parents. This "uninterrupted play of calculated gazes" worked from top to bottom-from state representatives to administrators, teachers and students— but also from bottom to top and laterally, as students were encouraged to indict their teachers, and teachers were encouraged to indict each other (Foucault Discipline 176). In the end, auditors identified six deficiencies in the school: poor classroom behavior; lack of academic rigor; unclear 
expectations for students, teachers and administrators; misuse of resources and insufficient guidance counseling (Konz and Kenning 2011).

As a result of these findings, the superintendent of Jefferson County Public Schools (JCPS) invoked Kentucky House Bill 176 to declare a state of emergency at Hughes and initiate the replacement of the school's principal and the restaffing of its teachers. Teachers were required to reapply for their positions and, ultimately, $30 \%$ of them were relocated as a result of the audit. The teachers who remained were subjected to increasingly restrictive policy and oversight governing their teaching methods and objectives. While unions and contracts prevented the overt governance of classroom practices, newly appointed administrators wasted no time in exerting disciplinary power through "humble modalities" and "minor procedures" to measure and (re)train staff and students (Foucault 170).

Hughes' newly appointed principal, who started in the late spring of my first year at the school, was a member of a taskforce assembled and trained by the district to tighten administrative control in and, thereby, "turnaround" low performing schools. Along with other newly appointed administrators, she was trained to "understand, predict, monitor, halt, and transform corporate failure" (Kentucky Department of Education "Turnaround," 1). Despite convincing evidence suggesting that "failing" schools are seldom successfully restructured by any of the remedies prescribed by No Child Left Behind (Ravitch 2010), JCPS officials implemented a "turnaround management" program to equip administrators of low-performing schools with strategies to increase reading and math proficiency rates on standardized tests, ensure students' readiness for college and career, and decrease dropout rates. Borrowing this program from two schools of business-Detroit-Mercy 
Graduate School of Business and the University of Virginia Darden School of BusinessJCPS focused administrative efforts on "inspiring staff obsession with targets and goals," "tracking and communicating Performance Measures and Growth Metrics," providing "relentless supervision and support," and requiring "persistent debriefing" to ensure "collective efficacy" (Kentucky Department of Education "Turnaround," 2).

In anticipation of Kentucky Senate Bill 1, requiring the implementation of a new assessment and accountability system by the following school year (2011-12), Hughes' principal set out to inspire staff and student obsession with and track progress toward the targets and goals of the new Kentucky Core Academic Standards (KCAS). Identical to the National Governors Association and Council of Chief State School Officers' Common Core State Standards (CCS), the thrust of the Kentucky Core English Language Arts standards is the achievement of "college and career readiness" for all students. To ensure this achievement, standards are "designed to be grade specific in a cumulative progression" (Wheat 3) ${ }^{25}$ In this highly regulated mobility system, students are ushered up a "grade-by-grade staircase" rising in complexity from beginning to college and career readiness levels and comprised of the "skills and understandings all students must demonstrate by the end of each grade" ("Kentucky Core Academic Standards").

Michael, a senior in AP English, described his understanding and experience of this curricular staircase like this:

I kind of think the way it's set up is like in the first two years [grades nine and ten] any writing you do is kind of the whole informal thing, sort of

\footnotetext{
${ }^{25}$ The official website of the CCSS also emphasizes that "no set of grade-specific standards can fully reflect the great variety of abilities, needs, learning rates, and achievement levels of students in any given classroom" (corestandards.org). However, the standards themselves use grade-specific standards as the sole measure by which to describe achievement.
} 
just getting out all of that need to write from personal experience. And then, once you hit your junior year, it's like you should have that all out of your system. Let's start writing the way you're going to have to write for the rest of your life.

Julie, another high school senior, describes the exploratory journal writing exercises that began each of her dual enrollment English classes as mechanisms of purgation: "I write what I want to write so that when we're finished journaling I can do what I have to write for the future." These students' expectations of writing demands for life after high school were shared by most every student I interviewed.

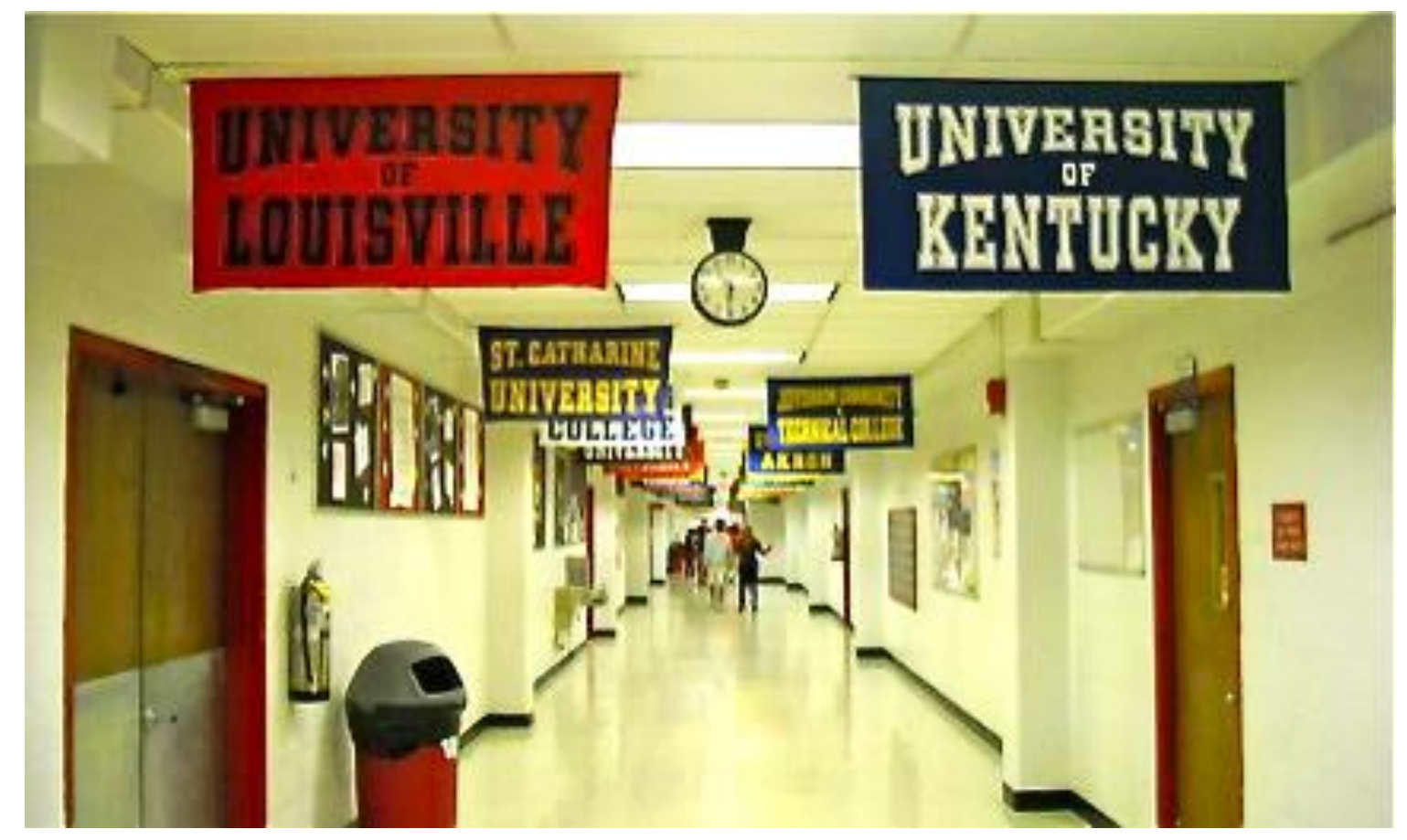

The discourse of readiness driving the new curriculum and internalized by these students was also circulated in an extensive school-wide rebranding campaign associated with the cultural reform efforts of the turnaround program. One way to "inspire obsession with targets" is to surround students and teachers with visual representations of these targets at every turn. The new administration began this process of rebranding by canvasing the school with reminders of the future. The above image is a photo of Hughes' 
main hall after the rebrand. As students move through this corridor, day in and day out, their projected futures literally hang over their heads. These banners can be conceived as signposts orienting students toward promises of the future intended to inspire their work in the present. The central location of the clock in this image serves as a reminder that progress toward this future is measured in bounded units of time. Every ring of the bell maintains a temporal organization in which time unfolds irreversibly toward the next step on the staircase.

I read this image as a representation of the way neoliberal education seeks to control students' mobilities under the guise of inspiration. A student who is effectively inspired to defer gratification for her work, to privilege the promised exchange value of her education over its use value in the present, is much easier to control and transport from one stair step to the next than a student who questions the nature of the work and challenges mediations apparently linking the present to the future. As I argue later in this chapter, I believe students inclined to question the value of their present educational activities are better prepared to meet the challenges of their inevitably unpredictable futures.

In addition to hanging banners, the new administration tightened control of representations of students, teachers and their work by converting spaces previously used for public announcement and personal expression (bulletin boards, classroom doors, whiteboards, television screens) into displays for the promotion of a "culture of high expectations"- another key component of the turnaround program. Like the banners, most of the displays on the walls of the hall are designed to inspire vertical mobility. For instance, the image below is of a display of seniors with college acceptance letters in 
hand. The backdrop for these photos reads, "Wildcats Have Options."

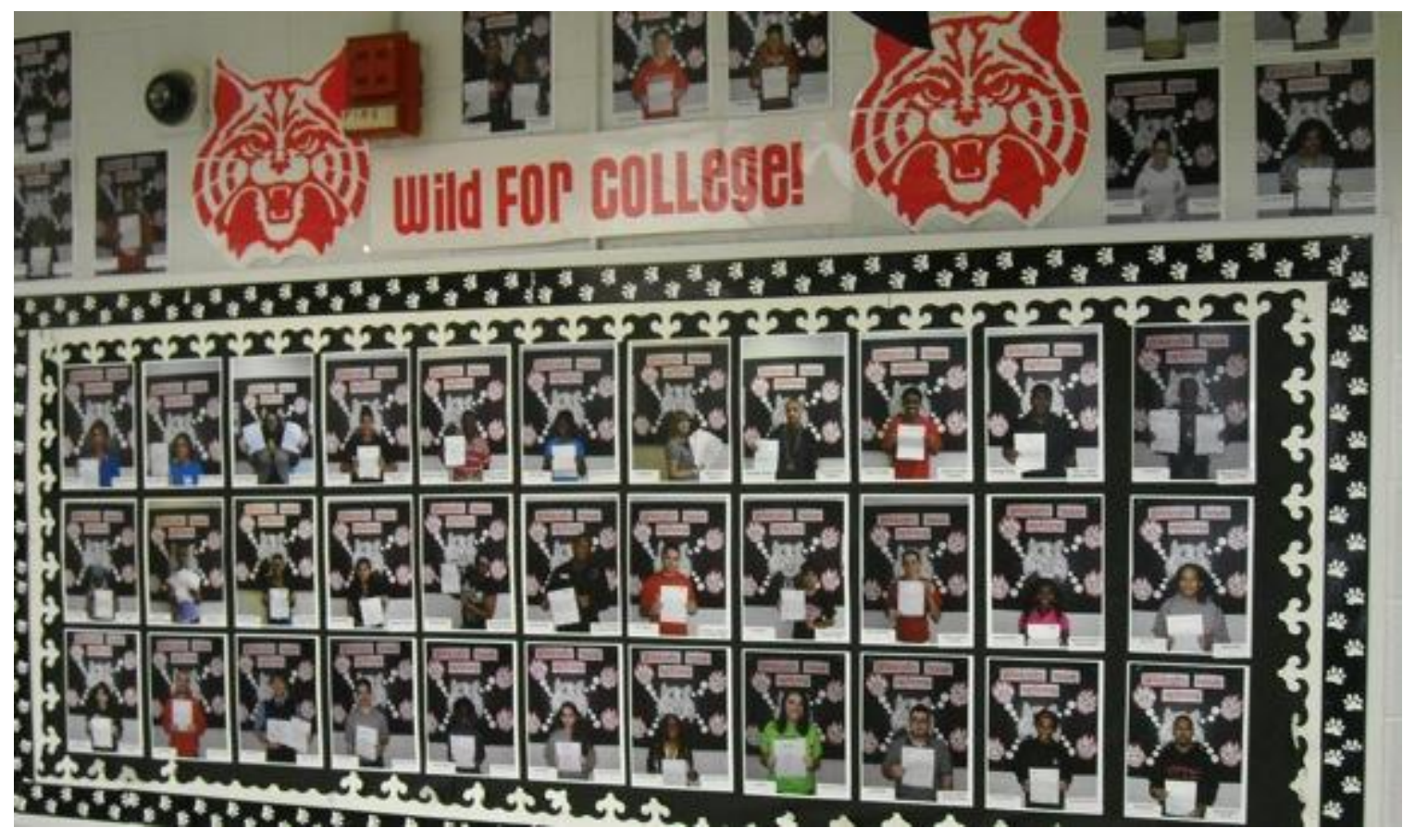

Of course, I agree that these options are well worth celebrating. However, the

display endorses the possible futures of 44 graduating seniors while excluding the futures of the 144 other students who graduated alongside them. In this way, a discourse of readiness celebrates trajectories that adhere to sanctioned pathways and conceals trajectories that don't point immediately in the direction of "college and career." To maintain a promise of prosperity, diversions from privileged pathways are excluded from public display. When such diversions are made know to the public, they are typically presented as statistics to bolster the need for more reform.

For instance, to demonstrate this need and generate monetary and political support for reform, the High School Center at the American Institutes for Research opens their "College and Career Readiness Fact Sheet" with an apparently startling statistic: "Ninetythree percent of middle school students report that their goal is to attend college. However, only $44 \%$ enroll in college, and only $26 \%$ graduate with a college diploma 
within six years of enrolling" (Amelga 1). As the Lumina Foundation might suggest, with numbers like these, the U.S. economy, along with its democratic system, are likely to collapse at any moment. And so supporters of reform, including Hughes' new administrators, work to prevent this collapse by building a culture of high expectations that names students who stay on track and numbers those who don't.

What I find most interesting, and also most disheartening, about these accounts is how students' expectations for future writing, shaped by this discourse of readiness, seem to prevent them from recognizing the value and complexity of their language and literacy practices in the present. Again, the only languages and literacies of value in this system are the ones presented as credentials apparently predictive of vertical mobility. As David Blacker asserts, this de-tethering of a credential from actual practice is part of the commodification drive: "the credential is one's goal, and the classes, any incidental learning that might take place, etc., are so many streamlinable means to that end" (244). Such mobility systems enhance motility for some, diminish it for others, and reduce everyone's needs and desires for reading and writing to individual and national economic concerns. As I suggested in the previous chapter, I believe students' economic concerns are real, often pressing and certainly worthy of our careful attention; however, I don't believe these concerns are always fully articulated, are trained on a stationary target or can be isolated from other motivations and values. The assumption that students are singularly motivated by economic and social advancement reduces the multiple and often conflicting needs and desires formed and transformed in their movements within and across scenes of writing. 


\section{Educating for the Future by Reducing the Past and Present}

This reduction clearly informs the design of the Common Core Standards, which currently govern most literacy instruction in the U.S., including most literacy instruction in Kentucky. ${ }^{26}$ In accordance with the Lumina Foundation's future oriented education for national prosperity, the standards claim to reflect the "knowledge and skills that our young people need for success in college and careers. With American students fully prepared for the future, our communities will be best positioned to compete successfully in the global economy" (CCS Mission Statement, emphasis added).

To explore possible ways in which student's understandings of language and literacy are shaped by the relentless future orientation of mainstream literacy education, I'd like to consider how the Common Core, as a boundary-based mobility system, might enhance and/or diminish the linguistic and literate motilities of the three students introduced in the previous chapter: Nadif, James and Katherine. ${ }^{27}$ To investigate how the standards influence potential for and recognition of mobile practice in the work of these students, I position a reading of essays composed by each student according to Common Core criteria alongside readings of these essays informed by the mobilities frame outlined in the previous two chapters. Each of the following essays was composed to accommodate the anchor standards for one of three text types designated as "collegelevel" by the Common Core: Argumentative, Explanatory/Informative and Narrative. ${ }^{28}$

\footnotetext{
${ }^{26}$ See Chapter One for an introduction to the CCS.

${ }^{27}$ In Chapter One, I describe boundary-based systems as those that imagine grade levels, classrooms, disciplines, discourse communities, etc. as self-contained and self-evident locations requiring predetermined skills, values, ideas and practices for access, acceptance, and progress.

${ }^{28}$ In addition to reducing language and literacy practices and skills to modular entities that can simply be picked up from one situation and dropped down in another, the CCS
} 
Rather than presenting these passages as complete units of discourse that might be subjected to CCS assessment or as representative of the complex bodies of academic writing composed by these students over the courses of their high school careers, I'm using the following passages to investigate how certain reading-writing moves might be evaluated according to the CCS. Moreover, I'm choosing the Common Core as a representation of boundary-based schemas because it is currently the most influential model of literacy education in the U.S. I believe similar readings could be preformed with most measures of literacy learning in the era of standardization.

I'll begin with an excerpt from an essay Nadif composed to meet the Common Core Standards for writing arguments. These standards are presented in abbreviated form in the following table:

\section{Common Core Anchor Standards - Writing Arguments}

(Grades $11 \&$ 12)

Introduces claims and seeks to support these with the texts

Develops claims or counterclaims thoroughly with evidence

Connects sections of the essays in a coherent whole

Establishes a formal and objective tone and attends to the norms and conventions of literary criticism

Provides a concluding statement that follows the argument

The excerpt below is from the final draft of a literary analysis written in response to Nadif's final assignment in senior AP English. In this text, he traces out relations among themes in three different works by Nigerian author Chinua Achebe: the role of women in African society, colonial education, and religious indoctrination. Here, Nadif is addressing the theme of colonial education in Achebe's Things Fall Apart:

reduce the complexity and fluidity of writing genres to three text types: Argumentative, Explanatory/Informative and Narrative. 
Achebe emphasis in his book "things fall apart" the British style of educating the elites of the region in order to backlash the expectation of the Igbo elders. The missionaries' message of new religion was not a goal they meant, but it was a plan to change divide among the people and get the attention of the young ones whom can easily be assimilated by educating them. Such lead to isolation of a father and a son "you all have seen the great abomination of your brother. Now he is no longer my son your brother. I will only have a son who is a man, who will hold his head up among my people," (Achebe 172). The Europeans had such a strong plan, which could lead them easily to divide the people against their wills and give them supporters by educating the young ones, though their goal was to colonize and start slavery across region. Using religion, as a tool to achieve your goal is what led the British to take over the Igbo people, thus Achebe in his novel "things fall apart" proves this claim is what made easy for the Europeans to divide the continent of Africa. ${ }^{29}$

According to the standards, Nadif begins with the introduction of a clear claim; that is, Achebe depicts the ways in which British colonists used education and religion as tools for dividing and conquering the people of Nigeria. And the standards would lead us to note that he seeks to develop this claim with a quote that provides evidence for the success of this strategy in a father's denial of his son (Okonkwo's denial of Nwoye). Most of Nadif's attempts to connect claims in this passage and to connect sections throughout the essay result in restatements of the original claim. He also attempts to establish a formal and objective tone and accommodate the conventions of literary criticism, but I suspect most readers familiar with these conventions would suggest Nadif falls short of this accommodation. For instance, he uses quotation marks instead of italics for the title of a major work, his phrasings and terminology are slightly askew, he uses punctuation before parenthetical documentation, etc. Finally, a conclusion is present, but since it is essentially a restatement of the original claim, it would be a stretch to suggest that it follows from the argument, as the final standard for this text type stipulates.

${ }^{29}$ The full text of this essay is included in Appendix B. 
So in response to Nadif's argument, and across text types, the Standards value the following: the presence of key content such as claims and counterclaims, evidence and conclusions; conformity to predetermined discursive and linguistic norms such as objective tone, standardized English, domain-specific vocabulary, correct usage and mechanics, and so on. ${ }^{30}$ The Standards also value the clear and coherent transmission of ideas through appropriate language and transitions, connections and cause-effect relations; appeals to authoritative sources of knowledge such as literary and informational texts and personal and sensory details in the case of narratives; and conformity to a preestablished process of writing — read, gather thoughts, write, revise, publish. With this final valuation, the Standards reduce process theories of writing to yet another series of steps on course to a predetermined target, a decontextualized product. When Donald Murray (1972) defines stages of writing eventually codified by schemas like the Common Core, he advocates for many considerations excluded from such schemas; specifically, for considerations of students' historical bodies: "It is the responsibility of the student to explore his own world with his own language, to discover his own meaning" (5). However, in the same way that neoliberal reform seeks to streamline students' life courses, it attempts to streamline writing processes to ensure products worthy of the future.

In their exclusive focus on his preparedness for the future, the Standards neglect a number of past and present mobilities shaping Nadif's and others students' texts. Among other things, the Standards are not concerned with: the desires, motivations, needs,

\footnotetext{
${ }^{30} \mathrm{CCS}$ 's valuation of standard written English and linear writing processes are evident in the criteria that comprise the Language Standards and standards for the Production and Distribution of Writing.
} 
allegiances and affiliations shaping and shaped by students' practices of reading and writing; the multiple and often conflicting histories of participation in curricular and extracurricular contexts also shaping and shaped by students' practices; students' perceptions of themselves as writers and of their own literacies and language resources; students' active constructions of meaning and transformations of convention; the people, objects, ideas and information aggregated in students' processes of composing; and material resources available to the writer, including time, space, quiet, access to computers, internet, library, etc.

By separating these concerns from the "real work" of schooling, boundary-based systems attempt to protect the school environment from the contamination of students' transcultural experiences. Boundaries are appealing to policy makers, and society at large, because they promote the promise of school as a pure, well ordered space capable of refining and retooling students for their roles as "human capital" (Conley and Gaston 2). In this process of retooling, cultural differences are presented and even celebrated in a multicultural curricula; however, institutions work to administer exposure to difference from the top down by limiting it to sanctioned sources in bounded units of space-time: Black History Month, Hispanic Heritage Month, Asian/Pacific American Heritage Week, etc. Through these discrete units, multicultural curricula often posit essentialist divisions among people based on race, color, class, gender, sexual orientation, religion, age, appearance, and so on. In this way, Alastair Pennycook's critique of multilingualism can be applied to pedagogies of multiculturalism: "they all too often operate with little more than a pluralization of mono[cultures]" (Language 132). 
To attend to the concerns that boundary-based mobility systems such as the CCS commonly neglect, a mobilities frame begins from a sociocultural perspective that takes processes of thinking, reading, writing and living to be distributed across persons, objects and contexts. Because scenes of writing are constantly being configured and reconfigured by circulations of people, objects, ideas and information and because students are constantly on the move within and across such scenes, I believe an examination of Nadif's reading-writing practices should involve an expanded series of questions concerning space, time and movement. For example, to attend to the mobile practices constituting his essay, I'm interested in asking the following questions: how does Nadif traverse or otherwise connect this particular scene of writing with others in his everyday life; how might the reading-writing opportunities or motilities in this essay be expanded through trajectories connecting multiple scenes of writing; how are the moving elements - people, needs, motivations, objects, literacies, languages, texts, ideas and information —of the scenes of writing in which he participates, including this one, configured and reconfigured across space and time; and how might engaging in reflective negotiations of these elements help him realize his own agency as he works to reproduce and transform conventions of discourse, genre and discipline with his language and literacy resources.

If we return to Nadif's text with these considerations in mind, we're compelled to attend to ways in which it is shaped by the complexity of his life, the multiple literacies and linguistic resources he's developed across scenes of writing, and his perceptions of literacy and language and of himself as a writer. As I noted in the previous chapter, Nadif is a first generation Somali immigrant who moved to the U.S. from the world's largest 
refugee camp in Dadaab, Kenya. After attending primary school in the camp, he purchased forged Kenyan identification papers with the help of his family and caught a bus from Dadaab to Nairobi to attend secondary school as a Kenyan citizen. To "pass" in this system, Nadif had to learn to navigate the linguistic and cultural flows that circulated in the school. Language flows included various Englishes (including the British English of official school discourse), Kiswahili (the national language) and other ethic languages (Somali, Kikuyu, Luo, and others). By the time he was granted a visa and entered Louisville's public school system as a junior at the age of 17 , he was well practiced in negotiating the language demands of multiple contexts. While he was initially tracked into developmental English courses as an English language learner, by the beginning of his senior year, he had worked his way into advanced level courses, Advanced Placement and a few Dual Enrollment courses, including Introduction to Pan African Studies, which he was taking onsite at the University of Louisville.

So while he was drafting his essay on Achebe for AP English, he was also studying the colonization of Africa in the context of this college course. Not only that, but he frequently engaged in virtual chats with friends and family in Kenya and other countries from his seats in both of these classes, and was adapting ACT test-prep worksheets into ESL teaching materials for his volunteer work at the Somali Community Center in Louisville. If we think of all these literacies as mobile practices through which Nadif is connecting scenes of writing across space-time, then it becomes very difficult to approach this essay as an isolated, static and individually authored text produced in a self-contained context. 
It is also difficult to read his writing as an attempted (and failed) effort to compose in standard written English (SWE). In fact, we have no reason to assume that Nadif is trying to approximate the standardized English promoted by the Common Core. ${ }^{31}$ Why would he when his ability to navigate flows of languages has served, perhaps, as his greatest resource for both accommodating and transforming the demands of various institutional contexts? Nadif's negotiation of languages in this essay includes engaging and incorporating Achebe's English; demonstrating enough knowledge of the conventions of standardized English grammar and usage to appease institutional demands; meeting the idiosyncratic language preferences of his AP English teacher and the expectations of his classmates; and finally choosing from a range of linguistic resources to find forms that can help him construct his own meanings and pursue his own purposes for writing.

For example, an assessment that assumes a target of SWE or academic discourse would most likely mark Nadif's verbal construction "change divide" as an error, characteristic of English language learners: “The missionaries' message of new religion was not a goal they meant, but it was a plan to change divide among the people and get the attention of the young ones whom can easily be assimilated by educating them." However, Nadif is emphasizing the British Empire's simultaneous and mutually reinforcing efforts of conversion and division, and he may feel that the insertion of a conjunction here would signal a causal relationship between these two verbs. In fact,

${ }^{31}$ CCS Language 11-12.1, Conventions of Standard English: "Demonstrate command of the conventions of standard English grammar and usage when writing or speaking." This standard applies to all students, including English language learners like Nadif. 
when his teacher suggested he add a conjunction ("and"), he chose to ignore her in this final draft of the essay. We can find more evidence that this construction is a deliberate choice in the quote that follows it: "Such lead to isolation of a father and a son 'you all have seen the great abomination of your brother. Now he is no longer my son your brother. I will only have a son who is a man, who will hold his head up among my people."” Achebe's construction, "my son your brother," emphasizes the totalizing affect of Okonkwo's denial of Nwoye's subjectivities, and, of course, we have no problem recognizing this construction as purposeful on the part of Achebe.

By reserving the possibility of writer error as an interpretation of last resort, a mobilities approach to Nadif's essay is in line with the translingual paradigm outlined by Horner, Lu, Royster and Trimbur (2011). A focus on linguistic motility—or possibilities for movement, fluidity and flux that inhere in linguistic systems-enables us to consider how Nadif makes particular linguistic choices to negotiate the demands of concurrent scenes of writing, investments, allegiances and ideologies. Such choices contribute to the (re)assemblage of apparently static language standards, as he employs a diversity of representational resources in the co-creation of this particular scene of writing and consequent relocalization of the CCS. Horner et al. assert that "by addressing how language norms are actually heterogeneous, fluid, and negotiable, a translingual approach directly counters demands that writers must conform to fixed, uniform standards." Moreover, this approach "recognizes that, to survive and thrive as active writers, students must understand how such demands are contingent and negotiable" (305).

Perhaps because of his experience moving within and across systems governed by diverse language and literacy standards, Nadif does understand and approach language 
demands as negotiable, and this approach enables him to assume agency in his movement among scenes of writing in high school and college. This is not to say that Nadif is more linguistically versatile or innovative than other students, only that he is accustomed to finding the exploit in seemingly fixed mobility systems. In the same way that he was able to use a fake ID to create an opening for himself in a Kenyan educational system to which he had no claim as a Somali refugee, Nadif utilized available linguistic and literate resources to fashion a place for himself at Hughes and later at the University of Louisville. According to Kaufmann's definition of motility cited above, Nadif is particularly adept at putting the potentialities of mobility in various systems to use for his own activities (37).

However, his is not a tale of individual achievement. Nadif's ability to find and act upon exploits in these systems depends, in large part, on the participation of a host of other human and nonhuman actors - an uncle who taught him English in Dadaab, a cousin who obtained forged identification papers, an affordable internet provider in Kenya, an American teacher who recommended he be placed into AP courses, a Somali diaspora in Louisville accustomed to sharing resources and protecting its youth, a cultural tradition that favors the first-born males of a family, a U.S. public school system that tends to be more accepting of the language and cultural differences of "immigrant minorities" than the differences of "involuntary or castelike minorities, " and so on (Ogbu 46). In other words, Nadif's motility is contingent upon a collective creating and delimiting his opportunities for particular types of movements within and among these systems. 
The other students presented in this chapter operate with(in) collectives composed of actors working on and against their mobilities in much different ways. While James and Katherine also demonstrate a great deal of linguistic and literate versatility through their mobile practices in high school and beyond, their stories reveal a number of material, social and psychological barriers to understanding standards and the mobility systems they structure as contingent and negotiable. This next excerpt from James' urban school survival guide, From the Hood to the Halls, speaks to such barriers. The assignment that prompted this text was designed to meet Common Core Standards for writing explanatory/informative essays in a regular (read developmental) English class.

Once again, here is an abbreviated version of the anchor standards for this text type:

Common Core Anchor Standards - Writing Explanatory/Informative Essays (Grades 11 \& 12)

Introduces a number of topics and relates these to each other in content and form Develops these topics thoroughly with facts, definitions, details, quotations, etc. Links major sections of the text with transitions Uses precise language, domain-specific vocabulary and techniques Maintains a formal style and objective tone. Attends to generic norms and conventions

Provides a concluding statement that follows from and supports previous material

In his contributions to this collaborative text, James cautions against common pitfalls in high school education, social life, family life and work. He concludes his guide by asking:

What will happen? What about these educational issues? Will they get worse or better? Will homelessness, drug use, and despair become huge problems? I believe that these issues are more likely to increase. It's a commonly shared theory that these issues are based off of the economy and society itself. As the world seems to grow darker and become filled with more hatred, people act out as there's no hope. It's Tragic but very true. I can say that societal issues in the U.S. are increasing quickly when we look at how many people use drugs now. We will need to change this, because if we continue this what will the consequences be? These societal 
issues will affect the behavior of the population that habits our country and will become a big problem in the U.S. ${ }^{32}$

In this passage and throughout his portions of the text, James and introduces homelessness, drug use and despair as interrelated educational issues, and thereby meets the first criterion on the CCS list. While this excerpt only provides a glimpse of the text's adherence to the second standard in its brief reference to economic and social theories, in the complete work James offers a good number of facts, details, definitions and quotations to make a case for the pervasiveness of these issues. Here and elsewhere, the primary transitional device is the rhetorical question, which James uses somewhat effectively to link major sections of the work. Moreover, he makes attempts, mostly successful, to use precise language and employ domain-specific vocabulary and techniques—using terms like "societal" and phrases such as "It's a commonly shared theory." While the style is formal, his use of first person may call his objectivity into question, and in much the same way as Nadif's essay, James' text approximates, but doesn't always successfully attend to generic norms and conventions. Finally, he does meet the final criterion on the CCS list by concluding the piece with an answer to his own rhetorical questions.

But here again, by focusing on the writing skills James apparently needs for scenes of writing in the future, the standards train us to gloss over the past and present expectations and perceptions that shape his text. Moreover, even as the standards claim to be rhetorical, they encourage James to take an a-rhetorical approach to this scene of writing, as he attempts to employ academic discourse to convince a generic audience to

\footnotetext{
${ }^{32}$ Portions of James' urban survival guide are included in Appendix C. I have only included portions of the text attributed to James. Because the entire guide was composed collaboratively, I am unable to include the full text.
} 
avoid the pitfalls of an urban high school. And, perhaps most importantly, I believe the standards condition students like James to approach school-based languages and literacies as tools of accommodation and conformity rather than as tools for making meanings, identities, and the relationships that constitute and connect scenes of writing. Once again, to better understand the reading-writing opportunities or motilities in this particular essay and in the scene of writing from which it emerges, we must reflect on the relations among the text, the scene, and James' historical body or, as Fairclough would suggest, the text, the context of situation and the context of culture manifesting through James' "member's resources." ${ }^{33}$

James and Nadif rode the same bus to school from an economically depressed neighborhood in South Louisville, but James' experience of the area was and still is much different than Nadif's. While Nadif benefited from the support and protection of the Somali diaspora in this neighborhood, James and his siblings were relatively unsheltered from the poverty, drugs and violence of the area. When I began working with James, his father was in prison for drug sales and his mother was in and out of recovery from drug addiction. This put James in the position of serving as a primary caretaker, along with his grandmother, of two younger siblings while attending school and working approximately twenty hours a week as a grocery store clerk. He remained in developmental courses throughout his high school career despite making A's and B's in these courses with relative ease. In the face of the material demands competing for his time and energy, James consistently attended class and performed well in his courses. He approached his education as not only a possible way out of his circumstance, but also as an opportunity

\footnotetext{
${ }^{33}$ See Chapter Two for a framing of such readings according to Fairclough's critical discourse analysis.
} 
to draw attention to, critique and transform the social structures that produce and maintain the conditions in which he and his family live. These pursuits are evident in James' urban survival guide, but they read as platitudes unless you know something about his historical body.

However, James isn't making this body explicit in his text. And, of course, this is his prerogative. As a teacher, I would not force him in this direction. However, as a researcher I was interested in the extent to which James recognized the inclusion of his own experiences in the text as an option in the first place. When I asked if he thought it would work to include accounts from his life or resources from the predominant languages and literacies of his home and neighborhood in his guide, he suggested it would "work for him but not for his grade."

The longer James and I worked together, the more we both realized that after twelve years in the public school system, he had become particularly adept at accommodating the demands of what was presented as academic discourse in the performance of his school identity and in his writing. It is perhaps this habit of accommodation that leads him to distance himself from the concerns he presents in this text and to project them into the future: "Will homelessness, drug use, and despair become huge problems?"

James encounters these problems in the present on a daily basis in very tangible ways. But he approaches this text as if his own life experiences have nothing to contribute to an academic investigation of the issues. Moreover, while he does draw upon a range of literacy resources in a blending of multiple media-print and hand-drawn text, graffiti, sketches and photographs - his writing is seemingly void of the language 
varieties circulating in an "urban" school, including the variations of black English he speaks in the hallways, at home and in his neighborhood. ${ }^{34}$ Ultimately, James does not conceive of his linguistic and discursive varieties as resources that might enable him to act on opportunities for mobility in this text, scenes of writing in his English class, or in the interconnected mobility systems of public education. And he has good reason to maintain this conception.

James' partitioning of language varieties in his writing and in his classroom speech is, in many ways, an act of self-preservation. W.E.B DuBois famously describes this partitioning as double consciousness, and Vershawn Ashanti Young asserts that it "shows up in one of its most pronounced and pernicious forms in both the theory and practice of teaching oral and written communication to black students, where code switching is offered as the best strategy" (52). By his senior year of high school, James could not remember receiving explicit instruction in switching between black and standardized English, but his ability to do so effortlessly demonstrated his habituation of this distinction. When I asked him to describe his relationship to standardized English, he didn't hesitate in asserting that "It is the language used in college and in good jobs. So I'll need it to get by in those places." In other words, for James, standardized English is the language of upward mobility, and its mythically monolithic nature is maintained, in part, by discourses of readiness circulating in our school systems.

However, accommodating the demands of fixed linguistic, discursive and generic standards was not enough in the case of James' survival guide and those of his

\footnotetext{
${ }^{34}$ The pages from James' survival guide reproduced in Appendix C demonstrate the ways in which he blends media in this text to communicate the daily reality of the issues he engages.
} 
predominantly black and Hispanic classmates. Even though his guide conforms, for the most part, to the standards listed above, the school's response to his blending of media through the inclusion of "urban" images was enough to confirm his need to maintain clear distinctions between his performances of self in and outside of school. James' English teacher, who did encourage her students to experiment with varieties of language and literacy in this and other assignments, designed these projects to be published and circulated for other students at Hughes, particularly first and second-year students at the school. To help present and future students avoid the pitfalls and confront the realities of life at Hughes, James' class distributed their guides throughout the school. They placed copies in the school library, delivered them to $9^{\text {th }}$ and $10^{\text {th }}$ grade English classes, and handed them out in the halls.

At first, the project seemed to me to be a clear depiction of possibilities for teacher and student agency in the face of increased regulation of classroom activities and performances. The student-writers of the guides seemed genuinely excited to share their work with the school and were optimistic about the impact this work might have on the trajectories of new and future students. Moreover, the teacher of the class had designed an assignment rooted in critical pedagogy that also encouraged students to meet the demands of the CCS. But the project's triumph was short lived. When several of the class' survival guides, including James', made it to the desk of Hughes' new principal, she promptly confiscated copies circulating in the school and banned any further distribution of the texts. Not only that, she suspended the teacher of the course, removing her from the class in the middle of term. While individual students were not punished for their 
texts, these administrative actions sent a clear message that their work was not only inappropriate but was also harmful to the audience it was intended to serve.

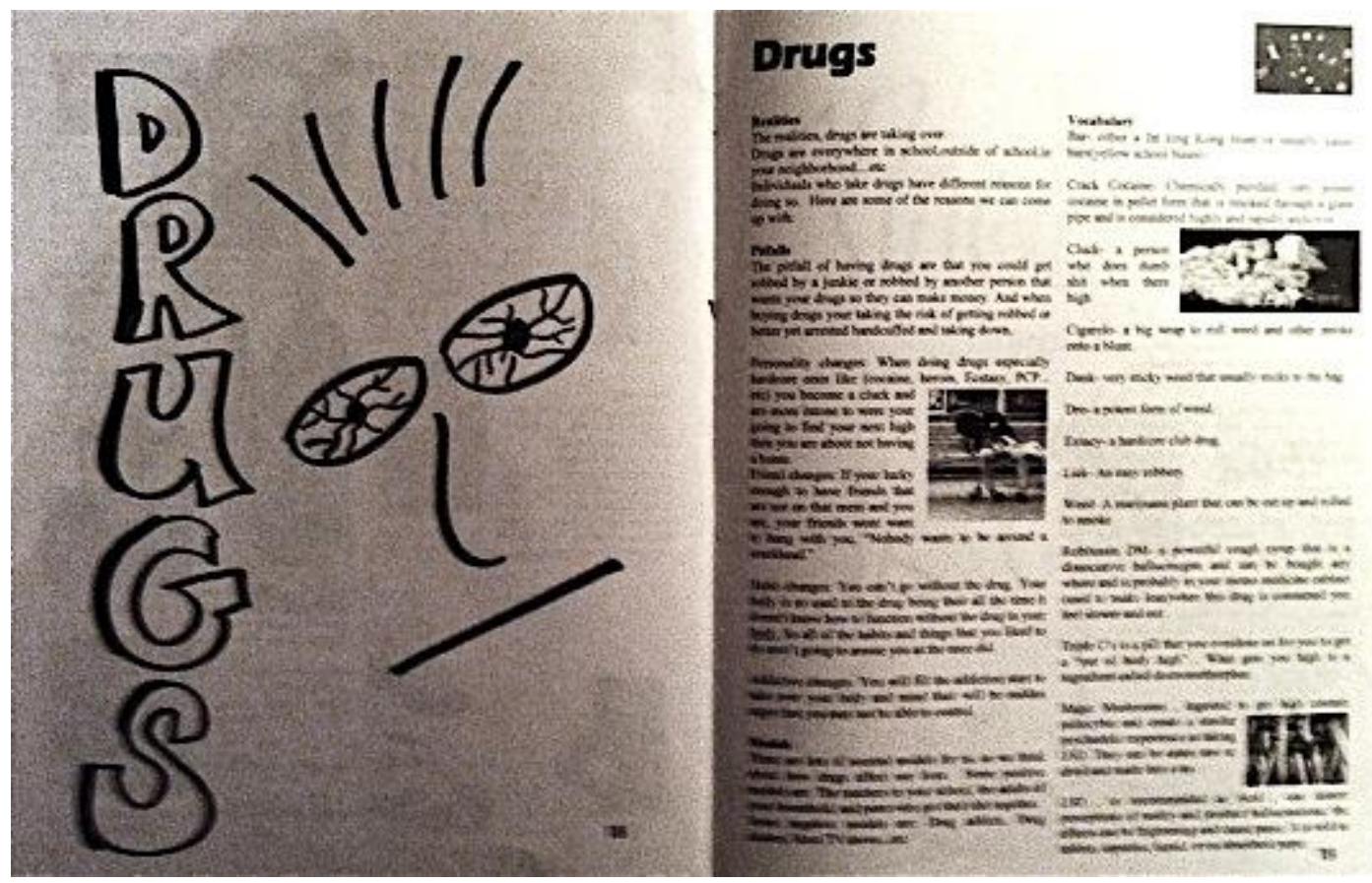

The realities confronted in the guides were not officially recognized by the school's "culture of high expectations," so like the whitewashed walls of the hallways, these perceived deviations from sanctioned pathways were erased or, at the very least, suppressed. The administration justified these act of suppressions by appealing to the inclusion of themes and images of drug use, poverty and violence in guides like James'. So, in effect, the daily realities James and his family struggled against in and outside of school were denied a place in official school discourse. As long as the urban (or what one teacher termed "ghetto") discourses of James and his classmates remained within sealed (developmental) tracks of study, the school could maintain an illusion of purity and order; however, when these students' racialized and classed differences seeped out into public spaces, the institution launched immediate strategies of containment, discipline and punishment. In fact, the mechanisms of control exerted to curtail the circulation of these 
survival guides were paralleled by methods used to control the circulation of student bodies between classes. Called to action by the school bell, police officers, coaches and administrators armed with two-way radios assumed strategic positions along major corridors to disperse congregating students and to usher them as quickly as possible from one class to the next. Students caught making inappropriate gestures, wearing inappropriate attire (jeans, hoodies, t-shirts, etc.) or wearing sanctioned attire in inappropriate ways, were punished with more solitary methods of confinement such as in-school suspension. ${ }^{35}$

Henry Giroux attributes such conditions to the pedagogies of containment, security and conformity increasing shaping public schooling. He asserts that contemporary educational reform in collusion with the growing corporatization and militarizing of public schools encourages "the increased use of harsh disciplinary modes of punishment, surveillance, control, and containment, especially in schools inhabited largely by poor minorities" (368). As the suppression of their survival guides and the control of their movements demonstrates, efforts to curtail James' and his predominantly poor minority classmates' texts, ideas, languages and bodies were heighted when they threatened to permeate the boundaries of their designated tracks. The survival guide incident was not the first and would not be the last time James' real and imagined mobilities would be restricted by institutional forces despite his attempts to conform to the standards of the system. But before I present more instances of blocked movement in

\footnotetext{
${ }^{35}$ On his first day of high school in the U.S., Nadif was sent to in-school suspension for wearing a pair of white jeans. He was spotted in the hall after his first class and was directed immediately to what he described as a room full of other black men where he spent the remainder of the day engaged in activities entirely unrelated to his school work. Nadif had no knowledge of the school dress code prohibiting jeans before this incident.
} 
James' mobility narrative, I'd like to explore how the pressure to conform to the demands of the future shapes Katherine's mobile practices as well.

This final excerpt is from a literacy narrative Katherine composed for a dual enrollment composition course to accommodate anchor standards for writing narratives.

\section{Common Core Anchor Standards - Narrative Essays}

(Grades 11 \& 12)

Engages and orients the reader by setting out a problem, situation, etc.

Uses narrative techniques

Sequences events

Uses precise words and phrases, telling details, and sensory language

Provides a conclusion that follows from and reflects on what comes before

In this essay, Katherine explores processes of translation among Spanish, English and

American Sign Language and discusses the influences of her multilingualism on her writing in standardized English.

ASL has significantly affected my English and Spanish for that matter. ASL [American Sign Language] is a "choppy" version of English. All this means is that sentences in ASL are broken up from the normal structured sentences. (Ex. Hi, How are you? Would translate to How you?) I had to learn how to break up sentences in both English and Spanish because my deaf friends would stay at my house and my father spoke only Spanish. When they were there I was usually the "Google translator" as my dad had put it. I would have to convert what he was saying in Spanish to English to American Sign Language (ex. ¿Cómo te va en la escuela? To How are you doing in school? To How School?) I am so use to speaking in ASL and Spanish I have to always make corrections on papers for English class. I write them how I am use to speaking. My papers always turn out being written in Spanglish and to the point. I ended up ruling out detail because in ASL it is always to the point. Looking back now there has been more Language Arts involved in high school than I expected, especially because of the extra work I had to put into my writing pieces to make them sound "normal." 36

In accordance with the first standard on the list, Katherine begins this section with a problem of translating between ASL, Spanish, and spoken and written English. She

${ }^{36}$ The full text of Katherine's essay is included in Appendix D. 
employs dialogue, reflection and humor as narrative techniques. The Standards would also have us recognize that the events that comprise this essay are sequenced to portray occasions that give rise to her need to engage in such processes of translation. Katherine uses precise words in English and Spanish and provides details in the form of specific examples of translated phrases. Finally, her conclusion reflects both what comes before it in the passage and on a history of accommodating the norms of writing in standard English. But, once again, this boundary-based lens misses much of the point of the narrative. Most significantly, this Common Core reading misses Katherine's need and desire to trace connections among scenes of literacy and to investigate relations among aspects of her own historical body.

Katherine is a partially deaf, second-generation Mexican-American. She's fluent in Spanish, English and multiple varieties of sign language. She took honors and advanced placement courses in every subject throughout high school. And, as previously discussed, she volunteered regularly at a local hearing and language academy and worked approximately ten hours a week at a law firm. Katherine described her work at the law firm - translating conversational Spanish to standardized English for official correspondences between attorneys and clients - in much the same way that she described her writing for school. As the above excerpt indicates, when she describes her movement among Spanish, ASL and English in dialogue, Katherine uses terminology of translation and conversion: "I had to learn how to break up sentences in both English and Spanish because my deaf friends would stay at my house and my father spoke only Spanish. When they were there I was usually the 'Google translator' as my dad had put it. I would have to convert what he was saying in Spanish to English to American Sign 
Language." In contrast, when describing her work at the law firm and at school, Katherine adds the terminology of correction and accommodation to her description: "I am so use to speaking in ASL and Spanish I have to always make corrections on papers for English class. [...] there has been more Language Arts involved in high school than I expected especially because of the extra work I had to put into my writing pieces to make them sound "normal."”

In our interviews, Katherine consistently associated her writing at work with her writing at school, presenting both as efforts of conforming her "natural" languages to the demands of fixed standards of English. During one conversation, she was on the verge of tears when she expressed her frustration with such processes: "I hate my writing. It always feels unnatural, like I'm writing for someone else in someone else's voice." It is perhaps this lack of ownership that caused Katherine, despite her proven record of success in school, to approached schoolwork with a great deal of anxiety, experiencing most every assignment, test and activity—especially those involving writing and speaking — as struggles. As the excerpt above demonstrates, she most often described this struggle in terms of language differences, focusing not only on phonetic, lexical and structural differences between the Spanish spoken in her home and the English of school, but also on the modal differences between these languages and sign language.

Unlike her frequent associations between writing for school and for the law firm, Katherine did not see her work with deaf students and their parents as contributing to her academic or workplace literacies, and she actively worked to keep these areas of her life separate in much the same way that James worked to partition his languages and performances of self. The social and academic pressures that Katherine felt throughout 
high school prevented her from presenting as openly deaf to her teachers and classmates. In fact, Katherine's teacher and most of her classmates learned of her disability for the first time through this literacy narrative composed toward the end of her senior year.

In response to a question I asked in one of our interviews conducted via virtual chat about what it was like to keep this aspect of her identity hidden in school, Katherine wrote:

I was ashamed because everyone around me was always immature and would attempt to impersonate my deaf friends by pretending to sign, which consisted of fingers crossing all sorts of ways, hand gestures, and the middle finger. This is where I had difficulties with my identity because I knew that if I revealed the fact that I was deaf the same thing would happen to me, so I would bicker back and forth in my head if that's what I wished for myself. Not being able to express myself with full honesty hurt me because I lost a part of myself that I loved not only because I was different but because it was a language that I had pride in.

Here, Katherine eloquently describes the internal struggle created by the social pressure to conform to certain expectations of (aural) ability, which she must demonstrate through adherence to the norms of standardized spoken English. Unlike the cases of Nadif and James, the language differences Katherine suppresses to accomplish this conformity are modal. Speaking with her hands could expose her to the sort of ridicule James might face if he were to incorporate black English into his survival guide. Moreover, the enforcers of the standards in Katherine's description are her peers rather than institutional authorities. In this way, her response reveals the ways in which the language demands of the institution are embodied and administered by all members of an institution.

Consequently, the mobility system enabling and managing Katherine's movement is not merely instituted from the top down through policy, curricula and assessment; this system is also instituted laterally as students police each other's language and literacy 
practices and thereby diminish and/or enhance each other's motilities. Rather than drawing upon ASL as a linguistic resource in social and academic contexts, Katherine feels compelled to suppress her (dis)ability in school, which diminishes her opportunities for mobility in and, perhaps, beyond high school. But before moving on to discuss Katherine's post-high school trajectory, I'd like to consider how the Common Core and other official predictors of college and career readiness project these three students into the future.

According to the Common Core Writing and Language Standards, Nadif is the least prepared of the three for college. But, admittedly, any attempt to determine a student's attainment of certain skills and understandings based upon a single text, and, even more, a small portion of that text, is entirely artificial. ${ }^{37}$ To expand the range of measures of readiness and to ensure students are meeting the standards comprising the Common Core, the Kentucky Department of Education administers a battery of ACT assessments as its statewide testing system. These tests, collectively called the Educational Planning and Assessment System (EPAS), include the ACT Explore for eighth grade students, the ACT Plan for tenth grade students, the traditional ACT for eleventh grade students, ACT QualityCore end-of-course assessments administered in all grades, and the ACT Compass exam for students who do not meet ACT benchmark standards in math, English or reading. ${ }^{38}$

\footnotetext{
${ }^{37}$ Of course, this doesn't prevent ACT, Inc. and the College Board from making and selling such determinations.

${ }^{38}$ The state pays ACT, Inc. $\$ 9.2$ million a year for this battery of exams (Spears).
} 
Since the fall of 2012, all public postsecondary institutions in Kentucky have agreed to adopt the state's benchmark indicators of college readiness for the traditional ACT or the Compass. Students scoring at or above benchmark standards must be admitted into entry-level college courses and cannot be required to take non-credit bearing developmental, supplemental, or transitional coursework. A score of 18 meets benchmark standards on the English/Writing portion of the ACT, and a score of 20 meets standards for Reading. For the Compass, the benchmarks are 74 for English/Writing and 85 for Reading. Below are Nadif's, James' and Katherine's scores on these portions of the exams:

\begin{tabular}{|l|l|l|}
\hline Student & ACT & COMPASS \\
\hline Nadif & $15-$ English & $68-$ English \\
& $15-$ Reading & $75-$ Reading \\
\hline James & $17-$ English & $80-$ English \\
& $21-$ Reading & N/A \\
\hline Katherine & $22-$ English & N/A \\
& $24-$ Reading & N/A \\
\hline
\end{tabular}

Clearly, these measure only confirm Nadif's apparent unpreparedness for college. But as I've already suggested, Nadif is the only student of the three currently enrolled in college. He is now a junior at the University of Louisville where he's double majoring in Political Science and Economics. His current GPA is 3.85, and he has made the Dean's Honor Role in every semester of his college career. Moreover, he has never scored lower than a B on an essay in college. In contrast, James' plans to attend a local community college after graduation fell through when his high school guidance counselor failed to submit several scholarship and admission applications that James had completed over the course of his senior year. Discouraged by what he perceived to be an intentional institutional roadblock, James found an additional part-time job, and is now working 
approximately 50 hours a week. And while Katherine's high school transcripts, grade point average, and test scores earned her admission into several research universities and one relatively selective private university, she decided to complete her general education coursework at a county community college in Louisville. After a difficult first year in which she struggled to find a place for herself in the college for many of the same reasons she struggled with her academic identity in high school, she decided to take a break from school to pursue a career as a hair stylist. And, for now, Katherine is satisfied with this "alternative" trajectory.

Admittedly, I did not find these disconnects between Common Core and ACT predictions and students' post-high school trajectories surprising. As a literacy researcher and writing scholar, I would not have expected these standards and their attendant assessments to provide accurate measures of readiness for the future. How could they given the unpredictability of the demands of the future and the needs of these individuals? However, by investigating the differences in the ways these and other students conceptualize the relations among literacy, language and their identities, commitments and desires, my study may help to reveal attitudinal and metalinguistic indicators of college and career writing and language readiness.

When I asked Nadif, James and Katherine at the end of their high school careers for their general thoughts and feelings about writing and language, here is how each student responded:

James: "Most of the time I hate writing. It's what they use to judge you." 
Katherine: Writing “is to help us get to college. Everyone assumes we're going to need it. In every job you have to know how to write a paragraph. It's not for anything else (pause) just getting ready for the future. We just do it cause it's there."

Nadif: "Learning to read, write, and speak in different languages has been a blessing. I feel as if there are no limits in my world, I could go to anywhere in the world today and be able to communicate and contribute there. Translating languages is a constant jogging, and that challenged me to think critically and grow my understanding of the human nature."

Of course, there are myriad influences shaping these students' different conceptions of languages and literacies and their own subjectivities in relation to these. I chose to engage in ethnography precisely to attend to the complexity of these influences. However, I do believe that the boundary-based presentations of writing that accompany our relentlessly future oriented educational-occupational system have a tremendous influence on students' metalinguistic, sociolinguistic and attitudinal preparedness for the demands of college and career. In other words, I suspect that Nadif's apparent preparedness for college and career can be attributed, in part, to his perception of languages and literacies as mobile practices that both accommodate and transform conventions and contexts. Contrastingly, authoritative sources of standardized English mark James' linguistic and discursive innovations as deficiencies that prevent him from progressing from one predetermined level of education to the next. And Katherine's relentless attempts to conform to perceived standards and conventions of "college-level" writing belie the transformative aspects of her language practice. 
While mobility systems of public education transform each of these students into objects and instruments of disciplinary power through strategies of normalization, examination and placement, institutional pressures of conformity are especially pronounced for James and Katherine because their race, class, gender and ability differences are marked by authorities and peers as especially threatening to the purity, order and neoliberal agenda of these systems (Foucault Discipline, 171). Their mobilities are impeded (and overtly blocked in the case of James) by instrumental discrimination (measuring, tracking and confining), relational discrimination (demanding acceptable identity and interpersonal performances), and symbolic discrimination (denigration of culture and language) (Ogbu and Simons 158). For James and Katherine, this record of discrimination is stored in historical bodies containing multigenerational accounts of systemic racisim and classism. Naturally, these collective memories affect their perceptions of and responses to schooling. Unlike Nadif and other voluntary immigrants participating in this project, James and Katherine worked tirelessly to remain within the boundaries of the system, trusting that it would transport them to the promised prosperity of the future. In this way, they were effectively disciplined to approach stages of education and scenes of writing as static and fixed.

While we cannot erase vast histories of discrimination or eradicate the social, economic, institutional and cultural boundaries that work to keep students like James and Katherine in their places, by presenting scenes of writing as emergent and transcultural rather than determined by the imposition of preconceived standards, ground rules and conventions, we might help these students recognize themselves as co-creators of these scenes, actively making the environments in which they participate. If students can 
recognize and reflect upon the ways in which their reading and writing choices both accommodate and transform conventions of discourse, genre and discipline as well as social relations, they may, like Nadif, come to see themselves as agents continually reproducing and remaking themselves and their communities with their multiple literacies and language resources.

In the next chapter, I seek to demonstrate the ways in which students employ such resources to co-create scenes of writing through interactions with mobile technologiessmartphones, search engines and city buses. These technologies serve as mediators and aggregators of the people, objects, ideas and information that constitute scenes of writing in high school, college and work. Following these objects as they participate in the construction of networks across space-time - in the relocalization and reframing of mobile practices- -helps me trace the intersecting and diverging trajectories of my coresearchers across educational and occupational locations. 


\section{CHAPTER IV}

\section{LITERACY IN MOTION: PLURALIZING LOCALITIES AND IDENTITIES THROUGH MOBILE COLLECTIVES}

At the entire root of all [Hughes'] problems is lack of transportation. - Nadif

Appropriately enough, Nadif and I recorded our first official interview on a city bus in transit from Hughes High to the University of Louisville. We had been working together for months in his AP English class - interpreting assignment prompts, reading essay drafts, and discussing course texts — and had been attempting for weeks to meet outside of class to share experiences and perceptions of writing in high school and desires and expectations for writing in college. But, as one might imagine, the schedules of high school seniors and doctoral candidates seldom align. Between his school schedule and a host of extracurricular and social commitments and my teaching, administrative and research responsibilities, we could not "find" overlapping and unreserved time and space to meet.

In fact, after months of attempting to listen to and record the thoughts of high school students, who seemed to operate in an even more accelerated state of hypermobility than myself, I had begun to recognize the futility of my search for unclaimed time and space. So when I discovered Nadif was taking a Pan-African Studies course at the University for dual enrollment credit and that he was riding a city bus to campus, I seized the opportunity to travel alongside him and make use of the space-time 
constituted by our shared movement. In the final months leading up to Nadif's high school graduation, we rode and talked once a week from Hughes to UofL through 79 potential stops about conceptions and experiences of writing in high school and expectations for writing in college. ${ }^{39}$

It was only later that I learned this method of moving with research participants was a well-established practice in the field of mobile ethnography. George Marcus and Michael Fischer describe the method of "following the people" as the most conventional mode of materializing a multi-sited ethnography (“Anthropology" 106). Unlike the single-sited mise-en-scène of traditional ethnographic research, mobile ethnography follows the movements of informants to attend to multiple forms of real and imagined presence occurring through objects, people, information and images traveling across and into multiple social spaces (Chayko 2002). Marcus asserts that this orientation assumes that identities and localities are constituted "by multiple agents in varying contexts, or places, and that ethnography must be strategically conceived to represent this sort of multiplicity" ("Imagining" 52). So, rather than naming objects of study and locating subjects in fixed spaces where identities are made static, mobile ethnography seeks to attend to connections, associations and circulations that facilitate the mutual constitution of identities and localities. As I've asserted throughout this dissertation, such attention reveals the scenes of writing students move within and among to be comprised of networks of dynamic relations rather than preexistent and fixed standards and conventions.

${ }^{39}$ See Appendix E for map of the bus route. 
Moreover, this orientation complicates categories that tend to naturalize students in particular groups and communities (Keller 213). And so in this project, I cannot unproblematically position my co-researchers at a common starting point for their posthigh school trajectories; they do not operate within a shared paradigm; and they are not reducible to singular subjectivities—student, Black, Hispanic, African, poor, disabled, low-performing and so on. Rather, they are multiply situated; they read, write, think and live from a plurality of subject positions; and these positions are perpetually reconstituted by circulations of people, objects, ideas and information within and across localities.

In the process of physically tracing relations among scenes of writing alongside Nadif and other participants, reflections on my observations and students' descriptions of their experiences moving in, through and among school and work environments began to initiate this epistemological and methodological shift in my research. What I originally conceived as a traditional longitudinal study of "entering college" students' attempts to transfer academic literacies from one location (high school) to another (college) developed into a study of the constitution of subjectivities, social relations and locations through mobile practice. This transformation can be attributed, in part, to the ways my bus rides with Nadif oriented me to processes in which mobilities mediate the journeys of other mobilities.

As any user of public transport can attest, the linear and relatively predictable routes of city buses belie the mobilities that circulate with, in and around them. From the moment it begins its journey through the city, the bus becomes a mediator of countless other mobilities as passengers fill its space-time with contradictory and transformative movements. With newspapers and finance reports, smartphones and iPods, school work 
and Sudoku, and the occasional conversation, riders transform the space-time of the vehicle's movement through the city into a collective of overlapping and diverging mobilities, a collective reconfigured at every stop. Likewise, as I've argue in previous chapters, even the most conventional school-to-college-and/or-career trajectories are comprised of overlapping and diverging mobilities that generate the constant and reiterate production of each by each. Like a bus route, the journey from high school to college and/or career comprises a complex network of mobile people, objects, ideas and information.

In the previous chapter, I sought to reveal the complexity of such networks by demonstrating how the mobile practices of Nadif, James and Katherine — spanning continents, countries, cultures, languages, neighborhoods, tracks and stages of education, workplaces, etc.—shape their academic literacies and expand possibilities for reading their texts. In this chapter, I combine methods of "following the people" with what Marcus refers to as "following the thing" to investigate how these students participate with objects to pluralize scenes of writing in high school, college and at work. In all of the scenes I observed over the course of this two-year project, whether stationary or on the move, students interacted with objects to alter the temporal and spatial arrangements of their physical contexts. Like passengers on a city bus, students and teachers (and researchers) interact with objects—computers, books, smartphones, tablets, assignments, standards and assessments, etc. - - to bring distant locations within the range of their senses and thus "violate the constraint that one can only be in one place at one time" (Moores 15).

Attention to these technologies of pluralization is especially fitting for a study of 
students' movements in space-time because, as Latour (1996) suggests, objects provide for and speak to connections beyond the present. They mediate our interactions with other places and times. Moreover, this orientation accounts for the materiality of literacy apparent in legible and durable objects (print, paper, hardware and software, etc.) and the ways in which these objects act within and across scenes of writing. As Deborah Brandt and Katie Clinton assert, the need to recognize that things are not just acted through or upon by readers and writers but are also actors in themselves is especially critical to investigations of the material dimensions of literacy. In this way, "Figuring out what things are doing with people in a setting becomes as important as figuring out what people are doing with things in a setting" (348).

To investigate how students and objects interact with and on each other across scenes of writing, this chapter attends to the ways human-object partnerships enable multiple and simultaneous forms of mobility. These mobilities relocalize students' literacies and languages to both accommodate and transform individual scenes of writing and entire institutions (Pennycook, Language 48). ${ }^{40}$ In addition to attending to the physical movements of people and objects that comprise scenes of writing, I consider the imaginative, virtual and communicative mobilities contributing to the constitution of these scenes. John Urry differentiates among these mobilities by describing imaginative movement as facilitated by "the images of places and peoples appearing on and moving across multiple print and visual media;" virtual movement as occurring in real time and "thus transcending geographical and social distance;" and communicative movement as consisting of person-to-person communication "via messages, texts, letters, telegraph,

${ }^{40}$ See Chapter One, page 23 for a discussion of Pennycook's notion of relocalization. 
telephone, fax and mobile" (47). As a result of these mobilities, overlaps always exist among multiple material scenes of writing and historical, imaginary, communicative and virtual environments, and thus analyses of such scenes must be sensitive to the pluralizations of space-time these interactions produce.

Through the complex assemblage of these various mobilities, students constitute and contingently maintain connections across varied and multiple curricular, extracurricular and occupational locations and embodied and electronic realities. Because of this interplay of mobilities, students are not only located in networks of disciplinary power but also continuously relocate themselves and others within and thus actualize these networks. As in de Certeau's account of "Walking in The City," these interdependent mobilities ensure that seemingly omnipotent mobility systems are always "prey to contradictory movements that counterbalance and combine themselves outside the reach of panoptic power" $(95) .{ }^{41}$

To tease out the threads of such assemblages, this chapter is divided into sections investigating overlaps among forms of mobility. I begin with an exploration of physical and imaginative mobilities accomplished through James' and Nadifs' interactions with school buses. By reading their perceptions of and experiences on buses in light of the history, politics and logistics of school busing in Louisville, I consider how they work through this mobility system to help transform Hughes, located in a predominantly white middle-class neighborhood, into an "urban" school at the same time that the institution works through the busing system to inscribe white, middle-class values upon James, Nadif, their classmates and their communities. Next, I explore how Nadif and Katherine

${ }^{41}$ See Chapter One, page 13 for more on de Certeau's "Walking in The City." 
invent locations of college and link domains of work, social life and family to these locations through imaginative, communicative and virtual mobilities propelled by information and communication technologies. Through their partnerships with material and virtual objects-televisions, computers, smartphones, wifi hotspots, software applications, websites, etc. - Nadif and Katherine project themselves into geographies of the future, bringing real and imagined features of distant locations to bear in present scenes of writing. Moreover, they pluralizes scenes of writing by augmenting face-to-face participation in these scenes with multiple and simultaneous dialogues conducted via virtual chat, email, social networks and text messages. In this way, the communicative mobilities afforded through the partnerships between students and smartphones enable them to maintain and intermingle simultaneous co-presence and distant communications in courses across high school and college. Once again, by demonstrating how these students' multiple and simultaneous mobilities contribute to scenes of writing as processes of becoming, I hope to reveal them as co-creators of dynamic and heterogeneous educational and occupational environments.

\section{Follow that Bus}

When anticipating the $21^{\text {st }}$ century technologies sure to figure prominently in a study of student mobilities, I did not imagine a central role for the bus. Primed by scholarship on the influences of information and communication technologies and new media on educational mobilities (Gee 2004; Jenkins 2006; Ito et al. 2009; Williams 2009), I was prepared to keep pace with passages across virtual highways into worlds desynchronized from historical contexts. While this preparation did pay off, as my coresearchers proved to be more than proficient transmedia navigators and networkers, my 
preoccupation with newer forms of mediation — no doubt influenced by my own middle class perspectives and assumptions - threatened to obscure the significance of older mobility machines for students' travels among scenes of literacy at home, school and work.

However, methods of "following the people" and "following the things" quickly revealed the enduring relevance of such machines, especially for students living in neighborhoods in south and west Louisville participating in the project. As James asserts, "My day starts and ends on a bus. I get to the stop at 6:50 to wait for the bus to Hughes, take the TARC [Transit Authority of River City] to work after school, take the TARC home after work—do it again tomorrow. I'm sick of buses, but I'm stuck without them." Or as Nadif describes in a proposal essay for AP English: "Most of our students live far away from school. ... It usually takes 1 to 2 hours to reach home if the students take the TARC, however this issues made them not to staying for after school activities" (2). Nadif goes on to consider how students' dependence on busing influences the positions they take up in relation to the institution, their teachers and each other: "The problem to students at [Hughes] behavior ... is lack of interaction with other students, and teachers beyond the class. This happened because students rush to the bus after the last bell and do not get a chance to interact with their teachers, and classmates" (3). ${ }^{42}$

These comments highlight issues of access and control underlying many of my co-researchers experiences with and perceptions of bus travel. They also demonstrate how buses consistently surfaced as "relevant propositions" in the scenes of writing shaping and shaped by students' mobile practices (Latour Politics, 110). As I express in

${ }^{42}$ See Appendix F for the full text of Nadif's proposal. 
Chapter Two, I believe that to account for the complexity of students' movements within and among scenes of writing, literacy researchers must seek to attend to all relevant propositions of humans and nonhumans constituting such scenes. And so in this section, I investigate the ways in which school bus travel occasions and shapes students' readingwriting practices and subjectivities.

\section{Busing for (Dis)Integration}

On the surface, bus riding seems an essentially passive activity. After the walk (or run) to the stop, the standing it wait, the spring into an unfolding doorway, and search for a seat, the slow lurch and tumbling acceleration of the vehicle coax passengers into relinquishing control of their trajectories through the city. Unlike the readily apparent embodied and sensuous natures of walking or driving, commonly associated with invention and a degree of free play in apparently rigid systems (de Certeau 1987; Katz 2000; Thrift 2004), riding seems distantiated, spectatorial and even restrictive. The world passing behind the windows of the bus appears to be one over which passengers have very little control. This question of control is central to James' depiction below.
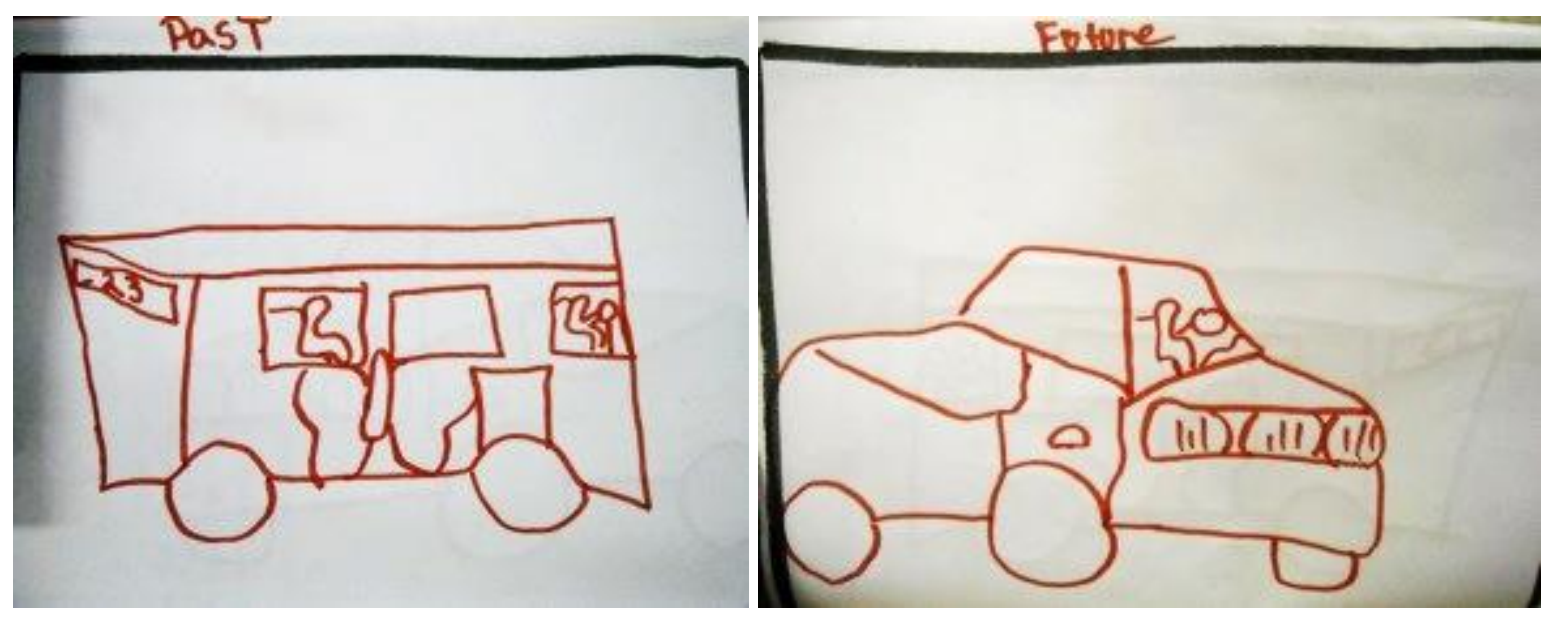
James sketched these images for a journal writing exercise in his senior English class in which he and his classmates were given fifteen minutes to compose representations and projections of the relationship between their educations and their lives before and after high school. ${ }^{43}$ As in all journaling exercises in the course, students were encouraged to respond to this prompt with whatever means of representation they felt would most effectively convey their ideas. Choosing his preferred medium (even while he regularly mocked his own ability to draw), James began working on this sketch with very little hesitation, as if these symbols of the past and future were already at the forefront of his mind.

When I asked about the meaning of the sketch, he suggested that after graduating high school he would be able to earn enough money to afford a car: "Right now, I make minimum wage and can only work like 20 hours a week, or something like that. I'm going to make more and work more after high school. So I'm going to be done taking these buses to school and work and everywhere — going to get a car to go wherever I want." On the surface, James' explanation of his sketch accords with predominant assumptions of student motivation in education. According to widely circulated sources such as the Cooperative Institutional Research Program's annual "Freshman Survey," which consistently trumpets an increase in job- and salary-related motivations for pursuing college, students like James want, above all else, to be well-off financially (Egan et al. 2013). However, as I assert in Chapter Two, these assumptions often reduce the multiple and conflicting needs and desires informing students' educational practices, decisions and aspirations. For instance, the second half of James' description conveys a

${ }^{43}$ See Appendix G for several of James' classmates' responses to this exercise. 
desire for freedom over and possession of his own movements through the city. While this desire is related to James' pursuit of material goods (a car in this case) it cannot be reduced to this pursuit.

To represent his past, James labels the bus in his sketch as Route 23, which runs back and forth from the Highlands down Broadway Avenue through downtown Louisville to Shawnee Park located on the far western boundary of the city ${ }^{44}$ In this trip, the bus connects one of the most economically advantaged neighborhoods in the city (the Highlands) with one of the most disadvantaged (Shawnee). While James was not living on the west end of Louisville at the time of this study, he identified as a member of the "extremely segregated" African American community in the area, having lived in westend neighborhoods until his final year of middle school (Fosl 8). When I asked why he chose TARC's Route 23 for this sketch, he suggested that he always thinks of it as the bus that takes him home: “I don't go out that way much any more, but it's where I come from. It's where my people are." I also suspect that by selecting this route, James was seeking to maintain credibility with the majority of his classmates who were bused to Hughes from west-end neighborhoods.

James' decision to memorialize a bus route that he seldom traveled by the time of this study emphasizes the symbolic significance of the choice. In the context of a prompt about the future payoff of his education, this association of his past with a bus linking west and east Louisville demonstrates the simultaneity and interdependency of his

\footnotetext{
${ }^{44}$ See Appendix E for a map of this route. While Shawnee Park is now widely recognized as a gathering place for African American youth, it served as a whites-only park until 1957. In fact, African Americans had to walk south through the expansive and meticulously manicured park to reach the much smaller and more scantily resourced Chickasaw Park, which was open to Blacks.
} 
material and imaginative mobilities. In this sketch, he seems to be mapping elements of his promised future — financial prosperity, freedom, control, etc. —onto the route of his historical and physical journeys to and within school. This imaginative travel is facilitated, in large part, by discourses of readiness discussed in the previous chapter, as representations of an eminent future inspire James' physical movements within scenes of writing, through the school building and across the city. The future is made ever-present in the relationship between these representations and James' imagination.

Through grade school and middle school, James was bused from west to east according to his grandmother's wishes and the district's desegregation policy, requiring institutions to maintain African American student populations of between 15 and 50 percent in grade school and between 16 and 46 percent in middle school (Courier Journal "Timeline"). For high school, James bused east to Hughes from his new neighborhood in south Louisville, again, in accordance with his grandmother's wishes and a revised assignment system designed to integrate schools by race, income and parents' education levels. And so for his entire primary and secondary school career, James traveled east for an education that was presented by both his family and his schools as a ticket into the middle class. ${ }^{45}$ Perhaps because Route 23 moves in the same direction as his physical journeys from home to school and back, James presents it as a symbol of the promise of education for his future: west to east, poverty to prosperity, marginalization to power. ${ }^{46}$

Of course, this symbol also carries an implicit threat: buses run both ways. While institutions located in predominantly white middle-class neighborhoods promised James

\footnotetext{
${ }^{45}$ See Chapter Three for presentations of education for the sake of individual and national prosperity.

${ }^{46}$ Granted, when I ran this interpretation by James, he just laughed and reminded me that I was thinking about him "way too much."
} 
financial stability and independence through a curricular stairway to prosperity, school buses, as agents of these institutions, delivered him, along with most of his classmates, back to largely segregated, economically depressed neighborhoods after school. In this way, the elliptical journey of the bus mirrors the ways in which the larger mobility system of public education tends to manage the movements of poor and working-class minorities (Guryan 2004; Alexander 2010; Rothstein 2013). As I revealed in the previous chapter, by blocking his access to tertiary education, this system ultimately worked, like the bus, to return James to his neighborhood - to his place in society. In many ways, for James and most of his regular-track classmates, the district's busing system carries out a strategy of containment similar to those presented in Chapter Three in the forms of academic tracking, hall monitoring, and the attempted erasure of urban discourses.

While it is true that students of diverse races, ethnicities and socioeconomic statuses are bused in every direction to schools across the Jefferson County Public School District, since the implementation of mandatory busing for desegregation in Louisville in 1975, the burden of travel has been born primarily by African Americans and other students of color. ${ }^{47}$ As Tracy E. K'Meyer asserts in From Brown to Meredith: The Long Struggle for School Desegregation in Louisville, Kentucky, 1954-2007, whites have traditionally "assumed that desegregated schools must be majority white," and "even the most ardent integrationists took for granted that black students would bear the burden of busing by being transported for more years than whites, and they rarely appreciated that something of value might be lost with the end of black-led institutions" (183). Because a

\footnotetext{
${ }^{47}$ According to the city's original desegregation plan implemented in 1975, black students were to be bused up to 10 of their 12 years in school, while white students would be bused 2 of their 12 years (Courier Journal "Timeline").
} 
particular construction of white, middle-class America still exists as the default for school culture at Hughes and has become even more pronounced as a result of the school's rebranding efforts after a state audit, busing works in the service of a larger system designed to contain and manage cultural differences. ${ }^{48}$

This is not to say that I disagree with the practice of busing for the pursuit of equality and diversity in schools. Alongside K'Meyer, I applaud the efforts of Louisville's activists, parents, students, teachers, administrators, politicians and voters to preserve this system in the face of sustained and sometimes violent opposition.

According to K'Meyer, Louisville is one of the most desegregated public school systems in the country, which reflects a history of support for integration and considerable community defense of busing as a means to achieve it ("Busing”). For instance, in 1983 when the superintendent of schools proposed changes to the city's desegregation plan that would shift the burden of travel almost exclusively onto black students while undermining the quality of schools in their neighborhoods, integration advocates decried the plan as “one-way busing” and organized to stop it. K'Meyer quotes African American civil rights activist Mattie Jones describing the plan as Jim Crow racism alongside a white mother from a middle-class neighborhood on the eastern edge of the city, who asserted that "any plan that does not bring kids from the suburbs into the city is morally wrong” (“Busing”).

While I agree with K'Meyer and those she cites here, I would argue that as long as white middle-class values and assumptions, presented as racially neutral, continue to dominate the cultural and academic standards of schools like Hughes, busing will always

${ }^{48}$ See Chapter Three for a discussion and evidence of this rebranding. 
be one-way regardless of the directions in which students are shuttled. While this mobility system does make Hughes a demographically diverse institution, with a total minority enrollment of $64 \%$ and an economically disadvantaged student population of $74 \%$, the school, in accordance with district and state policy, delimits interactions across differences by dividing students into separate tracks of study, creating separate academies and programs within the school to contain certain student populations (freshman, English language learners, special education, etc.), isolating a disproportionate number of black and Hispanic students in In-School Adjustment Programs and with suspensions (Skiba et al. 2002; Mendez and Knoff 2013), and failing to provide adequate transportation so that all students can participate in extracurricular activities (Division Data Management 20122013 Data Books).

Writing about his impression of the nature and affects of these mechanisms of partitioning and containment in a paper composed for his second-semester college composition course at the University of Louisville, Nadif asserts:

To my observations the school [Hughes] is divided into two sections: a small group of AP and Honors students and the rest of the school, these students are totally separated academically and socially because of the fact that they don't have classes together and of course they don't hang out together. While I was part of the AP students it still seemed to me like a class warfare, where the rich and the poor don't even shop at the same store, except at [Hughes], it's educational warfare where the same students in the same building don't get the same level of education. (3) ${ }^{49}$

Approximately one year before he composed this critique, Nadif highlighted the role of transportation in this process of resegregation in his previously mentioned proposal for AP English:

${ }^{49}$ See Appendix $\mathrm{H}$ for the full text of this paper. 
Students don't get to know themselves, neither did they get the chance to see what activities Hughes offers. They don't care about the school while some will say 'I don't go to school I go to Hughes.' The only way to clean that from the students mind is offer transportation, so they get the chance to show their school spirit. (4)

In these passages, Nadif associates students' shared sense of detachment from the school with a lack of collective participation due, in large part, to academic tracking and an inadequate system of transportation. Rather than feeling integrated, many students feel isolated from each other, their teachers and from the activity of the school.

Administrative efforts to combat this sense of isolation and fragmentation focus on celebrating academic and behavioral achievement, which, again, is measured according to a shared set of standards based on white middle-class norms and expectations.

As de facto means of resegregation, the policies and procedures Nadif addresses in these passages transfer responsibility for students' circumscribed or blocked mobilities unto the students themselves. As long as all students are measured according to the same standards, assessed by the same exams and granted access to the same opportunities - at least on paper-the system can exonerate itself from the injustices of social reproduction. By providing James his choice of schools along with transportation to and from these schools, supplying TARC vouchers for extracurricular activities, maintaining an open enrollment policy for advanced placement and so on, JCPS can maintain its claim of providing students equal access to opportunities for mobility. When James chooses not to act on these opportunities, he is the one to blame for his own immobility. And yet, his school choices are largely contingent upon racially biased standardized tests scores (Kidder and Rosner 2002; Freedle 2003; Santelices and Wilson 2010), his academic track is essentially set in the third grade and maintained by his scores on periodic Cognitive 
Abilities Tests (also racially biased), and his participation in extracurricular activities is limited not only by his part-time job and family obligations but also by time and safety concerns associated with TARC travel. ${ }^{50}$

Ultimately, the school system's dual strategy of 1) partitioning according to academic achievement, which tends to separate poor, minority and ESL students from their white middle-class peers (Garet and DeLany 1988; Mickelson 2001; Heilig and Holme 2013) and 2) promoting white middle-class literate, linguistic and behavioral norms as racially neutral standards transforms a system of busing for integration into a system for resegregation, exclusion and obstruction of student mobilities. ${ }^{51}$ In this way, the operations of the system accord with a history of literacy education in the United States that has traditionally served as a means of demarcating, containing, and managing literacy and language differences. As Catherine Prendergast demonstrates in Literacy and Racial Justice, "In American history, literacy has been treated as White property, whereas the paths for groups of color to lay ownership to literacy have been more obstructed" (166).

\footnotetext{
${ }^{50}$ Describing the problems associated with offering TARC tickets as an alternative to providing transportation in an interview conducted via virtual chat, Nadif writes: "The school use to give us a free TARC ticket, but first you had to walk all the way to Shepardville road and wait for the bus, that usually took like an hour. And that bus will drop you off at Downtown, then you have to take another bus to home, and then walk to home like a half a mile. It was rough."

${ }^{51}$ During the 2011-2012 school year, students at Hughes took 87 Advanced Placement exams, 19 of these exams were taken by African American students and 2 were taken by Hispanic students. These numbers are especially startling considering African Americans made up $47.3 \%$ and Hispanics made up $12.9 \%$ of the total student population during the same school year (Division Data Management 2012-2013 Data Books).
} 


\section{Riding in the City}

It is, perhaps, this sense of obstruction that James is resisting by claiming what he perceives to be a more agentive form of mobility — the car - for his future. According to his sketch, he is moving beyond the prescribed mobilities of formal education, which he associates with bus travel, to a future in which he is able to control his own comings and goings. In this way, James shares de Certeau's impression of public transportation, which the latter describes as a "travelling incarceration" in which human bodies are able to be ordered because, although the carriage is mobile, the passengers are immobile. Inside this "bubble of panoptic and classifying power... there is the immobility of an order....Every being is placed there like a piece of printer's type on a page arranged in military order" (111). Like Foucault's description of the examination as a "means of correct training," which captures and fixes individuals in "a network of writing," according to de Certeau, public transport holds passengers in a mechanism of objectification by pigeonholing and regulating them in the grid of the carriage (Discipline 189). Within this closed and autonomous insularity, disciplinary power constitutes and arranges individuals as objects without discourse (de Certeau 112).

In light of de Certeau's commentary on public transit, James' depiction of his educational past as a city bus is an apt metaphor for common conceptualizations of public schooling. Like Perl's presentation of the cognitive knots and tangles imposed on Tony by years of schooling and Sommers and Saltz's assumption of the mechanized and structurally determined nature of writing in high school, which forestalls students' “paradigm shifts” into college (140), de Certeau’s carriage conceals its essentially 
immobilizing operations with a promise of mobility. ${ }^{52}$ Like the movements of passengers from one predetermined stop to another, according to such depictions, students' movements between scenes and stages of education are predicated upon objectification and arrangement. Progress in a linear and vertical system appears to require a renunciation of lateral and recursive mobilities.

And yet, also like a bus, this system is not as determinative of practices and subjectivities as these depictions suggest. In the same way that my rides with Nadif helped me to recognize the carriage and route of the city bus as a mediator of countless other mobilities, I believe that K-16 literacy pedagogies and policies must help students like James recognize and make use of the possible mobilities that circulate with, in and around their prescribed movements across scenes of writing and educational systems. In other words, I want and have tried through this research to help James and others develop new and recognize existing tactics for exploiting openings in the apparently autonomous, boundary-based power structures of formal education. De Certeau describes a tactic as: "A mobility that must accept the chance offerings of the moment, and seize on the wing the possibilities that offer themselves at any given moment. It must vigilantly make use of the cracks that particular conjunctions open in the surveillance of proprietary powers" (37). As I've attempted to help James identify and extend these potential tactics, he has revealed openings for new spaces of action through his mobile practices that I would have never recognized on my own.

In fact, James' co-creation of the space-time of bus travel was more tactical than de Certeau seems to have imagined possible. Far from a "bubble of panoptic and

\footnotetext{
${ }^{52}$ See Chapter Two for a detailed discussion of Perl's and Sommers and Saltz's representations.
} 
classifying power," the school bus James and his classmates rode for their daily 30 - to 45-minute trip from south to east Louisville was exploited as a reoccurring crack in the surveillance of the school system's propriety power. Through the achievement of coordinated action around licit and illicit academic collaboration, students appropriated this vehicle and its mechanized route for the formation of collectives that worked across differences to create and share material and conceptual resources, challenge standards of individual effort and authorship, negotiate subjectivities and make use of literate and linguistic resources restricted within the confines of the school building. In other words, James and his classmates participated on and with the bus to open up a space-time of resistance against the pedagogies of containment described in the previous chapter (Giroux 2010).

I first learned about these bus collectives when I began asking students, including James, about what seemed to me to be unique associations across racial, ethnic and linguistic differences in one of the regular English classes I observed. After several weeks of working with students in the class, I began to notice patterns of exchange in which James, who almost exclusively socialized with his African American classmates from the west end, would travel to the other side of the classroom to partner with a group of Vietnamese and African students for group activities such as peer reviews and shared reading response worksheets. Not only that, but I noticed that James regularly exchanged papers and text messages after and occasionally during class with his international classmates.

At first, I assumed James had been assigned to work with this group. He wasn't the only student crossing ethnic, linguistic, and neighborhood boundaries for these 
activities and he had established himself as one of the more confident writers in the class, so I assumed his teacher had assigned him and a few others to serve as peer tutors for English language learners. I operated under this assumption for the four months I spent as a writing tutor in the class before interviewing and collecting texts from students and engaging in more formal observations as a researcher. In fact, one of the first questions I asked James in our initial interview was about his role as a peer tutor. He promptly suggested that I had him confused, assuring me there was no chance he would be asked, much less agree, to assume such a role: 'No, that's not me, man. Ms. X doesn't even like me, and I'm not really that kind of student." James proceeded to explain the formation of his small group: "We're busmates, we ride the school bus together from Iroquois [neighborhood in south Louisville].”

Brice: So, you became friends on the bus?

James: No, we just help each other out in classes sometimes. Brice: You work together because you ride to school together? James: Well (long pause), we work together on the ride to school. Brice: I see, so you do your work together on the bus on the way to school. James: Right, like homework and papers and stuff. No big deal.

At this point in the conversation, I could sense that James was feeling uncomfortable with the direction we were taking, so I asked a few more clarifying questions and quickly moved on to another subject.

However, I did note a few details from this brief exchange in a "talkback sheet" that would inform subsequent conversations with James (Lillis, Writing 147). First, I was curious about his need to differentiate his school self from the sort of student who might be appointed as a peer tutor. Despite his model behavior in class and consistently strong academic performances, James did not seem to see and/or want to identify himself as a "good" student. Second, I was interested in the assertion of his strictly academic 
relationship with busmates, as he seemed to want to establish that their collaboration in class and on the bus was not socially motivated — they were not friends. Third, I noticed James' desire to downplay the significance of the work of these collaborations, suggesting that the assignments were of little concern—-"no big deal.” Finally, I noted his indication of plural "classes," implying that these collectives worked across the curriculum as well as the city. I would return to these points in later conversations with James, which I discuss below.

In the meantime, this initial exchange served as a healthy reminder that after four months of participating in the activity of the course, I still had very little knowledge of the "underlife" of the class. Robert Brooke describes underlife as "the activities (or information games) individuals engage in to show that their identities are different from or more complex than the identities assigned them by organizational roles" (142). Following Erving Goffman, he identifies two primary forms of underlife-disruptive and contained - and suggests that most activities correspond with the latter, as individuals and groups often work "around the institution" to assert differences from assigned roles, rather than present overt challenges and threats to the institution (143). From his position of participant observer in a first-year college writing course, Brooke identifies four major types of student underlife activity: 1) Applying class materials and practices in ways unintended by the teacher; 2) Engaging in commentary on available and assumed roles in the course most often to exchange ideas about how to "get by" in the class; 3) Evaluating and critiquing the activity of the class; and 4) Dividing attention between class activities and concerns other than these activities. 
Brooke asserts that students participate in this underlife to demonstrate that they are more than just students: "The point is not to disrupt the functioning of the classroom, but to provide the other participants in the classroom with a sense that one has other things to do, other interests, that one is a much richer personality than can be shown in this context" (148). In other words, students engage in activities that might be perceived to be disruptive by a teacher to create space for their historical bodies in institutions that tend to neglect or reduce such bodies. ${ }^{53}$

Brooke's presentation of underlife helps to explain James' resistance to the role of compliant student, his collaborations with Vietnamese and African classmates, and his social distancing from these classmates. As demonstrated in the previous chapter, by this point in his educational career, James had undergone twelve years of discipline and punishment to maintain the separation of his school self from the rest of his historical body. However, when he is confronted with a reading of his identity that implies the institution has successfully accomplished this separation, such as my suggestion that he might be a peer tutor, he defends the differences from this institutional role that he has worked to preserve. As Brooke suggests, "students are highly aware of the roles the classroom asks them to play, and highly defensive of their differences from these roles" (147). This defensiveness might also help explain why James remained in regular-track

\footnotetext{
${ }^{53}$ Following postcolonial theory (Bhabha 1994) and postmodern cultural geography (Soja 1996), some literacy theorists (Gutiérrez, et al. 1995; Moje, et al 2004) and compositionists (Reynolds 2004; Grego and Thompson 2008) seek to make use of the classroom conflict Brooke describes for the creation of third space. This space is made possible through the disruption of the traditionally binary nature of student scripts and teacher scripts. While I think this concept of third space is a useful pedagogical tool, I find Brooke's concept of underlife more descriptive of the sorts of resistances I observed in high school and college classrooms because it emphasizes the persistently subversive nature of these activities, their resistance to being appropriated for institutional use.
} 
English classes throughout his educational career despite his seemingly effortless success in these classes. The process of jumping tracks into AP English would have placed more strain on his affiliation with the west end, which he was already working hard to maintain because of his residency on the south side. This maintenance also speaks to his denial of friendship with Vietnamese and African busmates. Ultimately, remaining in regular courses enabled James to stay connected to the community with which he most closely identified.

To prevent being twice removed from his neighborhood—physically by the bus and socially by curricular segregation—James participates in the institution's restrictions on his academic mobilities. Foucault describes this participation as characteristic of power relations in liberal democracies. Defining government as a structuring of the possible fields of action of others, he suggests that coercion requires the complicity of the coerced ("Subject" 790). In this sense, to govern is to affect the way in which individuals conduct themselves. As Graham Burchell notes, the process of governing involves "a versatile equilibrium, with complementarity and conflicts between techniques which impose coercion and processes through which the self is constructed or modified by himself" (182). In this way, James' distancing from proposed institutional roles and maintenance of subversive subjectivities keep him on this designated track of study.

However, by collaborating with his busmates across space-time and cultural, linguistic and literate differences, James works to reconstitute or relocalize the scenes that comprise this track. This extension of underlife activities to "get by" in a school that consistently devalues students' ways of reading, writing, thinking and living includes distributing the work of classes beyond the confines of these classes and among 
participants, exploiting blind spots in hierarchized surveillance, subverting strategies of atomization and permeating the boundaries between designated tracks of education. In these ways, the bus collectives highlight the fragility of disciplinary power. As John Ransom asserts, "The fact that we are vehicles of disciplinary power reveals...not the omnipotence of power but its fragility. Such vehicles might go off the designated path in directions that frustrate the purpose for which they were originally developed" (36). By co-opting the space-time of the school bus to pursue routeways otherwise blocked by the institution, James and many of his busmates are assuming agencies produced through their relations with each other, the school bus and a host of other actors. If James were to revise his journal entry sketch to account for this assumption of agency in his educational present (at the time of the study), he would need to acknowledge his adoption of both driver and passenger roles in the practice of his academic literacies. However, as I asserted in the previous chapter, the relentless future orientation of neoliberal education often prevents students from recognizing the innovation, power and complexity of and agencies produced through their literacy practices in the present.

\section{Mobile Collectives}

Ransom's metaphor is particularly appropriate for a system of education predicated upon designated pathways, and over the course of this project I did often observe students (and teachers and administrators) venture off these pathways in manners that frustrated the system. However, I observed few divergences that worked within and against this system as effectively as James' bus collectives. As we continued to develop our conversations about these collectives over time, James, Nadif and others who rode what students called the "international bus" from the south side began to provide more 
details about the ways in which the bus served to recruit and enroll students, objects, ideas and information into literacy networks extending across and beyond scenes of writing at Hughes (Latour 1996; Leander and Lovvorn 2006).

By our third interview, James seemed to trust that I was not interested in subjecting him to more punitive surveillance and reporting; although, we did discuss how research involves surveillance and interpretation of a different sort, with different risks and possible rewards. Starting with the talkback sheet described above, the topics of discussion in this third interview circulated around his English class/bus group's formation and operations. In this interview, James describes how he was initially hesitant to engage in conversation with his international busmates because he assumed their language differences would put too much strain on their exchanges: "I knew most of them [international students] from classes, but never really talked to them because I didn't think I could understand them. And I didn't think they could understand me either. ... I was always tired on the bus, so I just rode and tried to sleep and didn't really talk to anybody at first."

When I asked how his attitude and practice on the bus began to change, he mentioned noticing how certain groups of students studied together and divided schoolwork among themselves. He also noticed how students formed these groups across ethnic and linguistic differences: “The students working together weren't just from one place. ... different kinds were helping each other and other kids, and I saw them helping each other in classes too.” By highlighting his recognition of this collaboration, James points to a change in his own understanding of possibilities for accomplishing shared tasks by working across cultural and linguistic differences. This recognition is supported 
by speech accommodation theory, which shows how "speakers don't have to be experts in another variety of English in order to speak to other communities. They simply need the metalinguistic, sociolinguistic, and attitudinal preparedness to negotiate differences even as they use their own dialects" (Canagarajah 593). And so, through his observations of and eventual participation in this multilingual bus collaborative, James began to develop metalinguistic, sociolinguistic and attitudinal skills often neglected by the boundary-based standards and assessments that dominated his formal literacy instruction. James admitted that at first he would ask busmates to share their homework, specifically reading-review and math worksheets from which he could easily copy answers: "Sometimes I didn't get schoolwork done because of work or something else, so I would ask these guys who I knew were good at math and stuff to see their homework." However, over a period of time, he began to recognize reciprocation as a shared expectation of this collaborative and, consequently, started helping his busmates meet the demands of the standardized English required in their papers. As demonstrated in the previous chapter, James was adept at accommodating the standards of academic discourse presented in his classes, and this ability quickly made him a valuable member of bus collectives comprised primarily of English language learners.

While it would be easy to dismiss James' initial forms of participation in these collectives as common instances of cheating, the development of his role in the relationships and shared efforts of this group signals a much more complex and pedagogically valuable set of tactics employed to exploit gaps in institutional strategies of control and containment. These tactics are especially pronounced in James' collaborations with Nadif, who had come to rely on James' feedback on most all his 
writing for school. Below is a section of a draft composed by Nadif for AP English and marked by James on the bus ride to Hughes. ${ }^{54}$

An appeal to the people.

In an advertisement shown on TV, a boy is loaded with rifle, pistol, and multiple

$$
\text { ON What show? }
$$

grenades. The advertisement has been ajred from a TV show in America, to convince the American people give their support to Israel. A country that is in desperate for help with a fight what?

against Palestine. This is what puts one into a hopeless condition. The ad targets an audience who finds child soldier as afh offensive. The ad urges people to consider child soldier as foolish act. It appeals to ethos, logos, pathos, and kairos to convince the crowd in different ways. The director designer made his message clear at the way he loaded the young boy with weapons. Looking into the eyes of the boy in the picture, you feel ard passionate he is about his job. This ad ant?

exposes the dangers of a pro-lsrael stance that supports children as victims and participants of Transition?

It seems that children are already been convinced to consider going to war as an option. "What kind of society raises six-year old on dream of suicide, homicide, and hatred? A society that targets Israel." the children of Israel has an enemy that has exists, and the

As evidenced in this text, James' review of Nadif's work goes beyond surfacelevel corrections to include the sort of formative commentary we might associate with genuine investment in the meaning-making processes of Nadif's composition. In this way,

${ }^{54}$ See Appendix I for full text of Nadif's paper with James' markings. 
the collaboration involves the pedagogical value of genuine peer review often promoted and pursued in writing classes. However, this review could not have occurred within the confines of the institution because Nadif and James were separated into different tracks of study. ${ }^{55}$ Moreover, some of the marks James makes on Nadif's paper, such as replacing and correcting terms, might be seen as pushing the boundaries of collaboration, presenting a challenge to demands of individual authorship. When I asked Nadif if he would ever consider telling his English teacher about James' role in his process of composing, he responded by suggesting that she may get the wrong idea: "She may believe he does work for me. I would not want to risk of telling her."

Nadif's comment here represents a perspective that frequently emerged among students participating in this research. In both high school and college, students seemed to embrace ideas and practices of collaborative writing outside classes, but most often avoided showing signs of collaboration within official scenes of school space-time. While Nadif was frequently encouraged and even required to engage in peer review activities in high school and college English—activities that resembled his reviews with James in most every way — he was hesitant to admit to engaging in these activities outside institutionally sanctioned scenes of writing. This tendency to conceal collaboration was especially pronounced in the student-led writing collectives I observed after following Nadif and others to college. Like the high school bus collectives, these groups formed around shared space-times rather than shared tasks.

\footnotetext{
${ }^{55}$ James and Nadif were first acquainted in regular-track courses during their junior years. They maintained a tenuous friendship despite cultural, linguistic and social differences. In fact, I suspect it was Nadif who convinced James to participate in this project despite his initial skepticism.
} 
For instance, Nadif's Muslim Student Association at the University of Louisville often operates as a cross-curricular, interdisciplinary writing group, as students working on assignments and projects for different classes in different disciplines congregate in library study rooms, dormitory lobbies, dining halls, coffee houses, etc. to share material, discursive and conceptual resources in their work together toward different objectives. Most often students participating in such collectives were reluctant to admit their influences on each other's work. They seemed to conceive of their activities as anti- or, at least, counter-institutional. And in secondary and tertiary institutions that tend to privilege the apparently original productions of independent actors through individual assessments, plagiarism threats and detection strategies and software, physical and virtual surveillance and so on, these students' suspicions and anxieties are often well-founded (Williams Shimmering, 65).

In this way, according to the perceptions of most participating students (and observant teachers), collectives like the those formed on the "international bus" to Hughes and among ethnic and/or affinity groups in college, engage in forms of underlife that circulate around classroom activities. The students comprising these collectives make use of their daily patterns of physical mobility, often coordinated via virtual and communicative mobilities, to participate in underlife activities that enable them to not only maintain the complexity of their identities, but also to share tasks and resources across space-time, bodies, texts and objects. Of course, this division and redistribution of labor has significant impacts on the practices and performances that constitute the institutionally sanctioned scenes of writing around which these collectives circulate. 
Consequently, these underlife activities are not merely contained or even disruptive forms of resistance that work around or against institutions, as Brooke and Goffman assert; they are constitutive forms of resistance that (re)shape scenes of writing and, thus, institutions by pluralizing the space-time of these scenes. As demonstrated in James' movement across the space of his English class to resume work with busmates that began and would continue on their daily commutes to school or in the influences of impromptu peer reviews on Nadif's academic essays, the mobilities that configure students practices and realities outside scenes of writing reconfigure the space-time of these scenes and visa versa.

Up to this point in the chapter, I've focused primarily on how such pluarlizations are accomplished through student collaborations on and with school and city buses. But multiple objects are always involved in producing heterogeneous space-time (Leander and Lovvorn 293). As Latour asserts: "Any time an interaction has temporal and spatial extension, it is because one has shared it with non-humans" ("Interobjectivity" 239). In the next section, I continue to investigate constitutive underlife activities by attending to the ways in which Nadif and Katherine interweave face-to-face interactions with academic texts and information and communication technologies (ICTs) to extend the space-times of scenes of writing in high school and college.

\section{ICTravel}

Nadif's process of imagining the University of Louisville and himself within it began in a cybercafé in Nairobi. Because he spent his early childhood in Dadaab living with his grandmother, his United Nations identification number matched her household's rather than his immediate family's. Consequently, when his father, mother and two 
younger siblings received U.S. visas, they were forced to leave Nadif behind in Nairobi, where he was attending secondary school. As he explains, when UN officials select you for resettlement, "You don't want to lose the opportunity. If you're standing in front of somebody [offering you passage to the U.S.] and you delay, you will not get another offer. That's the one time you'll get it." And so, rather than risk forfeiting the passages of four people to retrieve one, his parents seized their opportunities for relocation and trusted Nadif's would come later. Over the course of the year it took to obtain appropriate identification, undergo security interviews and receive his own visa, Nadif was resigned to navigating his future destination city on a rented computer, network connection and search engine in the Burger Dome Cybercafé located a few blocks from his school.

When he learned his family had settled in an apartment complex eight miles from the University of Louisville, he began to regularly browse the school's website. Speaking of his initial impressions of the University, he laughingly suggested that "First, all I know about the college was a sport's stadium. Every time I went to the website, I saw a picture on the front page. I showed my friends how big it was and got excited and proud to go to school at this place." Eventually he began investigating the website of the University's Department of Political Science with aspirations of studying a subject that would enable him to serve his home country: "I was interested in politics because I understood that in order to be a good peacemaker, who could help solve Somalia's problems and educate others, I needed to have good understanding of politics." He studied the program's requirements, course offerings and descriptions, location on campus and images of the building, faculty photos and areas of expertise, internship opportunities and so on. By the time he left Kenya, Nadif had already spent hours experiencing and anticipating the 
"atmosphere of the place"-representations of the department's materiality, values, expectations and discourses - through virtual and imaginative mobilities (Halgreen 2004).

After months of this virtual and imaginative travel, Nadif received word from friends in Dabaab that UN officials were looking for him in the camp. He was in the process of taking an end-of-term chemistry test when he checked his cell phone and noticed 15 missed calls in a period of 20 minutes from the three people designated to watch the wall where all official communications were posted at the camp and notify him if his name appeared. Nadif describes his reaction to these missed calls: "As soon as I saw these calls, I knew something was up. So I just went to the restroom. That's the only way you can use your phone in the school. So I made a phone call and found out that my name is on the wall and I am needed, like, today." Upon receiving this news, Nadif immediately left school, called his parents to wire money for travel, packed his belongings and contacted a transportation service to drive him the 500 kilometers from Nairobi to Dadaab. He did not make it back to the camp until early the next morning, but after pleading with UN officials, he was allowed to take his place among a group of newly approved U.S. immigrants in route to New York City.

This brief sequence of Nadif's mobility narrative demonstrates the complexity of inter-relational dynamics among physical, imaginative, virtual and communicative mobilities. While it is clear that his physical journey to the U.S. required coordinated movements of people, objects, ideas and information across both distant and proximate spaces and times - movements of information through various bureaucracies, movements of messages across cellular networks, movements of money across wire transfer systems, movements of bodies via ground and air transportation, etc. —o particular significance to 
this exploration of educational mobilities are the ways in which the virtual, communicative and imaginative travel made possible by Nadif's partnership with information and communication technologies (ICTs) informed his perceptions of and practices in the scenes of writing in which he participated at Hughes and the University of Louisville. Like the intertwining of mobilities shaping his experiences with and on buses, Nadif's engagements with the internet and mobile phones blend physical, virtual, communicative and imaginative mobilities to project and transform scenes of writing in high school and college.

\section{Colleges of Collage}

By now, it is a commonplace that the proliferation of objects supporting virtual and communicative travel—mobile phones, personal computers, tablets, email, chat, text messages, search engines, etc.- - have contributed to a complex and rapidly changing technoscape (Castells 1996; Urry 2007; Thrift 2004). As Ilana Snyder asserts, a "new communication order, centred around information technologies, is part of the technological revolution that is reshaping the material bases of society. New technologies have made massive incursions into all facets of life, albeit unevenly in different parts of the world" (4). Despite the uneven local and global distribution of such technologies, elements of Nadif's mobility narrative demonstrate how ICTs create possibilities for relatively seamless multimodal, sensory and affective connections across space-time in even the most under-resourced environments.

In the case recounted above, Nadif's family's physical travel to Louisville initiated a pattern of imaginative, virtual and communicative mobilities through which he not only collected information about the city and the University but also reassembled this 
information to produce unique representations of these localities along with new ways of conceiving of the possible subjectivities he might take up in relation to them. In this way, Nadif's partnerships with rented computers, internet connections, websites and so on contribute to more than space-time compressions (Massey 1994; Harvey 1990; Soja 1989) or a utopian global community commonly associated with the proliferation of ICTs (Fox 2001). These partnerships contribute to virtual and material becomings of place by altering the ways in which Nadif represents these places to himself and others. ${ }^{56}$

Nicholas Burbules describes the navigational and semiotic elements of such becomings of place in his proposal of the World Wide Web as a rhetorical place. ${ }^{57}$

Calling the Web a rhetorical space captures the idea of movement within it, the possibility of discovering meaningful connections between elements found there; but it does not capture the distinctive way in which users try to make the Web familiar, to make it their space- to make it a place. Individual users do this by selecting a homepage for their browser, by bookmarking sites, by visiting the same familiar sites frequently, and by making their own webpages. (author's emphasis 78)

So as Nadif chats with relocated family and friends in Louisville, follows the University's Twitter feed, browses the city's official website and participates in conversations on the wall of the Young Somalis for Louisville Facebook page, all from a cybercafé in Nairobi, he is not merely bringing distant locations within the range of his senses or producing an “illusion of closeness," as Nedra Reynolds suggests (18). He is developing idiosyncratically meaningful ways of relating linked sites in the co-creation of a virtual geography that comes to represent his future destination city and University. By

\footnotetext{
${ }^{56}$ See Chapter One for a discussion of Pennycook's concept of becomings of place.

${ }^{57}$ As I suggest in Chapter One, to avoid potential semantic slippages between objectified place and relational place, following Alastair Pennycook, I employ the term "locality" rather than "place" to represent the socially or subjectively meaningful space Burbules has in mind here.
} 
establishing a pattern of web browsing and communication that connects frequently visited sites of institutions, affinity groups, and friends and family, Nadif is identifying and charting movements among key points in fields of future participation. In this way, he creates a virtual map - selecting, simplifying and schematizing representative aspects of the city and University and, thereby, developing concepts of the localities he will eventually occupy and transform.

After discovering that Nadif spent the year leading up to his resettlement engaged in such extensive virtual travel, I designed an activity for one of our bus rides from Hughes to the University to retrace and materialize a portion of the virtual map Nadif charted from Nairobi. My hope was that this process of remapping would provide an occasion for reflecting on his expectations for participation in college. The activity essentially consisted of working in reverse from his perceptions of college to locate them in particular sites of information. Of course, as in any attempt at remembering, the past is transformed in the process of retrieving and recounting it. Nonetheless, by the end of our ride, Nadif and I were able to reconstruct an interesting string of connections in his virtual map of the University and to consider its influences on his present practice and future expectations.

When I asked Nadif why he decided to attend UofL, I was surprised by his response: "Because the school and I both care about Africa. [...] People there will help me accomplish my goal to help and bring peace to Somalia." In addition to the suggestion of linguistic mobility and attitudinal preparedness presented in the previous chapter, the alignment Nadif perceives between his own interests and goals and those of the University provides another possible explanation for his success in college. Below is a 
representation of the map Nadif and I sketched to retrace one route by which he came to an understanding of this alignment:

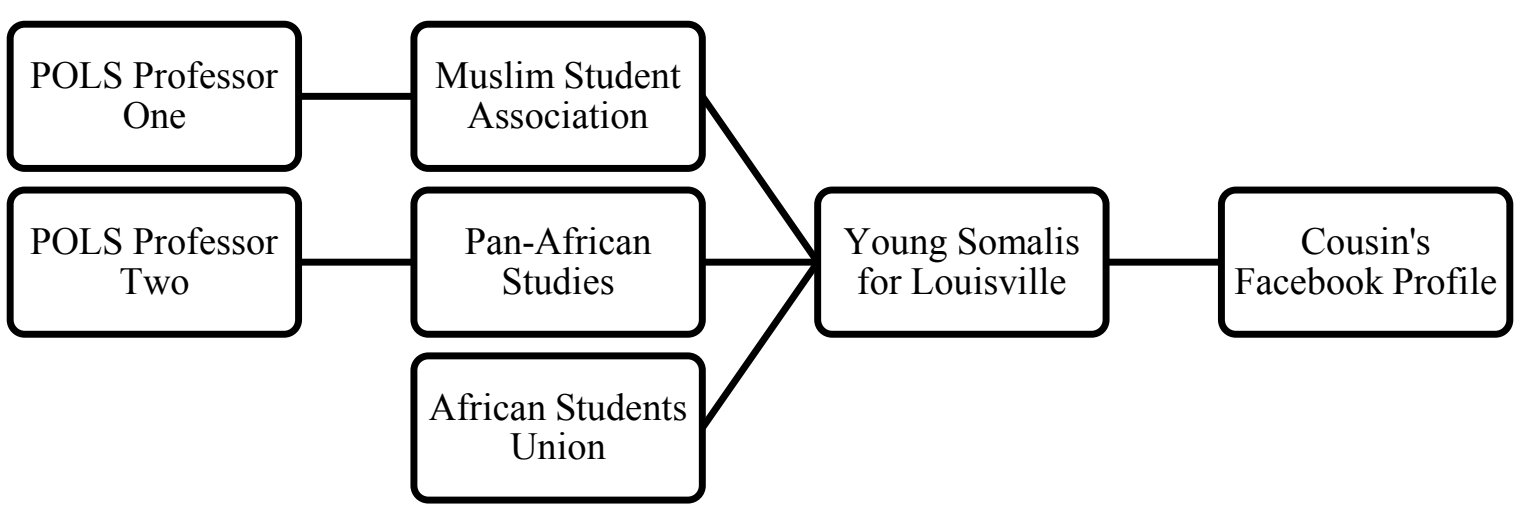

Nadif's map begins with the names of two professors in the political science department: "I found out these two teachers: [Professor One], who studies Islam, and [Professor 2], who does politics of Africa." While Nadif had not met either of these professors at the time of this interview, he knew their areas of expertise from searching the department's website. He remembered finding Professor One's name in an event description posted on the webpage of the University's Muslim Student Association (MSA), and he found Professor Two's name listed for a Pan-African Studies (PAS) course on religion and politics. He had learned of the school's MSA and PAS program, along with the African Students Union, through the Young Somalis for Louisville group page, which he had discovered on Facebook through a cousin's personal profile. This cousin had immigrated to Louisville two years before his parents' arrival in the city. While this visual traces the initial chronological formation of this chain of associations, in practice, Nadif would have revised this chain with every browsing session —altering the order and frequency of circulation, adding and removing sites from this progression, following different links to and from these sites and so on. 
While it would be interesting to observe how Nadif's process of rhetorical placemaking on and with the web changes over time and according to context, the key point here is that by Nadif's account on this particular occasion the virtual map contributing to his conception of the University as an institution that shares his concern for Africa was developed through patterns of movement among sites of information in a network he created before immigrating to the U.S. This conceptualization not only informed his choice to attend the University, but also influenced many of his decisions while still in high school. As previously mentioned, we sketched the above map in route to the University, where Nadif was already taking an Introduction to Pan-African Studies course for dual enrollment credit. Moreover, his topic selection for papers in high school was often motivated by his desire to prepare for future studies. Across his senior classes, Nadif wrote about the consequences of the colonization of Africa represented in the work of Achebe and about the possibility of a representative World Court. He wrote case briefs on several major U.S. Supreme Court decisions and researched NATO's invasion of Libya and U.S. intervention in Somalia. He expressed on multiple occasions that he chose to write about these issues because he knew he would need to understand them for his political science program.

It is interesting to note that Katherine engages in similar processes of mapping future geographies of tertiary education with representations assembled from television shows depicting college life. In an interview we conducted during her senior year of high school, Katherine responds without hesitation to a question about where most of her impressions of college come from:

T.V. [...] I watch Gilmore Girls a lot, and she [Rory Gilmore] goes to Yale, so, like, I have that impression of college. And there's another show; 
it's called Best Years of Our Lives or something. And it's based in college, and it's more focused on social life. And then I watch Greek, and it's more about fraternities and sororities, which I know I won't really be a part of, but it does seem fun.

Like Nadif's processes of imagining and charting the terrain of his future geographies, Katherine deliberately and inadvertently samples fictional scenes and experiences from these shows to piece together a collage of college. While there is very little novelty in the assertion that students develop their own gestalts of college from information and impressions provided by and circulating through various sources, including family members and friends, Katherine's assertion that popular culture sources are more prevalent in her gestalt than relational and academic sources is relevant to the discussion of rhetorics of college and career readiness presented in the previous chapter. While neoliberal reform efforts work to define and project college as a spatially and temporally fixed target with predictable and uniform standards and expectations, popular culture provides a range of alternative representations, which may be more compelling and, thereby, more influential to students' perceptions of and practices in college. And although these representations reduce the dynamic and heterogeneous spaces of college in many of the same ways as rhetorics of readiness, students' participation in popular culture might enable them to sample from a greater diversity of sources to create more complex projections of their lives in college.

Discussing online composing practices, Bronwyn Williams asserts that "popular culture provides the largest, most varied, and most accessible assortment of images, video, and sound for people to sample as they compose" (Shimmering 66). Drawing, in part, from de Certeau's concept of poaching to describe a process by which individuals appropriate pieces of text to assemble new creations that serve their own interests and 
experiences, Williams proposes that in their interactions with new media technologies, students are "like nomadic poachers roaming across texts hunting not just for meanings but for pieces they can incorporate and reuse in their everyday lives" (80). While Nadif and Katherine are not composing digital texts in these particular instances (though they are engaged in creating such texts elsewhere), the idea of poaching from popular culture for conceptualizations of college does accord with the accounts of many students participating in this project.

Processes of poaching from mass media representations and the experiences of fictional characters contribute to the development of ersatz memories - nostalgia without lived experience — that inform students' expectations, decisions and practices in college. For instance, when I asked Katherine why she made the decision to stop attending community college, she stated: “Because it didn’t feel like college, (long pause) like what college is supposed to be." As we continued to unpack the specific elements of her community college experience she felt conflicted with her preconceptions, we came to the conclusion that her experiences were different in most every way from those of the characters on her favorite television shows. Among other differences, the actual work of college is seldom depicted in these shows; characters are seemingly completely consumed with social life; their off-campus work is rarely displayed; and material needs are met behind the scenes. Ultimately, Katherine's experience of community college was nothing like Rory Gilmore's experience of Yale, which likely has very little in common with the experiences of students at the actual institution.

Here, it is important to note that the virtual and imaginative mobilities made possible by Nadif's and Katherine's partnerships with networked-computers, search 
engines, personalized web browsers and television are not limitless. Like students' movements on school and city buses and through the halls of Hughes, Nadif's and Katherine's virtual and imaginative mobilities are shaped and constrained by strategies directing and channeling navigation. Strategies employed to control portals, filter information, direct lines of inquiry, spread ideologies, divert attention and attract viewers have a significant impact upon the content and contours of Nadif's and Katherine's virtual and imaginary maps. Additionally, "accidental" diversions, such as outdated information, broken hyperlinks, slow processing speeds, cancelled shows, alternative programming, etc. delimit and prevent meanings they might otherwise make of their investigations. While there seems to be a high degree of choice in how and where users move within the space of the internet and mass media, barriers to virtual and imaginary mobilities, along with the pragmatics of limited material resources, can constrain possible meanings users and viewers derive from their investigations. As Burbules suggests, "Semantic possibilities relate to, and can be constrained by, navigational possibilities" (78).

Of course, the virtual maps and imagined localities formed by these possibilities and constraints eventually influence Nadif's and Katherine's patterns of mobility within and among geographies of tertiary education, as the values, desires, expectations and perceptions they develop through this process of virtual co-creation and navigation transform the college scenes of writing in which they participate. Of particular interest to this discussion are the ways in which Nadif and Katherine maintain connections across space-time by pluralizing present scenes of writing through their partnerships with ICTs. As I've argued throughout this dissertation, scenes of writing are always, already 
pluralized through interaction of participants' historical bodies; however, in the contemporary writing classroom these interactions are almost always augmented by mobile communications.

\section{Classrooms of Co-presence}

To bring Goffman's concept of underlife - along with Brooke's adaptation of it for composition studies - into the technoscape of the contemporary classroom, we must consider the ways in which a proliferation of mobile technologies affords new forms of student resistance, co-presence, collaboration, play and innovation. Regardless of level or location, most teachers recognize the prevalence of mobile devices as one of the most transformative features of education in the $21^{\text {st }}$ century. As Katherine's duel enrollment English teacher asserts:

I'm lucky if I look out at the class and make eye contact with a single student. Everyone's looking down at their laps, as if I don't know what they're up to. ... I've tried everything to get them off their phones. I've tried collecting them at the door, confiscating them when I see them out, sending students to the office, using them in class activities. By now, I've pretty much given up. Why try to stem the tide?

I can sympathize with this expression of frustration and futility. Admittedly, I have attempted to implement some of these same measures, and to the same effects. But as the portion of Nadif's mobility narrative recounted above demonstrates, even in schools with stringently enforced restrictions on cell phone usage, students (and teachers, staff and administrators) will find ways to maintain connectivity to and through them-if only from bathroom stalls. This is largely because many individuals experience their devices as extensions of themselves. As Larsen, Urry and Axhausen (2006) demonstrate in their research of mobile phone usage on public transit, "many young adults describe their mobile phones as prosthetic, as physically coterminous with their bodies. Mobile phones 
allow them to be 'proper' social beings. Without them, they are 'lost' being dependent upon such systems" (113).

Of course, an increasing number of teachers, programs and institutions are making use of the connectivity afforded by mobile devices to extend opportunities for teaching and learning (Cortesi et al. 2014). While tensions among institutionally sanctioned and restricted uses of these devices represent an important site of ongoing and future study (Motiwalla 2007), in the final section of this chapter I am most interested in investigating the ways in which students partner with mobile ICTs to exploit cracks in systems of institutional surveillance, increase linguistic and literate possibilities, connect scenes of writing across lifeworlds and, thereby, transform localities. Like James' and his busmates' transformations of the space-time of their school bus to extend and connect academic scenes of writing, students' partnerships with mobile devices create possibilities for forms of underlife that draw upon otherwise marginalized aspects of historical bodies and thereby reconstitute historical localities.

As previously suggested, students are not merely engaging in forms of underlife to resist the available activities and identities of school scenes of writing. Rather, through partnerships with mobile technologies, they are actively reconstituting these scenes through a multiplication of spaces, times and subjectivities. Urry describes this process of multiplication as a creation of “interspaces," "where different 'fields' or 'domains' of activity overlap" (176). He asserts that "this merging and overlapping of fields engenders simultaneity rather than linearity," which "means that identities may well be less placebased and more engendered through relations made and sustained on the move, in liminal 'interspaces"” (177). In this way, students' face-to-face-to-interface forms of underlife 
enable them to maintain the complexity of their identities in classrooms through communicative mobilities across multiple institutional, academic, social, cultural, and home/life interspaces.

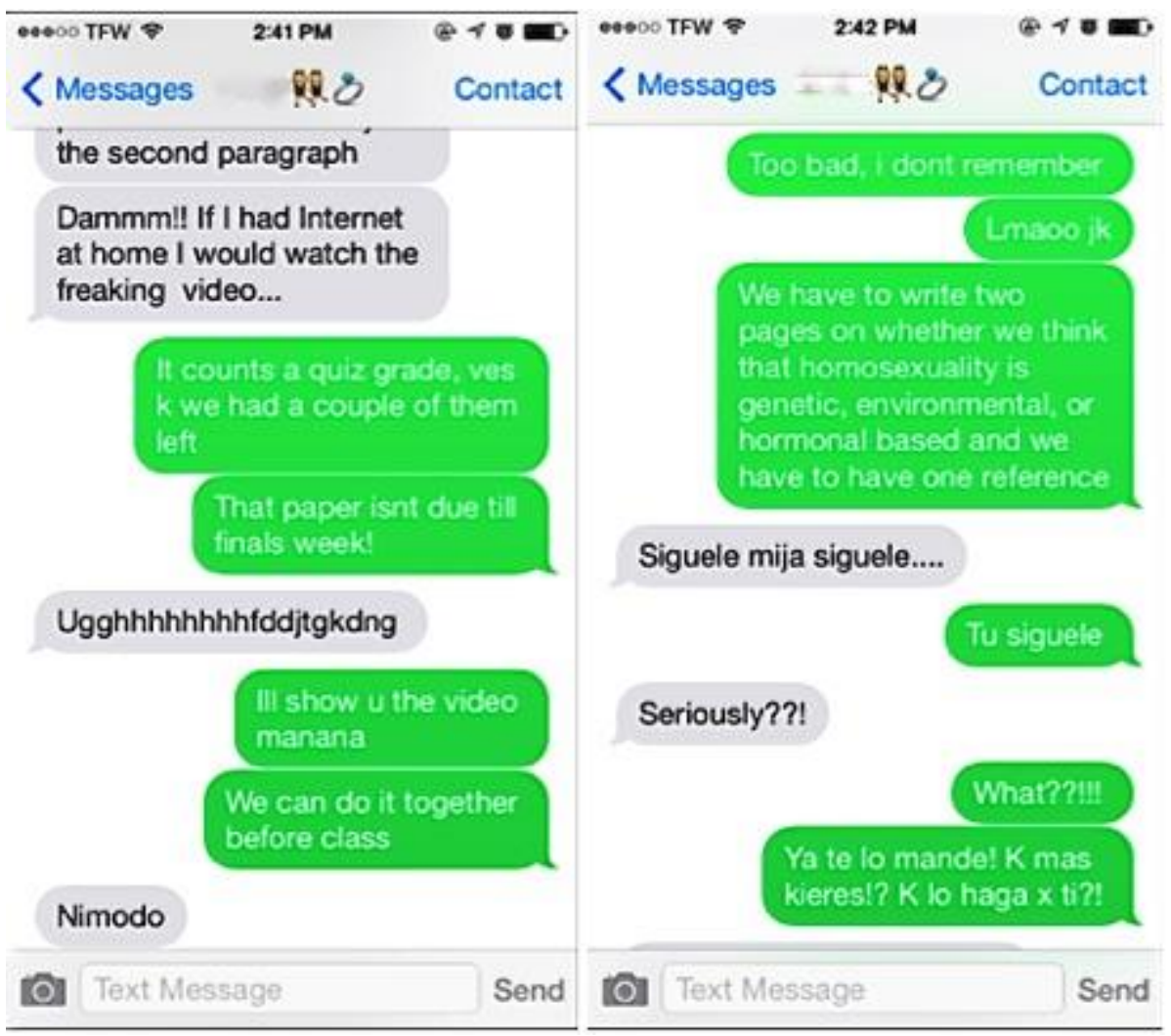

The portion of Katherine's text message conversation reproduced above demonstrates the "simultaneous multiplicity of spaces" and subjectivities accomplished through such constitutive forms of underlife (Massey 3). ${ }^{58}$ Katherine engages in this conversation in her intermediate-level composition class at the community college. As she participates in face-to-face peer review with a partner in class, who is also texting from her smartphone, Katherine is simultaneously engaged in the exchange excerpted here and is contributing to a Facebook group chat excerpted below.

${ }^{58}$ I have erased Katherine's name in the banner of this image to preserve her anonymity. 
In this portion of a conversation that spans approximately 20 minutes of a 50minute course and includes over a hundred individual messages, Katherine is fielding school-related questions from a friend and classmate. Up to this point, the exchange has covered a wide range of topics from weekend plans to South Korean pop music and, finally, to schoolwork. The friend, represented in grey text bubbles, is expressing her anxiety about end-of-term deadlines. In the screenshot on the left, Katherine is attempting to assuage her friend's anxiety by reassuring her of the time she has to finish assignments and by offering to help her with work she is unable to complete because she lacks internet access at home.

In the screenshot on the right, Katherine is providing an overview of an essay assignment for a shared introductory psychology course and is teasingly fending off requests to offer more information about the essay. After sending the basics of the assignment, her friend asks her to continue: "siguele mija siguele [go on, girlfriend, go on]." To which Katherine responds: "y te lo mande [I already sent it to you]. K mas kieres [what more do you want?]. K lo haga $\mathrm{x}$ ti [What? Do you want me to do it for you too?]. ${ }^{59}$ Discussing the language of this exchange and explaining her need to translate, Katherine asserts:

Just like in English there is text language, this is the same in Spanish. To be specific, this conversation is in Spanglish, so it has its own slag. The $K$ stands for Que because my friend and me know English and Spanish- the sound is the same. $X$ in Spanish is times, which is por. For example one times one would be uno por uno. The sentence correctly is supposed to be Que lo haga por it, and it is said sarcastic.

\footnotetext{
${ }^{59}$ Katherine translated these texts during an interview focusing on these and other examples of text message conversations she engaged in while in class.
} 
In many ways, this translingual exchange works like the mobile collectives James, Nadif and their classmates co-create with and on the school bus. Through a similar process of negotiation around licit and illicit forms of collaboration, Katherine and her friend partner with their devices to share resources - information and interpretations - and school work across space-time.

Similarly, Nadif responds to prompts from his smartphone (the prod of a glowing screen and gentle buzz) to co-create a work collective from his second-semester composition class at UofL: ${ }^{60}$

Nick: Did you work 1st or 2nd half?

Nadif: I work 2nd half

Nick: Nice. Will you and/or Ryan make sure that time sheets make it to Pinkie? Brian is supposed to pick them up, but if he hasn't by early afternoon, make sure they get to pinkie by 5 ! Thanks [Nadif]! \$\$

Nadif: I can take of that. Take care

Nick: Thank you [Nadif]. I'm Michael and you are Dwight. Thanks \#2 :) Haha.

Nadif: Haha! Yes were Dwight and Jim? So who signs the DA time sheets? But you aren't as funny as Jim, maybe you could be Michael. Lol ${ }^{61}$

Like Katherine's appropriations of popular culture sources for her projections of college, Nick and Nadif appeal to characters from the U.S. version of the popular television show The Office to define and negotiate their roles within this collective. Moreover, both Katherine's and Nadif's communicative mobilities occasion physical mobilities, as they serve to coordinate co-present collaborations. Katherine: "Ill show you the video manana. We can do it together before class." Nick: "Brian is supposed to pick them up, but if he hasn't by early afternoon, make sure they get to pinkie by 5!" Unlike the timetabled,

\footnotetext{
${ }^{60}$ All names in these exchanges have been changed to maintain participants' anonymity. ${ }^{61}$ Nadif transcribed this conversation into a Word document to share with me rather than saving it in a screenshot.
} 
rational and linear organization of traditional space-times of school and hourly labor, the space-times created and coordinated through these communicative mobilities are fluid and negotiated. As Urry suggests, "Mobile phonespaces afford fluid and instantaneous meeting cultures where venue, time, group and agenda can be negotiated with the next call or text" (174). In this way, the flexibility and continuity of the mobile collectives Katherine and Nadif form through partnerships with ICTs reconstitute the clock-times and bounded spaces of school and work localities.

Moreover, the languages and discourses of these exchanges contribute to performances of identities distinct from those Katherine and Nadif take up in their respective classes and in additional virtual exchanges. Participants in the following group chat conducted on Facebook are responding to an image of Katherine and her older sister, Abby, recently posted on the latter's profile page. Katherine pivots from her more continuous text and face-to-face peer review conversations to periodically review and respond to comments on the photo.

Irene: OH MY GOD i didn't know you all were sisters!! I feel so dumb right now.......but so happy i know both of you !!

Katherine: Yeah the other day I told her that you sang in my high school and she was like oh yeah I know Irene. I was like no way!

Irene: what a small world!

Katherine: Thts exactly what I was thinking!:D

Meagan: Aww que linda!

Abby: Ya lo se Meagan Hope you have fun in Nashville Stay safe!

Meagan: Thanks girl! I saw mi hermanita today too so I feel great!

Abby: Que bueno, me da gusto Te cuidas y que te diviertas

Meagan: ¡Muchísimas gracias! Por fin me siento llena jeje..que the diviertas también;)

Katherine: Haaaaa k lindas yo kiero una mija haci .... Gracias x su amistad a las dos son muy lindas y tiernas $\mathrm{k}$ Dios las siga bendiciendo.

In this portion of a longer exchange, Katherine moves among languages

associated with different audiences and domains. Rather than blending Spanglish-text and 
English-text in single responses as she does in her text message conversation, she responds to Irene, a monolingual English-speaking friend from high school, in Englishtext and reserves Spanglish-text for her older sister, Abby, and her sister's MexicanAmerican friend, Meagan. Moreover, unlike the sarcasm with which she concludes her text conversation, her final contribution to this chat is quite sentimental: "Haaaaa $\mathrm{k}$ lindas yo kiero una amiga haci [How sweet, I want a friend like that $]. .$. Gracias x su amistad a las dos son muy lindas y tiernas $\mathrm{k}$ Dios las siga bendiciendo [Thank you for your friendship; you both are very kind and sweet. God bless you.]

Moved by this image of and support for sisterly affection, Katherine assumes the role of gracious and devout younger sibling by praising her sister's friendship and offering a formal blessing in the language of their shared household. When I asked how she would describe the linguistic and discursive differences among her responses, Katherine stated: "My sister and her friends are more, like, (pause) traditional. I guess I was more serious in this last response because I'm more used to talking like this around my family." In this group chat and simultaneous text message exchange, Katherine is drawing upon a range of linguistic and discursive resources to create and maintain connections across and position herself within various domains of school, social and family life. In Urry's terms, she's partnering with her smartphone to create an interspace in the overlap among these fields of participation. This partnership enables her to maintain the complexity of her identities in the school space-time of her composition class. 


\section{Mapping and Translating Mobile Practice}

Perhaps most interestingly, these communicative mobilities reorganize the spacetimes of Katherine's and Nadif's physical presences, as their interactions in scenes of writing are mediated by and connected to a host of other meetings. Through their communicative mobilities, their material localities are pluralized by "the absent presence of others" (Callon and Law 6). Among other things, this co-presence creates possibilities for translingual and transmedia negotiations in scenes otherwise demarcated by institutionalized languages (i.e., standardized English) and literacies (academic and discipline-specific). And as I've asserted throughout this chapter and dissertation, the metalinguistic, sociolinguistic and attitudinal preparedness students develop in and through their mobilities across localities can, in many ways, be more valuable than the development of literate and linguistic competencies in apparently discrete disciplines promoted by boundary-based pedagogies and curricula.

The notion that literacy learning is always already distributed across space-time and among individuals and objects in localities that cross-cut, intersect, and align with one another or exist in relations of paradox or antagonism has transformative implications for literacy research and teaching. For ethnographies of literacy, a mobilities approach challenges the concept of a circumscribable "literacy event" (Heath 1983) and instead focuses on continuities and discontinuities among scenes of writing, practices, resources and social alignments. As Mary Hamilton asserts: "Visible literacy events are just the tip of an iceberg: literacy practices can only be inferred from observable evidence because they include invisible resources, such as knowledge and feelings; they embody social purposes and values; and they are part of a constantly changing context, both spatial and 
temporal" (18). As I suggest in the introduction to this chapter, attention to complexities of associations created and assembled by reading-writing practices requires the adoption of epistemologies grounded in the fluidities of space-time. Moreover, such attention requires the implementation and innovation of research methods that can follow and represent fleeting, distributed, multiple, non-causal, chaotic and complex language and literacy practices and their sensory and affective dimensions.

A concerted examination of basic research methods for attending to mobile literacies has only emerged relatively recently in concert with a growing demand among researchers for analytical frames and methodological strategies that can account for the complexity of literacy practices across localities (Brandt \& Clinton 2002; Lillis 2008, Ivanič et al. 2009; Perrin 2012; Brent 2012). This effort has generated a number of methods for mapping students' everyday literacy practices. Through time-space journaling (Leander 2003), video ethnography (Fraiberg "Military"), photo elicitation (Hamilton 2000), annotative and iconographic mapping (Mannion and Ivanič 2007), rhizomatic analysis (Leander and Rowe 2006) and other methods, researchers seek to trace students' literacy networks across contexts, cultures, languages, media, tracks and stages of education. I hope that my investigation of students' mobile practices contributes to these efforts and opens up possibilities for future study and methodological development.

By sketching partial and subjective maps of Nadif's, James' and Katherine's movements within and among scenes of writing, I have attempted to demonstrate the difficulty of locating their literacy practices, languages, and identities in bounded sites of activity. While a great deal of meaning could be made from observing, interviewing and 
analyzing texts produced by these students in single sites of activity, participating in their patterns of movement across virtual and physical highways, from high school to college and/or work, among institutions and between classes reveals the meanings they make in perpetual motion. This focus demonstrates the ways in which students are involved in ongoing productions of space-time. By tracing Nadif's projection of the University of Louisville back to a cybercafé in Nairobi, following the writing collectives James forms in the space-time of bus rides between home and school, and mapping the intertwining threads of Katherine's multiple face-to-face-to-interface dialogues, this chapter has attempted to show how student-object collectives constitute, connect and pluralize scenes of writing across space and time.

Of course, this concept of mobile literacies has implications not only for new frameworks for understanding literacy but for the teaching of literacy as well. As students translate meanings across discourses, languages, media and localities—often through their underlife activity - they are negotiating the demands of concurrent and conflicting contexts, investments, allegiances, and ideologies. Rather than prohibiting, discrediting and marginalizing these mobilities, as is often the case in boundary-based systems, literacy pedagogies might make use of them by providing students opportunities to connect and reflect upon their processes of translation so that they come to see themselves as contributors to becomings of dynamic and heterogenous scenes of writing. As demonstrated in Katherine's, James' and Nadifs' contributions to this chapter and the larger project, when provided an occasion and conducive material conditions, students reflect on their mobilities in ways that often provide valuable insights into how meanings are made in and through convergences of physical, imaginative, virtual and 
communicative mobilities. The following conclusion to this dissertation briefly considers affordances and limitations of metaphors of mapping and translating for designing reading-writing activities and larger projects that make use of a mobile literacies framework. I suggest that by creating opportunities for students to map their literacy practices within and across scenes of writing and prompting them to reflect on translations across asymmetrical relations of power that attend these mobile practices, they might locate agencies, or ways to appropriate, resist, and transform dominant discourses, genres, ideologies, and disciplines with their language and literacy resources. 


\section{CONCLUSION}

\section{PEDAGOGICAL POSSIBILITIES FOR MOBILE LITERACIES}

The focus on activism draws attention to the point that this is not a question of ... reveling in difference and the fascinations of cultural incommensurability; rather; this is a question of unsettling common relations, not only of entering traffic but of disrupting the traffic. - Alastair Pennycook

It is perhaps unsurprising that most of the field's studies of the development of college writers begin in the first year of college. For those who conceive of the academy as a unified and relatively stable discourse community_ or even a composite of discrete disciplinary communities - formed in accordance with stable standards, practices and genres sanctioning certain ways of doing, being and knowing, the first-year of college can be viewed as the "threshold" of a new "paradigm" (Sommers and Saltz 127). Following this conception, composition scholars often begin their longitudinal studies of transitions into college with what they perceive to be a student's initial point of engagement with an entirely unfamiliar environment. ${ }^{62}$ Ann Herrington and Marcia Curtis articulate this preconception in their study of students' movements into and through the academy: "The first year of college is a time of instability and turmoil as students move into a totally new academic and social environment and begin to think about preparing for their futures in a more immediate and pressing way than they had before" (124).

${ }^{62}$ See Haswell (1991, 2000), Sternglass (1997), Beaufort (1999, 2007), Curtis and Herrington (2000, 2003), and Carroll (2002) 
In contrast to this depiction, I have attempted to show how students borrow and assemble representations from a range of sources to imagine college and themselves within it long before they arrive on a college campus and, as in the case of James, even when they are not afforded such an opportunity. I've also shown how students partner with objects and each other to connect distant and proximate times, spaces and participants in processes of familiarizing, pluralizing and, thus, co-creating scenes of writing in college. Moreover, I have argued that far from postponing preparations for the future until they graduate high school, our neoliberal educational-occupational system proffers constant promises and threats of the future to "inspire" students" work in the present.

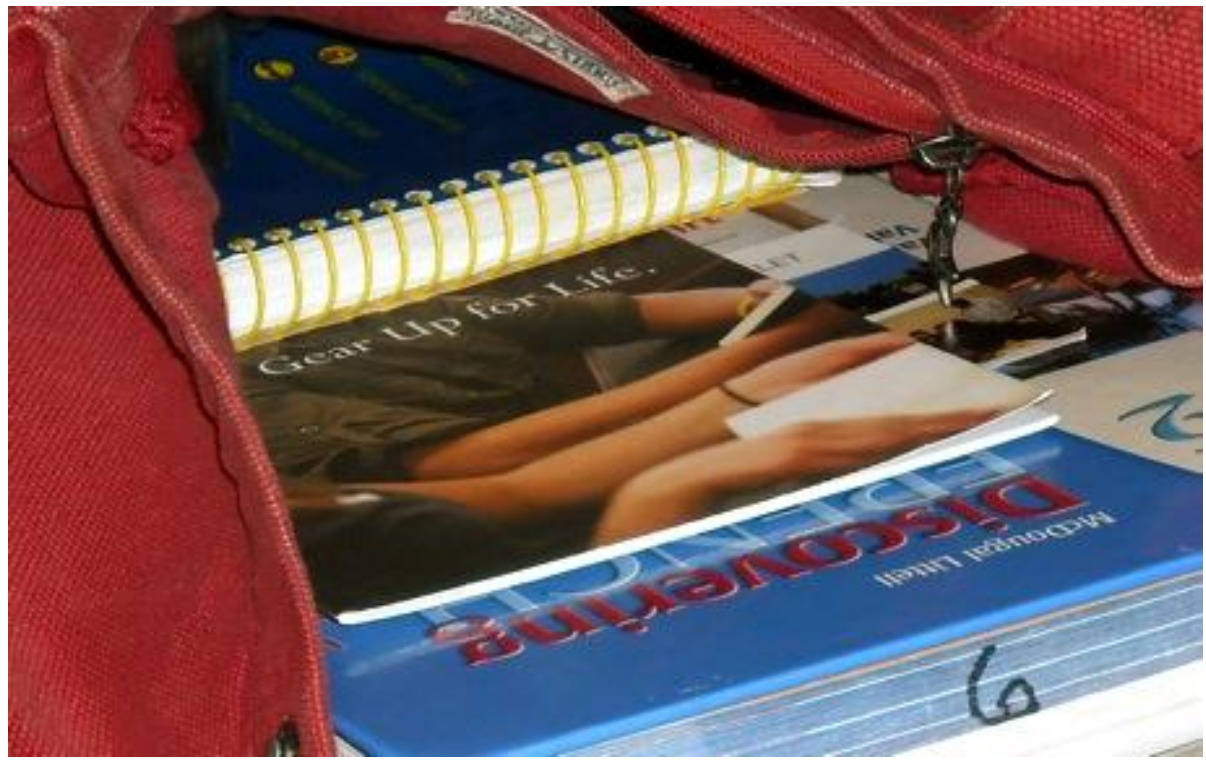

This photo captures the ubiquity of these reminders of the future. ${ }^{63}$ It is of Katherine's school bag spilling open on the floor of her high school English classroom to reveal an ACT college-prep brochure sandwiched between a handbook of writing standards and other texts and materials. The brochure exhorts Katherine to "Gear Up for

${ }^{63}$ See Chapter Three for more examples of such reminders. 
Life," as if she has spent her previous eighteen years doing something other than living. The familiarity of this sentiment belies its widespread acceptance and disguises its potentially damaging effects. Among these effects are an invalidation of Katherine's past and present experiences, skills and knowledge and a separation of her present practices of reading and writing from past, present and future habits of thinking and living ( $\mathrm{Lu} 2006$ ). Rather than shaping and being shaped by her ways of knowing, being and doing in the present, the message implies that her in-school and out-of-school literacy practices have, up to this point, only been preparing or failing to prepare her for the future. As I've asserted throughout this dissertation, such messages reduce the value and complexity of students' literacy practices and identities and delimit what we as literacy teachers can accomplish alongside them in the space-time we co-create and share. By designing pedagogies, curricula, outcomes and standards to, above all else, accommodate the apparent needs and demands of the future, we miss opportunities to attend to transformations of material conditions and social relations in the present.

I see the juxtaposition of this brochure alongside a writing handbook, which purports to contain the linguistic, discursive and generic standards Katherine will need to master for college, as a symbol of composition's participation in the development and maintenance of this relentless future orientation. As I argued in Chapter Two, the field's tendency to position students on trajectories from fixed points of departure to fixed points of arrival works to preserve the academic capital of such handbooks. If students are not moving in a straight line toward fixed and stable targets of "college-level" writing, it becomes more difficult to sell such guides and, more importantly, to maintain an institutional position as the corridor between students' literacy histories and futures. 
While I have learned a great deal and have a great deal more to learn from the aforementioned studies of students' transitions into college, I see many of them participating in this boundarying activity by depicting academic discourse communities as unified and stable and, subsequently, simplifying scenes of writing and students' identities. And while I acknowledge the limits of any study, including this one, that attempts to tell a particular story from a particular set of locations, I also believe that expanding our circumference of analyses diachronically and geographically beyond the contexts of college courses, as I've attempted to do here, can provide productive perspectives on how the localities in which entering college students participate before, within and outside institutions of tertiary education inform their preconceptions, experiences and projections of academic literacies and career opportunities. This effort accords with Williams' call to expand our purview of student writing beyond the college classroom so that we may join a conversation already taking place in $\mathrm{K}-12$ literacy education, ethnographic and international literacy studies, and media studies concerning the "writing that happens before and after students step on to university campuses" ("Seeking” 133). And so rather than focusing on the skills, experiences and values incoming college students apparently lack, in this work, I have attempted to consider how students' historical bodies mediate their efforts to contribute to the becomings of localities and identities that cross-cut and constitute the academy.

In addition to producing scholarship that tends to fix student trajectories and reify academic discourse, our pedagogies often present contexts of writing in and outside of college as temporally and spatially fixed sites of exigency, constraint, and discourse. Our teaching materials — textbooks, handbooks, assignments, assessments, etc.—and 
classroom activities often frame occasions for writing as rhetorical situations represented with singular and static triangles and predetermined actors, exchanges and relationships. To complicate these situations, we may encircle our triangles in context and add a few arrows (multidirectional if we're feeling particularly dynamic) to represent movement.

But, as I've attempted to show through representations and analyses of Nadif's, James' and Katherine's mobilities, scenes of writing are better conceived as fluidities of everyday practices, affects and uncertainties. To encourage this conceptual shift, Jenny Edbauer envisions rhetoric as a living environment. She defines rhetorical space as an ecology in which discursive events are "held together transsituationally" and are "the effects of trans-situationality on rhetorical circulation" (20). We misstep, she suggests, when we attempt to identify a specific exigency because constantly evolving exigencies are neither singular nor static: they encompass more than a collection of single situations that can be named, classified and positioned. In an Althusserian sense, rhetoric is an overdetermined space because no one situation affects future outcomes by itself: each situation contributes to change by collaborating with past beliefs, concurrent (though often unclearly linked) circumstances, and imagined possibilities.

Acknowledging this overdetermination means that "we are never outside the networked interconnection of forces, energies, rhetorics, modes, and experiences" (Edbauer 20). In other words, we never participate in scenes of writing that exist independently of the prior and ongoing rhetorical situations emerging through interactions of historical bodies and historical localities ${ }^{64}$ Edbauer's presentation of rhetorical ecology pushes us to replace conceptions of trajectories from high school to

\footnotetext{
${ }^{64}$ See Chapter Two for a discussion of the relations between historical bodies and
} historical localities. 
college and/or work as collections of scenes that add up to rational wholes (i.e., chains of rhetorical situations) with understandings of these trajectories as rhetorical circulations - living totalities of events that flow, change, and cohere in both predictable and unpredictable ways (Chaput 12).

Having attempted to offer glimpses of such circulations in the research that comprises this dissertation, I would like to conclude by imagining what an exchange of rhetorical situations for circulations might look like in the context of a high school or college writing course. While I believe a complete pedagogy of mobile literacies could be sketched out in accordance with the observations and arguments presented in this text and with those made in scholarship on mobilities from a range of disciplines, here, I only touch on possibilities for mobile literacy projects or activities that could work in the context of more traditional approaches to teaching writing. To frame these possibilities, I consider some of the affordances and limitations of metaphors of mapping and translation, often used to research and theorize spatiotemporal dimensions of literacy practice. I return to examples of Nadif's, James' and Katherine's mobile practices from previous chapters to demonstrate how these metaphors can be applied to literacy pedagogies. And I assert that by approaching these practices as not only productive sites of research but also as opportunities for critical reflection, negotiation and agency, we may expand possibilities for the teaching and learning of reading-writing in high school and college.

\section{Mapping Mobile Practice}

Through reading-writing activities that attend to the ways in which individuals and collectives traverse and connect scenes of writing in their everyday lives, students and teachers can pursue two key objectives of critical pedagogy or the pedagogical 
activism Pennycook (2008) promotes in the epigraph above. First, we can seek better understandings of how mobile literacies produce, maintain, disrupt, and transform identities in and among social spaces and across lines of race, gender, class, language, ethnicity, nationality and more. Second, such reflections may help us locate agencies, or ways to appropriate, resist, and transform dominant discourses, genres, ideologies, and disciplines with language and literacy resources. In Chapter One, I suggested that we conceive of such activities as Latourian "tracings of associations" (Reassembling 9). By tracing and reflecting on mobile or transsituational literacies, students might come to see how their own reading-writing practices contribute to progressive compositions of collectives or becomings of place. To design and describe such tracings and represent literacies as interrelated, many researchers and teachers adopt metaphors of mapping (Clarke 2002; Leander and Rowe 2006; Mannion and Ivanič 2007).

Whether in reference to material or conceptual terrains, mapping involves boundary making — ordering, categorizing and flattening —often with far-reaching political, social, cultural and economic effects (Mannion and Ivanič 18). While maps always provide a subjective view of reality, they may pretend to be or be read as objective and final. In this way, assumptions of scientific exactitude and objectivity can serve as constraints when using metaphors of mapping in research or teaching.

However, postmodern geographers have demonstrated how mapping and map reading can be conceived as dialogical processes connecting space-time and practice. As I noted in Chapter One, critical geographers conceive of place as continually produced through practices creating, altering and cutting off relations to other places. As Massey asserts, rather than imagining places as bounded, they are better understood as "networks 
of social relations" (120). Because places are emergent and networked, each mapping practice provides different interpretations and therefore different maps of the terrains under investigation. In this way, maps are approached as texts, as negotiable attempts at representing $a$ reality rather than reality itself. According this conceptualization, mapping affords not only a method for representing connections across space-time and practice but also for composing objects of inquiry that can be read alongside and against representations offered by other maps.

For literacy pedagogies, making use of this affordance might involve prompting students to map literacy practices across scenes of writing - in classrooms, libraries, coffee shops, dorm rooms, at home, on course web sites, social media, etc.- -and then read their maps alongside and against other individual and institutional representations of the same or similar practices and locations. These maps can be comprised of literacy artifacts that serve as guideposts—-student, teacher and institutional texts; images; video; audio; graffiti; posters; social media; text messages; etc.- - with reflective commentary or annotation connecting one guidepost to another and, thus, fleshing out the map.

Annotated maps could be composed, shared and revised on interactive platforms such as blogs, digital portfolios and archives, or wikis. Through processes of composing, sharing and revising maps, such projects engage students in reflexive practice, as they attend to how and why they and others construct meanings and realities through processes of mapmaking. As Richard Edwards and Robin Usher assert, "meaning is made through mapping rather than found" (138).

After rereading and revising maps of their literacy practices in light of each other's maps, students and teachers could then focus on the ways in which their practices 
are located by various mechanisms - standards and assessments, program outcomes, evaluations, curricula, degree plans, etc.- - on larger institutional maps designed to orient and make sense of these practices. On both secondary and tertiary levels, this process of reading individual maps alongside and against institutional maps, such as the Common Core Standards or the Council of Writing Program Adminstrators' Outcomes Statement for First-Year Composition or Framework for Success in Postsecondary Writing, can reveal patterns of inclusion and exclusion, access and denial, embraces and threats, and other means of creating and policing social and institutional boundaries. In other words, by engaging in processes of collaborative map-making and reading, students and teachers might come to better understandings of the ways in which meanings are made through boundarying activities. By studying their own literacies across space-time in relation to standardized representations of these literacies, new patterns of containment, security and conformity (Giroux 2010) and also of innovation, resistance and transformation may become visible to students and teachers, patterns that indicate literacy's present and potential roles in maintaining and challenging social divisions. ${ }^{65}$

For instance, if James and Nadif had been provided opportunities to map their literacy practices over a period of time and then share their maps across academic tracks, they would have likely discovered significant differences in the types and quantities of reading-writing tasks assigned in their high school courses, texts used to facilitate such tasks, teacher and peer support and feedback, material resources provided, and so on. After reflecting on the ways in which the boundaries that created and maintained these differences assigned them particular identities and interpreted and measured their

${ }^{65}$ See Chapter Three for examples of strategies of containment, security and conformity. 
language and literacy practices, they could have read the similarities and differences depicted in their individual maps in the context of the Common Core Standards, as an idealized map of their supposedly shared academic literacy practices and experiences. They could have then worked together to trace out the ways in which their practices and the rhetorical transsituations occasioning them accorded with and diverged from the standards. By making the boundaries that defined and delimited their work and identities more apparent, James and Nadif might have helped each other gain critical perspectives on their own institutional situatedness and, subsequently, developed tactics that responded to this situatedness by exploiting and expanding possibilities for movement within boundary-based systems. ${ }^{66}$

Of course, the institutional boundaries that separated James and Nadif according to perceived academic ability would have made it very difficult for them to collaborate in this way in the context of their high school writing classes. And this concern points to a limitation, or perhaps more accurately, a missed opportunity in the design of my own research. Rather than approaching James, Nadif, Katherine and the other students participating in this project as a research team, I treated them primarily as individual coresearchers. Apart from the time I spent as a participant-observer in their high school writing classes, we essentially worked together in dyads, meeting individually to share and interpret data. While it would have been risky or even impossible for James' and Nadif's high school English teachers to create occasions for their students to collaborate across academic tracks, as a researcher committed to interventionist practice and as an institutional outsider, I was in a better position to build occasions for this sort of

\footnotetext{
${ }^{66}$ See Chapter Four for an application of de Certeau's notion of tactics in the context of educational systems.
} 
collaboration into my research design. By conducting group interviews in which participants could have shared artifacts and asked questions of each other concerning their literacy practices, I may have facilitated the kinds of collaborative mapping proposed above. While the privacy and intimacy of individual interactions afforded opportunities that group interviews would have likely limited, some combination of individual and collective interviewing might have helped students share critical perspectives on the boundarying activities that occasioned and constrained their literacies and identities. This is one potential way in which my pedagogy could have informed my methodology, and it is certainly a design choice I will consider for future projects.

\section{Translating Mobile Practice}

By mapping (tracing and annotating) literacy practices across space-time and rereading and rewriting their maps in the context of other individual and "official" maps, students and teachers create opportunities to reflect upon and make sense of the ways in which literacies, languages and meanings are ordered and reordered, networked and translated across locations and identities and to consider the ways in which people, objects, ideas and information interact in these processes of translation. Along with metaphors of mapping, metaphors of translation for the teaching of literacy have proliferated in an age of globalization. As translation theorist Susan Bassnett proclaims,

"The twenty-first century is the great age of translation" (1). And in this era of global flows accelerating and complicating our lives in unprecedented ways, perpetual mobilities necessitate perpetual translations. These translations involve not only linguistic transactions but also social, economic, geopolitical, and cultural transactions across asymmetrical relations of power. As Lu and Horner assert, "In such transactions, 
meaning is necessarily and always the product of translation across differences, even in ostensibly monolingual settings" ("Translingual" 27-28). In this way, meaning is made, exchanged and transformed in and through motion.

For Claire Kramsch this "traffic in meaning" is precisely what language teaching should consist of, so that language competence is measured not as the capacity to perform in one language in a specific domain, but rather as "the ability to translate, transpose and critically reflect on social, cultural and historical meanings conveyed by the grammar and lexicon" (103). From this perspective, the role of the language teacher is "to diversify meanings, point to the meanings not chosen, and bring to light other possible meanings that have been forgotten by history or covered up by politics" (103). In this way, language and literacy teaching is indelibly tied to translation and a diversity of meanings. As I've asserted throughout this dissertation, I believe the pedagogical value of a mobile literacies approach can be located primarily in its potential to develop metalinguistic and sociolinguistic skills and dispositions open to negotiations across differences by challenging students to recognize and reflect upon the ways in which their mobile practices require them to translate meanings across identities, languages, texts, cultures, discourses, media and localities. This approach moves beyond identifications and accommodations of rhetorical situations to focus on the ways in which participation in rhetorical circulations requires literate and linguistic facility within and across diverse languages, markets, discourses and texts.

One potential limitation of the metaphor of translation for literacy pedagogy is its association with conversions of seemingly discrete and unified languages into other languages. Like assumptions of objectivity and exactitude that may attend students' and 
teachers' perceptions of mapping, for many, the notion of translation signals one-to-one correspondence between language and meaning. Katherine demonstrates this assumption in the paper cited at length in Chapter Three in which she describes herself as a "Google translator": "I would have to convert what he [my father] was saying in Spanish to English to American Sign Language.” Again, aligning with a translingual approach to teaching reading-writing (Horner et al. 2011), a pedagogy of mobile literacies might ask Katherine to consider how and why this process of shuttling across languages, modalities and audiences requires translations of meanings as well as translations of lexicons and grammars.

Pennycook's concept of "translingual activism," which seeks to "grapple with the tensions around the politics of translations across spaces, times, ideologies and cultures," productively frames this expanded notion of translation for mobile literacies ("English" 34). His approach attends to the multiplicity of available meanings within language as much as, if not more than, the multiplicity of seemingly discrete languages (42). Unlike other approaches to linguistic diversity, which tend to focus on forms rather than meanings in the face of globalization, translingual activism centralizes the need for boundary transgression by presenting a heteroglossic condition that necessitates the translation of meanings within and among languages created and shaped through processes of dialogic exchange. In this way, the translation of meanings from one language to another becomes a "central aspect of social and global life that challenges the very notion of languages and their discrete operation." In line with a mobilities frame, this transgressive activity seeks to enable individuals and collectives to identify and contest processes of institutional boundarying and, consequently, "displace 
the hegemonic and subaltern locations of disciplinary knowledge" (41). While translations of meanings are always already reproducing and transforming scenes of writing in and outside of school, literacy teachers could encourage students to actively participate in this traffic of meaning by making use of the mobilities circulating within their ostensibly bounded classrooms.

We can return to the face-to-face-to-interface mobilities Katherine practices in her community college writing class to demonstrate how this traffic in meaning might be illuminated and reflected upon in the writing classroom. ${ }^{67}$ Again, this activity begins with mapping. Recognizing that students will likely not share all the mobilities that intersect with and diverge from their physical presences in class, nor should they be compelled to, they could be asked to map the literacies they engage in (and feel comfortable sharing) over the course of a single class period along with the transsituations these practices contribute to. Ongoing exchanges serve as the guideposts for these maps, as students trace out the identities, localities, activities, histories, and discourses evoked in these dialogues.

Below is a depiction of what Katherine's map might look like in accordance with the scene discussed in the previous chapter. In this map, simultaneous exchanges - peer review, essay, text message conversation and Facebook chat—serve as primary nodes. Branching off from these guideposts are localities and texts evoked and identities and languages performed in each exchange. Of course, these branches are not comprehensive;

${ }^{67}$ See Chapter Four, pages 44-47. 
they represent a small number of associations Katherine may or may not trace out in such an activity. ${ }^{68}$

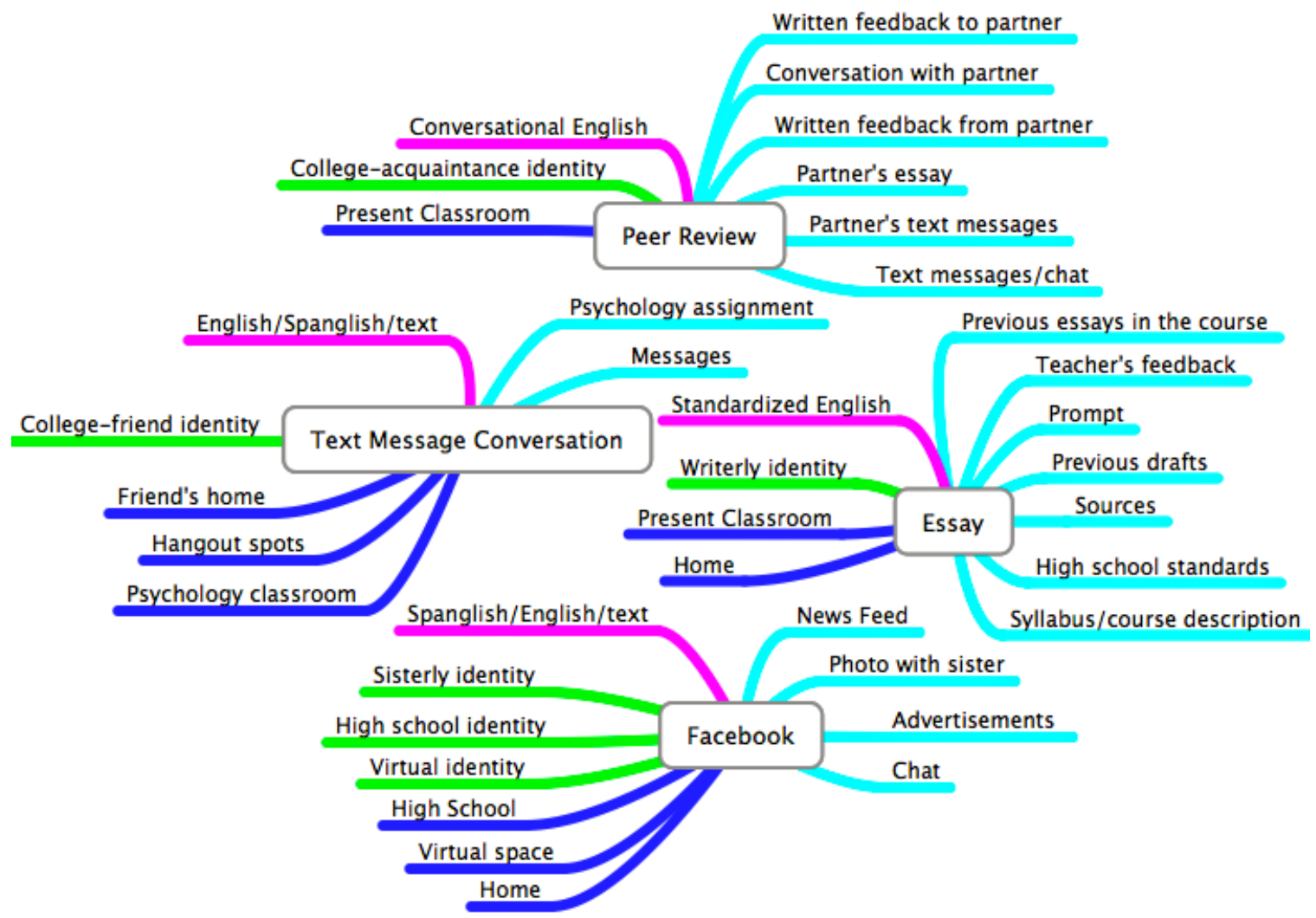

For example, the map reveals Katherine's peer review session as mediated by a number of texts (light blue)—written and spoken feedback, her own and her partner's essays, and the text messages interrupting and augmenting their face-to-face interactions. The identity (in green) she performs in this exchange is different from those she takes up in other exchanges; while she is friendly and compliant, Katherine also communicates verbally and physically that she is only marginally invested in the activity, a level of investment that seems to match her partner's. The language she and her partner use to discuss their essays approximates the slightly elevated conversational English used by the

${ }^{68}$ Moreover, the identities, languages, localities and texts referenced here are not singular or static. 
teacher of the course, and the only locality referenced (dark blue) in this particular exchange is the classroom itself.

As this map demonstrates, the possible influences shaping and shaped by Katherine's contributions to this peer review activity and the larger scene of writing are relatively easy to trace out. A more difficult, but perhaps more productive, task is creating opportunities for her to reflect on and make new meanings from transactions and translations within and across exchanges. In other words, after mapping associations that comprise these primary exchanges, Katherine and her classmates should be prompted to consider how one seemingly discrete exchange shapes and is shaped by another. For instance, Katherine might consider how her text message conversation, which spans the duration of the peer review, influences the oral and written feedback she provides her partner and the identities or languages she performs in the session. By reading her text messages alongside her written review, Katherine might recognize similarities and differences in the ways she positions herself, frames her commentary, draws upon diverse language resources, and so on.

After considering the relations among these similarities and differences and notions of audience, purpose, genre, exigency, medium, context, etc., she could then attempt to translate meanings across exchanges by investigating the ways in which meanings are lost, changed and gained in translations of her peer review comments into the Spanglish of her text messages or by considering how the content and tone of her text conversation would change if it were conducted face-to-face in the context of her writing classroom. This practice of translating across differences might highlight the influences enabling and constraining her identities, languages and literacies. And through this 
process of identifying affordances and constrains, she could locate possible agencies or ways to exploit and create openings for new mobilities and, thus, new processes of meaning-making within and across boundary-based systems. To add a final dimension to this traffic in meaning, Katherine and her peer review partner could exchange maps to consider similarities and differences in the meanings and realities they construct through processes of map-making. Again, this process of comparative mapping might allow students to share critical perspectives and develop tactics for contesting institutional constraints and expanding and creating possibilities for movement.

In this way, pedagogies that attend to students' mobile literacies focus on how to best enable them to negotiate the demands of intersecting and often conflicting markets, challenging them to identify, reflect upon and employ language and literacy choices to achieve personal, civic, educational and professional objectives across scenes of writing. Grounded in the epistemological and ontological orientations informing this dissertation, such pedagogies approach students not as novices faced with tasks of conforming to the demands of specific academic discourse communities, but rather as agents continually reproducing and remaking themselves, the communities and the discourses they co-create with their multiple literacies and language resources. To help them realize the agencies that emerge from their language and literacy practices, such pedagogies seek to create opportunities for students to recognize and reflect upon the ways in which their mobile literacies both accommodate and transform conventions of discourse, genre and discipline as well as social relations across scenes of writing.

While I believe the work of exchanging conceptions and practices of rhetorical situations for circulations should begin in the classroom, I also believe that literacy 
teachers and researchers must simultaneously work across levels of education, disciplines, programs, institutions and communities to form strategic alliances that can mobilize people, resources, information and ideas to challenge and ultimately transform neoliberal systems of education and the social and cultural assumptions that support them. As I've demonstrated throughout this dissertation, the structures that comprise these larger systems reduce the value and complexity of students' transsituational literacy practices in the present. To reject such reductions and facilitate the systemic change called for in this text, the epistemologies, methodologies and pedagogies of mobility informing our work as literacy teachers, researchers and administrators must also transform the thoughts and practices of policy makers, community leaders, parents and, most importantly, of the students themselves. While global educational reform calls for large-scale and long-term political, social and economic change, by recognizing the sophistication and innovation of their daily literacy practices, students might discover new ways of mobilizing these practices to challenge and transform systems incrementally and from within. By working against the system to privilege the value and complexity of their shared work in the present, students might recognize themselves and each other as makers of the becomings of dynamic and heterogeneous educational locations and systems shaped in part by their historical bodies and mobile practices. 


\section{REFERENCES}

Achebe, Chinua. Things Fall Apart. Portsmouth, NH: Heinemann, 1996. Print.

Adey, Peter. Mobility. New York: Routledge, 2010. Print.

Alexander, Michelle. The New Jim Crow: Mass Incarceration in the Age of Colorblindness. New York: New Press, 2010. Print.

Althusser, Louis. For Marx. New York: Verso, 1969. Print.

Amelga, Makeda. "College and Career Readiness: A Quick Stats and Fact Sheet." National High School Center at the American Institutes for Research. n.p. Web. 3 March 2014.

Amin, Samir. "The Right to Education." Pambazuka News. 10 Nov. 2011. Web. 12 Jan. 2013.

Appadurai, Arjun. Modernity at Large: Cultural Dimensions of Globalization. Minneapolis: U of Minnesota P, 1996. Print.

Barton, David and Mary Hamilton. Local Literacies: Reading and Writing in One Community. New York: Routledge, 1998. Print.

Bassnett, Susan. Translation. London: Routledge, 2014. Print.

Beaufort, Anne. Writing in the Real World: Making the Transition from School to Work. New York: Teachers College P, 1999. Print. 
—. College Writing and Beyond: A New Framework for University Writing Instruction. Logan UT: Utah State UP, 2007. Print.

Bhabha, Homi K. The Location of Culture. New York: Routledge, 1994. Print.

Bizzell, Patricia. Academic Discourse and Critical Consciousness. Pittsburgh: U of Pittsburgh P, 1992. Print.

Blacker, David. "The Illegitimacy of Student Debt." Works and Days: Cultural Logic 31 (2013): 235-250. Print.

Blommaert, Jan and Jie Dong. "Language and Movement in Space." The Handbook of Language and Globalization. Ed. Nikolas Coupland. West Sussex: WileyBlackwell, 2010. 366-385. Print.

Blommaert, Jan and April Huang. "Historical Bodies and Historical Space." Journal of Applied Linguistics 6.3 (2009): 267-282. Print.

Bloor, David. "Wittgenstein and Priority of Practice." The Practice Turn in Contemporary Theory. Eds. Karin Knorr Cetina, Theodore R. Schatzki, Eike von Savigny. London: Routledge, 2001. Print.

Borges, J. L. "Del rigor en la ciencia." A Universal History of Infamy. Trans. Norman Thomas de Giovanni. London: Penguin Books, 1975. Print.

Bourdieu, Pierre. Language and Symbolic Power. Boston: Harvard UP, 1991. Print.

—. The Logic of Practice. Stanford, CA: Stanford UP, 1990. Print.

Bourdieu, Pierre and J.P. Passeron. Reproduction in Education, Society, and Culture. Beverly Hills, CA: Sage, 1977. Print. 
Brandt, Deborah and Katie Clinton. "Limits of the Local: Expanding Perspectives on Literacy as a Social Practice.” Journal of Literacy Research 34 (2002): 337-356. Print.

Brannon, Lil. “(Dis)missing Compulsory First-Year Composition.” Reconceiving Writing, Rethinking Writing Instruction. Mahwah, NJ: Erlbaum, 1995. Print.

Brent, Doug. "Crossing Boundaries: Co-op Students Relearning to Write." College Composition and Communication 63.4: 558-592. Print.

Brodkey, Linda. "Writing on the Bias." College English 56.5 (1994): 527-547. Print.

Brooke, Robert. "Underlife and Writing Instruction." College Composition and Communication 38.2 (1987): 141-153. Print.

Burbules, Nicholas C. "The Web as a Rhetorical Place." Silicon Literacies: Communication, Innovation and Education in the Electronic Age. Ed. Ilana Snyder. New York: Routledge, 2002. Print.

Burchell, Graham. "Liberal Government and Techniques of the Self." Foucault and Political Reason. Eds. Andrew Barry, Thomas Osborne and Nikolas Rose. Chicago: U of Chicago P, 1996. Print.

Büscher, Monkia, John Urry and Katian Witchger, Eds. Mobile Methods. New York: Routledge, 2011. Print.

Callon, Michel and John Law. "Guest Editorial." Environment and Planning D 22 (2004): 3-11. Print.

Canagarajah, A. Suresh. The Place of World Englishes in Composition: Pluralization Continued." College Composition and Communication 57 (2006): 586-619. Print. 
Carter, Peter. The Sound In Between: Voice, Space, Performance. Kensington: New South Wales UP, 1992. Print.

Carroll, Lee Ann. Rehearsing New Roles: How College Students Develop as Writers. Urbana: NCTE, 2002. Print.

Castells, Manuel. The Rise of the Network Society. Oxford: Blackwell, 1996. Print. Chaput, Catherine. "Rhetorical Circulation in Late Capitalism: Neoliberalism and the Overdetermination of Affective Energy." Philosophy and Rhetoric 43.1 (2005): 125. Print.

Chayko, Mary. Connecting: How We Form Social Bonds and Communities in the Internet Age. New York: State U of New York P, 2002. Print.

Clarke, Julia. "A New Kind of Symmetry: Actor-Network Theories and the New Literacy Studies." Studies in the Education of Adults 34.2 (2002): 107-122. Print.

Colorado Department of Education. "Postsecondary Pathways." Chart. n.p. Web. 23 March 2014.

Conley, David T. and Paul L. Gaston. "A Path to Alignment: Connecting K-12 and Higher Education via The Common Core and The Degree Qualification Profile." Lumina Foundation. Oct. 2013 Web. 3 Dec 2014.

Cooper, Marilyn M. "Rhetorical Agency as Emergent and Enacted." College Composition and Communication 62.3 (2011): 420-449. Print.

—_. "The Ecology of Writing." College English 48.4 (1986): 364-375. Print.

Cortesi, Sandra, Paulina Haduong, Urs Gasser, Osman Tolga Aricak, Mark Saldaña, and Zach Lerner. "Youth Perspectives on Tech in Schools: From Mobile Devices to 
Restrictions and Monitoring." Berkman Center Research Publication. 15 Jan. 2014. Web. 3 April 2014.

Council of Writing Program Administrators. "WPA Outcomes Statement for First-Year Composition." WPA Writing Program Administration 23.1-2 (1999): 59-66. Print. Council of Writing Program Administrators, National Council of Teachers of English, and National Writing Project. "Framework for Success in Postsecondary Writing." Jan. 2011. Web. 27 May 2014.

Courier-Journal.com. "Timeline: Desegregation in Jefferson County Public Schools." 4 Sept. 2005. Web. 23 March 2014.

Cresswell, Tim. On the Move: Mobility in the Modern Western World. New York: Routledge, 2006. Print.

Crowley, Sharon. “A Personal Essay on Freshman English.” Pre/Text 12.3-4 (1991): 155176. Print.

Curtis, Marcia and Anne Herrington. "Writing Development in the College Years: By Whose Definition?” CCC. 55.1 (2003): 69-90. Print.

—. Persons in Process: Four Stories of Writing and Personal Development in College. Urbana: NCTE, 2000. Print.

De Certeau, Michel. The Practice of Everyday Life. Trans. Steven Rendall. Berkeley: U of California P, 1984. Print.

Deleuze, Gilles. Negotiations. Trans. Martin Joughin. New York: Columbia UP, 1995. Print.

Deleuze, Gilles and Félix Guattari. A Thousand Plateaus: Capitalism and Schizophrenia. Trans. Brian Massumi. Minneapolis: U of Minnesota P, 1987. Print. 
Division Data Management, Planning and Program Evaluation. 2011-2012 Data Books. Jefferson County Public Schools. 15 Nov. 2011. Web. 13 March 14.

Division Data Management, Planning and Program Evaluation. 2012-2013 Data Books. Jefferson County Public Schools. N.d. Web. 13 March 14.

Durst, Russel K. Collision Course: Conflict, Negotiation, and Learning in College Composition. Urbana: NCTE, 1999. Print.

Edbauer, Jenny. "Unframing Models of Public Distribution: From Rhetorical Situation to Rhetorical Ecologies." Rhetoric Society Quarterly 35.4 (2005): 5-24. Print.

Ede, Lisa. Situating Composition. Composition Studies and the Politics of Location. Carbondale: Southern Illinois UP, 2004. Print.

“Educational Pathways.” Bill and Melinda Gates Foundation. n.d. Web 13 March 2014. Edwards, Richard and Robin Usher. Globalisation and Pedagogy: Space, Place and Identity. London: Routledge, 2000. Print.

Egan, Kevin, Jennifer B. Lozano, Sylvia Hurtado and Matthew H. Case. The American Freshman. Los Angeles, CA: Higher Education Research Institute, 2013. Web. 3 April 2014.

Fairclough, Norman. Discourse and Social Change. Cambridge: Polity Press, 1992. Print. Fosl, Catherine. Making Louisville Home for Us All: A 20-Year Action Plan For Fair Housing. Louisville, KY. University of Louisville Anne Braden Institute for Social Justice Research, 2013. Web. 13 April 2014.

Foucault, Michel. Discipline and Punish: The Birth of the Prison. Trans. Alan Sheridan. Vintage, 1977. Print.

—_. "The Subject and Power." Critical Inquiry 8.4 (1982): 777-795. Print. 
Fox, Kate. "Evolution, Alienation and Gossip: The Role of Mobile Telecommunications in the $21^{\text {st }}$ Century." Oxford: Social Issues Research Centre, 2001. Web. 24 April 2014.

Fraiberg, Steven. "Composition 2.0: Toward a Multilingual and Multimodal Framework." College Composition and Communication 62.1 (2010): 100-126. Print.

_. "Military Mashups: Remixing Literacy Practices." Kairos 14.3 (2010). Web. 6 April 2014.

Freedle, Roy. "Correcting the SAT's Ethnic and Social-Class Bias: A Method for Reestimating SAT Scores." Harvard Educational Review 73.1 (2003): 1-43. Print.

Gal, Susan and Judith T. Irvine. "The Boundaries of Languages and Disciplines: How Ideologies Construct Difference." Social Research 62 (1995): 967-1001. Print.

Garet, Michael and Brian DeLany. "Students, Courses, and Stratification." Sociology of Education 61 (1988): 61-77. Print.

Gates, Bill. National Education Summit on High Schools. Washington, D.C. 26 February 2005. Address.

Gee, James Paul. Situated Language and Learning: A Critique of Traditional Schooling. New York: Routledge, 2004. Print.

Geertz, Clifford. "Thick Description: Toward an Interpretive Theory of Culture." The Interpretation of Cultures: Selected Essays. New York: Basic Books, 1973. Print. Giddens, Anthony. Runaway World: How Globalization is Reshaping Our Lives. New York: Routledge, 2000. Print.

Gintis \& Bowles. Schooling in Capitalist America. New York: Basic, 1976. Print. 
Giroux, Henry. "Dumbing Down Teachers: Rethinking the Crisis of Public Education and the Demise of the Social State." Review of Education, Pedagogy \& Cultural Studies 32.4 (2010): 339-381. Print.

Grego, Rhonda C. and Nancy S. Thompson. Teaching/Writing in Thirdspaces: The Studio Approach. Carbondale: Southern Illinois UP, 2008. Print.

Guryan, Jonathan. "Desegregation and Black Dropout Rates." American Economic Review 94.4 (2004): 919-943. Print.

Gutiérrez, Kris, Betsy Rymes, Joanne Larson. "Script, Counterscript, and Underlife in the Classroom: James Brown versus Brown v. Board of Education." Harvard Educational Review 65.3 (1995): 445-471. Print.

Halgreen, Tue. "Tourists in the Concrete Desert." Tourism Mobilities: Places to Play, Places in Play. Eds. Mimi Sheller and John Urry. New York: Routledge, 2004. Print.

Hamilton, Mary. "Expanding the New Literacy Studies: Using Photographs to Explore Literacy as Social Practice." Situated Literacies: Reading and Writing in Context. Eds. David Barton, Mary Hamilton and Roz Ivanič. New York: Routledge, 2000. Print.

Harris, Joseph. "The Idea of Community in the Study of Writing." College Composition and Communication 40.1 (1989): 11-22. Print.

Harvey, David. Spaces of Global Capitalism: Towards a Theory of Uneven Geographical Development. London: Verso, 2006. Print.

—. The Condition of Postmodernity: An Enquiry into the Origin of Social Change. Oxford: Blackwell, 1990. Print. 
Haswell, Richard. "Documenting Improvement in College Writing: A Longitudinal Approach." Written Communication 17 (July 2000): 307-52. Print.

—. Gaining Ground in College Writing: Tales of Development and Interpretation. Dallas, TX: Southern Methodist UP, 1991. Print.

Heath, Shirley Brice and Milbrey McLaughlin. "Learning for Anything Everyday. Journal of Curriculum Studies 26.5 (1994): 471-489. Print.

—. Ways with Words: Life, Language, and Work in Communities and Classrooms. Cambridge: Cambridge UP, 1983. Print.

Heidegger, Martin. Being and Time. Trans. John Maquarrie and Edward Robinson. New York. Harper \& Row, 1962. Print.

Heilig, Julian Vasquez and Jennifer Jellison Holme. "Nearly 50 Years Post-Jim Crow: Persisting and Expansive School Segregation for African American, Latina/o, and ELL Students in Texas.” Education and Urban Society (2013): 1-24. Web. 4 March 2014.

Horner, Bruce. "Mapping Errors and Expectations for Basic Writing.” English Education 26.1 (1994): 29-51. Print.

Horner, Bruce, and Min-Zhan Lu. 'Resisting Monolingualism in 'English': Reading and Writing the Politics of Language." Rethinking English in Schools: A New and Constructive Stage. Ed. Viv Ellis, Carol Fox, and Brian Street. London: Continuum, 2007. 141-57. Print.

Horner, Bruce, Min-Zhan Lu, Jacqueline Jones Royster and John Trimbur: "Language Difference in Writing: Toward a Translingual Approach." College English 73.3 (2011): 303-321. Print. 
Hughes Dual Enrollment Teacher. Personal interview. 11 October 2011.

Hull, Glynda and Mike Rose. “"This Wooden Shack Place': The Logic of an

Unconventional Reading." College Composition and Communication 41.3 (1990): 287-298. Print.

Ito, Mizuko, Heather Horst, Matteo Bittanti, danah boyd, Becky Herr-Stephenson,

Patricia G. Lange, C.J. Pascoe, and Laura Robinson. Living and Learning with

New Media: Summary of Finding from the Digital Youth Project. Cambridge,

MA: MIT Press, 2009. Web. 16 April 2014.

Ivanič, Roz. Writing and Identity: The Discoursal Construction of Identity in Academic

Writing. Philadelphia: John Benjamins Publishing Company, 1998. Print.

Ivanič, Roz, Richard Edwards, David Barton, Marilyn Martin-Jones, Zoe Fowler, Buddug Hughes, Greg Mannion, Kate Miller, Candice Satchwell and June Smith. Improving Learning in College: Rethinking Literacies Across the Curriculum. London: Routledge, 2009. Print.

James. Personal interview. 13 September 2011.

James. Personal interview. 19 October 2011.

James. Personal interview. 14 April 2012.

Jenkins, Henry. Convergence Culture: Where Old and New Media Collide. New York: New York UP, 2006. Print.

Julie. Personal interview. 7 October 2011.

K'Meyer, Tracy E. From Brown to Meredith: The Long Struggle for School Desegregation in Louisville, Kentucky 1954-2007. Chapel Hill, NC: U of North Carolina P, 2013. Print. 
_. "Busing and the Desegregation of Louisville Schools." University of North Carolina Press Blog. 12 Aug. 2013. Web. 23 April 2014.

Katherine. Personal interview. 25 September 2011.

Katherine. Virtual chat interview. 7 March 2012.

Katherine. Personal interview. 14 April 2012.

Katherine. Personal interview. 5 October 2012.

Katz, Jack. How Emotions Work. Chicago: U of Chicago P, 2000. Print.

Katz, Michael B. "The Origins of Public Education: A Reassessment." History of Education Quarterly 16.4 (1976): 381-407. Print.

Kaufer, David and Richard Young. "Writing in the content areas: Some theoretical complexities." Theory and Practice in the Teaching of Writing: Re-thinking the Discipline. Ed. Lee Odell. Carbondale: Southern Illinois UP, 1993. Print.

Kaufmann, Vincent. Re-thinking Mobility. Contemporary Sociology. Aldershot: Ashgate Press, 2002. Print.

Keller, Christopher. "Unsituating the Subject: 'Locating' Composition and Ethnography in Mobile Worlds.” Brown, Stephen G., and Sidney I. Dobrin, eds. Ethnography Unbound: From Theory Shock to Critical Praxis. Albany: State U of New York P, 2004. Print.

Kentucky Department of Education. Jefferson County Public School District. “JCPS High School Turnaround Training.” Louisville: JCPS, 2010.

—. Kentucky Core Academic Standards. Frankfort: KDE, 2013. 
Kidder, William C. and Jay Rosner. "How the SAT Creates Built-In Headwinds: An Educational and Legal Analysis of Disparate Impact. Santa Clara Law Review 43.1 (2002): 131-212. Print.

Kirsch, Gesa and Joy Ritchie. "Beyond the Personal: Theorizing a Politics of Location in Composition Research." Cross Talk in Comp Theory $2^{\text {nd }}$ Edition. Ed. Victor Villanueva. Urbana, IL: NCTE. 2003. 523-546. Print.

Kochhar, Rakesh, Richard Fry and Paul Taylor. "Wealth Gaps Rise To Record Highs Between Whites, Blacks, Hispanics." Pew Research: Social and Demographic Trends. 26 July 2011. Web. 13 March 2014.

Konz, Antoinette and Chris Kenning. "Audits: Iroquois, Waggener, Southern must replace principals, lose school councils.” Courier-Journal.com. 16 Feb. 2011. Web. 20 Feb. 2011.

Kramsch, Claire. "The Traffic in Meaning." Asian Pacific Journal of Education 26.1 (2006): 99-104. Print.

Larsen, Jonas, John Urry, and Kay Axhausen. "Geographies of Social Networks: Meetings, Travel and Communications." Mobilities 1 (2006): 261-283. Print.

Latour, Bruno. Reassembling the Social: An Introduction to Actor-Network-Theory. Oxford: Oxford UP, 2007. Print.

—. Politics of Nature: How to Bring the Sciences into Democracy. Trans. Catherine Porter. Boston: Harvard UP, 2004. Print.

—. "On Interobjectivity: Symposium on 'The Lessons of Simian Society." Mind, Culture, and Activity 3 (1996): 228-245. Print. 
Lave, Jean and Etienne Wenger. Situated Learning: Legitimate Peripheral Participation. Cambridge: Cambridge UP, 1991. Print.

Leander, Kevin M. and Jason F. Lovvorn. "Literacy Networks: Following the Circulation of Texts, Bodies, and Objects in the Schooling and Online Gaming of One Youth.” Cognition and Instruction 24.3 (2006): 291-340. Print.

Leander, Kevin M. and Deborah W. Rowe. "Mapping Literacy Spaces in Motion: A Rhizomatic Analysis of a Classroom Literacy Performance.” Reading Research Quarterly 41 (2006): 428-460. Print.

Leander, Kevin M. “Writing Travelers' Tales on New Literacyscapes.” Reading Research Quarterly 38.3 (2003): 392-397. Print.

Lefebvre, Henri. The Production of Space. Trans. Donald Nicholson-Smith. Malden, MA: Blackwell, 1991. Print.

Lillis, Theresa M. Student Writing: Access, Regulation, Desire. New York: Routledge, 2001. Print.

—. "Ethnography as Method, Methodology, and 'Deep Theorizing': Closing the Gap Between Text and Context in Academic Writing." Written Communication 25 (2008): 353-388. Print.

Lu, Min-Zhan. "Metaphors Matter: Transcultural Literacy.” JAC 29.1-2 (2009): 285-293.

—_. "Conflict and Struggle: Enemies or Preconditions of Basic Writing." College English 54.8 (1992): 887-913. Print.

—. "Living English Work." College English 68.6 (2006): 605-618. Print.

Lu, Min-Zhan and Bruce Horner. "Composing in a Global-Local Context: Careers, Mobility and Skills." College English 72 (2009): 113-133. Print. 
__. "Translingual Literacy and Matters of Agency." Literacy as Translingual Practice. Ed. A. Suresh Canagarajah. New York: Routledge, 2013. Print. Mannion, Greg and Roz Ivanič. "Mapping Literacy Practices: Theory, Methodology, Methods." International Journal of Qualitative Studies in Eduation 20.1 (2007): 15-30. Print.

Marcus, George E. "Ethnography in/of the World System: The Emergence of Multi-Sited Ethnography.” Annual Review of Anthropology 24 (1995): 95-117.

—. Ethnography through Thick and Thin. Princeton: Princeton UP, 1998. Print.

—. "Imagining the Whole. Ethnography's Contemporary Efforts to Situate Itself." Critical Anthropology 9 (1989): 7-30. Print.

Marcus, George E. and Michael M.J. Fischer. Anthropology as Cultural Critique: An Experimental Moment in the Human Sciences. Chicago: U of Chicago P, 1986. Print.

Massey, Doreen. Space, Class and Gender. Cambridge: Polity, 1994. Print.

Maturana, Humberto R. and Francisco J. Varela. The Tree of Knowledge: The Biological Roots of Human Understanding. Boston: Shambhala, 1987. Print.

Michael. Personal interview. 19 October 2011.

Mickelson, Roslyn Arlin. "Subverting Swann: First- and second-generation segregation in the Charlotte-Mecklenburg Schools." American Educational Research Journal 38 (2001): 215-252. Print.

Mignolo, Walter D. Local Histories/Global Designs: Coloniality, Subaltern Knowledges, and Border Thinking. Princeton, NJ: Princeton UP, 2000. Print. 
Moje, Elizabeth Birr, Kathryn McIntosh Ciechanowski, Kathryn Kramer, Lindsay Ellis, Rosario Carrilllo, and Tehani Collazo. "Working Toward Third Space in Content Area Literacy: An Examination of Everyday Funds of Knowledge and Discourse. Reading Research Quarterly 39.1 (2004): 38-70. Print.

Moores, Shaun. Media, Place \& Mobility. New York: Palgrave Macmillan, 2012. Print. Motiwalla, Luvai F. "Mobile Learning: A Framework and Evaluation." Computers and Education 49 (2007): 581-596. Print.

Murray, Donald. "Teaching Writing as a Process Not Product." Cross Talk in Comp Theory 2nd Edition. Ed. Victor Villanueva. Urbana, IL: NCTE. 2003. 3-6. Print. Nadif. Personal interview. 22 September 2011.

Nadif. Personal interview. 6 November 2011.

Nadif. Personal interview. 5 April 2012.

Nadif. Personal interview. 12 May 2012.

Nadif. Personal interview. 7 September 2012.

The National Commission on Excellence in Education. A Nation at Risk: The Imperative for Education Reform. United States Department of Education. Washington, D.C. 26 April 1983 Web. 5 August 2012.

National Governors Association Center for Best Practices \& Council of Chief State School Officers. Common Core State Standards. Common Core Standards Initiative, 2014. Web. 17 May 2014.

New London Group. "A Pedagogy of Multiliteracies: Designing Social Futures.” Harvard Educational Review 66.1 (1996): 60-92. Print.

Newkirk, Thomas. "Seduction and Betrayal in Qualitative Research." Ethics and 
Representation in Qualitative Studies of Literacy. Eds. Peter Mortensen and Gesa E. Kirsch. Urbana, IL: NCTE, 1996. Print.

Obama, Barack. "Three Things the President Plans to Do Concerning Education." Henninger High School, Syracuse, New York. 22 August 2013.

Office of Press Secretary. "FACT SHEET on the President's Plan to Make College More Affordable: A Better Bargain for the Middle Class.” The White House.

Washington, D.C. 22 Aug. 2013. Web. 22 April 2013.

Ogbu, John. "Minority Education in Comparative Perspective." Journal of Negro Education. 59.1 (1990): 45-57. Print.

Ogbu, John and Herbert Simmons. "Voluntary and Involuntary Minorities: A CulturalEcological Theory of School Performance with Some Implications for Education.” Anthropology and Education Quarterly 29.2 (1998): 155-188. Print.

Osborne, Erin. "Keep Fox News out of the Classroom! Rupert Murdoch, Common Core and the Dangerous Rise of For-Profit Public Education.” Salon. 16 Dec. 2013. Web 25 March 2014.

Perrin, Daniel. "Coming to Grips with Complexity: Dynamic Systems Theory in the Research of Newswriting." International Advances in Writing Research: Cultures, Places, and Measures. Eds. Charles Bazerman, Chris Dean, Jessica Early, Karen Lunsford, Suzie Null, Paul Rogers, and Amanda Stansell. Fort Collins, CO: WAC Clearinghouse, 2012. 539-558. Print.

Pathways to Prosperity Project. Pathways to Prosperity: Meeting the Challenge of Preparing Young Americans for the $21^{\text {st }}$ Century. Harvard Graduate School of Education, 2011. Web. 12 Aug. 2012. 
Petraglia, Joseph. Reconceiving Writing, Rethinking Writing Instruction. Mahwah, NJ: Erlbaum, 1995. Print.

Pennycook, Alistair. Language as a Local Practice. London: Routledge, 2010.

—_. "English as a Language Always in Translation." European Journal of English Studies 12.1 (2008): 33-47. Print.

Perl, Sondra. "The Composing Processes of Unskilled College Writers." Cross Talk in Comp Theory $2^{\text {nd }}$ Edition. Ed. Victor Villanueva. Urbana, IL: NCTE. 2003. 17-42. Print.

Powell, Katrina M. and Pamela Takayoshi. “Accepting Roles Created for Us: The Ethics of Reciprocity." College Composition and Communication 54 (2003): 394-421. Print.

Pred, Allan. "Social Reproduction and the Time-Geography of Everyday Life." Geografiska Annaler 63.1 (1981): 5-22. Print.

—. "Place as Historically Contingent Process: Structuration and the Time-Geography of Becoming Places." Annals of the Association of American Geographers 72.1 (1984): 279-297. Print.

Prendergast, Catherine. Literacy and Racial Justice: The Politics of Learning after Brown v. Board of Education. Carbondale: Southern Illinois UP, 2003. Print.

Raffaele-Mendez, Linda and Howard M. Knoff. "Who Gets Suspended from School and Why: A Demographic Analysis of Schools and Disciplinary Infractions in a Large School District." Education and Treatment of Children 26 (2003): 30-51. Print. Ransom, John S. Foucault's Discipline: The Politics of Subjectivity. Durham: Duke UP, 1997. Print. 
Ravitch, Diane. The Death and Life of the Great American School System: How Testing and Choice are Undermining Education. New York: Basic Books, 2010. Print.

Reardon, Sean F. "The Widening Academic Achievement Gap Between the Rich and the Poor: New Evidence and Possible Explanations." Whither Opportunity? Rising Inequality, Schools, and Children's Life Chances. Eds. Greg J. Duncan and Richard J. Murnane. New York: Russell Sage, 2011. Print.

Reither, James. "Writing and Knowing: Toward Redefining the Writing Process." College English 47.6 (1985): 620-628. Print.

Reynolds, Nedra. Geographies of Writing: Inhabiting Places and Encountering Difference. Carbondale: Southern Illinois UP, 2004. Print.

Rose, Mike. Why School? Reclaiming Education for All of Us. New York: The New Press, 2014. Print.

Rothstein, Richard. For Public Schools, Segregation Then, Segregation Since: Education and the Unfinished March. Economic Policy Institute. 27 Aug. 2013. Web. 5 March 2014.

Santelices, Maria Veronica and Mark Wilson. "Unfair Treatment? The Case of Freedle, the SAT, and the Standardized Approach to Differential Item Functioning." Harvard Education Review 80.1 (2010): 106-134. Print.

Sarangi, Srikant "The Anatomy of Interpretation: Coming to Terms with the Analyst's Paradox in Professional Discourse Studies.” Text \& Talk 27 (2007): 567-584. Print.

Scollon, Ron and Suzie Wong Scollon. Nexus Analysis: Discourse and the Emerging Internet. New York: Routledge, 2004. Print. 
Scollon, Ron. Mediated Discourse: The Nexus of Practice. New York: Routledge, 2001. Print.

Selzer, Jack. "Exploring Options in Composing." College Composition and Communication 35.3 (1984): 276-284. Print.

Skiba, Russell J., Robert S. Michael, Abra Carroll Nardo and Reece L Peterson. "The Color of Discipline: Sources of Racial and Gender Disproportionality in School Punishment. Urban Review 34 (2002): 317-342. Print.

Slevin, James F. Introducing English: Essays in the Intellectual Work of Composition. Pittsburgh: U of Pittsburgh P, 2001. Print.

Soja, Edward W. Postmodern Geographies: The Reassertion of Space in Critical Social Theory. London: Verso, 1989. Print.

—. Third Space: Journeys to Los Angeles and Other Real-and-Imagined Places. Malden, MA: Blackwell, 1996. Print.

Sommers, Nancy and Laura Saltz. "The Novice as Expert: Writing the Freshman Year." CCC 56.1 (2004): 124-149. Print.

Snyder, Ilana. Silicon Literacies: Communication, Innovation and Education in the Electronic Age. New York: Routledge, 2002. Print.

Spears, Valarie Honeycutt. "Kentucky Students Might Have to Use Pencil, Paper for ACT Inc. Test.” Kentucky.com. 6 Nov. 2013. Web. 14 April 2014.

Sternglass, Marilyn S. Time to Know Them: A Longitudinal Study of Writing and Learning at the College Level. Mahwah, NJ: Lawrence Erlbaum, 1997. Print. Sullivan, Patricia. "Ethnography and the Problem of the 'Other." Ethics and Representation in Qualitative Studies of Literacy. Eds. Peter Mortensen and Gesa 
E. Kirsch. Urbana, IL: NCTE, 1996. Print.

Swales, John. Genre Analysis: English in Academic and Research Settings. Cambridge: Cambridge UP, 1990. Print.

Thernstrom, Stephan. Poverty and Progress: Social Mobility in the Nineteenth Century. Boston: Harvard UP, 1964. Print.

Thrift, Nigel. "Time and Theory in Human Geography: Part II." Progess in Human Geography Vol. 1 (1977): pp. 413- 457. Print.

—_. "Driving in the City." Theory, Culture and Society 21.4-5 (2004): 41-59. Print.

Trimbur, John. "Consensus and Difference in Collaborative Writing." College English 51.6 (1989): 602-616. Print.

Tuan, Yi-Fu. Space and Place: The Perspective of Experience. Minneapolis: U of Minnesota P, 1978. Print.

Urry, John. Mobilities. Cambridge: Polity Press, 2007. Print.

Wenger, Etienne. Communities of Practice: Learning, Meaning, and Identity. Cambridge: Cambridge UP, 1998. Print.

Wheat, Lynne. "Common Core Standards Brief/Kentucky Core Academic Standards." Kentucky Department of Education, 2011. Web. 28 Nov. 2013.

Williams, Bronwyn T. Shimmering Literacies: Popular Culture \& Reading \& Writing Online. New York: Peter Lang, 2009. Print.

—. "Seeking New Worlds: The Study of Writing Beyond Our Classrooms." College Composition and Communication 62.1 (2010): 127-146. Print.

Williams, Bronwyn T. and Mary Brydon-Miller. "Changing Directions: Participatory Research, Agency, and Representation.” Ethnography Unbound: From Theory 
Shock to Critical Praxis. Eds. Stephen G. Brown and Sidney I. Dobrin. Albany: State U of New York P, 2004. Print.

Williams, Joseph M. "Two Ways of Thinking about Growth: The Problem of Finding the Right Metaphor.” Thinking, Reasoning, and Writing. Eds. Elaine P Maimon, Barbara F. Nodine and Finbarr W. O’Connor. New York: Longman, 1989. 245255. Print.

Yancey, Kathleen Blake. "Literacy Demands of Entering the University." Handbook of Adolescent Literacy Research. Eds. Leila Christenbury, Randy Bomer and Peter Smagorinsky. New York: Guilford Press, 2009. Print.

Young, Vershawn Ashanti. “'Nah, We Straight': An Argument Against Code Switching." JAC 29.1-2 (2009): 49-77. Print. 


\section{APPENDICIES}

\section{APPENDIX A}

\section{Overview of Student Participants}

\begin{tabular}{|c|c|c|c|c|c|c|}
\hline Student & $\begin{array}{l}\text { ENG } \\
\text { Section }\end{array}$ & Gender & Race/Nationality & Languages & Class & $\begin{array}{l}\text { Post } \\
\text { H.S. }\end{array}$ \\
\hline Chi & Regular & Female & Vietnamese & $\begin{array}{l}\text { Vietnamese } \\
\text { English }\end{array}$ & 2012 & $\begin{array}{l}\text { Two-year } \\
\text { College }\end{array}$ \\
\hline James & Regular & Male & $\begin{array}{l}\text { African } \\
\text { American }\end{array}$ & English & 2012 & $\begin{array}{l}\text { Full-time } \\
\text { employment }\end{array}$ \\
\hline Jonathan & Regular & Male & Liberian & $\begin{array}{l}\text { English } \\
\text { Liberian- } \\
\text { Creole } \\
\text { Bassa }\end{array}$ & 2012 & $\begin{array}{l}\text { Full-time } \\
\text { employment }\end{array}$ \\
\hline Julie & $\begin{array}{l}\text { Dual } \\
\text { Enrollment }\end{array}$ & Female & White & English & 2011 & $\begin{array}{l}\text { Two-year } \\
\text { College }\end{array}$ \\
\hline Katherine & $\begin{array}{l}\text { Dual } \\
\text { Enrollment } \\
\text { Advanced } \\
\text { Placement }\end{array}$ & Female & $\begin{array}{l}\text { Mexican } \\
\text { American }\end{array}$ & $\begin{array}{l}\text { Spanish } \\
\text { English }\end{array}$ & 2012 & $\begin{array}{l}\text { Two-year } \\
\text { College }\end{array}$ \\
\hline Kim & Regular & Female & $\begin{array}{l}\text { African } \\
\text { American }\end{array}$ & English & 2011 & $\begin{array}{l}\text { Full-time } \\
\text { employment }\end{array}$ \\
\hline Ling & $\begin{array}{l}\text { Dual } \\
\text { Enrollment }\end{array}$ & Female & $\begin{array}{l}\text { Chinese } \\
\text { American }\end{array}$ & $\begin{array}{l}\text { Mandarin } \\
\text { English }\end{array}$ & 2012 & $\begin{array}{l}\text { Four-year } \\
\text { University }\end{array}$ \\
\hline Michael & $\begin{array}{l}\text { Dual } \\
\text { Enrollment } \\
\text { Advanced } \\
\text { Placement }\end{array}$ & Male & White & English & 2011 & $\begin{array}{l}\text { Four-year } \\
\text { University }\end{array}$ \\
\hline Nadif & $\begin{array}{l}\text { Dual } \\
\text { Enrollment } \\
\text { Advanced } \\
\text { Placement }\end{array}$ & Male & Somali & $\begin{array}{l}\text { Somali } \\
\text { Kiswahili } \\
\text { Arabic } \\
\text { English }\end{array}$ & 2012 & $\begin{array}{l}\text { Four-year } \\
\text { University }\end{array}$ \\
\hline Muhammad & Regular & Male & Somali & $\begin{array}{l}\text { Somali } \\
\text { Arabic } \\
\text { English }\end{array}$ & 2012 & $\begin{array}{l}\text { Two-year } \\
\text { College }\end{array}$ \\
\hline Sean & $\begin{array}{l}\text { Dual } \\
\text { Enrollment } \\
\text { Advanced } \\
\text { Placement }\end{array}$ & Male & White & English & 2011 & $\begin{array}{l}\text { Four-year } \\
\text { University }\end{array}$ \\
\hline
\end{tabular}

*All names are pseudonyms. 


\section{APPENDIX B}

\section{Nadif's Literary Analysis (Argument) for AP English}

Africa through the eyes of Achebe.

Chinua Achebe is one of Africa's greatest and recent writers. His books are mostly written for African readers who are mainly familiar with his point of views; however, over the last years Achebe's works have been translated into many languages. All his books talk about impact of colonialism and African cultures.

Achebe was born in Ogidi, Eastern Nigeria in 1930, having born to Isaiah Okafo, a Christian churchman and Janet N. He was the fifth of six children having been brought up under the new religion of Christianity. He belonged to the Igbo tribe, which one of the largest and prominent tribes in Nigeria. Most of the Igbo tribe members also speak English due to British colonialism (Metzger 3). Achebe who is now 81 years old lives in the United States due to health issue after a car accident left him paralyzed in Nigeria.

Achebe is naturally talented person and always excelled best in education. After sitting for the final high school test Achebe achieved great scores where he was admitted to the Government College of Umuahia in Nigeria, an institution established by the British colonizers, in order to educated future elites of Nigeria, especially boys only. He later attended University College, Ibadan in order to learn medicine, but later switched his career to English, History, and theology. He then on received a B.A in broadcasting at British Broadcasting Corp in London University (Metzger 3).

The theme of Achebe's books focus on the impact of British colonialism such as conversion to Christianity in which the British was trying to destroy the old ways and traditions of African countries. When British rulers imposed new cultures the African people thought 
civilization was coming, but Achebe believes it is far different. They later started practicing inhumanity and brutality across the region. Chinua Achebe seeks to show the effect of postcolonial tribalism and Igbo culture, role of women, and education in his books "things fall apart," his first novel, "Girls at war and other short stories," and "the education of a British protected child," in order to give readers knowledge of Achebe's on the Igbo culture and the continent of Africa at large.

Things fall apart.

\section{Woman in Society}

Achebe's book "things fall apart" focuses the likeness of women being weak while strength in linked to men. Although people across the globe share many things, the only think many African countries are different than the rest of the world is the role woman play. Character Okonkwa once finds out that his daughter Enzima is growing to be strong a person, Oknokwo wishes that "she should have been a boy,"(Achebe 64). It is such believe that makes woman in Africa to be considered much weaker while they are again highly needed in their communities. Through the eyes of Achebe woman in the Igbo culture are not considered to be humans, but instead as laborers, property and child producers. Achebe offers such a depiction in order to educate people about the Igbo culture and the continent of Africa.

In addition, the term woman is used an insult over the Igbo culture and continent of Africa. Okonkwo calls his father woman because of his laziness and his lack of title in his tribe, and his borrowing habit which led him to higher dept. Even OKonwko asks himself this question which is the worst insult to him "when did you become a shivering old woman," (Achebe 65), after killing a young man and became agitated. Women in Africa live in a very difficult life even after the colonial period, where they are not well represented in public offices and always have 
no value at all in their communities. Achebe shows what it means to be a woman over the Igbo culture and the continent of Africa as a whole.

Eventhough women were considered a very lower class people children knew that their mother was more important to them than anybody else. Okonkwo's son kenw that his mother had a lot better story than Oknowks, "So Okonkwa encouraged the boys to sit with him in his obi, and he told them stories of the land — masculine stories of violence and bloodshed. Nwoyes knew that it was right to be masculine and to be violent, but somehow he still preferred the stories that his mother used to tell him,"(Jeyifo 1). Okonkwo feminist beliefs will always leave a hate for woman because of his ways of threatening his wife, which even lead to his son Nwoye follow the ways of the British which taught him love for everybody.

\section{Cultural change.}

In the novel "things fall apart," the Igbo culture is facing a dramatic influence enforced by powerful forces. The British colonizers are placing such an effect in order to change the gender roles, family structure, trade, and etc. Okonkwo a hero and a title holder realizes the presence of the white men is leading to division among the region, "he has put a knife on the things that held us together and we have fallen apart,". The arrival of the white men is a loss to the Igbo culture leading them to live their ancestor's cultures behind. Such impacts will positively affect woman leading them to have a voice in the presence of the white men who viewed woman were equal and had equal voices. Although it is rather a stressful situation to a man like Oknowkwo who enjoyed beating his wife even during the week peace in which according to the Umuofia tribe no evil things were allowed to happen. Achebe is placing this in order to show how the British dramatically changed the ways of the Igbo culture and the 
continent of Africa.

Furthermore, the people of Igbo belief sacrificing for specific days and specific people is the way of the land and who ever violates will receive the goddess punishment. Such a belief places the Igbo's to an extent in which they believe in order to be successful you will need to fulfill the needs of the goddess.

Okonkwo who is such an extreme believer of the Umuofia culture says "before I put any crop in the earth, I sacrifice a cock to Ani, the owner of all land. It is the law of our fathers," (Achebe 17). Believe of how fathers use to do is a strong believe to many African cultures, they believe in such a way that it is their obligation to practice what their fathers used to do. Okonkwo is in a position of fulfilling rituals to a goddess that has no control over him, while the presence of the western cultures is falsifying that there should be no small gods to belief other than the greater God. Achebe is showing how such an impact will change the ways of the Igbo culture.

\section{Education.}

Achebe emphasis in his book "things fall apart" the British style of educating the elites of the region in order to backlash the expectation of the Igbo elders. The missionaries' message of new religion was not a goal they meant, but it was a plan to change divide among the people and get the attention of the young ones whom can easily be assimilated by educating them. Such lead to isolation of a father and a son "you all have seen the great abomination of your brother. Now he is no longer my son or your brother. I will only have a son who is a man, who will hold his head up among my people,"(Achebe 172). The Europeans had such a strong plan, which could lead them easily to divide the people against their wills and give them supporters by educating the young ones, though their goal was to colonize and start slavery across region. Using religion, 
as a tool to achieve your goal is what led the British to take over the Igbo people, thus Achebe in his novel "things fall apart" proves this claim is what made easy for the Europeans to divide the continent of Africa.

Furthermore, use of good language and proverbs to communicate was a tool men used to show how strong and skilled they are. According to Merriam Webster dictionary education is defined as the knowledge and development resulting from an educational process, however in Igbo culture people get educated according to their ages, meaning the older you grow the more educated you become. That nation gave many African cultures that the more proverbs and saying you use from the past to get your point done, the more respect you get. Okonkwo one of the greatest people in the tribe and a member of the tribes head is among those who never had some form of education. Again smart and wise one in his tribe by praising himself from quoting from the past, "The lizard that jumped from the high iroko tree to the ground said he would praise himself if no one else did," (Achebe 21). It is these rather form that many African's use in order to explain their capacity of thinking and handwork. Achebe places this to share the meaning of education to the Igbo region and the continent of Africa at large.

Girls at war and other short stories.

I. Woman's role.

In his book "Girls at war and other short stories," Achebe now focuses on what role do women play in marriage even after the impact of the western cultures. Achebe wrote these book years after Nigeria underwent a whole revolution period where cities have been created, education started and women were now being some howl accepted by their communities. The acceptance of woman to the developing Nigeria only came from men who have been open to the 
western culture, but not the elders who lived over the doctrine of women being property and laborers. Character Nnaemeka who is a young man plans to marry a girl he meet with while in the city, he unveils the plan to his father who reacts due to his sons betrayal of marrying a woman teacher, "Teacher, did you say? If you consider that, a qualification for a good wife I should like to point out to you, Emeka, that no Christian woman should teach. St. Paul in his letter to the Corinthians says that women should keep silence," (Achebe 25 G.W). African elders still stick to the barbaric doctrine that woman must remain valueless in their community. No religion has ever allowed separating people according to their gender or what so ever, however the questions still remains, where did the African cultures inherited such fundamentalism believes of considering woman as valueless people, while they are mothers, sister, and grandmothers? Achebe puts this forward in order to show the movement woman made over the time.

In addition, according to Achebe's book "Girls at war and other short stories," show how the view of Marriage changed for the new generations. The Igbo elders stick to the uncivilized cultures, which determined woman less value than men, but still use values which many men all over in the world today might use to find a wife, "what one looks for in a wife are good character and a Christian background,'(Achebe 24). These values are not only used by the men, but women as well to find men of their choice, however the Igbo's interpreted in a way that defined Christian woman should not go to school neither work. Such rootless beliefs that left woman in the Igbo culture and the continent of Africa to be considered less human. Achebe brings ups such an issue in his books in order to show how such a baseless ideological beliefs dominated women in Africa.

I. Culture. 
In his short story book "Girls at war and other short stories," Achebe teaches Igbo's belief of goddess instead of the greater God. It is a belief of idols (goddess) that led to the traditions such as burying twins. The Igbo's belief magicians and medicine men can bring dead people alive "take a matchete and cut away the strangling climber. The spirits which have bound your sister will then release her,". Although it is believed that humans originated from Africa around 250,000 years ago, there is a myth that says early hunting men had small gods, however it is the possibility that many African cultures inherited the belief of goddess from their ancestors. Even though humans it is possible people to inherit certain things from their cultures, it is shame to have the Igbo's burry their twins alive. This is ugly and inhuman practices Africans believed until the arrival of the European missionaries. Achebe placed such stories in order to give people hint of knowledge of the Igbo culture.

In addition Achebe takes his heritage more superior to him than anything else, he proves this by writing about his traditions in his books. in his "Girls at war and other short stories" there is a story named "the madman" in that story, characrater Nwibe, an enterprising and eminent middle-aged man is about to take the Ozo title, one of the most prestigious awards his community,(Ogede 2). According to the Igbo beliefs titles are not achieved based on your level of education, but are achieved on your strength in terms of war, talk, and age as well. These are the principles that defined for a man to be an Igbo leader, however; title holders in the region were men who glued their brains the customs of the region such as burying twins alive, marrying more wives, and men whom their children followed the customs of the region. Such cultural beliefs were what made the young Igbo's who were growing up during the arrival of the missionaries to betray their fathers beliefs and follow the ways of the Europeans which were easy to follow, and learn more. Achebe displays his cultures in terms of writings in order to show 
what his people belief though he himself does not practice them.

\section{Education.}

In his short stories book "Girls at war and other short stories," Achebe writes a short story named "The voter" in which he reveals the effects of the British education over the region. The continent of the Africa, as well as the Igbo region was ruled by tribe men who were elected by the elders of the region based on ages, warrior and experience from the past, however; after the arrival of the British things changed and leaders had to be elected. The new British system had both positive and negative impacts on the region, the negative impacts were, people who wanted to be elected started bribing for their vote, which lead to higher corruptions. Vote seekers made promises that never get fulfilled, leaders could only be seen when the election was coming nearer. While the positives were, people learnt a lot and the life style of people improved while urban life style started. The British brought some form of education that led to the deterioration of the Igbo culture. In Africa it is rare to believe the promises of a politician, and people always know few politicians seek the truth, "we believe every word you say to be true," (Achebe 16). He writes about these issues in order to share with the reader how the politics and cultures of African people moved from tribe decisions to real politics.

In addition, it is rare to find free education across Africa. This is because of lack of trusted leaders who can sacrifice their time and lives for their people. Leaders in Africa run for public offices in order to get rich and fame, which they do these by using the public funds. This is due to lack of transparency to know what the government does, and what happens behind the offices. The short story "Vengeful creditor" Achebe talks about a situation where the Nigerian government had proposed a free primary education. That was what free education had brought. It had brought even worse to the homes, Mrs. Emenike had lost three servants including her baby- 
nurse since the beginning of the school year, (65). This level of inhumanity and corruption can be traced back to the Europeans who divided the African people against their wishes, creating tribe and ethnicity divisions. That is why leaders in Africa do not feel helping their country, but only their tribe members. Achebe focuses on how the rich abuses the poor in the continent of Africa.

The Education of a British Protected Child.

\section{Woman.}

In his essay Book "The education of a British Protected Child," Achebe talks about other difficulties women face than being vulnerable in their communities. Death related to childbirth is a very common and a disaster to the lives of many African mothers, "my father. He was an orphan child: his mother, had died in her second child birth,(35), Achebe tells his own family history. Death related to childbirth literally comes from lack of health care or unaffordable care, which is an issue in the African regions. This really threatens and discourages women to think of marriage, although many African cultures consider marriage as a priority. It is lack of governmental support that leads to death of women in childbirth, which should not happen; however, in many situations women are not given the chance to have other options such as birth control, or family plan if she knows she will not afford to afford to seek good health care. Achebe, his own personal story tells the difficulties women in Africa face.

$$
\text { I. Culture. }
$$

Achebe's essay book "The Education of a British Protected Child," reveals how his father's acceptance into the missionary religion of Christianity changed their lives. Achebe who belongs to the Igbo people believed strong traditional customs which sometimes inhuman; however after the spread of Christianity his father followed the new religion. Although Achebe's 
parents died and he grew up as an orphan, these might be an issue that led him to follow the ways of the Missionaries. My father had a lot of praise for the missionaries and their message, and so have I (37). Achebe himself unveils how thankful he and his father are of the changes brought by the missionaries, however, he is not happy with the slavery secret that was brought by the missionaries who use the bible as a tool to divide the people of Africa. This method of using religion as a tool to achieve ones goal is highly affecting the $21^{\text {st }}$ century we live today, leading to divisions among nations. Achebe is here thankful on one side while on the other his heart is broken by the ways the British used. Achebe teaches his readers how bad and the good side of the arrival of the missionaries in Africa.

\section{Education}

Achebe overall appreciates the arrival of the Europeans because of exposing dominated Africa to the rest of the world. Achebe himself is an educated African who lived during the colonial period and underwent the British method of Education, as well as his father. Once explaining the great gifts from his father "his great gifts to me were his appreciation for education, and his recognition that whether we look at one human family or we look at human society in general, growth can come only incrementally,"(37). This pretty explains how Achebe the senior appreciated the ways of education brought by the Europeans while letting the Igbo traditional ways cease. The Method of Education was a benefit to the African people in order to develop and change their ways, which gratefully led to the outcome of great men like Achebe himself. However, Africa did not benefit the education of wisdom of a man like Achebe; he always lived outside of the continent. If Achebe would have taken back his knowledge to the continent, Africa would have produced millions and millions of Achebe's who could in turn let 
the people forget the past and move on the present. Achebe in his book tells how they appreciated as a family the arrival of the missionaries.

In conclusion, Achebe's books definitely teach the ways in which African people used to live. The books set scene for someone who never hard to experience what the early Africa was like. The language used Achebe to write about the ways people do is something that is true about how the people speak. In his book Character Okonkwo who rises from the bottom to the top while again dies in fear, this character reveals what many African heroes tried to accomplish, like Jomo Kenyatta of Kenya. His theme of the impact of British colonialism over the Igbo region can be experienced over his wirings. Achebe is such a strong writer who could teach his readers what I mean to be an Igbo or an Africa.

Work cited page.

Achebe, Chinua. Things Fall Apart. New York: Doubleday, 1959. Print.

-------. Girls at War and Other Short Stories. New York: Anchor Books, 1972. Print

------. The Education of a British Protected Child. New York: Alfred A. Knopf, 2009. Print. Jeyifo, Biodun. "Okonwkwo and this mother: Things fall apart and issues of gender in the constitution of

African Postcolonial discourse.” Literature Resource Centre. Web. May 17 2012.

Ogede, Ode. "The Politics of Story Telling." Literature Resource Center. Web. May 17, 2012. Metzger, Linda, et al. Black Writers. Michigan” gale Research Inc, 1989. Print. 
APPENDIX C

Selections from James' Urban Survival Guide

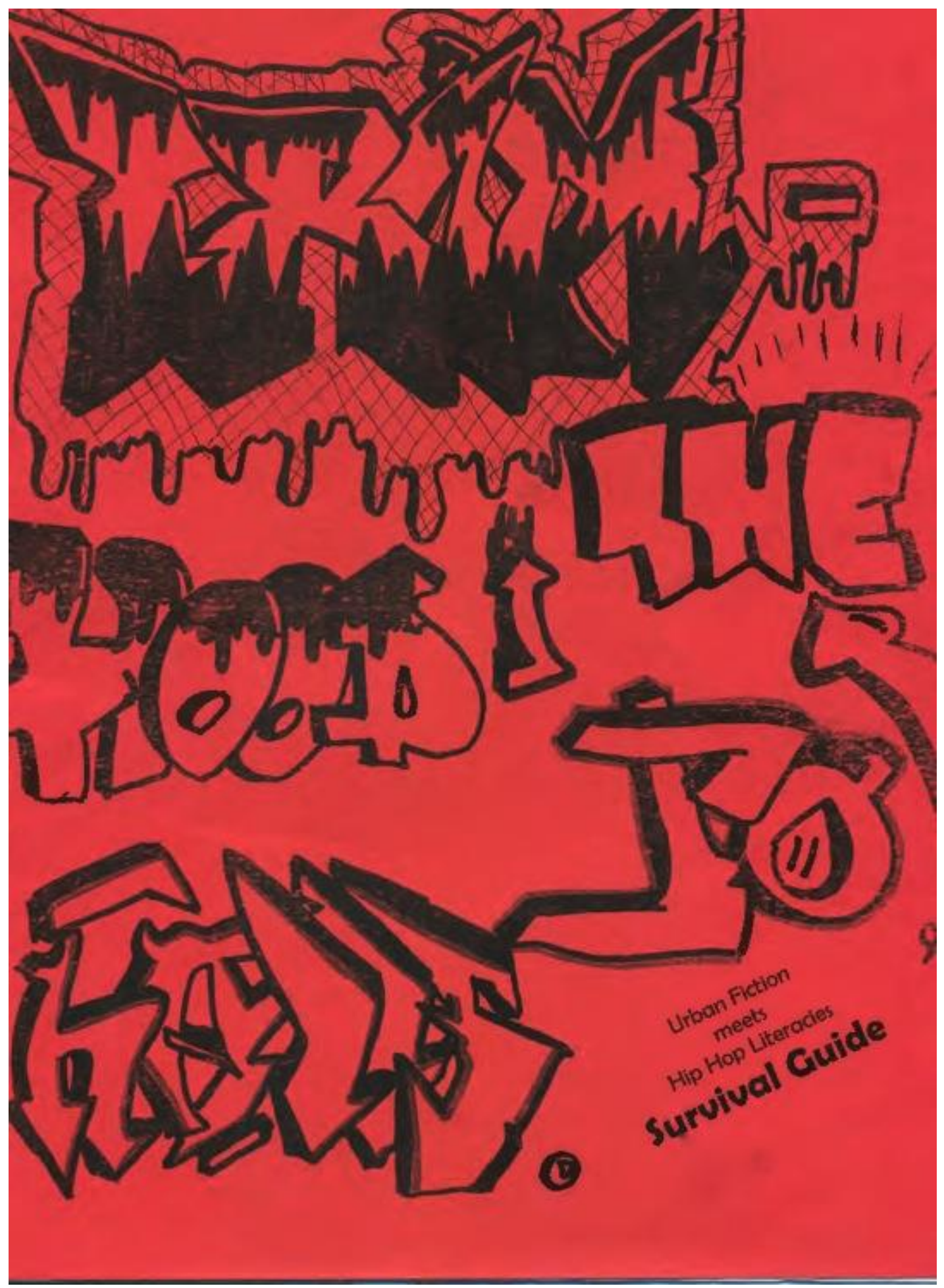




\section{From the Hood to the Halls}

Urban Fiction Meets Hip Hop Literacies Survival Guide

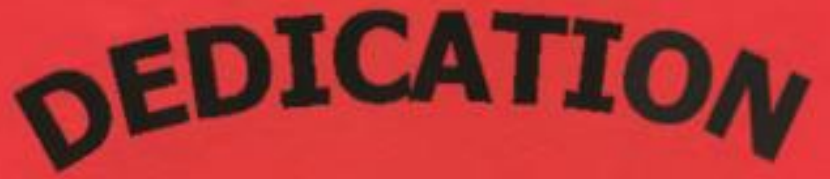

We dedicate this book to all of you who are trying to figure out how to survive in an urban high school. You show up every day, but then what?

As Sapphire says in her dedication in Push,

"Every blade of grass has its angel that bends over it and whispers, 'GROW.'”

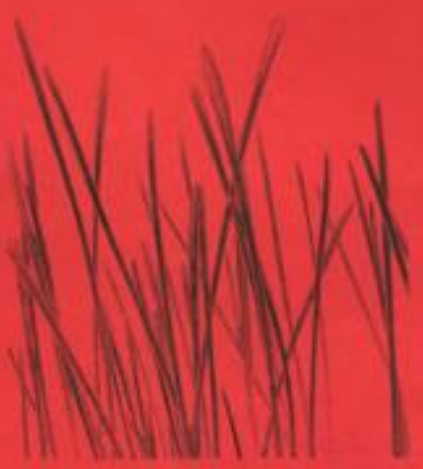

Our hope is that you GROW strong and tall and confident and that you survive ... maybe even thrive in the halls of Waggener and beyond! 


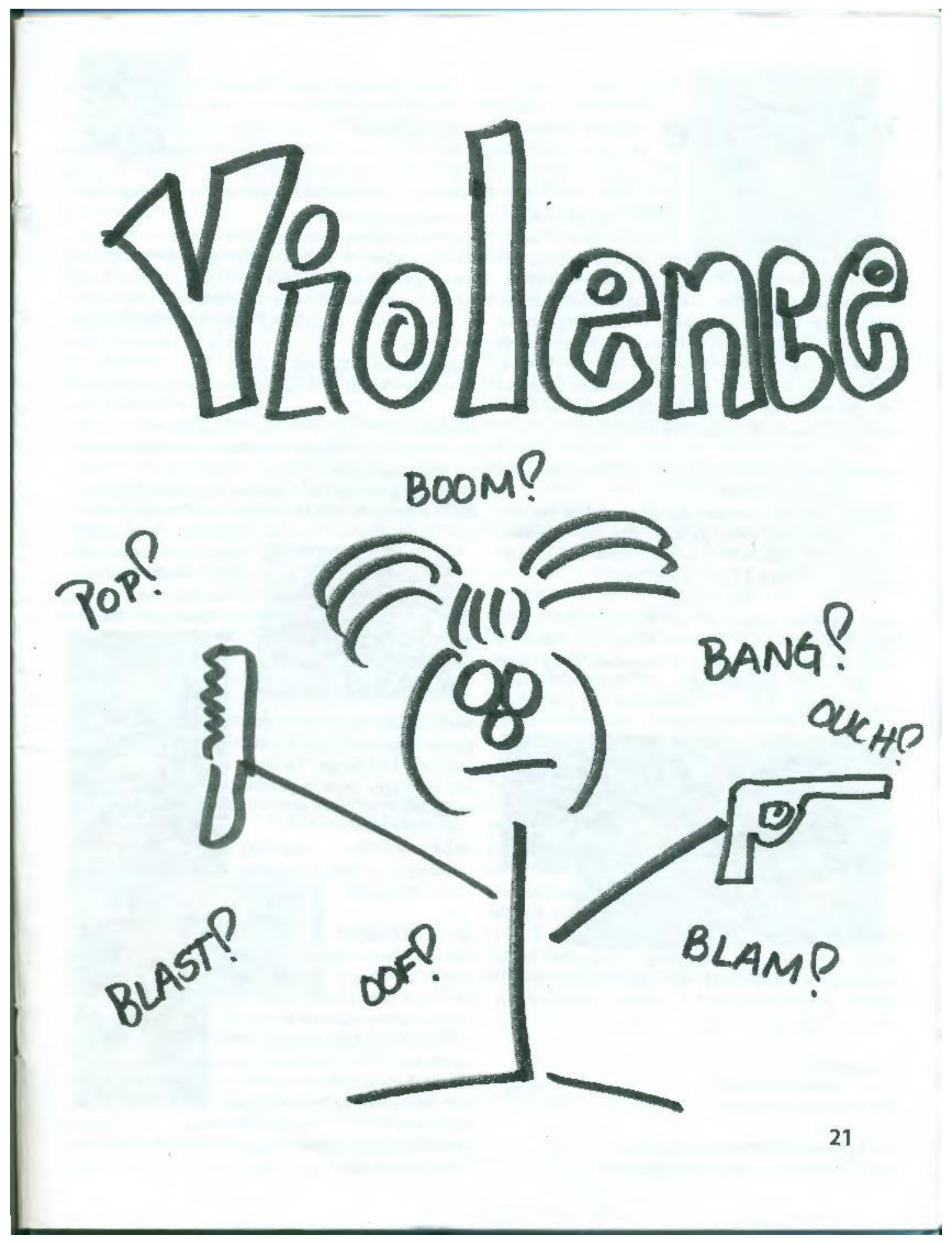




\section{Violence}

\section{Realities}

Knives, shanks, needles, ice picks - are no joke. A relatively unskilled thug can cut you dozens of times before you ever have a chance to defend yourself. Awareness is the best way to avoid an attack. Violence is a reality that all of us have to understand. Even people who are not violent need to know about violence. Unfortunately, it is the way people ussert power in our world. Hip Hop students have a different type of flavor then their teachers. Some of the younger teachers has the flavor of Hip Hop students. This flavor means that you

Another reality is that violence lots of people don't know any other options.

because they have nothing else to do and no positive men in their life nobody to show then the right way, It seems like the only men they know are famous people who show off their violent ways.

Violence is all around us -on television and in real life. Just think about fights at Waggener. All of us enjoy watching them. What is that about? People like to see other people fight. They think it's entertainment.

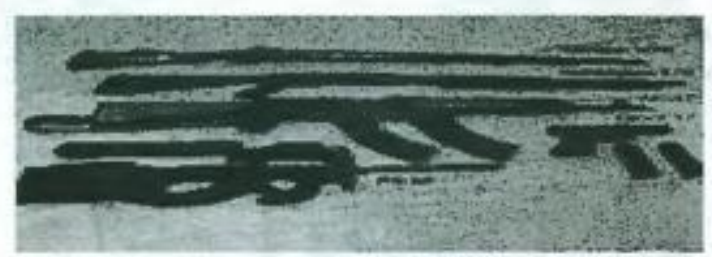

There is a big debate about whether violence creates more violence. If you get in a fight at school for the first time, are you more likely to do it again? Well, 1 think that there is something contagious about fighting, but it is the way urban high schools role. If you've got to stand up for yourself, you fight. It allows you to take a stand.

\section{Vocabulary:}

Fire - means good as hell, Bar: means absolute no

On butt-basically means act a donkey Piff--means you on fire in the dice game
Rolling __ deep--means that you're walking with that number of people

To steal someone-means that you hit them in the jaw

To crack someone--to hit someone really hard

Swag--a person style of fashion

Beef-utwo people don't like each other

Crackin'-means a girl that's going around doing everybody

Shake--means I am about to leave

Square up--means let's fight

\section{Models:}

Lil Webbie, Lil Wayne, Yo gotti, the coldest rappers out there right now. You can't leave out Lil Boosie that nigga goes hard he's realistic and speaks the truth. Busta rhymes is cold too. He is a fast rapper, but if you listen closely you can understand what he is

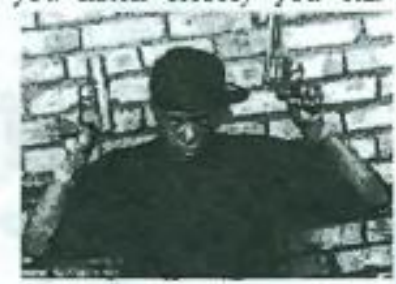

been locked up for having people murdered. Lil webbie been in jail for drugs. Yo Gotti and lil Wayne been in jail for drugs too.

What is the connection between drugs and violence? Here's the answer:

\section{Do's and Don't's}

Do what you need to do then you'll do what you wanna do, and your dont's will make you have a difficult time of what you did back then like I said Karma can be a

nice looking female.

Just don't treat her bad and watch what you do.

Do's. finish high school. My plan's to go to college so I can be successful. 
Dont be a drop out. You will be a failure, and it would be hard for you to get a decent job the only job you might get is working at McDonald or being a person that deliver pizzas.And for the people that say they not going to college because its going to be hard you would never know how it would be unless you go and give it a try.

Here are some suggestions:

-Do.. know how to defend yourself.

Dont.. fight just to fight.

Do.. graduate from high school

Dont. drop out of school

Do.. get a job

-Dont. become a drug dealer

Do.. your on dirt

Don't .. kill somebody for the fame and name

Do .. keep your personals to your self

\section{Next Steps:}

Violence is not the answer. just avoid all the nonsense, and you'll be all right. If violence comes to you, then handle your business. RNS! To be successful when you get older and become a adult, you have to start from the beginning. You can still have fun, etc., but in order to do that you have to stay away from the violence. Think about it: if you have kids and you don't have a job or you do but you don't make that much, how will you be able to take care of your kids. Take a second and think about it. Violence is a good, temporary answer, but the real truth is that if you want to survive in this world, you have to.

\section{The Future}

The future is the thing you need to focus on because the future is now. Whatever you do in the present will come back on you in the future, so Karma can be

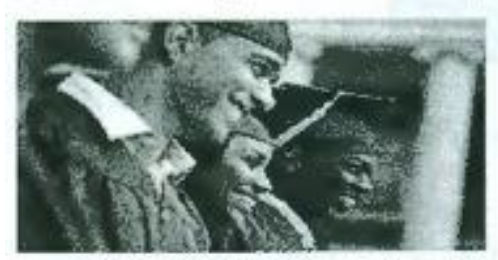
beautiful just watch what you do to her, because if you treat her bad she's gone make you have a hel! of a ride. The future always depends on what you do in the past. For example, if you go to college and finish college you can get a good job that pays a good amount of money but if you dont if you dont go to college you will get a decent amount of money but not as much as the person that finish college because they would have a college degree. If you are one of those people that drop out of high school it would be hard for you to find a job because you dont have a high school diploma and you was a drop out so they wont take you serious.Then when you cant find a job then that's when you start to sell drugs, commit to rob

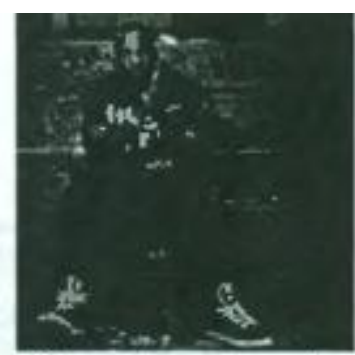
people to get money.So your future depends on what you do in the past.

Can violence get you in trouble? yes, you can end up in jail from violence like for example you get locked up for getting caught up with some drugs or something you gone be in there for some years. Will it mess up your future if you're involved in violence as a teenager? yes, say if you get caught up with a gun or some drug its gone effect your voting rights and etc. Here's where I come down on that issue:

Imagine what you did in the present, say you pulled a gun out on a individual and he gets terrorized. All I have to say is don't make a mistake or you'll have to face the consequences of what you did in the past. make your picture positive don't mess up your picture have a good back-ground for yourself but handle your business if it comes down to a fight. Imagine you going back home from shopping you walk in your house and everything is gone. If something like that happen to me then $\mathrm{i}$ would go knocking on peoples doors around the neighborhood asking did the hear or see anything then if $i$ get any information then that's when me and peoples is gone go out and look for the people that rob

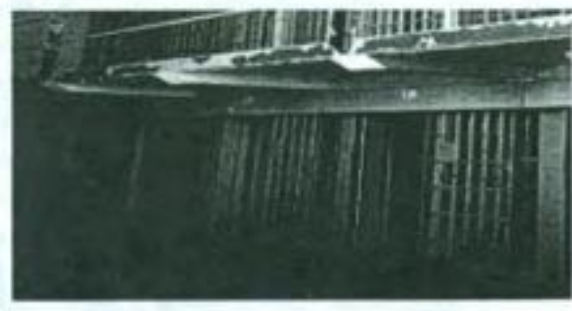
my house and take my stuff back plus more. 


\section{APPENDIX D}

\section{Katherine's Autobiography for Dual Enrollment English}

"Because I am different and speak with my hands, not my mouth, does not determine who I am, it simply states I am capable of learning something new"- unknown. The quote shows that the way you speak, write, or communicate does not show your identity but it clarifies that no matter what language you speak it does not show who you are. I know this from personal experience because I am actually deaf in one ear. I do not wish pity, sympathy, nor special treatment just because I am partially deaf such as yelling at me. I have spent my whole life training myself to not reveal my secret but I was told that I needed to prove how this paper was related to identity and language. When I was first told that I was deaf in my left ear I realized that one day an accident could occur and I would not be able to hear completely. So, with much enthusiasm I voluntarily decided to learn American Sign Language (aka ASL). On November 22, 2007, I was a freshman, and in the ASL class. I can remember my teacher telling/asking me that she needed me to give a tour to a new student who will be arriving around lunch time. Little did I know that she was deaf, and would soon be my best friend. When I arrived I was told to sit in the back and wait patiently because the new students meeting had gone longer than they expected. So as I sat there I can recall thinking to myself "she prolly thinks Ima creeper" just because I was sitting there without her knowing why I was there. When it was time for me to give the tour my teacher told me "if you succeed you will make a great interpreter one day." I had no idea what she was trying to tell me because I was focused on not trying to be the creeper I thought I was being.

So, the tour started and as I was talking she stopped me and started to sign. My 
first reaction consisted of my mouth dropping and I instantly took my hand shaped it into a fist and in a circular motion waved it around my chest, this decelerated motion meant "SORRY" in Sign Language. I now understood exactly what my teacher was speaking of. So we restarted the tour but this time in ASL. As the day progressed we grew closer and closer and before we knew it, we became best friends by the end of the year. Sitting there and knowing that the stares all around and side conversations were about us, we decided to stop our own conversation and go home from where ever we were. In my town it wasn't everyday someone would see a deaf person holding a conversation and wondering what was being said.

I had many experiences such as this where we would be "speaking" but people would only notice and remember the fact that we did not "talk" back and forth but just signal. I had always been the girl to be around "different" people so I was use to the constant stares but unfortunately for my friend, she was not. She had come from a school where everyone spoke her language so there were no weird looks or constant asking of "What did she say?" I became immune to it all because I didn't want to show her that it bothered me as much as it did her. I felt as if I should have said something but I felt ashamed that I didn't. Eventually, I started to let people know that I was partially deaf because I have come to notice that I have trouble understanding what is going on within my surroundings. As a high school student the days are busy and I have many people trying to communicate with me at the same time which makes it difficult to capture everything that is being said.

This brings me to the point of how ASL affected my English and Spanish for that matter. ASL is a "choppy" version of English. All this means is that sentences in ASL are 
broken up from the normal structured sentences. (Ex. Hi, How are you? Would translate to How you?) I had to learn how to break up sentences in both English and Spanish because my friend would stay at my house and my father spoke only Spanish. When she was there I was usually the "Google translator" as my dad had put it. I would have to convert what he was saying in Spanish to English to American Sign Language (ex. ¿Cómo te va en la escuela? To How are you doing in school? To How School?) I got so use to verbally speaking and writing in ASL and Spanish I had to always make corrections on papers for English class. I would write them how I was use to speaking. My papers would always turn out being written in Spanglish and to the point (ex. Me remember la hombre that help translation I remembered the man that helped me). I wouldn't described what he helped me with and why. I ended up ruling out detail because in ASL it was always to the point there was no time to describe any details. Even song lyrics when interpreted were to the point (ex. "Jesus take the wheel" would translate to "God help me"). My teachers would have to work with me when it was time to submit a final draft because my papers all looked liked rough drafts before turning them in. They would also give me ideas on how I could use my "unique" writing techniques in my papers. Looking back now there was more Language Arts involved than I expexted especially because of the extra work I had to put into my writing pieces to make them sound "normal."

Although I have had to let others know that I am Partially deaf I feel more at ease with myself. I can be completely who I am suppose to be, not the person who has a medical condition, or the person who has a passion for communicating without verbal words but, ME! 


\section{APPENDIX E}

\section{Bus Routes}

\section{Eastern Parkway}

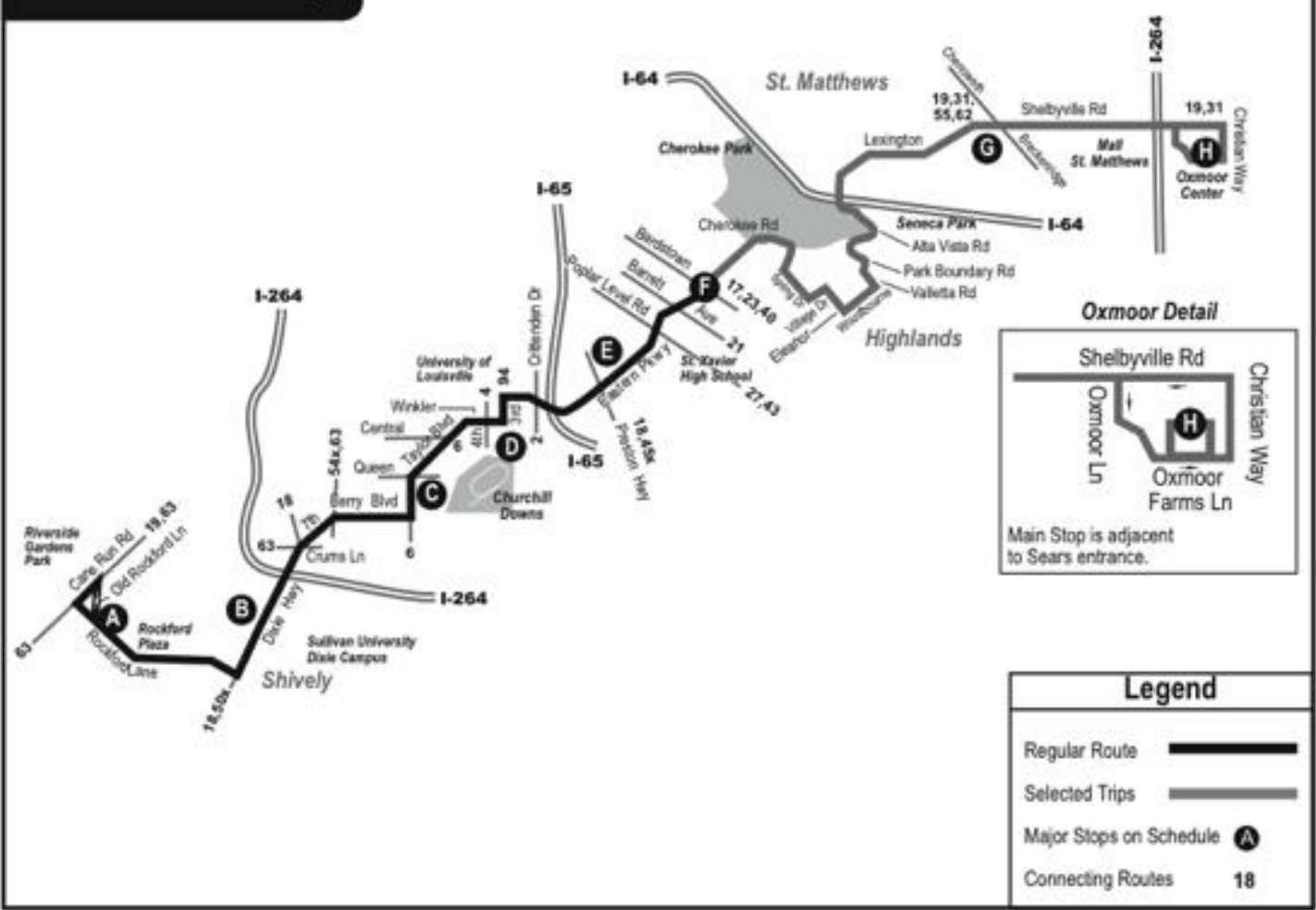

23 Broadway

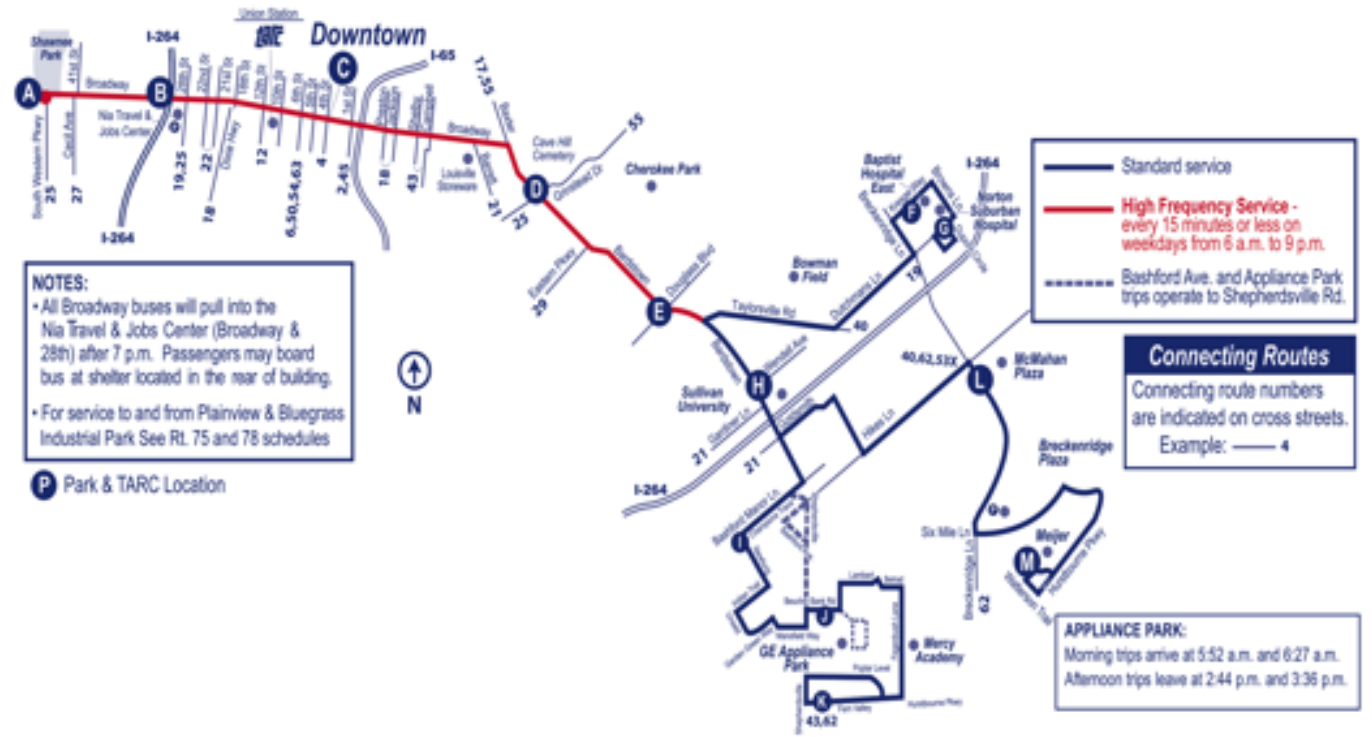




\section{APPENDIX F}

\section{Nadif's Transportation Proposal}

(Rather than alter Nadif's text, I have blacked out names to preserve anonymity. Markings in the text are mine and were made during an interview with Nadif.)

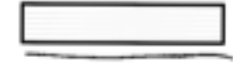

Attached is a proposal that addresses

need for after school activities

transportation. The proposal gives the reasons why

needs to provide transportation to

students who stay for after school activity transportation. As a senior student who likes to see better

I hope this remarks will help bringing back the school it's right position.

My proposal suggests that if after school transportation activities are offered, it will bring back life back to the dead school spirit. This process has been applied to many schools in different states, and helped improve students' academic performance, and behavior. The transportation can be provided by free or free reduced prices.

As a student who loves to see better I hereby forward my concern that will be of interest to future $\square$ students, parents, and administrators who will love to see better students. We know that $\square$ wants to have a diverse environmen (where students can shape their life). I believe my proposal helps you lean towards students needs where immediate improvements are hightly needed. 


\section{Proposal summary.}

This proposal argues that by not providing after school activities transpiration at

school spirit will fade out and the expectation for doing better on the KCCT test, and ACT test will not happen in which the state uses that scores to determine how the school is doing. I propose that

to offer transportation to students who stay for after school activities to have a better school that can produce the leaders of tomorrow.

\section{Problem and Background}

As known $\square$ is under state pressure after the students scored low on the state monitored test (KCCT). The state uses the result of this test to determine how well the school is doing. Due to a bill a passed by the state that gives, power the education board to regulate any school that does not improve well. However, State audit has been sent by the education board to prove if the result were true, and come to conclude with six defiance including "behavior plans," and replacement of the school principal.

Most of our students live far away from the school, although the AP office couldn't figure out the percentage, but approximately the majority live far away from school. It usually takes 1 to 2 hodrs to reach home if the students take the TARC, however this issues made them not to staying for after school activities.

The school has many activities and clubs like the National Honor Society, and the Green club who do work after school. The National Honor society paints school doors, and poor attendance had 
3.

been an issue, and no students could stay to help, since they all worry about who will pick them up. The Green club works on planting, and usually stays Fridays after school, the same happens to the club. At the entire root to all this problems lack of transportation. )

\section{Benefits}

1-Improving student behavior

Student behavior is a big issue in schools, and ways of improving are always appreciated tried. The problem to students at $\square$ behavior in which that audit has seen it in two days is lack of interaction with other students, and teachers beyond the class. This happened because students rush to the buss after the last bell and do not get the chance to interact with their teachers, and classmates while doing some fun activities.

2-Improving lower test scores.

The board of education is trying all the possible means to see better test scores here at

$\square$ but the one important thing to remember is letting students having fun by not worrying (about who will pick them up which helps them have more time at school. Alachua County Public Schools in Florida provided after school activities transportation at school, and aimed in "improving the academic performance and behavior of adolescents and pre-teens when school is not in session and increase the overall engagement of students in school and in learning activities," (Guardian)

3- Student teacher relations

Students at $\square$ don't get to see teachers after class, due to lack of chance. Students leave the building as soon as classes finish while many have problems that they need help with. 
Below is pie chart that shows the view of 20 students

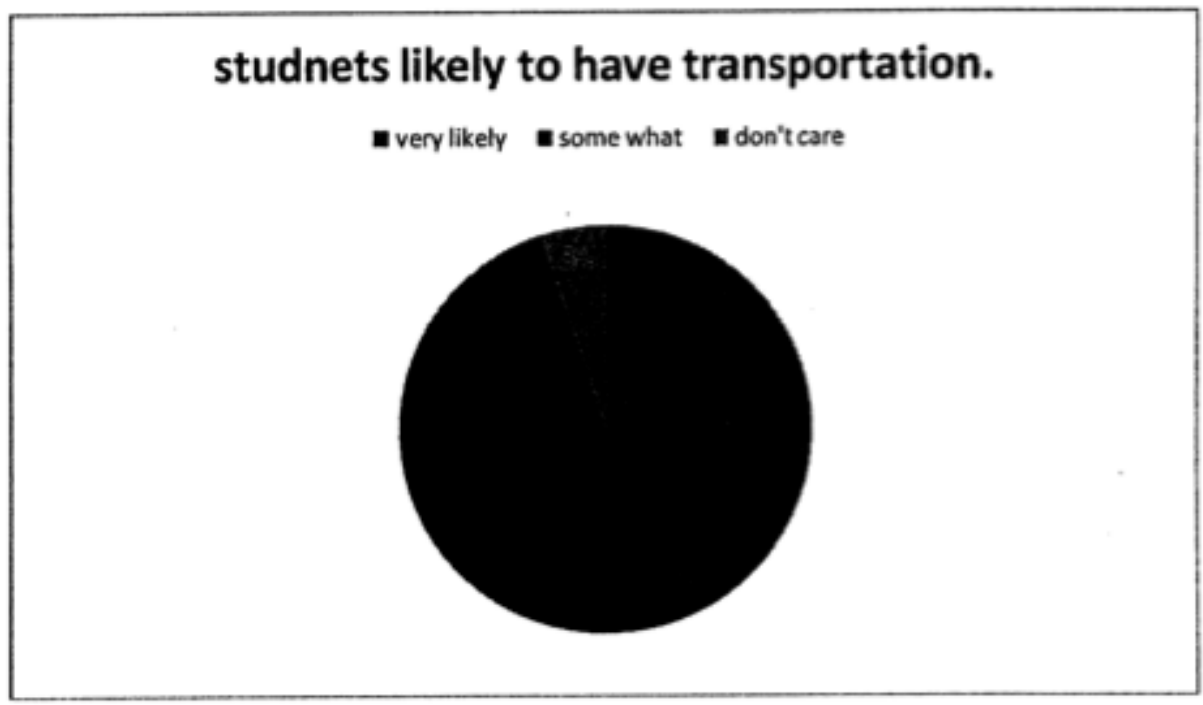

\section{Costs}

The cost to such program will be cheap, compared to the needs of the student. It costs $\$ 150$ per bus each day. There are so many ways the school can get help with this money such as state funds, as well using the school money. Having a better school where the student graduation rate is $100 \%$ is the Kentucky education board first priority, and to have so such little money should be available. 
4.

Students worry about who will pick them up, and how they might reach home. If this burden is taken out students will probably stay and improve. Teachers usually stay after for some time, but fewer students

meets with them. If after school, transportation is provided students will have the opportunity to meet with teachers, and get one-on-one help.

4-School spirit.

$\square$ School spirit gets worse day after day due to lack of emphasis. Student don't get to know themselves, neither did they get the chanee to see what activities $\square$ offers. They don't care about the school while some will sa "I don't go to school I go to that from the students mind is offer transportation, so they get the chance to show their school spirit. (

5

\section{Conclusion}

It's my wish that if $\square$ offers after school activities transportation, great improvements will be seen in both students behavior, and academics. Furthermore the introduction of such plan creates a legacy that will show the real $\square$ and remove the bad name in the community. 
APPENDIX G

Journal Responses from James' Regular English Class

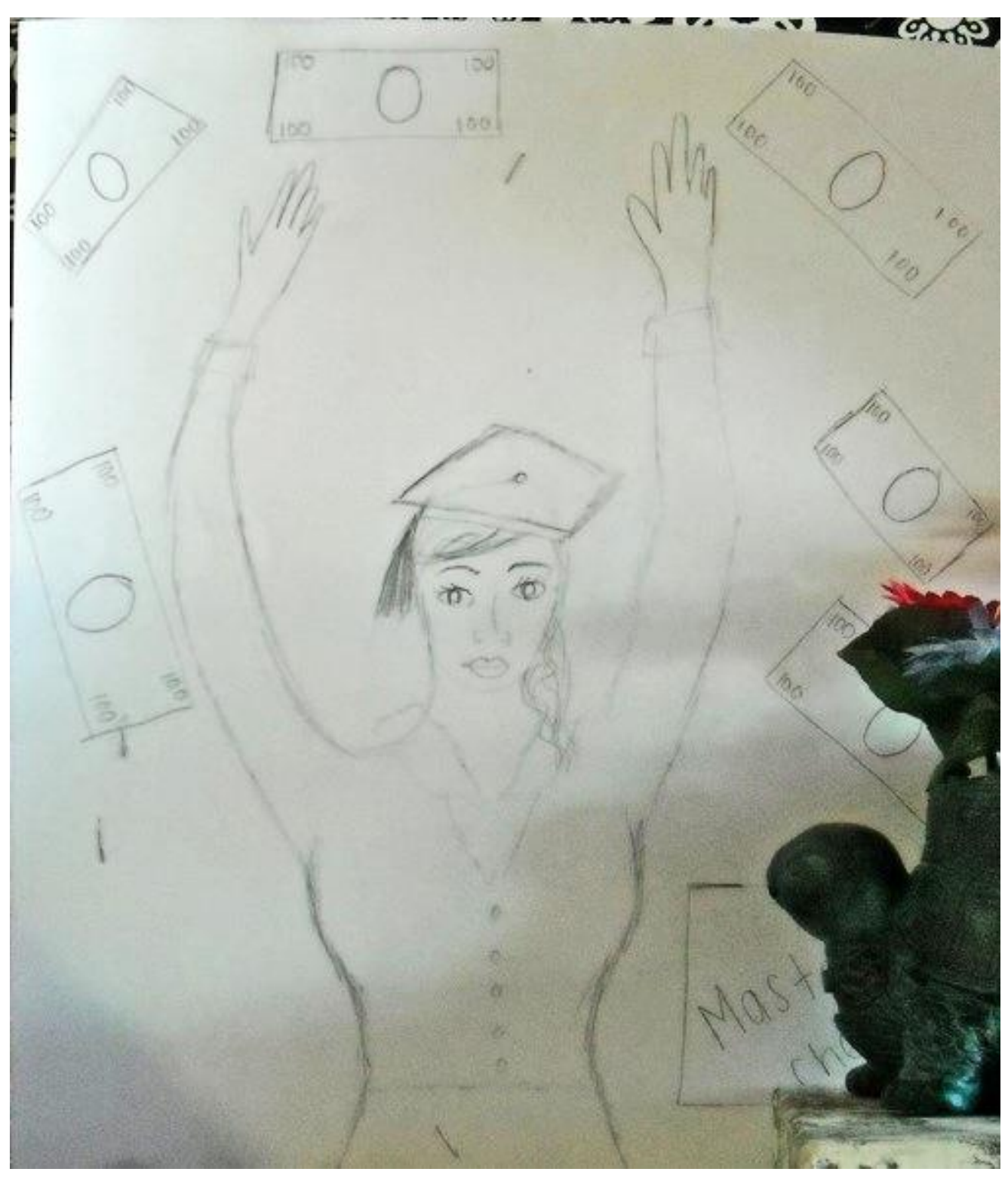



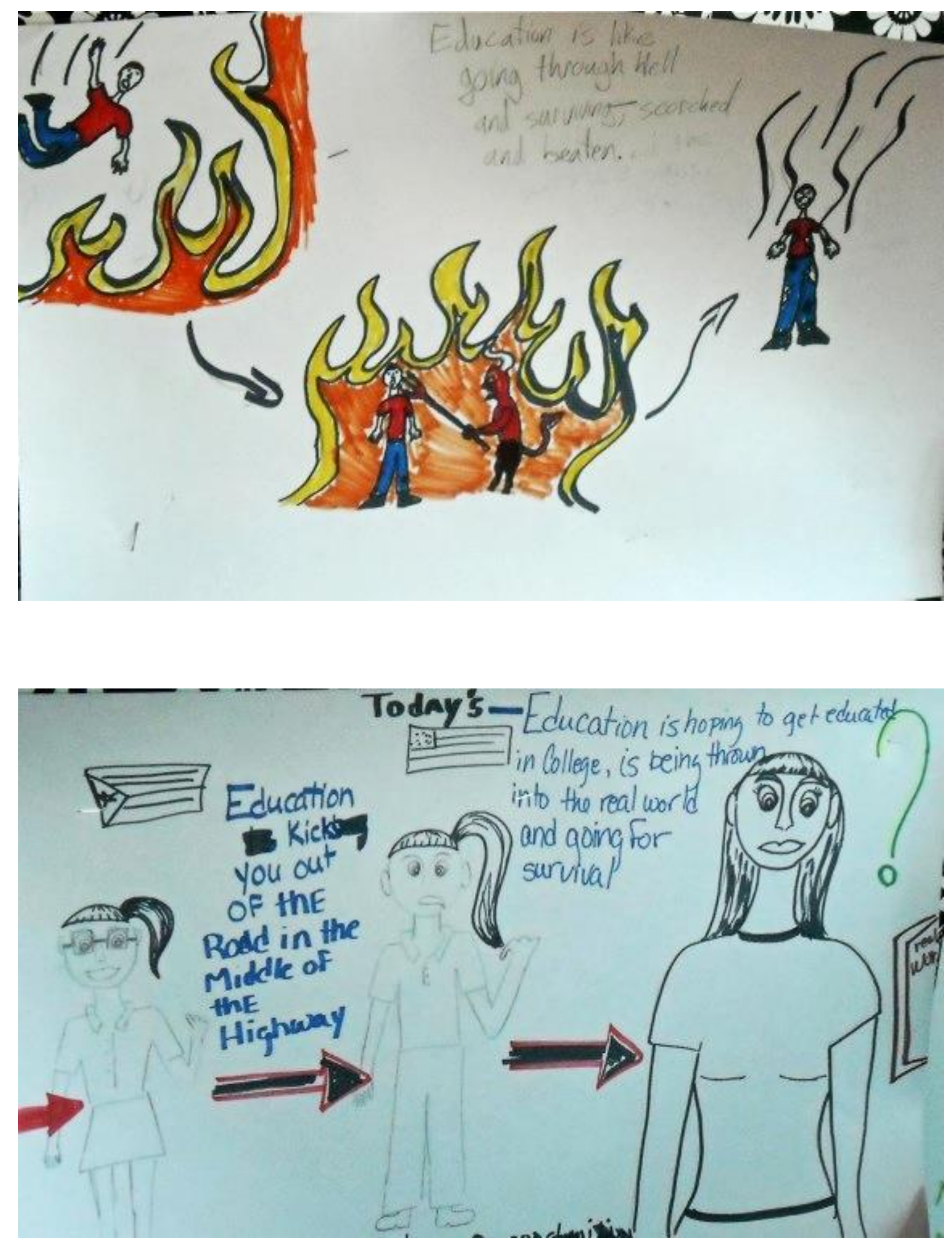


\section{APPENDIX H}

\section{Nadif's essay for ENG 102}

(Rather than alter Nadif's text, I have blacked out names to preserve anonymity)

\section{Inside story of Traditional High School}

Traditional High School is located in the heart of Louisville's St. Matthews area, where Louisville's most middle and upper class people live. Looking at where the school is located, everyone will assume _ is a home to the middle class neighbors who live there, but the story is different. Despite the school being located at such a strategic place, most of its students come from Louisville's low-income neighborhoods, such as West Louisville and south Louisville while few live around the school's neighborhood. "Of the 790 students who attend $\quad, 39.7 \%$ are white, 47.3\% African American and 12.9\% others" (Westerfield, Egan). According to the school principal, who just took over weeks before the end of 2010-2011 school year, the school is also famous for its diverse students body that comes from more than 30 countries. took over after the school failed to perform well on the Kentucky Core Content Test (KCT), the state's benchmark measure for student's improvement. After the school failed the test, the state sent auditors who found that the school principal wasn't fit for the job, which later resulted in the departure of the school's long term principal. I remember attending the Jefferson County Public Schools (JCPS) board meeting months before my graduation as a reporter for the Chit-Chat, a student run newspaper. That night the board decided the fate of $\square$, in which they said the principal will be replaced with a new principal who will then have the power to reinterview all the teachers and hire only the best. The new principal will be powerful, but she only has two years to turn around the school, otherwise she too will be fired. That's how a former deputy principal from high school, came to , an enthusiastic and energetic principal took over Waggener promising new immediate improvements on students' performance in discipline and academics with the rule of an iron fist.

is always known as "the trashy school" where most of those who get kicked out of other schools were allowed to attend, however, there were also many good people who attended or still attend the school. Emily w who now attends the University of Louisville, graduated from last year. Emily is very optimistic of the future of and when I asked if the students can change, she told me "I have always believed the kids were so impressionable especially high school kids, if you provide them with a warm, kind and uplifting environment then they'll do great." I wonder if provided the kind of environment Emily is hoping for. For the last 2 years that I attended there were all sorts of rumors and low expectations of the students. It's true that many students who attend the school really don't care about their life; the school was a day-care to them. However, the school is different this year, is taking the school into a different direction with a speedy change. Last year when I interviewed her for the Chit-Chat newspaper, she had the same expectations as Emily has now: told me "Raising the bar, the level of instruction we will provide will be rigorous, help students earn the pride they need which they deserve." To make that happen, the school underwent all sorts of change, from the transfer of half of the teachers, 
harsh discipline measures, dress code change, and many other changes. I am still confident that students at $\quad$ could be served better but its only possible when a major change is made to the state or the federal government; A change that favors the low-income students such as those who attend

While offers courses in advanced placement, medical magnet, culinary, and ENGL-101, which is offered through the University of Louisville, few students are in those programs compared to the 800 students who attend the school. To my observations the school is divided into two sections: a small group of AP and Honors students and the rest of the school, these students are totally separated academically and socially because of the fact that they don't have classes together and of course they don't hang out together. While I was part of the AP students it still seemed to me like a class warfare, where the rich and the poor don't even shop at the same store, except at , it's educational warfare where the same students in the same building don't get the same level of education. Mike $\square$, who graduated from last year and now attends Spalding University told me he will suggest to keep it that way "because it will motivate those who are less involved to work harder in order to join the 'hierarchical group'." It's not only Mike who believes this, Emily also agrees with him saying "It wasn't the healthiest thing to do [she means to provide students the same rigorous learning], to divide a school like that, but I think it was necessary." But why what it necessary? Emily says because "she didn't wanted to be in a class with a kid who doesn't know the answer to ' $4 * 4$ '." Yes it's true that there are students who can't solve that and still attend . Emily labels case as a "unique case" because of the diverse students.

Based on the schools diverse background there are many English as a Second Language (ESL) students who attend the school, and the KCCT score didn't provide the specific performance of the ESL students. As a reporter for the Chit-Chat and once ESL student I was able to find out how well the ESL students performed on the tests. When I was first enrolled at , I was placed in an ESL class taught by the cruelest teacher I know of so far. In the class the teacher would ask us to do what I believe was third grade English level. That was the most embarrassing moment in my life, not because it's embarrassing to be a third grader, but for the fact that I was a third grader 8 years ago. There were also some students in the class who couldn't do the work, because they were never taught well and no ESL teachers was willing to teach them. After spending months in the program I was able to take the federally regulated ESL exam and which determined my ability to test out of the program. I am confident to say that most of the ESL students didn't perform well on the KCCT test or any other exam because of the school administrations rejection. Most ESL students at $\square$ are required to take ESL classes taught by special teachers in which the government spends millions of dollars to help students get to a good level. However, this didn't happen at the last two years I was there. The ESL teachers we given more power and freedom thanother regular teachers to teach the students, but they misused that and taught students nothing, making them "dumber" as the ESL students will say. It's different this school year; introduced a "literacy campaign" because of the ESL students as she said "they are capable of doing great, they just need more support." Of course to make such a campaign possible, it needs more effort, once asked how it will be enforced she said, 
"Genitors, cafeteria people, teachers, P.E teachers and everybody will be responsible for teaching students literacy."

According to Emily and Mike, last year there were 200 seniors and only 90 of them were able to graduate. Those who graduated, less than 50 are to going to college; with the rest being what Emily calls " $\quad$ stereotypes." The $\quad$ Stereotype means students dropping out of school, some even weeks before graduation, or committing a crime. To find about the crime issue I was told about Kelly, a student at

She has a "crime times" wall in her room (wall of shame) where she features people she knows who commit a crime, and shamefully a couple of weeks ago a famous Basketball player who graduated in 2010 appeared on her wall of shame after he stabbed his girl friend who was pregnant with a baby. He's now in jail and may face double manslaughter if she and the baby die, or even the senior who brought a gun to school a couple of weeks ago. All these events give the school a bad name and even many in the community assume the school as bad and risky environment, but Emily disagrees with those people saying, "going to made me want to go to school just so to prove everyone wrong,"

Compare to to High School, an all AP school known for its high academics and even trying to invite President Obama for the coming graduation year. While has only 3 AP courses. Both schools are public schools managed and regulated by JCPS, why it is that the schools are different? I asked both Emily and Mike. Emily accepts that society will not always be at the same level and she says "we can't do anything about it," on the other side Mike looks down and says,

"I wonder, _," in a low voice, I could feel angriness in his voice, as he continues "the district is not dividing the money to schools evenly, they give less to those schools that need a lot of improvement, and give more to those schools that are doing fine." It's true as Mike said, but why? Why can't we have fairness in the education system? Someone knows the answer to those questions.

\section{$\underline{\text { Work cited page }}$}

Westerfield, Jennifer and Egan, Susan. "2011-2012 school profiles.” JCPS, November 2011.Web. 21 February. 2012.

Personal interview. March 31, 2011. Emily. Personal Interview. February 15, 2012. , Mike. Personal Interview. February 12, 2012. 


\section{APPENDIX I}

\section{Nadif and James' Peer Review on School Bus}

An appeal to the people.

In an advertisement shown on TV, a boy is loaded with rifle, pistol, and multiple

$$
\text { OW What show? }
$$

grenades. The advertisement has been ajred from a TV show in America, to convince the

American people give their support to israel. A country that is in desperate for help with a fight What?

against Palestine. This is what puts one into a hopeless condition. The ad targets an audience who finds child soldier as afh offensive. The ad urges people to consider child soldier as foolish act. It appeals to ethos, logos, pathos, and kairos to convince the crowd in different ways. The director designer made his message clear at the way he loaded the young boy with weapons. Looking into the eyes of the boy in the picture, you feel arg passionate he is about his job. This ad anti?

exposes the dangers of a pro-lsrael stance that supports children as victims and participants of Travostion?

It seems that children are already been convinced to consider going to war as an option. "What kind of society raises six-year old on dream of suicide, homicide, and hatred? A society that targets Israel." the children of Israel has an enemy that has exists, and the 
message has been passed to them by their parents. According to Israel, we know there if fias being a long existing problem between Israel and Palestine. This advertisement criticizes those who use children soldiers to destroy nations. Linking America to Israel shows that Israel is going with the modern world, and letting its enemy know they moved as well 2 'obeyed children's rights. Although the text makes clear the logical argument that children should be innocent. The ads appeals to ethos emphasizamerica's values of change "They target Israel because Israel shares America's value-democracy, freedom of religion, women's' rights and a free people also press." The ad makes clear that respect the ways of the modern world, and who too follow it. The ad appeals to its enemy by defining their expectations they can only move with developing countries, not people who use children as a source to fight against nations. The publishing of such an ad may change the opinions of some who supported child soldier.

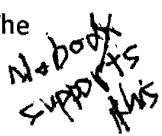

Though the ad's child is innocent, the photo complicates the appeal to pathos. The picture shows us how cruel and pathetic child soldiers are especially at a time when the world is talking of freedom for women, press, and so on. "ISRAEL the front line of the free world," makes clear the that this message reaches the rivals in picture or in words that is Israel is among the leading nations of the free world. The designer also makes an appeal to kairos. How?

Finally the advertisement about the child soldier seem to be persuasive and convincing 7 those who see Israel's link with America as a way to walk with the free line and America's value of children. The persuasive ad influences each and everyone who reads and tells that innocent children shouldn't be guarded with weapons. As well, the ads appeal to a time Israel is in need given? 
of help, since the ad is shown in America to plea for help. The ad is effective in making its points; however, the intended audience will have the two choices of whether the message changes their views to continue their attacks, those who make children victims of war will not see this ad as something useful instead, it might help. do what? 


\section{CURRICULUM VITAE}

Brice Nordquist

1226 Springdale Dr.

Louisville, KY 40213

(502) 994-5255

bricenordquist@gmail.com

\section{EDUCATION}

Ph.D. in Rhetoric and Composition, University of Louisville, Louisville, KY

(Defended June 2014)

Dissertation: "Composing College and Career: Mobility, Complexity and Agency at the Nexus of High School, College and Work."

Bronwyn Williams (chair)

Min-Zhan Lu

Bruce Horner

Ann Larson

Aaron Jaffe

Areas of Interest: First-Year Composition, K-16 Writing and Literacy Instruction, Translingual Theory and Writing, Writing Program Administration, Writing Across the Curriculum

M.A. in English Literature, Abilene Christian University, Abilene, TX (Dec. 2007)

Culminating project: " $(\mathrm{Re})$ Visioning Bounds of Operation: Beguine Spirituality in the High and Late Middle Ages."

B.A. in English, Midwestern State University, Wichita Falls, TX (Dec. 2004)

\section{PUBLICATIONS}

"Mobility, Complexity and Agency at the Nexus of High School and College."

Transitions in Writing. Ed. Kristyan Spelman Miller, Eva Lindgren, and Marie Stevenson. Brill, forthcoming.

Economies of Writing: Revaluations in Rhetoric and Composition. Co-edited with Bruce Horner and Susan Ryan. In process. 
"English Only through Disavowal: Linguistic Violence in Politics and Pedagogy." Reworking English in Rhetoric and Composition. Global Interrogations, Local Interventions. Ed. Bruce Horner and Karen Kopelson. Carbondale: Southern Illinois UP, forthcoming.

Economies of Writing. Co-edited with Bruce Horner, Nancy Bou Ayash, and Carrie Kilfoil. Spec. issue cluster of $J A C$ 32.3-4 (2012).

"In (Virtual) Space No One Can Hear You Scream: Towards Fostering Collaboration in Online Writing Centers." Co-authored with Eric Detweiler. Kentucky English Bulletin 60.2 (2011): 27-32.

"Recovering and Deconstructing Composition 'Five Hundred Years Later." JAC 29.1-2 (2009). 266-270.

Working English in Rhetoric and Composition: Global-local Contexts, Commitments, Consequences. Co-edited with Bruce Horner, Min-Zhan Lu, Samantha NeCamp, and Vanessa Kraemer Sohan. Spec. issue cluster of JAC 29.1-2 (2009): 9-293.

"Global Englishes and Language Difference." Co-edited and co-authored with Bruce Horner, Nancy Bou Ayash, Carrie Kilfoil, Samantha NeCamp, and Vanessa Kraemer Sohan. Comppile Research Bibliography.

"Translingual Writing Bibliography." Co-edited with Bruce Horner, Carrie Kilfoil, Samantha NeCamp, and Vanessa Kramer Sohan.

$<$ http://www.translingualwriting.com/translingual-writing-bibliography.php $>$

Assistant Editor. Working Papers on Negotiating Differences in Language and Literacy: Practices and Pedagogies. $<\mathrm{http}: / /$ louisville.edu/workingpapers $>$

\section{CONFERENCE PRESENTATIONS}

"Literacy by Numbers: Responding to Common Core Productions of School Space-Time." Thomas R. Watson Conference in Rhetoric and Composition, Oct. 2014, Louisville, KY.

"Following the Creators of College and Career: Three Stories of Mobility and Complexity." Conference on College Composition and Communication, March 2014, Indianapolis, IN.

"Economies of Difference at the Nexus of High School and College." Featured Presentation. Thomas R. Watson Conference in Rhetoric and Composition, Oct. 2012, Louisville, KY.

"Constructing Possible Pasts and Futures: Movements into and Through the Academy." National Council of Teachers of English, Nov. 2011, Chicago, IL. 
"Translating Expectations and Desires in the Movement from High School to College." Penn State Conference on Rhetoric and Composition, July 2011, State College, PA.

"Cultural Materialist Curriculum Design.” Teaching Reading and Writing as Intellectual Inquiry, Symposium at Fudan University, May 2011, Shanghai, China.

"Remembering to Forget Linguistic Heterogeneity in Politics and Pedagogy."

Conference on College Composition and Communication, April 2011, Atlanta, GA.

"English Only through Disavowal." Thomas R. Watson Conference on Rhetoric and Composition, Oct. 2010, Louisville, KY.

"Resignifying the Transsexual Self." Rhetoric Society of America, May 2010, Minneapolis, MN.

"Assessing the Present and Constructing the Future of Asynchronous Online Writing Center Consultations." Conference on College Composition and Communication, March 2010, Louisville, KY.

"In (Virtual) Space No One Can Hear You Scream: Fostering Community and Continuity in OWI." Conference on College Composition and Communication, March 2009, San Francisco, CA.

"(Re)Designing (Our) Selves and Our Sequences-New Perspectives on FYC Course Development." College English Association, March 2009, Pittsburgh, PA.

"Integrating Technology in the Classroom: From Print to Podcast." Thomas R. Watson Conference on Rhetoric and Composition, Oct. 2008, Louisville, KY.

"Contemplatively (Re)visioning Bounds of Operation in the Mystical Love Lyric of Hadewijch of Brabant." Southeastern Medieval Association Conference, Oct. 2008, Saint Louis, MO.

"Spiritual Gender-Bending and Breaking: The Construction and Expansion of Self in the Devotional Practice and Expression of $13^{\text {th }}$ Century Beguines.” International Congress on Medieval Studies, April 2007, Kalamazoo, MI.

\section{AWARDS, GRANTS, HONORS}

Watson Dissertation Fellowship

University of Louisville, 2012

Ann Braden Social Justice Research Paper Award, Honorable Mention University of Louisville, 2012 
Carolyn Krause Maddox Award for Best Graduate Paper in Women's and Gender Studies University of Louisville, 2009

Qualitative Research Award for Best Graduate Paper Graduate Student Association, Abilene Christian University, 2007

\section{TEACHING}

Assistant Professor of English, Midway College, 2012 - Present

English 100 Introduction to College English

English 101 English Composition I

English 102 English Composition II

English 210 Introduction to Literature

English 215 Introduction to Literary Criticism

English 301 Women's Literature

English 305 Studies in World Literature

English 312 Professional Writing

English 320 Studies in Poetry

English 328 British Literature II

English 330 Major Playwrights

English 371 Minority Voices in American Literature

English 497 Senior Seminar I

English 498 Senior Seminar II

Interdisciplinary Studies 401 Senior Seminar

Graduate Teaching Assistant, University of Louisville, 2008 - 2012

English 101 Introduction to College Composition

English 102 Intermediate College Composition

English 105 Honors Advanced Composition

English 301 British Literature I (Pre-1700)

Part-time Lecturer and Graduate Teaching Assistant, Abilene Christian University, 2006 2008

English 111 Composition and Rhetoric

English 112 Composition and Literature

Part-time Lecturer, Cisco Junior College, 2008

English 1301 Composition

English 1302 Composition and Literature

Writing Consultant, Abilene Christian University Writing Center, 2005 - 2006 


\section{ADMINISTRATIVE EXPERIENCE}

Director, Interdisciplinary Studies Program

Midway College. August 2013 - July 2014

Director, Mindspring Open Educational Resources Initiative

Midway College, Spring 2013 - July 2014

Assistant Director, Thomas R. Watson Conference on Rhetoric and Composition "Economies of Writing." University of Louisville, Department of English, June 2011- Oct. 2012

Director, Min-Zhan Lu

Assistant Director, Thomas R. Watson Conference on Rhetoric and Composition "Working English in Rhetoric and Composition: Contexts, Commitments, Consequences"

University of Louisville, Department of English, June 2009 - Oct. 2010

Director, Min-Zhan Lu

Assistant Director, Composition Program

University of Louisville, Department of English, June 2009 - June 2011

Director, Joanna Wolfe

Assistant Director, University Writing Center

University of Louisville, Department of English, July 2008 - May 2009

Director, Mary Rosner

\section{ACADEMIC SERVICE}

Member, General Education Curriculum Committee

Midway College, Fall 2013 - July 2014

Member, Provost and Vice President of Academic Affairs Search Committee Midway College, Spring 2013

Faculty Advisor, Gamma Beta Phi Honors Society

Midway College, August 2012 - July 2014

Member, Thomas R. Watson Conference Committee, Department of English

University of Louisville, Summer 2011 - Fall 2012

Member, Thomas R. Watson Conference Committee, Department of English University of Louisville, Summer 2009 - Fall 2010

First-year Teaching Mentor, Department of English

University of Louisville, Fall 2010 - Spring 2011 
Organizer, Celebration of Student Writing, Department of English

University of Louisvillle, Spring 2010 and Spring 2011

Developer, Virtual Writing Center Workshop Series, Rewriting

University of Louisville, 2011

"Coming to Terms" - http://breeze.louisville.edu/rewritingwks1/

"Forwarding" - http://breeze.louisville.edu/rewritingwks2/

"Countering" - http://breeze.louisville.edu/rewritingwks3/

Chair, Mentoring Committee, English Graduate Organization

University of Louisville, Spring 2009

\section{COURSEWORK}

ELFH 601 Applied Statistics (Namok Choi)

ENGL 602 Teaching College Composition (Bronwyn Williams)

ENGL 620 Research in Rhetoric and Composition (Joanna Wolfe)

ENGL 670 Composition Theory and Practice (Min-Zhan Lu)

ENGL 672 History of Rhetoric (Carol Mattingly)

ENGL 674 Writing, Cognition and Culture in Curriculum Design: Histories,

Theories and Practices (Bruce Horner)

ENGL 674 Politics of Language in the Teaching and Study of Composition (Bruce

Horner)

ENGL 681 Popular Culture and Literacy: Reading and Writing in a Mass-Mediated

World (Bronwyn Williams)

ENGL 681 The Literature of U.S. Slavery (Carol Mattingly)

ENGL 681 Creative Nonfiction: Practice and Pedagogy (Bronwyn Williams)

ENGL 688 Biology, Technology and Writing (Visiting Professor, Marilyn Cooper)

ENGL 692 Queer Theory (Karen Kopelson)

Other Courses:

ENGL 578 Poetry

ENGL 581 Medieval British Literature

ENGL 600 Medieval Theory: Augustine and Aquinas

ENGL 610 Studies in American Literature

ENGL 612 Studies in British Literature

ENGL 613 Literary Theory and Faith

ENGL 640 Feminist Rhetoric

ENGL 640 Literary Modernism

ENGL 652 Rhetorical Theory and Praxis

\section{LANGUAGES}

Proficient in Spanish reading and writing 


\section{PROFESSIONAL AFFILIATIONS}

Conference on College Composition and Communication

Council of Writing Program Administrators

National Council of Teachers of English

Rhetoric Society of America

Modern Language Association 